\title{
New governance under limited statehood: the case of local government reform in Kosovo
}

Citation for published version (APA):

Agimi, I. (2014). New governance under limited statehood: the case of local government reform in Kosovo. [Doctoral Thesis, Maastricht University]. Boekenplan. https://doi.org/10.26481/dis.20140617ia

Document status and date:

Published: 01/01/2014

DOI:

10.26481/dis.20140617ia

Document Version:

Publisher's PDF, also known as Version of record

\section{Please check the document version of this publication:}

- A submitted manuscript is the version of the article upon submission and before peer-review. There can be important differences between the submitted version and the official published version of record.

People interested in the research are advised to contact the author for the final version of the publication, or visit the DOI to the publisher's website.

- The final author version and the galley proof are versions of the publication after peer review.

- The final published version features the final layout of the paper including the volume, issue and page numbers.

Link to publication

\footnotetext{
General rights rights.

- You may freely distribute the URL identifying the publication in the public portal. please follow below link for the End User Agreement:

www.umlib.nl/taverne-license

Take down policy

If you believe that this document breaches copyright please contact us at:

repository@maastrichtuniversity.nl

providing details and we will investigate your claim.
}

Copyright and moral rights for the publications made accessible in the public portal are retained by the authors and/or other copyright owners and it is a condition of accessing publications that users recognise and abide by the legal requirements associated with these

- Users may download and print one copy of any publication from the public portal for the purpose of private study or research.

- You may not further distribute the material or use it for any profit-making activity or commercial gain

If the publication is distributed under the terms of Article $25 \mathrm{fa}$ of the Dutch Copyright Act, indicated by the "Taverne" license above, 


\section{New Governance Under Limited Statehood}

The Case of Local Government Reform in Kosovo 
(c) 2014, Ilire Agimi

ISBN 9789086663286

Publisher: Boekenplan, Maastricht www.boekenplan.nl

All rights reserved. No part of this publication may be reproduced, stored in a retrieval system, or transmitted in any form, or by any means, electronic, mechanical, photocopying, recording or otherwise, without the prior permission in writing, from the author. 


\title{
New governance under limited statehood: The case of local government reform in Kosovo
}

\author{
DISSERTATION
}

To obtain the degree of Doctor at Maastricht University, on the authority of Rector Magnificus, Prof. dr. L. L. G. Soete in accordance with the decision of the Board of Deans, to be defended in public on Tuesday 17 June 2014, at 14:00 hours

by

Ilire Agimi 


\section{Promoter:}

Prof. dr. Luc Soete

\section{Co-promoters:}

Prof. dr. Adam Fagan, School of Politics and International Relations, Queen Mary University of London, London

Prof. dr. Martin Doornbos, Emeritus Professor, Institute of Social Studies, The Hague

\section{Assessment Committee:}

Prof. dr. Mark Bevir, Chairman

Prof. dr. Will Bartlett, London School of Economics, London

Prof. dr. Thomas Conzelmann

Prof. dr. Khalid Koser, Maastricht University and Geneva Centre for Security Policy Dr. Oisin Tansey, King's College, London

Financial support for this dissertation has been provided by the Netherlands Fellowship Programme NUFFIC. 


\section{To my parents}





\section{Acknowledgments}

The PhD process has been an intellectual journey and a personal adventure. During these four and a half years I have been fortunate to interact with many people who have influenced me greatly. One of the pleasures of finally finishing the $\mathrm{PhD}$ is this opportunity to thank them.

For this dissertation I am grateful for the guidance and support of my supervising team, Adam Fagan, Martin Doornbos and Luc Soete. I am particularly indebted to Adam for inspiring me to ask interesting questions and the patience to guide me as I attempted to answer them. It was a pleasure to work with you both in Maastricht and London. I could not have asked for a more insightful supervisor. I am also grateful to Martin for the farsighted comments and the continuous encouragement. Our long discussions in The Hague and Maastricht were essential in ensuring the quality of my research. My research project and my supervising team were enriched by the support of Luc Soete without whom this dissertation could not have been completed.

I am grateful to the members of the Reading Committee for their critical review of the thesis. Your comments inspired me to improve the manuscript and to consider the $\mathrm{PhD}$ an accomplishment and a successfully completed project.

I would like to extend my gratitude to the Harriman Institute at Columbia University for hosting me as a Visiting Scholar in the spring of 2014. In particular, I am grateful to Prof. Elise Giuliano for her efforts to connect me with other scholars who shared the same research interests. I also thank Prof. Anna di Lellio for her interest in my work and for inviting me to lecture at The New School for Public engagement.

I gratefully acknowledge the funding sources that made my $\mathrm{PhD}$ work possible. I would like to express my gratitude to NUFFIC for their generous funding of my research through the Netherlands Fellowship Program and the Open Society Foundation Global Supplementary Grant Program for their support in the initial phase of my $\mathrm{PhD}$ research.

The extensive empirical work conducted for this book was the result of the cooperation of a large number of interviewees I met during fieldwork in Kosovo. Each one of them has contributed tremendously to my research. The support of my friend and colleague Nikola Gaon at the OSCE Mission in Kosovo was especially important for granting access to OSCE officials.

In these years of working in Maastricht, there was one person who remained accessible and willing to help at all times. I am grateful to Mindel for the readiness to find answers to any possible question I could come up over the years. Thank you 
also to Franziska for supporting my research project from the very start. A special note of appreciation is dedicated to Susan for managing the research grant that funded my studies. I am likewise thankful to Eveline for responding to my inquiries while always wearing a smile. The help of Floortje, Janneke and Mieke were also much appreciated throughout these years.

My learning experience at the School was greatly enriched by teaching in the Masters of Public Policy program. Thank you Lutz for the opportunity. It was a great pleasure working with you.

The successful completion of this project is also the result of the unending support from my friends in Maastricht. On the first day of the $\mathrm{PhD}$, Sonila greeted me in Albanian. It was the start of a wonderful friendship. Sonila, you have been my mentor and my friend for all these years and I thank you immensely. I am grateful to you Soni and Flori for welcoming me into your family where I found a piece of my own home in Maastricht. Ju falenderoj nga zemra.

A simple 'hellow' is the special bond with my partners in fun, favourite travel companions, chocolate keepers, patient listeners and wisest advisers, Josy and Charlotte. I cherished our many adventures across the world as much as I loved our time together in Maastricht. Distance has never been a problem for us! Google and Skype will vouch for that as we set up talks across time zones tuning in from New York, Seville, Prishtina, Singapore, Lyon and Santiago. I cannot wait for our next adventure!

Özge'cim, thank you for being such a wonderful friend. You have been my soulsearching confidante, festival companion, favourite art critic and music inspiration. I always felt understood and supported like only a sister can make me feel. I cherish every moment of our friendship and look forward to new ones.

I was fortunate to get to know people who inspired me with their strength and character. Luciana and Irina, I am grateful we got to share the Maastricht experience. Irina I admire your resilience and Luciana you are a model of integrity. I value your friendship. A special thank you also to Andrea, Jennifer and Patricia for your friendship and encouragement. I am thankful to Sepideh for your generous heart and to you Renée for your kindred spirit. I am especially grateful to my girls, Laura, Larissa, Immy, Claire and Rowena, you are my rock. I would have left Maastricht a long time ago were it not for your presence. Thank you for being a part of my life. Oriane and Morgan, I am thankful for your friendship through all these years. My life in Maastricht was brighter because of Alban and Malisa, thank you for the beautiful memories.

I consider myself lucky to have been based in the best offices with the most excellent companions Luciana, Oksana, Sachin, Flo and Richard. The PhD program would not have been as exciting without the company of Carlos, Güney, Kristine, Sonja, Katie 
and Silja as well as Treena, Cheng, Denisa, Metka, Melissa and Paula. Uniting with UNU-MERIT brought me wonderful new friends especially Simone, Giorgio, Andi, Rodolfo, Shuan, Lilia, Francois, Marco, Daniel, Samyukta, Ale and Franceska.

I am especially glad to have had the chance to meet many of the GPAC fellows. It was a pleasure to discuss governance literature with Sebastian and politics with Mumbi. A great addition to my PhD colleagues was my dear friend Bernard. I wish you success in your mission as Minister of Trade and Industry in Kosovo. In addition, I am especially glad to have found new friends in Karen and Abel. I wish you both success in your new academic journey.

The best present that remained with me from our former building at Kapoenstraat 2 was my friend Su-Mia. How wonderful it has been to get to know you and I wish you all the best in your new projects.

The frequent research trips to the UK allowed me to spend time with my friends Semra, Visar, Besa and Astrit. Thank you for showing me how to fall in love with London and for being the perfect hosts.

I am also grateful to my wonderful cousin Zana, for being as excited as I was to be at Columbia University and for taking time to explore New York with me. Falemnderit Zanë!

During the many field visits to Kosovo, I was fortunate to have the support of many friends at home, particularly Luanda and Albana who filled me with energy every time we met. Thank you also to the best debaters I have known for 12 years, my dear friends Mimoza, Shqipe, Florent, Liridon and Blerim.

I dedicate this book to my parents. They have taught me about hard work and persistence, without which this project could not have been accomplished. Their support was unconditional knowing that doing so contributed greatly to my absence these years. Mam edhe Bab, falemnderit që jeni sot me mu. Ju dua shumë.

I am grateful to my family who have supported me with love and guidance. They have endured endless discussions about the struggles of my research as well as celebrated with me the milestones of every completed chapter. Most of all, I am grateful for the beautiful moments with my wonderful niece Erika. Her bright smile filled me with love and life. Falemnderit Rrezarta, Zamira, Artan, Ylli, Ylla, Hana dhe Erika!

Completing the $\mathrm{PhD}$ has special value because I get to share it with Joel, my partner and my biggest supporter. Thank you for your pure heart and your pouring love. I am grateful to the chance that brought us together in the vastness of space and the immensity of time. 



\section{Table of Contents}

1. Introduction 1

1.1. Reforming local administration in Kosovo 2

1.2. Research Questions and Hypotheses 5

1.3 Key concepts for studying local government reform in Kosovo

$\begin{array}{ll}\text { 1.4. Methodology } & 10\end{array}$

1.5 Overview 13

Appendix 1A. List of interviews conducted between 2011-2013 15

Appendix 1B. List of open and selective coding categories $\quad 17$

2. Clarifying the conceptual terrain 19

2.1. Introduction 20

2.2. Defining governance 21

2.2.1. Local Governance 25

2.2.1.1. Opening up of local decision-making processes 27

2.3. European conceptualisation of governance 31

2.3.1. EU, Europeanization and governance promotion outside the Community 34

2.4. The ideal state of Good Governance 36

2.5. Governance under Limited Statehood 37

2.6. International role in state-building and democracy promotion 40

2.6.1. State-building: The battle between international and domestic reformers 41

2.7. State-building at the local level $\quad 47$

2.8. Conclusion 50

3. Local governance in Kosovo:

A domestic or external drive for local government reforms? 53

3.1. Introduction 54

3.2. Local governance in Kosovo 63

3.2.1. Limited authority in the North 65

3.3. Institutions engaged in local governance reform 65

$\begin{array}{ll}\text { 3.4. Case studies } & 70\end{array}$

3.4.1. EU Regional Economic Development - EURED 71

3.4.2. USAID Democratic Effective Municipalities Initiative - DEMI 74

$\begin{array}{ll}\text { 3.5. Conclusion } & 77\end{array}$

4. Heritage governance in Kosovo $\quad 81$

4.1. Introduction 82

4.2. Cultural heritage management in divided societies $\quad 85$ 
4.3. Cultural heritage in Kosovo: A background 88

4.4. Cultural heritage governance since $1999 \quad 92$

4.5. The Historic Center of Prizren: A city within a city 98

4.7. The politics of reforming heritage governance 103

4.8. International agency involvement 107

4.9. The civil society opposition 109

4.10. Conclusion $\quad 112$

Appendix 4A. Chronology of law drafting process 116

Appendix 4B. Institutional structure of cultural heritage management 117

5. The young (unemployed) Europeans:

Enabling youth participation in local decision-making $\quad 119$

5.1. Introduction $\quad 120$

5.2. Case study: engagement of young Europeans 121

5.3. Policies and institutions working on youth participation 122

5.5. Youth Action Councils 126

5.6. The Gjilan model 136

5.7. The case of Prishtina and Ferizaj 139

5.8. Conclusion 142

6. Developing local partnerships in environment and welfare services 145

6.1. Introduction 146

6.2. Case Study on Environmental Governance 147

$\begin{array}{ll}\text { 6.3. The legal framework } & 148\end{array}$

6.4. REC collaborations and developing of Local

Environmental Action Plans $\quad 151$

6.5. Podujeva: An example of cooperation 156

$\begin{array}{lll}\text { 6.6. Obiliç } & 158\end{array}$

6.7. Mitrovica 159

6.8. Gjakova 161

6.9. Case Study: Provision of Welfare Services 162

6.10. Policies addressing Persons with Disabilities 164

6.11. Offering services at municipal level 167

$\begin{array}{ll}\text { 6.12. Conclusion } & 170\end{array}$

$\begin{array}{ll}\text { 7. Conclusion } & 173\end{array}$

$\begin{array}{lll}\text { 8. } & \text { References } & 181\end{array}$ 


\section{Abbreviations}

AI

AKM

CEE

$\mathrm{CHwB}$

$\mathrm{CoE}$

CoEDM

CoR

DEMI

DLA

EC

ECA

ECLO

EU

EUOK

EURED

EUSR

FIQ

GIZ

$\mathrm{HPO}$

ICNYP

ICO

ICR

IKS

IMC

IMF

IMWG

IPA

IPMP

IRPP

$\mathrm{KCCH}$

KCSF

KEPA

KES

KIPRED

KLGI

KMDRI

KYC

KYN

KYSAP
Administrative Instruction

Association of Kosovo Municipalities

Central and Eastern Europe

Cultural Heritage without Borders

Council of Europe

Council of Europe Decentralization Mission in Kosovo

Committee of the Regions

Democratic Effective Municipalities Initiative

UNMIK Department of Local Administration

European Commission

European Court of Auditors

European Commission Liaison Office

European Union

European Union Office in Kosovo

European Union Regional Economic Development

European Union Special Representative

Forumi për Iniciativë Qytetare (Forum for Citizen Initiative)

German Society for International Cooperation/Gesellschaft für

Internationale Zusammenarbeit

High Performing Organisation

International Council on National Youth Policy

International Civilian Office

International Civilian Representative

Kosovo Stability Initiative

Implementation Monitoring Council

International Monetary Fund

Inter-Ministerial Working Group

Instrument for Pre-Accession Assistance

Institute for the Protection of Monuments

Integrated Rehabilitation Project Plan

Kosovo Council for Cultural Heritage

Kosovo Civil Society Foundation

Kosovo Environmental Protection Agency

Kosovo Environmental Strategy

Kosovo Institute for Policy Research and Development

Kosovo Local Government Institute

Kosovo Mental Disability Rights International

Kosovo Youth Council

Kosovo Youth Network

Kosovo Youth Strategy and Action Plan 
LG

MCYS

MESP

MLG

MLGA

MLSW

$\mathrm{MF}$

$\mathrm{MoU}$

NATO

NEAP

NYAC

OECD

OPM

OSCE

PISG

RDA

REC

RED

RIC

SAAH

SDSKiM

SEE

SIAP

SIDA

SKMS

SOC

SRSG

UN

UNDP

UNESCO

UN-Habitat

UNICEF

UNMIK

UNSC

US

USAID

WB

WG

YAC
Local Government

Ministry of Culture, Youth and Sports

Ministry of Environment and Spatial Planning

Multi-level Governance

Ministry of Local Government Administration

Ministry of Labor and Social Welfare

Ministry of Finance

Memorandum of Understanding

North Atlantic Treaty Organisation

National Environmental Action Plan

National Youth Action Council

Organisation for Economic Co-operation and Development

Office of the Prime Minister of the Republic of Kosovo

Organisation for Security and Cooperation in Europe

Provisional Institutions of Self-Government

Regional Development Agency

Regional Environmental Center

Regional Economic Development

Reconstruction and Implementation Commission

Survey of the Architectural and Archaeological Heritage

Serbian Democratic Party of Kosova and Metohija

South Eastern Europe

Service Improvement Action Plan

Swedish International Development Cooperation Agency

Serbian Party of Kosova and Metohija

Serbian Orthodox Church

Special Representative of the Secretary General

United Nations

United Nations Development Programme

United Nations Educational, Scientific and Cultural Organization

United Nations Human Settlements Programme

United Nations Children's Fund

United Nations Mission in Kosovo

United Nations Security Council

United States

United States Agency for International Development

World Bank

Working Group

Youth Action Council 


\section{Introduction}


The focus of this thesis is local government reform in Kosovo. The perspective of local decision-making, allocation and enforcement, as well as numerous internationally-driven reforms presents the political scientist interested in Kosovo's transition to democratic statehood with a complex and pertinent research portal. The core puzzle of this thesis is that whilst the realm of local politics has, since the collapse of Yugoslavia, been subject to numerous structural reforms - mostly as a consequence of externally-pursued state building initiatives - weak institutional capacities appear to remain. This is manifest in what appears to be persistent levels of poor implementation of the legislation and the failure of existing structures to be transformed. How can this be explained? Which factors determine progress and the pace of change? What does this suggest about the reforms, the international intervention, and the particular case of Kosovo?

Policies aimed at reforming the local level emerged onto the political agenda due to the uncertainties of national statehood and the need to secure basic services after the 1999 war. When and where it has occurred, decentralization and local government reform in Kosovo is the product of conditionality pressure from the international community. In the context of a weak central government with limited bureaucratic capacities and contested authority and jurisdiction, the international community was able to cast an external shadow of hierarchy at the local level. In general, the reforms have often been sudden and ambitious and not based on a particular blueprint or a particular Western model (Ebel and Péteri 2007). The common denominator of all of the local government reforms has been an emphasis on good governance, open and inclusive decision-making and accountability measures for intergovernmental relations (Tansey 2009). The EU has been a critical player in driving local government reform, introducing as part of its wider assistance for Kosovo a range of initiatives for opening up local decision-making processes and facilitating a closing of the gap between citizen and state institutions. Thus, the perspective of local government reform provides a valuable lens on the impact of international intervention in general, and the initiatives of the EU in particular.

\subsection{Reforming local administration in Kosovo}

The basic governmental structure of Kosovo has its roots in the Socialist Federal Republic of Yugoslavia, where local authorities exercised formal municipal functions as an extended arm of national government control (Ebel and Péteri 2007). In federal Yugoslavia of 1945-1991, local government was based on a model of selfmanagement socialism and planning was decentralized (Sörensen 2009, 7). The Communist Party, however, remained powerful and local elites were loyal representatives. Under the Yugoslav system Kosovo was an Autonomous Province 
with the Socialist Republic of Serbia. After the abolishment of Kosovo's autonomy in 1989, local services were managed by a centralized administration under the Albanian-led parallel system separate from the Serbian-led government (Sörensen 2009, 190-193). ${ }^{1}$ At the point of Yugoslavia's disintegration, the territory of Kosovo was divided into five regional districts and 30 municipalities (komuna / opština) including the capital city of Prishtina².

Following the end of the war in Kosovo in June 1999 until the Declaration of Independence in February 2008, local administrations were faced with a rapidly changing set of responsibilities and a change of direction in local government reforms. Between 1999 and 2002, the newly established UN Administration in Kosovo (UNMIK) led a phase of recentralization of authority, which stripped municipalities of the little authority they had enjoyed in the pre-1989 Yugoslav period. Violent inter-ethnic clashes between Albanians and Serbs in March 2004 brought decentralization back on the political agenda and UNMIK promoted devolution of powers to the local level as a mechanism to encourage the participation of isolated Kosovo Serbs in local institutions (KIPRED 2004). After the Declaration of Independence in February 2008, Kosovo authorities, under international pressure, adopted decentralization as one of the main mechanisms for diffusing inter-ethnic tensions between Albanians and Serbs and integrating the Serbian population in the socio-political environment (Burema 2013, 101).

Between 2000 and 2009, legislation delineating local competences, restructuring of local administration, reforming local elections, changing the authority of local mayors and new territorial arrangements was modified almost annually by UNMIK and later on by the Prishtina authorities. ${ }^{3}$ In May 2013, the Kosovo government approved the establishment of two new municipalities bringing the total number of local government units to 40 (OPM 2013). The post-Independence legal framework introduced further reforms of local government and added seven new municipalities to the municipal structure in June 2008 with the new Law on Administrative Boundaries. During these changes in local competences, local authorities have slowly progressed towards accepting greater responsibilities. This occurred amidst many challenges due to the ever-changing and vague delineation of local competences as well as limitations of local capacities to implement new legislation and fulfill increasing obligations.

\footnotetext{
${ }^{1}$ A more detailed overview of the institutional structure during Yugoslavia is presented in Chapter 3.

${ }^{2}$ For Serb-majority municipalities, I use both the Albanian and Serbian name together whereas for all other municipalities the official Albanian names are used.

${ }^{3}$ Legislation changes directly impacting the structure and competences of municipalities were adopted in 2001, 2004, 2005, 2007, 2008, 2009 and 2013. The relevant legal framework is listed in the References section.
} 
It is imperative to keep emphasizing the broader political context in which local reforms have taken place. This thesis highlights that Kosovo is a particularly unique situation where limited state authority and contested legitimacy at the central level, locked down power at the local level. The international community's reforms and assistance agenda further reinforced this. Thus the challenge becomes relinquishing some of the captured power at the local level while not completely stripping away the autonomy of the local level. At the central level, devolving power to local elites was highly contentious because it was interpreted as an attempt to undermine the central authorities and thus thwart attempts at independent statehood. At a time of state formation and national uprising, power is most likely to be centripetal rather than centrifugal. Any attempt to reconfigure the balance of power under such circumstances is likely to be highly controversial and meet a high level of resistance. This was indeed the case in Kosovo: by 2003, local reforms were being pursued at the same time as the gradual withdrawal of UNMIK from executive decisions at the national level necessitated the central government to take on more responsibility. However, the authority of the central government was contested due to weak institutional capacities and the government's failure to bridge the ethnic divide between the Albanian and Serbian population in Kosovo. Internationally its authority was contested by the lack of a final political status.

In terms of the democratic transformation of local decision-making, the reform process involves more than just the devolution of power. What is also required is the establishment of access points for other non-state actors to engage with the decision-making process. Thus, in examining local governance in a context of transitioning democracies, local government reform is seen as embodying three critical elements. Firstly, there should occur a process of power re-distribution involving a vertical devolution of authority from central to lower tiers of government (Hohe 2002). Secondly, there should be evidence of increased openness of local governance, defined in terms of a shift in relations between state and nonstate actors and thereby a horizontal distribution of power (Marks and Hooghe 2004). Thirdly, good local governance is enabled when institutionalised mechanisms are in place securing accountability within local structures as well as between central-local levels (Newman et al. 2004).

This study starts from the premise that local governance reform is likely to constitute a much greater challenge than reforming decision making at the national or central level. The extensive involvement of international agencies in the country since 1999 and the frequent legislation changes altering functions of local authorities add to Kosovo as a notable and valuable context for further study. The thesis examines the degree to which a transformation is occurring under the impact of international agencies and what are the particular constraints in establishing good governance at the local level. The main question raised is the extent to which good 
local governance can emerge in a context of limited statehood and high involvement of external agencies. Scholars have pointed out that local governance reform can only occur in the context of an effective and capacious state, able to cast a shadow of hierarchy (Héritier and Lehmkuhl 2008). Consequently, an environment of limited statehood (Risse 2012, 702) where the central government fairs weak both in terms of bureaucratic capacities and its contested authority challenges progressive change at the local level. On the contrary, the overriding position that this thesis advances is that local governance reform is possible under such conditions, but what emerges is likely to reflect the specific circumstances.

The analysis is not based on a normative assumption that more local autonomy and authority vis-à-vis the central government is always desirable. Rather the fundamental premise is that a post-conflict environment requires a reconfiguration of state authority at the local level. Case studies are selected in this thesis in order to explore the levels of empowerment within the local context and the configuration of power between state and non-state actors, international / external and internal actors. The empirical sections particularly examine the progress in establishing and implementing new mechanisms of cooperation between state and non-state actors in the field of heritage, youth, environment and social services and the extent to which these have introduced and sustained a new decision-making process at the local level. The aim of the case studies is not to measure the outcomes of particular initiatives or the success rate of schemes in a particular area (e.g. the rise in youth employment or improvement of environment protection) but rather to evaluate new activities, partnerships and networks in the local governance sphere. The research findings show that the voice of the local in Kosovo remained unheard despite the increase in local competences to the local level. The international community involvement was crucial in promoting policy changes for local government reform, and at times its role clashed with local interests. The research findings substantiate the view that reform at the local level constitutes a highly complex process requiring due attention and thus cannot be considered at a subordinate state in connection to central government reforms.

\subsection{Research Questions and Hypotheses}

The overarching research question of the thesis is to what extent has there been a shift of power at the local level during Kosovo's transition process? The dependent variable explored embodies the devolution of power and the openness of decision-making at the local level. Emerging from the overarching questions are two core questions of this study: (i) To what extent has local government reform evolved in Kosovo? and (ii) Which variables and factors explain the shift towards more open and inclusive decision making at the local level? Through mapping of institutions, legislation and actors in 
several policy areas, this research seeks to explain the drivers of progressive change towards democratic local governance and more open decision-making. The large number of international initiatives in the country may suggest progress but the empirical data presented in this thesis show that despite the substantial amounts of assistance allocated to democracy promotion efforts, the impact has been mixed, varying from one case to another. Led by the proposition that externally driven local government reforms have had a limited impact on the distribution of power and resources at the local level, this study explores the extent to which this is true on the ground. With the aim to further advance the research into international democracy promotion and good governance the study also examines external initiatives for reform and the models of governance promoted. These initiatives must embody two dimensions in order to achieve an impact on local governance, namely advocate for stronger intergovernmental relations and vertical accountability as well as strengthen horizontal modes of cooperation. These factors are likely to be reflected in the reforms implemented at the local level. The overriding position that this thesis advances is that local governance reform is possible under such circumstances, but what emerges is likely to reflect the specific circumstances.

Kosovo authorities have witnessed multiple changes of legislation and administrative restructuring which have impacted upon government institutions at central and local levels. Territorial reorganization of municipal boundaries has rearranged institutional structures and transformed executive power in the hands of political elites. These changes have undoubtedly confronted the expectations of the local administration in serving citizen and cooperating with non-state actors. Historic legacies of state authority remain a factor in the functioning of the local administration. Institutions of decision-making and policy-enforcement are largely outmoded and slow to change, particularly at the local level. Current decisionmaking processes are constrained by previous institutions. Whereas legislation may be adopted swiftly and altered frequently, institutional change is gradual and evolutionary (Easterly 2008, 95).

The study thus pays particular attention to new legislation and institutional structures established during local reforms to enforce new bridges between state and non-state actors raising the question to what extent do formal and institutional changes lead to a change in local decision-making? This thesis provides commentary on how, or whether new laws, initiatives and policies governing local decision-making are working and functioning. It looks at the situation on the ground and considers whether formal and institutional change make an essential difference. According to Crook and Manor (1998, 302-3), establishing solid institutions and mechanisms will develop a "culture of accountability" which is necessary for democratic local governance. Institutionalisation is also critical to secure the sustainability of these initiatives and to embed these in the local political culture. 
Decentralization reforms require the central government to relinquish control to lower tiers of government. Establishing and enforcing effective mechanisms of accountability and oversight between the center and periphery ensures the successful implementation of policies at the local level. In understanding the intergovernmental dimension of reforms, this begs the question to what extent does the central government exercise a steering role over local governance?

At the local level a series of agencies with varying levels of power may facilitate or obstruct reforms. The case studies selected in this thesis show the dynamics of power, the balance of resources and the lines of accountability and authority between the center and local level. The intention is to explore the domestic factors that may enable shifts towards democratic local governance to occur, including identifying which actors establish themselves as the leading agents of change and which agencies act as gatekeepers?

Recognizing the vital role of domestic actors as agents of reforms, the study also addresses the importance of participation and an active civil society in engaging in local decision-making. Participation of domestic actors in policy reforms is critical, particularly civil society actors (Jackson and Scott 2007). Strong networks of civil society organisations increase their chances of accessing municipal institutions and exercising an impact on the decision-making process. Hence, it is worth addressing the question to what extent is a shift in power at the local level contingent upon the presence of an efficacious civil society?

Through answering these questions, the study aims to contribute to the wider discussion on political change and democratic transformation in the Western Balkans, where post-conflict Kosovo arguably represents the final and most difficult challenge following the collapse of the Yugoslav federation. The transformation of Kosovo involves dealing with compound legacies (statehood, post-socialism, conflict and contested sovereignty); reforming local decision making and power in such a context has thus far received the least scholarly attention and yet represents a particularly profound challenge.

\subsection{Key concepts for studying local government reform in Kosovo}

The most obvious and relevant concept for this study is that of governance. When studying the local level, a governance perspective allows for an exploration of drivers of change amongst state and non-state actors, as well as at different levels of power and authority (international, national, local, community-level etc.). In a postconflict environment, a myriad of actors compete for survival in the new reality and may resolve to capture power to influence the outcome of policies (Woodward 2002, 
19-20). This is particularly so at the local level where political elites remain powerful even if the state itself is weak. Disentangling power, understanding how it is being exercised and by whom is made more difficult where there is a myriad of actors, internal and external, local and national, state and non-state, public and private. As a framing concept, governance acknowledges the potential legitimacy and efficacy of each (Rosenau 1999).

In this thesis, the ideas of governance are important as they help us locate power amongst the multitude of actors involved in local government reform in Kosovo. In particular, governance acknowledges that non-state actors should have a say in decision-making (Hill and Lynn 2005). Kosovo as a contested and emergent state represents a complex and unique context in which to study governance and shifts in decision making. It is a context in which the state apparatus is weak, and the challenge is not just to reconfigure the power of the state but to also reconstruct the relationship between the central and local levels (Risse 2012, 7). The normative benchmark for this relationship is one where central government steering ensures compliance of local authorities as well as inclusion of non-state actors. In order to secure a shift towards 'good' or 'new' governance at the local level, there should be evidence of the integration of local actors within a broader network of multi-level governance. That is, we seek evidence of local elites and civil society actors becoming integrated within national and, potentially, regional decision making networks. It is vital to recognize that such a shift will not diminish the role of the state. Indeed, the notion 'bringing the state back in' (Evans, Rueschemeyer, \& Skocpol, 1985, 3) can be applied to this context as the central level authority needs to be strengthened through regulated interactions with other government tiers. As Charles Tilly argues, "no democracy can work if the state lacks the capacity to supervise democratic decision-making and put its results into practice" (Tilly 2007, 15).

As already noted, despite its significance as a marker of reform, there has been little scholarly analysis of governance reform at the local level in Kosovo. The literature, such that it exists, comes mainly from Prishtina-based non-academic policy centers and think-tanks. These include reports by the RIINVEST Institute for Development Research (2000), the Kosovo Institute for Research and Development - KIPRED (2004; 2009), the Kosovo Local Government Institute (KLGI) $(2010,2011)$ and the Kosova Democratic Institute (2009). Baskin (2004) conducted one of the first indepth studies on local governance in Kosovo to evaluate local democracy, including the local institutions, elections and local economy. The study provided recommendations for international organizations and local authorities in further advancing local democratic decision-making $(2004,7)$. This was followed by two larger studies by Ebel and Péteri (2007) and Hajnal and Péteri (2010) which provided a comprehensive review of local governance in Kosovo. The latter studies were 
funded by the Kosovo Foundation for Open Society funded and FORUM 2015 respectively.

The second important concept for this study is that of state-building. The externally driven local level reforms that have taken place in Kosovo have been pursued as part of a wider objective to transform political authority and bureaucratic capacities. Such intervention has taken place under the guise of 'state-building'. State-building has been a dominant, though controversial, approach to studying post-conflict transformations (Caplan 2002; Chesterman 2004; Fukuyama 2004; Zaum 2007). In addition to mapping power and reform at the local level, this study seeks also to contribute to our conceptual understanding of state-building as a framework for examining intervention and what often appear to be non-democratic interventions by external actors in domestic politics (Gilbert 2012). This study aims to bring further insight into the bargaining process between international and domestic political elites (Woodward 2007, 18-20). It also intends to highlight the tension in the design of power sharing arrangements in divided societies (Bieber 2004, 6).

Critics of state-building, however, are too dismissive of the impact of international agencies on enabling good governance (Chopra 2002, 981; Richmond 2008; 14). Debates on international state-building and democracy promotion have tended to focus primarily on the transformation of central government institutions and the interaction between state and non-state actors at this level (Fukuyama 2004; Rothchild and Roeder 2005; Paris and Sisk 2007; Tansey 2009; Bliesseman de Guevarra 2010; Zürcher 2011). Although local institutions, organisations and contexts are not ignored as such, the emergence of good local governance is implicitly predicted to occur at a later stage, once reforms have been established at the core and hierarchical structures are set up. A critical assumption found in this literature is that there will occur a trickle-down effect whereby innovations at the central government level (e.g. new institutions and procedures) will eventually strengthen local structures and practice (Manning 2003). The reality on the ground, however, suggests a far more complex picture, with reforms not easily permeating the local level. Over the last decade, comparative analysis of post-conflict countries has drawn attention to the local level looking at the impact of local governance reform in social reintegration and economic recovery (Woodward 2002, 17-29) and decentralization policies as a viable instrument for stability after conflict (Monteux 2006). Contributions by Manning reveal the local challenges in implementing peace agreements during the 1990s and the need for broad inclusion of stakeholders throughout government tiers when negotiating sustainable political arrangements (Manning, 2003). Other studies by Pickering $(2007,2010)$ bring attention to the impact of externally-led local government reforms on communities and highlight citizen evaluations of these reforms. It is argued that people's idea of good governance is closely related to visible infrastructural improvements in their 
communities, which do not necessarily coincide with western liberal models of governance being promoted in the Balkans by international donors (Pickering 2012, 567).

The collection of different types of data is needed to make sense of the quality of local governance and of how and why a host of factors interact to explain the impact of internationally led initiatives for reform. The following section explains in detail the methodology used to inform the aforementioned hypotheses. Building on the literature on governance and state-building, chapter two develops a conceptual framework to situate the research within existing academic debates.

\subsection{Methodology}

To answer the research questions, an exploratory case study research design is used here to allow a process of discovery amongst multiple events and agents (Stebbins 2001). This study used qualitative within-case methods of analysis and its process tracing method developed by George and Bennett (2004). Process tracing involves exploring the observable implications of hypothesized causal processes within a single case and accepts new leads found within the detailed data (George and Bennett 2004, 205). The use of process tracing increases the number of theoretically relevant units of analysis through tracing sequences of events. This helps overcome some of the dilemmas of small $N$ studies (King, Keohane \& Verba, 1985). It is necessary to point out, nevertheless, that this research design explores illustrative cases studies and seeks only contingent generalizations that apply to other contexts similar to the ones being studied here.

Yin's (2009) guidelines on case study research were followed more precisely. For all cases explored, case study protocols were developed to ensure data reliability and maintain a target on the topic during data collection. As prescribed by Yin (2009, 8081), the case study protocol follows several key elements including: a) Introduction to case study and purpose of protocol; b) Data collection procedures; c) Outline of case study report; d) Case study questions and e) Evaluations. This process allows for the researcher to return to the very first step of theoretical discussions to review and redesign the propositions after the initial data collection. To encompass a wide range of issues, the cases are selected based on a set of criteria, i) cases represent different policy areas in different regions in Kosovo; ii) Minimum 3 different actors are involved - international agency, civil society/private sector with at least one public institution represented; iii) each one of the actors has a role in planning, decision-making and implementation and last iv) minimum institutionalisation in 
the form of regular meetings and structured decision-making. ${ }^{4}$ The criteria were beneficial for the thought process and facilitated the collection of data. With each step of the research process, the data allowed to reflect on the initial research questions and further define the units of analysis. After the initial review of a broad range of policy issues, the data was screened for particular characteristics setting apart different policy areas. This allowed the development of new dimensions including the political contentiousness of a particular policy reform, centrality of policy area in central government agenda and high variation in state/non-state actor interaction. As this study is not based on a rigid hypothesis-testing model and the case studies are not a sample representative of a larger population but rather specific illustrative examples of issues, the challenge remains generalizing the results to a larger scale. To enhance external validity of the study results, a variety of policy issues were chosen. These remain illustrative case studies that may have salience for other issue areas in Kosovo at a time of rapid political and social transition.

Primary data was collected through interviews in Kosovo with key stakeholders. Qualitative interviewing based on semi-structured interviews provides rich indepth information revealing the interviewee's point of view (Bryman, 2008). The advantage of using in-depth interviews rests in their capacity to reveal a great degree of insight into the issue being studied. Considering the extensive information gathered through the interviews as well as the suggestions raised for other people to interview on the matter, an interviewee may be considered as taking on the role of an 'informant' rather than a mere respondent (Yin 2009, 107). In this study, face-toface interviews were done with the majority of contacts established during field visits to Kosovo from 2011 - 2013. Instead of conducting a fixed set of interviews for a limited period of time, interviews were conducted in separate revisits to the field until a satisfactory number of contacts had been reached and the questions exhausted. The interview guideline, while based on a predetermined research framework, included a set of questions and topics to discuss with each interviewee. There was enough flexibility in the ranking and selection of questions depending on the interviewee's position in the organisation and information revealed. This flexibility allowed to pursue more in detail certain issues during the interview process which the researcher deemed to be integral to the study. This discursive nature of interviews allowed for a continuous process of refinement.

Selection of contacts to be interviewed was done with the aim of representing all institutions studied in each case. This included civil servants or political staff from

\footnotetext{
4 Similar criteria were used for the case study selection in the European wide research project: Multistakeholder Partnership in Post-Conflict Reconstruction: The role of the European Union. http://www.multi-part.eu/
} 
respective Ministries at the central government, officials from state agencies, local government officials, representatives or international organisations working with local government programs and civil society representatives. Priority was given to those institutional representatives directly involved in the development of a policy under study. ${ }^{5}$ After this initial stage of identification of all contacts for each category of institutions, a snowball method of interviews was employed whenever interviewees proposed a second person affiliated with the institution to be contacted due to their immediate involvement in a decision or their general knowledge about the topic at hand. In these cases, further interviews were organized with said officials and representatives. A total of fifty interviews were conducted with government institutions at (4) central level, (12) local government authorities, (2) state agencies, (17) non-state actors including civil society experts and organisations and (15) international organisation representatives working with local government programs. The full list of interviews stipulating their functions is on Annex $1 \mathrm{~A}$ of this chapter. ${ }^{6}$ With the permission of each interviewee, interviews were taped. The language used in the interviews with representatives from Kosovo institutions and civil society organizations was Albanian. Interviews with international representatives of organizations were conducted in English. Extensive notes where taken during the interviews. Each interview was transcribed soon after being held as to maintain all record of details and perceptions on discussion. Both interview transcripts and secondary data were coded with main categories matching the concepts important to the case explored. Qualitative data coding was used to systematically classify and examine the data. While mostly used for grounded theory, initial open coding and selective coding (Bryman, 2008) were helpful in examining the data and relating it to concepts explored. A list of the main coding categories is presented in Annex 1B. Secondary data consisted of country legislation, policy documents and official reports produced by Ministerial bodies, state agencies and the assembly, policy briefs, reports and evaluations conducted by international organisations in and outside Kosovo, analysis produced by civil society organisations throughout Kosovo as well as reports published by Kosovo-based think-tanks and research institutions. In few instances, media reports from local media sources were also analysed for content and further information.

\footnotetext{
${ }^{5}$ Whereas the study refers to civil society broadly and encompassing the country as a whole, the case study analyses were conducted mainly with Albanian civil society organisations. This was primarily due to the data collection on municipalities with an Albanian majority population.

${ }^{6}$ Despite the attention paid on the case study on youth participation, I was unable to conduct interviews with officials from the Ministry of Culture, Youth and Sports. The latter failed to respond to requests for meetings even after four different officials were contacted. Official documents produced by the Ministry of Culture served as data for informing on their policies regarding youth participation.
} 


\subsection{Overview}

The following chapter constructs the conceptual framework and presents a detailed discussion on existing scholarship on governance and state-building, situating this research within current academic debates and analyses. The chapter begins with a review on the concept of governance, exploring in detail the emphasis placed on the diffusion of power and authority amongst state and non-state actors. In particular the chapter identifies the various principles of good governance, which is important to explain why the ideas of governance and its core principles are particularly relevant at the local level. The rest of the chapter reviews the state-building literature and the conceptualization of political and bureaucratic change during post-conflict and post-authoritarian transitions to democracy. Both literatures (governance and state-building), used in conjunction, are helpful in understanding the role of the international community in driving reform at the local level in Kosovo, and the variety of actors, institutions and initiatives that congregate at the local level, whether as drivers or impediments of change.

Chapter three provides the reader with an outlook on Kosovo local government reviewing the main reforms that have taken place since the end of Yugoslavia. The second half of the third chapter examines two recent initiatives of international agencies designed to strengthen local government. This chapter closely examines the resulting mechanisms of decision-making implemented at the local level and the challenges encountered during the implementation of these initiatives.

Chapters four to six present case studies from various policy areas based on extensive primary data collected in the field. In-depth analysis of four different policy areas provides revealing information on the impact of local government reform in setting up institutional mechanisms of cooperation between state and nonstate agencies. Chapter four focuses on heritage governance, presenting one of the most contentious issues in Kosovo politics in recent years. It examines the power clashes between a highly complex web of actors including international agencies, the central government, local authorities, civil society and religious communities as they each attempt to influence the mechanisms of heritage protection.

In chapter five the case of youth participation at local level is analysed in detail. The case is chosen to illustrate the potential of local leadership in advancing youth policies through an active approach. At the same time, the case factors in the central government prioritization of policies supporting youth participation and its impact on the effective implementation of youth policies.

The last empirical chapter explores two additional policy areas based on in-depth interviews with municipalities. In environmental governance an in-depth analysis into mechanisms of drafting local environmental plans gives insight into new modes 
of cooperation between local authorities and civil society organisations. Looking into the welfare services case, the second part of the fifth chapter illustrates the factors contributing to successful collaboration schemes of service provision for persons with disabilities. In both areas, the research looks into the challenges of policy implementation and the approaches taken by local authorities and civil society organisations towards improving local governance. Finally, the concluding chapter sums ups the research findings and their implications for contemporary scholars and practitioners. 
Appendix 1A. List of interviews conducted between $2011-2013$

Nr. Institution:

01. UNMIK

02. OSCE

03. ICO

04. USAID / DEMI

05. EURED

06. EURED

06. RDA

07. UNDP

08. OSCE Prizren

09. EU Office in Kosovo

10. EC

11. Expert

12. KCSF

13. EC Ma Ndryshe

14. FIQ

15. INPO

16. HandiKos

17. HandiKos

18. FOL

19. Ministry of Agriculture

20. MLGA

21. MLGA

22. $\mathrm{CHwB}$

23. ICO

24. MESP

25. OSCE

26. OSCE Gjilan

27. OSCE

28. REC

29. REC

30. Mitrovica

31. Prizren Municipality

32. Prizren Municipality

33. $\mathrm{KCCH}$

34. University of Prishtina

35. Kosovo LGI
Function:

Director of Office of Political Affairs

National Program Officer

Head of Local Government Unit

Deputy Chief of Party

Technical Assistance Key Expert

Fund Advisor

Director of RDA South

Manager, Support to Decentralization in Kosovo

Human Dimension Officer

Decentralization Task Manager

Support to Decentralisation Project, Senior Expert

Local Government Reform Expert Group in 2004

Program Director

Executive Director

Executive Director

Executive Director

Director

Drenas Office, Programme Coordinator

Executive Director

Permanent Secretary

Head of Division for Monitoring of Municipalities

Permanent Secretary

Programme Manager

Deputy Head of Community Affairs Unit

Senior Legal Officer

Human Dimension Officer, Youth Projects

Senior Human Dimension Assistant

National Programme Officer

LEAP Project Manager

Project and Information Officer

Municipal Environment Officer

Director, Directorate of Spatial Planning

Engineer, Directorate of Spatial Planning

President

Professor, Faculty of Philosophy

Executive Director 
36. YAC Prishtina

37. YAC Gjilan

38. YAC Ferizaj

39. National YAC

40. Gjilan Municipality

41. Prishtina Municipality

42. MAR

43. Gjakova Municipality

44. REC

45. Podujeva Municipality

46. EkoTrepca

47. Obilic Municipality

48. Drenas Municipality

49. KMDRI

50. KMDRI
Chairman

Former Chairman

Chairman

General Secretary

Youth Official

Youth Official

Director

Spokesperson

Coordinator for Gjakova Municipality

Environment Officer

Director

Director, Directorate for Environment Protection

Officer, Directorate for Health and Social Welfare Executive Director

Project Manager 
Appendix 1B. List of open and selective coding categories

\begin{tabular}{|c|c|}
\hline Open codes & Selective codes / core themes \\
\hline $\begin{array}{l}\text { Democratic decision-making } \\
\text { Distribution of power } \\
\text { Legitimacy } \\
\text { Efficiency } \\
\text { Improved services } \\
\text { Economic development } \\
\text { Inter-ethnic reconciliation }\end{array}$ & AIMS \\
\hline $\begin{array}{l}\text { Decentralization - Vertical } \\
\text { Collaboration - Horizontal } \\
\text { New contacts / partners } \\
\end{array}$ & \multirow[t]{2}{*}{ PROCESS OF CHANGE } \\
\hline $\begin{array}{l}\text { Legacy } \\
\text { Institutional history }\end{array}$ & \\
\hline $\begin{array}{l}\text { Cooperation } \\
\text { New / old relationships between actors } \\
\text { Formal / Informal mechanisms } \\
\text { Short-term / Long-term } \\
\text { Local government with civil society } \\
\text { Local government with businesses } \\
\text { Local government with central government }\end{array}$ & \multirow[t]{2}{*}{$\begin{array}{l}\text { INTERACTION \& } \\
\text { NETWORKS }\end{array}$} \\
\hline $\begin{array}{l}\text { Intergovernmental relations } \\
\text { Accountability }\end{array}$ & \\
\hline $\begin{array}{l}\text { Extensive involvement of international } \\
\text { community } \\
\text { Commitment to international community } \\
\text { Obligations deriving from Ahtisaari package } \\
\text { Unequal power between actors } \\
\text { Volatile political context } \\
\text { Improved conditions on the ground } \\
\text { Aid coordination } \\
\text { Enhanced capacities }\end{array}$ & \multirow[t]{2}{*}{ IMPACT } \\
\hline $\begin{array}{l}\text { Project design } \\
\text { Transfer of knowledge } \\
\text { Measures of success/failure }\end{array}$ & \\
\hline $\begin{array}{l}\text { Participation by all actors } \\
\text { Role of municipal leadership } \\
\text { Requirements by international community } \\
\text { Requested by non-state actors }\end{array}$ & INCLUSIVENESS \\
\hline
\end{tabular}




\begin{tabular}{|c|c|}
\hline $\begin{array}{l}\text { Leadership } \\
\text { - Contact or cooperation initiated by local } \\
\text { government official } \\
\text { - Initiated by central government regulation } \\
\text { - Initiated by CSO } \\
\text { - initiated by international agency } \\
\text { Strategizing (how to maintain cooperation) } \\
\text { Role of businesses } \\
\text { Role of core executive }\end{array}$ & ACTOR AGENCY \\
\hline $\begin{array}{l}\text { New legislation } \\
\text { - Values attached More legislation is better } \\
\text { - Perceived vagueness of obligations } \\
\text { - Financial resources }\end{array}$ & \multirow[t]{2}{*}{ IMPLEMENTATION } \\
\hline Oversight by central government & \\
\hline $\begin{array}{l}\text { Formal / legal recognition Acceptance by local } \\
\text { authorities } \\
\text { Acceptance by CSOs } \\
\text { Central government role }\end{array}$ & INSTITUTIONALISATION \\
\hline $\begin{array}{l}\text { Financial resources (Lack of) } \\
\text { Staff limited expertize } \\
\text { Bureaucracy } \\
\text { Political power (Lack of) } \\
\text { Weak capacities } \\
\text { Limited disciplinary actions }\end{array}$ & \multirow[t]{2}{*}{ CONSTRAINTS } \\
\hline $\begin{array}{l}\text { Ethnic conflict } \\
\text { Ahtisaari } \\
\text { Boycott } \\
\text { Incentives }\end{array}$ & \\
\hline $\begin{array}{l}\text { Political clashes over policy reform } \\
\text { Protests } \\
\text { Ethnic division }\end{array}$ & CONFLICTS \\
\hline $\begin{array}{l}\text { Reform priorities on central government } \\
\text { agenda } \\
\text { Reform requests from local level } \\
\text { Evaluation of success/failure }\end{array}$ & POLICY AGENDA \\
\hline $\begin{array}{l}\text { Ties with political elite } \\
\text { - Personal networks } \\
\text { - Allegiance to central government ruling } \\
\text { party } \\
\text { Political pressure for/against reform }\end{array}$ & LOCAL POWER \\
\hline
\end{tabular}


2. Clarifying the conceptual terrain 


\subsection{Introduction}

The aim of this chapter is to construct a conceptual framework for examining local governance in Kosovo and for assessing the various reforms instigated by the international community to transform decision-making at the local level. This will involve firstly defining the concept of governance and identifying what is generally understood by the term; particularly its emphasis on networks and the diffusion of power and authority amongst state and non-state actors. The discussion will explore different depictions of the concept as offered within the sub-disciplines of political science namely public policy, international relations and development politics. There will also be considerable discussion about the EU insofar as it offers and represents a particular model of decision making and governance that is both innovative and seemingly reflective of the principles of governance, namely diffusion of authority, networks and a plurality of decision-making powers. The EU is also, as a significant pillar of the international community in Kosovo, instrumental in trying to reform political authority and decision making in Kosovo. Their role in inciting domestic shifts is important considering Kosovo's EU membership perspective. However, at this point in the thesis the EU will be considered primarily from the perspective of how the Commission understands governance and what lessons, if any, can we learn about multi-level governance from the EU model of decision making. In other words, this chapter will not be evaluating the role of the EU in Kosovo.

However useful and relevant it is to discuss the concept of governance, it needs to be acknowledged from the outset that much of the governance literature has been written by scholars wishing either to describe the transformation of central government power and authority, or to map power beyond the state. The objective of this thesis is somewhat different and it is therefore important to explain why the ideas of governance and its core principles are particularly relevant at the local level. Thus, using the general governance literature, this chapter will identify what effective governance should look like and how it should operate at the local level.

This chapter advances the position that the ideas of governance, though they usually refer to the transformation of power at the core, i.e. the central state or above, are nevertheless absolutely critical for successful democratic decision making at the local level. However, the thesis also accepts the premise that for effective local governance to occur, capturing all the normative ideals of subsidiarity, participation and deliberation, then reform at the state level is also vital - that is, one cannot exist without the other. 'Good' governance at the local level cannot fully occur, nor be sustainable without new modes of governance occurring at state level. 
However, in order to construct a comprehensive framework for discussing and researching local governance reform in present-day Kosovo, it is necessary to delve into additional literatures. The literature on state-building is particularly important as it offers a critique of international intervention designed to restructure, recreate and transform political power and authority. The vast literature on this subject is used here as context for understanding the role of the international community in driving local governance reform, and for appreciating the extent to which externally driven initiatives can clash with domestic institutions. In other words, in assessing local governance in Kosovo we need to be aware of the fact that many of the initiatives have come about as a result of international or external intervention and may thus not be properly embedded or institutionalised, not to mention accepted by the population.

Nonetheless, building local governance and transforming political authority at the local level in Kosovo does not just entail understanding the role of the international community in the process. It also necessitates a discussion as to the extent to which the Prishtina government has limited and contested authority over a proportion of the physical territory of Kosovo. In developing an inclusive conceptual framework this chapter considers what scholars understand by limited statehood (both in terms of bureaucratic capacities, and in this case also contested authority) and discusses the question of whether, and how, local governance reform is affected by such scenarios. Scholars have pointed out that local governance reform can only occur in the context of an effective and capacious state, able to cast a shadow of hierarchy (Héritier and Lehmkuhl 2008); others argue that new modes of governance can emerge in cases of limited statehood (Risse 2012). The study of Kosovo will shed light on the extent to which this has occurred on the ground considering the challenges these limitations impose on the local level.

\subsection{Defining governance}

This study uses the governance definition provided by Thomas Risse to denote governance as the institutionalised modes of social coordination set 'to produce and implement collectively binding rules, or to provide collective good' $(2012,700)$. The review of literature reveals definitions including one or both of two dimensions. The first one is structure and concerns the architecture of multiple actors, the various formal and informal set of rules and practices and the plurality of decision-Centers. The second one is process and concerns the modes of coordination between levels in hierarchy and the various actors in networks characterized by a dynamic nature and a continual interaction and fluid, never-ending decision-making process (Levi-Faur 2012). 
The increased interconnectedness of countries during economic globalization brought about new paradigms of cooperation and coordination on a global scale. At the national level, public sector reforms in various countries brought about interorganizational networks between the different government levels and across the state-society divide (Kjaer 2011). Recognizing these shifts, scholars demanded serious consideration for a new way of looking at the state, the changing nature in which states were dealing with issues and working with each other. Early attempts at defining governance focused on distinguishing governance from government. Scholars pointed to governance as separate from government. This distinction pointed to the multiplicity of actors and a broader set of rules over social matters. Most importantly this implies governance covers areas in which 'networks and markets, not directly under the authority of the government, replace the government' (Lynn 2010). This interpretation refers to what Rhodes called the "hollowing out" and decline of the state (1997a). The latter's definition of governance aligns with networks and refers to 'self-organizing, inter-organisational networks characterized by interdependence, resource-exchange, rules of the game, and significant autonomy from the state' (Rhodes 1997, 15). For other scholars, governance implies the process of steering the economy and society and reaching collective goals (Pierre and Peters 2000). In reiterating the distinction between government and governance, Bevir $(2010,3)$ points out that governance refers to processes of rule wherever they occur whereas government is directly linked to political institutions.

An important element in the definition of governance was the diffusion of power and authority amongst state and non-state actors. Governance presented a notion challenging centralized authority and thus promoted a dispersion of power among formal and informal institutions at various levels. These shifts mark the opening up of the decision-making process to extend access to non-state actors (Hill \& Lynn 2005). Governance thus implies a 'plurality of decision centers', operating under unclear hierarchy and decision structures consisting of networks (Benz and Papadopoulos 2006, 2-3).

A fundamental part of these discussions on governance was the inclusion of informal norms and practices. According to another scholar, governance thus refers to 'the formation and stewardship of the formal and informal rules that regulate the public realm, the arena in which state as well as economic and societal actors interact to make decisions' (Hyden 1999, 185). Thomas Risse's definition, on the other hand, places more importance on the systems of rules, regimes of laws and practices, and thereby the institutionalised modes of social coordination (2012a, 700). 
Other scholars define governance as 'the general exercise of authority' (Michalski, Miller, and Stevens, 2001, 9), where authority refers to systems of accountability and control. It includes global and local arrangements, formal structures and informal norms and practices, and spontaneous and intentional systems of control (Williamson 1996). Lynn (2010) defines governance in a government related frame as 'the action or manner of governing -- that is, of directing, guiding, or regulating individuals, organisations, or nations in conduct or actions'.

To further explore the use of governance both in theory and in practice, it is important to look at the different depictions of governance across three subcategories of political science literature. Firstly, within international relations, governance deals with the state role in influencing issues and policies whose impact is far larger than only the state itself. On a global scale, the state is no longer the only actor to influence or solve problems. Within international relations, two main branches developed in literature regarding the interpretation of governance vis-àvis the power of the state. Whereas the state-centric standpoint upholds the state as the principal actor (Pierre and Peters 2000), the society-centric approach maintains that 'the state relies upon non-state actors to fulfil its duties' (Robichau 2011, 117).7 On the society-centric front, James Rosenau was forthright in his assertion that the state was no longer necessary for governance to 'prevail'. He defined governance as systems of rule and control mechanisms which can exist without the formal authority of the state. ${ }^{8}$ However, others dispute this view arguing that "trends in the forms and instruments of governance prove the adaptability, not the obsolescence, of traditional hierarchical/bureaucratic governance and confirm the historical path dependence of national institutions" (Lynn 2010). Other scholars support this by highlighting that the state's ability to exert its shadow of hierarchy and implement new governance in fact leads to effective governance (Héritier and Lehmkuhl 2008; Börzel 2010). New governance includes a change of power play, yet this is not to be understood as the state relinquishing authority or decision-making primacy, but rather strengthening its steering role by accepting a shift towards new relations with non-state agencies, especially civil society. Promoting new modes of governance is in fact promoting new mechanisms of interaction between state and non-state agencies while preserving the state's capability to enforce these new interactions in policy-making (Matthews 2012). New modes of governance entail a combination of hierarchy and networks, where non-state actors are significantly empowered and become part of networks whilst the shadow of hierarchy persists.

\footnotetext{
${ }^{7}$ Referencing Jordan (2008)

${ }^{8}$ Kooiman et al (2008) are on the same lines when they point out that governance is 'post-bureaucratic' and, in advanced democracies, signifies fewer boundaries between states and the institutions of civil society as the government's role in societal guidance is reduced.
} 
As the academic debate on governance evolved during the last decades, it also influenced policy implementation and the work of practitioners around the globe. This second school of thought refers to the use of governance in public policy. In analysing public policy-making, governance systems are scrutinized and compared in order to understand the design, adoption and implementation of public policies at different levels of government. Over the last four decades, the complexity of issues increased resulted in a crisis of governability due to government limitations to generate policies which fulfilled citizen's complex and diverse needs. Governance is thus used to describe the changing nature of the policy process in recent decades and the versatile terrains and actors involved in the policymaking process (Richards \& Smith 2002). Governance stresses a focus on the implementation side of the policy process. ${ }^{9}$ In German academic literature, the concept of steuerung is used as a synonym of governance (according to Mayntz 1993, 11) which covers both governance and governing. Under this characterization the role of the government is to steer rather than to row (Osborne \& Gaebler 1992). The Dutch literature on governance defines it as 'directed influence of social processes' covering all mechanisms of guidance that are connected to a public policy process (Kjaer 2004, 41).

At this stage it is important to note the distinction between the normative perspective and the empirical approach to governance. According to Risse and Lehmkuhl (2006), governance entails both a normative quality as it represents certain standards in political authority, rulemaking, security, welfare; as well as an analytical quality for analysing actors, modes and goals of governance. This normatively- laden approach has had a tremendous impact on international aid programs designed by developed countries for the Third World.

The third strand of governance use can be found in development politics. The donor community, led by the World Bank in the 1990s, attached certain values to the term governance and as such it became a driving force for evaluating how other countries function and how they should be functioning. Democracy promotion and statebuilding are based on normative values and all fall in this particular use of governance as they embody particular policies of international organisations and direct financial and technical assistance to countries outside of the developed world. However, at this point, there is a detachment between the normative position promoted by Western democracies and the reality and context in target countries. This imposition of practices and structures of governance has led to warnings that 'changes in governments have tended to become, at least partly, externally

\footnotetext{
${ }_{9}$ According to Kjaer (2011) depending on which definition of governance is used, policy analysis varies. For example, when choosing the narrow definition of governance as networks, then types of network i.e. public-partnership become the focal point of analysis.
} 
determined' (Doornbos 2001, 4). By using the terms governance and good governance international donors 'seem to imply and favor a certain de-politicization of political processes' (Doornbos 2003, 5).

Before moving to the next discussion specifically on local governance, it is important to clarify the notion of multi-level governance used to capture political and economic developments at supranational and subnational levels. Multi-level governance includes a web of dispersed authority and decision-making power across a wide range of actors. ${ }^{10}$ Marks and Hooghe differentiate between two types of multi-level governance. The first type refers to a limited number of jurisdictions operating at different territorial levels (national, regional, local) that do not intersect. The second type of multi-level governance, however, refers to a large number of fragmented and specialized jurisdictions operating on specific policy areas. The latter type is more flexible and jurisdictions adapt or leave way for others to be created, as governance requirements change (2003, 236). In it jurisdictions are flexible and task-specific, 'there is no up or down, no lower or higher, no dominant class of actor; rather a wide range of public and private actors who collaborate and compete in shifting coalitions' (Marks and Hooghe 2004, 20-21). ${ }^{11}$ The focus is on the process and interaction between actors at the local level and new norms introduced including accountability, transparency and openness.

\subsubsection{Local Governance}

During the process of opening up decision-making, the role of the local level is crucial (Bolleyer and Börzel 2010). This section identifies how effective governance operates at the local level. This study uses the definition of local governance provided by Goss $(2001,11)$ as the "emerging new forms of collective decisionmaking at local level which lead to the development of different relationships, not simply between public agencies but between citizens and public agencies". According to Andrew and Goldsmith, local governance encompasses the role of local decision-making in promoting democracy through the enhancement of citizenship and participation by the individual (1998). As a model, local governance

\footnotetext{
10 The initial use of multi-level governance was to study developments of European Union structural policy in early 1990s (Marks 1991, 1993). The concept is also a referral to the implications of an increased interdependence between governments and non-state actors across the various levels (Bache \& Flinders 2004).

${ }^{11}$ In addition, Bolleyer and Börzel (2010) argue that multi-level systems within and beyond the nationstate offer 'a wide repertoire of modes of policy coordination to solve collective problems nonhierarchically' for lower-level governments (provinces, regional governments, or member states) operating in multi-level systems. The resulting outcomes vary over government's willingness and capability to enter agreements.
} 
includes mechanisms, processes and institutions through which citizen and interest groups can articulate their interests, exercise their rights and by which relations between local authorities, civil society and the citizen are continuously improved (UNDP 2004).

The European Charter of Local Self-Government (1985) lays out the rights of local authorities to govern their own affairs:

Local self-government denotes the right and the ability of local authorities, within the limits of the law, to regulate and manage a substantial share of public affairs under their own responsibility and in the interests of the local population.... The basic powers and responsibilities of local authorities shall be prescribed by the constitution or by statute. However, this provision shall not prevent the attribution to local authorities of powers and responsibilities for specific purposes in accordance with the law. ... Local authorities shall, within the limits of the law, have full discretion to exercise their initiative with regard to any matter, which is not excluded from their competence nor assigned to any other authority.

Countries within the EU have opted for local government reform in attempts to improve efficiency and service delivery. In an illustrative case study, the Local Governance Research Program in British local government was designed with the aim of transforming local government into a system of local governance involving complex sets of organisations drawn from the public and private sectors. What was intended as market reform in effect resulted in the emergence of new flexible networks involving actors across the state and non-state sphere (Rhodes, 1999). Empirical research into local governance implies that despite the fragmentation of power, networks are contributing to efficient service delivery that is more responsive towards the needs of the users as compared to only government institutions (Kjaer, 2004).

The increase in networks in policy implementation may be best observed at the local level, where most service delivery takes place (Kjaer, 2004). To enhance their chances of guiding society towards politically defined goals, local, regional and national political elites can all forge coalitions with private businesses, voluntary associations and other societal actors. This way they can mobilize resources across the public-private border (Pierre and Stoker 2000). A recent study of local government performance supports this claim by looking at municipal efficacy across municipalities in Bulgaria concluding that municipal efficacy grows with the increasing involvement of social and economic actors in the policy-making process (Petrova 2011). On the other hand, other scholars highlight the potential opposition of evolving governance actors. Cases of privatization or delegation of tasks in public 
service provision are sometimes opposed by local community members (Börzel 2010).

In order to achieve high performance in policy-making and representation of local interests, local government reform policies often include decentralization or some form of devolution of power from the central level to the local governments. Decentralization can provide varying degrees of services and benefits appropriate for and based on local constituent preferences (Hooghe \& Marks, 2003). This would, consequently, present different provisions in comparison to the more uniform levels of services provided under national direction. Areas such as environment protection, waste management or urban planning should be locally or regionally dealt with (2003). Others argue that decentralization policy may be limited by insufficient local capacities - government units that are too small are expected to suffer from lack of competence and expertise, but also from lack of resources. Allen and Tommasi argue that in addition to ethnic issues, 'the administrative capacity of subnational governments, and the administrative and compliance costs of decentralization must be taken into the account when assigning expenditure among levels of government' (Allen and Tommasi 2001, 74).

Scholars and practitioners have also agreed on decentralization as a mechanism for conflict resolution. Devolving authority to the local level empowers communities and eases tensions in divided societies emerging from conflict (Brinkerhoff 2005; Siegle and O'Mahony 2007; Gjoni, Wetterberg and Dunbar 2010). The Western Balkans, however, have shown the opposite to be true as decentralization has entrenched ethnic divisions. The case of Bosnia) and Macedonia point to the risks of decentralizing along ethnic lines as this may result to making formal decisionmaking dysfunctional and inefficient (Bieber 2004; Monteux 2006).

\subsubsection{Opening up of local decision-making processes}

Within the concept of local governance, participation in local decision-making processes constitutes a criterion for enhancing democracy at the local level. The assumption in democracy literature is that bringing in non-state actors will boost democratization. Encouraging participation is hereby defined as taking part in processes of formulation, passage and implementation of public policy (Wilson 1999). According to Fung (2006), participation serves three fundamental democratic values: legitimacy, justice and the effectiveness of public action. At the local level, municipalities also improve their output and quality of policy-making by utilizing the expertise of local civic organisations. As Petrova states 'local governments seek to enhance local state capacity and consequently improve government efficacy by devolving parts of their authority to societal actors through civic participation in the 
different stages and aspects of policy-making' (2011, 776). Civil society contribution is valuable as it provides citizens with institutionalised leverage for relating to the state and pressuring the state to protect their interests (Petrova 2011). This type of horizontal cooperation between state and non-state actors enables horizontal accountability, which operates 'in the shadow of hierarchy' and thereby does not substitute hierarchical accountability (Schillemans 2008). New formal mechanisms of cooperation facilitate learning between the different agencies through knowledge transfer. Critics of traditional accountability models have called for a 'more dispersed' regime of accountability (Bovens, 2005; Braithwaite, 1999) and a model of 'de-centered governance' (Fung, 2006).

Other scholars echoing these propositions make the case for a shift towards collaborative governance enabled by public participation mechanisms. Newman et al. (2004) argue that the expansion of new mechanisms of state-citizen engagement is evidence of a new form of collaborative governance that can respond to more complex and diverse societies. Representative democracy which at instances may be hierarchical and bureaucratic must be complemented with new mechanisms of participation. Constitutional forms of parliamentary democracy must be supplemented with institutionalised forms of participatory governance. The latter is based on the capacity of citizens as stakeholders (Olsen 2003). In 'traditional' modes of decision-making, dialogue between the voters and their elected representatives is limited with political elites and strong interest groups capturing the process. In order for new mechanisms to succeed, institutionalisation is key. This is enabled through elements of compulsion in the form of demonstrating requirements for participation in bids for funding (Newman et al. 2004, 206). New forms of horizontal and vertical coordination bring the relevant and affected actors from the public and private sectors together in processes of negotiated governance and concrete problem solving (Piattoni 2009). Deliberative forums such as youth forums and area-based committees are useful means of encouraging a more active, participating mode of citizenship. Once-off participation will not produce the desired effects of change in the decision-making process. Thus participation must be reiterated over time and supported by institutional rules, norms and procedures (Skelcher and Torfing 2010, 79). According to Newman (2005), it is this process of fostering new forms of statecitizen relationships and remaking of governance that shapes our understanding of politics, changing the ways in which citizens engage with political power (Newman, 2005).

At the local level, openness of decision making and citizen participation in local policy is largely promoted with the underlying assumption that if citizens become actively involved as participants in their democracy, policies emerging from this process will be more effective (Irvin \& Stansbury, 2004). Benefits resulting from this process impact both the government and citizens by increasing acceptance of 
government decisions, thereby easing their implementation and empowering informed and involved citizens. Local governments may have various motives for introducing participatory policy making. The main argument is that involving stakeholders and (groups of) citizens at an early stage of the policy process rather than consulting them immediately before the implementation phase, can create a broader support for policy decisions and, therefore, make government policy more effective and legitimate (Michels \& De Graaf, 2010).

Many developed countries have institutionalised mechanisms of participation and established collaborative governance, citizens' advisory committees, and participatory budgeting. There has been an increase in using direct democracy mechanisms across developed countries (Dalton, Scarrow, \& Cain, 2003). To further develop this trend, the OECD released a practitioner's guide designed for use by government officials for building robust frameworks for informing, consulting and engaging citizens during policy-making. Strengthening government-citizen relations, according to the organization, results in better public policy, greater trust in government and stronger democracy (OECD, 2001). Both the EU White Paper on European Governance (European Commission, 2001) and the EU White Paper on Multi-level Governance (CoR 2009) emphasized citizen participation as part of the EU's core values in addition to openness, accountability and effectiveness. The principal reason for enhancing citizen participation in any area of governance is that the authorized set of decision-makers is somehow deficient. They may lack the knowledge, competence, resources or legitimacy to command compliance and cooperation. Promoting participation mechanisms thus provides legitimacy of policy actions (Fung, 2006). Thus, enabling active citizen engagement will produce relevant policy outputs, 'a better aggregation of relevant interests, ideas and resources and a better integration of the relevant and affected actors' (Skelcher \& Torfing, 2010).

Lowndes and Sullivan (2004) refer to structured mechanisms for cooperation between local authorities and non-state actors as local partnerships. These can include forums for discussion amongst local government and community members for debates and information sharing as well as policy-making forums or contractual relationships with civil society organizations for service delivery. While local partnerships may not directly deliver enhanced public participation, the authors claim that when public participation is designed into local partnership mechanisms, they serve to enhance efficiency, integration in a multi-stakeholder setting and accountability of local authorities. The main aim of local partnership is about sharing responsibility and overcoming the inflexibility created by organizational, sectoral and even national boundaries (Sullivan and Skelcher, 2002 referenced in Lowndes and Sullivan 2004). Wilson (1999) highlights that participation at the local level is valuable due to its practical implications considering that services most 
important to citizen are at the local level (environment, planning, education and housing). In addition, participation is important for democratic reasons namely that citizens are most likely to feel a sense of concern for and involvement in the life of their immediate community.

The UK is an often-cited example of reforms initiated to develop central-local relations, which recognize the role of community leadership at the local level and enhanced public participation policies (Mckenna, 2011; Sullivan, Knops, Barnes, \& Newman, 2004). The government made it a statutory duty for local authorities to consult widely when producing community plans. By strengthening the legitimacy of the local government, citizen participation strengthens the government's authority with regards to establishing partnerships with local agencies (Sullivan 2001). Yet, even in advanced democracies, state institutions retain considerable influence over the power of key agents of local governance. Hence, the capacity of local actors to act in their own interests is supported by the opportunities presented in a multi-level governance environment (Sullivan et al., 2004).

Some scholars argue that certain countries, such as Scandinavian states, are more prone to employ participative strategies for citizen involvement at the local level as the state tradition includes a consensual character (Beukenholdt-ter Mors \& Noppe, 2000). In the case of Hoogeveen municipality in The Netherlands, municipal authorities joined forces with the police, housing corporations, welfare organisations and citizen representatives to enforce a new system of decision-making on housing. The core idea was to give local residents decision-making power in designing their own environment with local council and civil society professionals adding to the policy (Geurtz \& Van de wijdeven, 2010). Yet, these processes are not without challenges. Scholars have argued that constraints on public participation in the local policy process include citizen apathy towards local politics and a general public disengagement from formal politics (Pratchett and Wilson 1996). Complex bureaucracy and formal rules of local government institutions also deter citizens from approaching formal local decision-making (Pratchett 2004). Michels and De Graaf (2010) also posit several key assumptions on citizen engagement in local decision-making, including that citizen involvement is limited to providing information and ideas rather than as co-producers of policy and that local governments are drivers of the process taking initiative and leading the cooperation. Evaluating these issues in The Netherlands, they demonstrate that civil servants and businesses participating in local partnership forums believe that citizens lack the necessary knowledge to participate, and are highly critical about the value of the information and suggestions provided by citizens. Despite the openness of decisionmaking processes, the authors maintain that civil servants hold most of the power in decision-making. Their innovative approach in pushing forward participatory governance is pivotal in the process. If civil servants do not act, citizens have a 
harder time entering the decision-making process regardless of their interest (Michels \& De Graaf, 2010). On a similar line, Lowndes and Sullivan (2004) point to weaknesses of mechanisms of broad local partnerships including the unequal power between local governments, businesses and community representatives. The different resources available to each stakeholder and the varying level of capacities influence their power in the discussion table.

Good local governance embodies an advanced state of open and efficient decisionmaking and service delivery with formal and functioning accountability measures in the horizontal and vertical structures of governance. In examining local governance in a context of transitioning democracies, good local governance should embody three critical elements: firstly, power should be distributed involving a vertical devolution of authority from central to lower tiers of government (Hooghe and Marks 2003). Secondly, openness of local governance is defined by a shift in relations between state and non-state actors, whereby participation of non-state actors in the decision-making process is enabled and encouraged. This presents a horizontal distribution of power amongst state and non-state actors (Schillemans 2008; Skelcher and Torfing 2010; Lowndes and Sullivan 2004). Finally local governance change is critical when institutionalised mechanisms are in place securing accountability of the local level to higher hierarchical state structures thereby reinforcing the role of the state in steering broader development (Newman et al. 2004).

\subsection{European conceptualisation of governance}

As one of the most important international actors in post-1999 Kosovo, it is important to look at the EU conceptualisation of governance. This offers a perspective of particular models of state-society relations and shifts required of decision-making processes Kosovo. The EU is part of the international community in Kosovo and its pursuit of democracy is according to its own understanding of democratic governance, instrumentalised through its aid programs and Instrument for Pre-Accession Assistance (IPA).

The EU foreign policy engagement demands of target countries to adopt governance reforms and is driven by general principles of good governance. This is also evident in its democracy promotion efforts, when its programs promote normative objectives. The 1991 Agreement Establishing the European Bank for Reconstruction and Development explicitly includes a commitment to democracy as a condition of membership. ${ }^{12}$ Ten years later the EU White Paper 'European Governance' (2001)

12 See "Agreement Establishing the European Bank for Reconstruction and Development," http://www.ebrd.com/pubs/insti/basic/basicl.htm. 
was a clear attempt to define the Union's conceptualization of governance. The document was a policy looking inward, inside the EU structures at possibilities and demands for change and improvement rather than a look at how it can promote governance outward. It is worth noting the normative value attached to the European concept of governance considering that these influence the way its actors and institutions perceive of the concept. The EU principles of good governance, as noted in the White Paper include openness, participation, accountability, effectiveness and coherence. The EU White Paper does also note two additional important principles, namely proportionality and subsidiarity. These concern decisions, on design as well as implementation of EU policy, which should be taken at the appropriate level (from EU to local level). At the EU level, the EU White Paper remains a broad vision rather than a specific policy request for change. It is based on this broad normative vision that EU promotes good governance principles, rather than on a particular model of one EU member. At the European level, European governance is about setting up the political rules of operation and about 'regulating hierarchies, networks and markets' at all levels (Kjaer 2004, 100). General descriptions declare that European governance includes both formal and informal institutions as well as the rules which enable actors from all levels to influence the decision-making process. As Kjaer states 'EU regulation is as much about the 'old' as about the 'new' governance, in the sense that there is as much top-down steering as network coordination' $(2004,112)$.

The European Union as a system of governance offers a particular model or interpretation of multi-level governance. The European multi-level 'political system' represents a distinct governance model including intensive 'transgovernmentalism', merged regulatory powers in the EU community and a growing importance of private actors in policymaking. EU multi-level governance posits that 'decision-making authority is not monopolized by the governments of the Member States but is diffused to different territorial levels of decision-making - the subnational, national and supranational levels' (Kohler-Koch \& Rittberger 2006). Multilevel governance thus signifies the interdependence of actors while 'governance' refers to the 'growing importance of nonhierarchical forms of policy-making such as dynamic networks which involve public authorities as well as private actors' (Hooghe and Marks 2001). This policy model enables competence sharing between actors across the different levels as well as bargaining between the networks. In 2009, the EU Committee of the Regions published the first White Paper on multilevel governance promoting a mode of governance which involves local and regional authorities in the formulation and implementation of Community policies $(2009,46)$. This document emphasizes multi-level governance as a stepping stone for the EU as it undergoes a process of change and evaluation of its own role in the global arena. The White Paper highlights the need for protecting the regional and 
local level during times of financial crises when 'attempts could be made to renationalise common policies and centralize resources' $(2009,8)$.

At the EU level, the Principle of Partnership promoted through the EU Cohesion policy includes new innovative modes of governance to engage in multi-level and multi-actor type of governance 'regardless of the given country's past experience with regionalism, subsidiarity and regular dialogue with stakeholders' (Dezséri and Vida 2008a). Nonetheless, Central and Eastern European countries (CEE), characterized by a 'bigger shadow of hierarchy' and weaker non-state and sub-state actors' were still subject to promotion of new modes of governance which focused at strengthening central state capacities (to ensure economic freedoms) rather than empowering non-state and sub-state actors (Dezséri and Vida 2008b, 1). This Europeanization process of CEE new member states brought to the surface many issues such as management of funds, absorption capacity of economies, institution building etc. as these countries were adapting to new governance structures and processes, issues possibly caused by the legacy of the past in the new member states, in terms of public administration, societal structures and economic systems' (Dezseri and Vida 2008, 2). During the integration process, there was a general lack of consideration and undermining of local government. Many 'institutional experiments' were undertaken at the sub-national level in the 1990s. Whereas in Czech Republic and Hungary, the central state government was the main actor in few cases of institutional experimentation, in Poland, actors from the region were the main drivers of series of institutional redesign or restructuring (Dezséri and Vida 2008a). In Poland, institutionalised cooperation between state and non-state actors was common and there was devolved authority to the regional level whereas in Czech Republic and Hungary, local governments were weak and fragmented. Central government policies to devolve power, restructure the economy or deal with market problems were terminated or removed once the crisis was over. Regional development programming was done without having regional actors as beneficiaries or without their involvement in the design and implementation of the program. With a weak 'vertical accountability', sub-national actors failed to make effective demands on the central state. For Central and Eastern European countries the adoption and implementation of these new elements facilitated their path towards EU integration by securing 'more efficiency, transparency and legitimacy' (Dezséri and Vida 2008a, 1-3). 


\subsubsection{EU, Europeanization and governance promotion outside the Community}

The EU role in democracy promotion is relevant for the Western Balkans due to the latters EU membership perspective. The EU is thus regarded as a leading agent inciting reforms of political structures and processes. The literature on EU enlargement and Europeanization in Central and Eastern Europe (CEE) is relevant for further deconstruction of the role of the external in Western Balkan countries aspiring to join the EU. Whereas earlier work on CEE focused on the positivist rational-choice overtones namely that EU conditionality effectively transforms postcommunist states, recent studies in the field offer insight into the importance of domestic factors (Börzel 2010). While this thesis is not a study of Europeanization, this literature is important as it helps explore the constellation of these domestic factors.

For targeted countries in the Western Balkans, it is absolutely necessary to reach EU standards and to 'transform weak states, mitigate the political, economic and social legacies of conflict and socialism' (Fagan 2010, 2). Within the international community, the EU is regarded as a key player in promoting institutional reform and development of new modes of governance outside its member states. ${ }^{13}$ Its actorness is tested through various indicators including, amongst others, its foreign policy programs i.e. the Neighborhood Policy, the Instrument for Pre-Accession Assistance of the EU Regional Policy, funds allocated for democracy promotion, integration or Europeanisation assistance, the role of EU conflict prevention and conflict management missions etc. In the agency approach of transition theory, the EU presents an additional external factor in the process of transition influencing the choices available to the political actors involved. Through political conditionality the EU encourages aspiring countries to adopt of democratic rules and practices in exchange for financial assistance (Schimmelfennig and Scholtz 2008). The Copenhagen criteria adopted in 1993, which include stability of institutions guaranteeing democracy, the rule of law, human rights and respect for all protection of minorities; the existence of a functioning market etc., provide the EU with a set of norms and expectations to promote in aspiring countries (Börzel 2005).

Contemporary scholarship recognizes the importance of the domestic context and the power of domestic agents to sabotage or facilitate substantial reforms in their country (Börzel 2010). Recent scholars contest the argument that EU membership

\footnotetext{
${ }_{13}$ The European Council of Minister's defines democracy promotion as "the full range of external relations and development cooperation activities which contribute to the development and consolidation of democracy in this countries ... (and) all measures designed to facilitate development" (European Council of Ministers, 2006).
} 
offered to the Western Balkans is a "golden carrot" to encourage implementation of reforms. In Kosovo's case where the EU has had extensive involvement for more than a decade new studies downgrade their role to a mere minor importance in the reform process (Petrov and Papadimitriou 2011). Furthermore, despite the major financial and technical assistance contribution of the EU towards reconstruction and institutional capacity building, its hesitation to deal with settling territorial conflicts has been to the detriment of statehood in the Western Balkan countries. Börzel argues that 'Europeanisation has remained largely shallow giving rise to formalistic, short-term and technocratic reforms rather than sustainable and transformative domestic change' $(2011,9)$.

Accession countries face great difficulties in restructuring their economic and political institutions in order to meet EU membership requirements. Weak states often lack state capacity to enforce policy changes thus the state shadow of hierarchy is not applicable or successful at all times. Non-hierarchical modes of steering, which involve private actors in policy-making might be more appropriate to ensure the implementation of acquis (Börzel 2005). Weak state capacities and ethnic conflicts have reduced the willingness and capacity to implement EU requirements (Börzel 2011). Moreover, considering the long legacy of authoritarian regimes and centralized administration, non-state networks and collective selforganisation processes cannot survive in weak states (Risse and Lehmkuhl 2006). The time variable is important when assessing government and governance reform considering that state capacity is built up over longer periods of time and the hierarchical authority distribution is established over time. Consequently, assessment of reforms and shifts towards governance need consider the conditions in place to elevate government to 'new heights' (Goetz 2008).

In comparison to the CEE pre-accession period, South East European countries remain behind major political and economic reforms. In the same comparison, Western Balkan countries have all experienced problems of limited statehood and are deficient in some form of state capacity over their own territories. The approval of EU legislation and policies requires state capacity, which in most cases is concentrated at the central level. However, Börzel acknowledges that capacities to implement EU policies are mostly needed at the decentralized level of government (Börzel 2011, 9). A big challenge, similar to CEE, is the prevalence of informal structures and 'rule-inconsistent behavior', which are detached from changes occurring in the formal institutions. 


\subsection{The ideal state of Good Governance}

The discourse on good governance grew together with policy analysis and practitioner's input in analyzing international organisations role in assigning benchmarks for aid programs for developing countries (Smith 2007; Rothstein 2011). International agencies and their democracy promotion programs tend to lean towards Western normative conceptualisations of governance assuming 'the modern Western nation-state is the model for good governance' (Risse 2012, 703). The World Bank definition of good governance ${ }^{14}$ (Kaufmann, Kraay and ZoidoLobatón 2000,10) reads:

The traditions and institutions by which authority in a country is exercised for the common good. This includes (i) the process by which those in authority are selected, monitored and replaced, (ii) the capacity of the government to effectively manage its resources and implement sound policies, and (iii) the respect of citizens and the state for the institutions that govern economic and social interactions among them.

Good governance, understood purely on a normative basis, as the aspirational and overarching goal of international mandates, has often been criticized for being too idealistic and presenting a benchmark too high to reach for post-conflict societies. Scholars debate whether the academic discourse translates into practice and point to issues that arise from the analysis of governance. Grindle (2007) challenges the credibility of the good governance approach contesting its ability to grasp the evolution of institutions and their capacity within a transitioning country. Attention should be focused on what she terms 'good enough governance'. This framework of analysis 'directs attention to considerations of the minimal conditions of governance necessary to allow political and economic development to occur` (Grindle 2007, 554). Good enough governance requires aid organisations and international interventions in general, to be tailored to conditions of individual countries. A 'Good Enough Governance' agenda would be based on a more nuanced understanding of the domestic institutions and government capabilities thus presenting a workable agenda for the international actors to engage with target countries. The latter, however, will prioritize the opening up of the government to promote an inclusive decision-making only when the states are institutionalised and functioning (Grindle 2007). Institutionalisation of open decision-making mechanisms thus becomes pivotal in the political transition of a country.

\footnotetext{
${ }_{14}$ The World Bank Governance Matters Indicators evaluate countries based on their rule of law, control of corruption, voice and accountability, government effectiveness, regulatory quality and political instability and violence (Kaufmann, Kraay and Zoido-Lobatón 2000).
} 


\subsection{Governance under Limited Statehood}

Bearing in mind that the governance discourse is largely based on developed, democratic and modern nation-states, Thomas Risse and Ursula Lehmkuhl (2006) caution against the limitations of exporting notions of (good) governance to developing, transition or failing states where there are areas of 'limited statehood'. In fully functioning states, the government, or the general state apparatus has the ability to enforce political decisions and thereby conduct hierarchical steering. In a limited statehood setting, the state apparatus has limited resources and legitimacy, thus serious deficiency in its sovereignty to control and exercise its authority in implementing decisions (Risse and Lehmkuhl, 2006). Furthermore, central government limited capacities reinforce their unwillingness to engage in substantive reforms (Börzel 2010, 11).

The limited statehood concept is based on Max Weber's conceptualization of statehood as an institutionalised rule structure with the ability to rule authoritatively and to legitimately control the means of violence (Risse 2012). Consolidated states embody domestic sovereignty ${ }^{15}$ in which authority structures ensure 'a society that is peaceful, protects human rights, has a consultative mechanism, and honors a rule of law based on a shared understanding of justice' (Krasner 2004, 88). States thus retain the option of hierarchical steering if only to cast a "shadow of hierarchy" (Risse 2012). The absence of a consolidated state necessitates the recognition of limited statehood. To clarify, limited statehood, is not restricted to failed states and Risse draws attention to the fact that most developing and transition states encompass areas of limited statehood 'as they only partially control the instruments of force and are only partially able to enforce decisions, mainly for reasons of insufficient political and administrative capacities $(2012,702)$. Areas of limited statehood are then defined as:

those parts of the country in which central authorities (governments) lack the ability to implement and enforce rules and decisions and/or in which the legitimate monopoly over the means of violence is lacking, at least temporarily (ibid.)

Governance without government cannot occur in states with weak governments. Governance without government occurs in liberal democracies, where according to Börzel (2010), it is least needed. When government fails civil society and business organisations do not have the capacity or the autonomy to step in and contribute in the provision for the common good (Börzel 2010). Governance thus requires a

\footnotetext{
${ }^{15}$ Domestic sovereignty is defined by Stephen Krasner as 'the formal organization of political authority within the state and the ability of public authorities to exercise effective control within the borders of their own policy' (Krasner 1994, 4).
} 
functioning hierarchy to exert authority in order for networks to function. Areas of limited statehood, however, are defined by weak "shadows of hierarchy" (Risse $2012,709)$. In this context of limited statehood, external or international actors play a significant role in setting up the rules of the game. According to Börzel, international agents cast an external shadow of hierarchy through their involvement in domestic reforms, (Börzel 2010, 19). This allows for the international community to partially substitute the authority of the state and ensure higher conformity from domestic state and non-state actors under the standards of good governance. The involvement of international actors thus contributes to the establishment of multilevel governance in Kosovo considering their contribution to public services (Risse 2012, 709).

Governments require autonomy; resources as well as efficiency in order to 'produce a credible shadow of hierarchy' (Börzel 2010, 14). The existence of hierarchy is only possible when actors have the ability to coerce others. ${ }^{16}$ Governance structures do not determine but rather promote specific modes of coordination. Government actors have incentives to compromise for reforms or certain decisions as a result of 'the perceived threat of a unilaterally imposed decision' from the higher ranks of the hierarchy. Governance is thus presented as an institutionalised form of political coordination. EU policy making, as an example, relies on the strong shadow of hierarchy cast by supranational institutions ${ }^{17}$ (Börzel 2007). However, at the global level, due to the lack of a world government to provide for a legitimate monopoly over the use of force, 'global governance has to rely solely on non-hierarchical modes of steering' (Risse 2004).

International agencies ultimately strive to set up authority structures which are capable of providing security and designing policies for serving their citizen. There is an evident need for help that badly governed states require considering they 'will not fix themselves because they have limited administrative capacity, not least with regard to maintaining internal security' (Krasner 2004, 86). Whether this presents an imperialist position is highly doubtful. The imperialist criticism rose from a group of scholars who condemn intrusive mandates and the international usage of veto in pushing forward policies. The 'excessive' executive authority according to Chandler (2006; 2010) does not contribute to strengthening domestic institutions and weakens sovereignty of countries controlled by international missions. It imposes Western models of state governing without the consent of domestic actors. This 'Empire Light' labeling (Chandler 2006), however, portrays a rather unidirectional relation

\footnotetext{
${ }^{16}$ As Börzel puts it: "Only those actors that have the capacity to enforce collectively binding decisions against the resistance of those who have to bear the costs or whose preferences are not accommodated can cast a credible shadow of hierarchy" (2010, p. 14).

${ }_{17}$ Private self-regulation and public-private co-regulations are rarely to be found at the EU level, while they exist at the national levels (Börzel 2007).
} 
between external and domestic institutions and actors. As this research will verify, domestic structures, both formal and informal, are important actors who can both initiate and drive change.

This study takes into consideration the issues raised by Grindle, Risse, Lehmkuhl and Börzel and acknowledges that governance is not inherently a liberal concept. It also recognizes that structural reforms promote a model of governance that embodies enhanced democratic principles. In the Kosovo case, overcoming the challenges of limited statehood, limited resources and legitimacy, presents a move towards reinforcing the role of state authority as well as introducing new mechanisms of vertical and horizontal links. This marks a shift towards the standard of developed, democratic and modern states. To explore what governance looks like in an environment of limited statehood, a series of case studies in Kosovo are explored where the state is weak and unable to exert its shadow of hierarchy.

Governance literature offers models of opportunities for actors to engage in. The emergence and successful implementation of open governance is tempered by the context. The assumption in the literature is for actors, both at local and central level to utilize the opportunities available in governance structure to shift towards new governance modes. However, the extent to which these shifts can occur, if these are in fact successful or not, is heavily influenced by the context. Certain meanings of governance serve as a framework for analysing institutional evolution in fullydeveloped democracies, which some scholars consider inappropriate for understanding governance in 'immature and struggling democracies emerging from autocratic rule and having only rudimentary democratic and administrative institutions' (Lynn 2010,3). Nonetheless, when considering the context of limited statehood, the governance concept is useful for analysing policies and politics because it helps in acknowledging the role of international and non-state actors involved (Risse 2012, 711). To complete the conceptualization of governance in a post-conflict environment, the following section reviews state-building literature discussing its approach on reconstructing state power after conflict. Embedded in this literature is the understanding that international actors are an integral part of the country's politics and decision-making scene (Tansey 2009).

In the context of limited statehood, we may expect peculiar forms of governance that bear resemblance to multi-level governance in so far as they appear to include empowered non-state actors. However, this may be rather superficial. Modes of governance may appear new but on closer inspection are strongly hierarchical and centralized reflecting communist structures. Hence the local level allows for a clear identification of the modes of governance emerging on the ground and the factors enabling these shifts. Local agents are thus influenced by both the limitations of a weak central government and the intense involvement of the international 
community. Under the microscope the local level is a particularly interesting field because of the shared power between the international community and the central government, both lacking in either legitimacy or capacity to exert a shadow of hierarchy.

\subsection{International role in state-building and democracy promotion}

In this study, the international community, with its extensive involvement and countless activities, is inevitably an important dimension in the transition process and must be factored into the research. When international administrations are vested with executive powers, overruling of national legislation or enforcing new legal frameworks is within their authority. ${ }^{18}$ Nevertheless, there is a danger that mandates and roadmaps of international agencies are taken too literally. Their potential to succeed in reaching their objectives of complete transformation of postconflict environments must be taken with caution.

Terms referring to international involvement, state-building and democracy promotion are discussed extensively in the literature of democratization and regime change in post-conflict societies. The concepts, state-building and democracy promotion, do not merge into one whole but can neither be split entirely into independent parts. The common denominator is the broad aim proclaimed by external agencies or drivers of change to achieve an environment of functioning governance structures with democratically elected representatives and clear lines of accountability across state institutions and civil society organized units. Scholars sometimes refer to state-building as an extreme form of democracy promotion due to the authority of international agencies to assume state functions and executive authority. This dimension has been long criticized for impeding 'home grown' democracy and obstructing domestic involvement in the transition (Chandler 2006). However, this interpretation is opposed by others as insufficient and lacking the process-oriented dimension of continuous dialogue and interaction between

\footnotetext{
18 These executive functions are not predominant in international administrations. For studies on international administrations see: Caplan, R. (2002). "A New Trusteeship? The Administration of War Torn Territories", International Institute of Strategic Studies Adelphi Paper 341; Caplan, R. (2005). "International Governance of War-Torn Territories. Rule and Reconstruction". Oxford: Oxford University Press; Berdal, M. and Caplan, R. (2004) "The Politics of International Administration". Global Governance: A Review of Multilateralism and International Organisations, 10(1); Chopra, J. (1999). "Peace-Maintenance: The evolution of international political authority". London: Routlege; Chesterman, S. (2004). "You, The People. The United Nations, Transitional Administration and State-Building". Oxford: Oxford University Press; Zaum, D. "The Sovereignty Paradox. The Norms and Politics of International Statebuilding". Oxford: Oxford University Press. In this study, references to the international community or international agencies, encompasses a larger set of agencies than solely the UN administration.
} 
international and domestic actors in strengthening institutions and civil society organizations (Narten and Zurcher 2009; Bliesemman deGuevara 2010). Statebuilding is also defined to include political and economic reconstruction efforts in the immediate aftermath of conflict to differentiate it with democracy promotion which covers all development assistance and support for consolidating democracy once domestic liberal processes are already underway and institutions and formal procedures are in place.

\subsubsection{State-building: The battle between international and domestic reformers}

In the time period 2000-2009, the Stockholm International Peace Research Institute (SIPRI) recorded some 600 multilateral peace operations, both UN and non-UN deployed worldwide. In their most intrusive form, international administrations present "a formally constituted international body that has been entrusted temporarily with responsibility for the principal governance functions of a state or territory" (Caplan 2009, 359). This international authority temporarily assumes some or all powers of the state (Chesterman 2004). In the 1920s and 1930s the League of Nations occasionally exercised administrative powers in various territories. These included the city of Memel (now Klaipeda in Lithuania), Danzig (now Gdansk in Poland), the district of Leticia (a disputed territory between Colombia and Peru) and the Saar territory bordering France and Germany (Willingen 2009). In the aftermath of the second World War, the United Nations were the leading organisation in interventions assisting decolonization processes in the African continent (Congo), transitions to independence (New Guinea, West/South Africa-Namibia) as well as operations in Cambodia, Often these operations have been labeled as peacekeeping. ${ }^{19}$ In recent decades immediately after the Cold War, the United Nations was again in the frontline of missions involving intervention in Cambodia, Somalia, Eastern Slavonia and East Timor.

Empirical studies conducted by Doyle and Sambanis (2000) show that multilateral UN peacekeeping operations do make a positive difference in ending violence and are positively correlated with democratization processes after civil war. The international presence is usually established with a short-term mandate with the main overall objectives of fostering the transition to a status of rule of law and supporting the consolidation of governing institutions. Nevertheless, their presence is often extended due to prolonged political and ethnic issues within the country. Hence, a key objective is creating a 'multi-ethnic' environment in conditions of

\footnotetext{
19 The concept is explained further down in the text. See also: United Nations Department of Public Information (1996), The Blue Helmets: A Review of United Nations Peacekeeping. New York: United Nations.
} 
deeply divided societies and promoting participation. Needless to say, proclaiming these objectives is easier than achieving them in reality. The international administration does not have an intrinsic formula for success. The lack of a blueprint for these initiatives allows for interpretations of mandates and alterations of process while increasing the risk of failure. These general goals have been criticized for their vagueness, but also for being driven by the dominant Western perception of democracy. The harshest critics have termed this as Western imperialist interests aspiring at implanting Western conceptualizations of democratic states and good governance upon other societies (Chandler 2006; Ignatieff 2003).

A string of international military engagements in conflict societies in the last two decades has drawn attention to the challenges faced during state-building while reinstating functioning institutions. The growing academic literature has gradually shifted the discourse from advocating intervention in conflict regions towards evaluating the impact of external involvement in state-building. A series of scholars agree that there has been an important shift in peacebuilding strategy, which now incorporates elements of rebuilding of institutions and governance (Chesterman 2005, Chandler 2006, Fukuyama 2004, Paris and Sisk 2009). Together with the actions taken and the expectations of an intervention, a shift also occurred in terminology. What used to be peacekeeping is now often referred to in different concepts, peacebuilding, nation-building or their substantive agendas: democratization and liberalization. It is thus not surprising that international administrations are commonly preoccupied with "governance of a comprehensive nature" (Caplan 2005, 21). Certain modes of governance are thus prioritized by international administrations' work i.e. democratically elected institutions and minority protection as well as policy reforms to open up the economy. Governance, good governance and democratic governance are all entangled broad concepts guiding this extensive involvement serving both as the means and end goals of their mission.

'Blueprints' for internationally led governance reforms must be viewed with caution as they do not necessarily present concrete steps taken on the ground. Strategies of international agencies are repeatedly redesigned and altered during the course of their mandate thus deviating from initial reforms intended. Initiatives and actions are highly influenced by the politics on the ground and the negotiation between international and domestic actors, be they central, local, state or non-state is a continuous process during the entire course of transition. External efforts may also be influenced by the approaches (beliefs, interests and models) of the different actors participating in the international administration. These concern Western oriented viewpoints on democracy and institutional structures with the conviction that establishing a certain set of institutions will facilitate development and stability 
and resolve the roots of conflict in the country being administered. The same applies also for expectations of foreign actors that they will help state-society relations (Doornbos 2008). External efforts are also charged with the mission to generate political legitimacy for the (new) set of state institutions being built (Brinkerhoff \& Azfar 2006).

Influenced by Western-democracy models, reforms in a post-conflict context include policy changes for a market-oriented economy (privatization, tax laws, fiscal control) and enhancement of civic democracy (minority protection laws, civilian control of military etc.). By forming a coalition with domestic elites external actors strive to influence the choices or alternatives at hand. In order to achieve certain standards of governance 'at times implies changes in political organisation, the representation of interests, and processes for public debate and policy decision making' (Grindle 2004, 525). External 'forces' can only come to existence if they operate in tandem with domestic influences and as such need to convince the domestic leadership that 'change is a good idea' (Jacoby 2006, 625).

In attempts to evaluate international involvement in guiding post-conflict transition, scholars draw attention to various risks including holding early elections (Caplan 2004), mal-coordination and lack of commitment (Chesterman et al 2005; Chandler 2006), creating political and aid dependency (Bieber 2002), lack of local ownership and inclusion of local actors (Reich 2006) etc. As one of the most vocal critics, David Chandler $(2010,6)$ protests against external involvement in setting up new governance structures stating the following:

Rather than legitimize policy making on the basis of representative legitimacy, post-liberal frameworks of governance problematize autonomy and self-government, inverting the liberal paradigm through establishing administrative and regulatory frameworks as prior to democratic choices. This process tends to distance policy making from representative accountability, weakening the legitimacy of governing institutions in Southeastern European states which have international legal sovereignty but lack genuine mechanisms for politically integrating society.

This conception of an external imposition, scholars argue, may foster public mistrust of democratic institutions and the 'gap dividing elites from the public [may] become a troubling political liability' (Belloni 2008, 177). In studying international intervention in the African context, Doornbos (2010) draws attention to the risk of donors bypassing the autonomy of state structures through partnerships with private stakeholders or direct funding of NGOs. These factors increase the state society gap thereby increasing the propensity for state failure (Doornbos 2010). In decentralization policies, donor preferences for privatization and non-governmental initiatives undermine the role of the state institutions 'occasionally leaving questions 
as to which bodies would theoretically still be responsible for guarding the common interest' (Meynen and Doornbos 2004, in Doornbos 2010).

Scholars have boasted the assumption that international actors possess a stronghold over the entire process of transition and are in 'unequal partnership' with domestic counterparts (Chandler 2010). Scholars who argue that this approach amplifies the power of the international actors contest this approach. If this were the case, then the international administration successful completion of its mission would have a direct correlation with its establishment in a post-conflict country. It would reach its objectives and would solely depend on the coordination of actors and funding. International administrations and organisations in general do not possess an inert ability for success. A crucial factor to consider is that these governance interventions are not introduced in a vacuum where power and resources of the domestic factor are nonexistent. There is some sort of existing (even if low) capacity on the domestic front (Grindle 2007). Domestic actors including organized political entities, government officials, elected members of Parliament as well as political parties, associations and interest groups with political activities (such as war veterans or mobilized ethnic groups) have their own aspirations during the transition period. The realization of existing domestic interests and domestic conceptualizations of a state is important and must be considered when engaging with various actors during the transition (Bliesemann de Guevara 2010). Assuming that the domestic actors uphold their interests, externally introduced ideas will be ignored, interpreted or rejected as a consequence of local conditions and interests. Given the big and deeply embedded differences between foreign and domestic actors, it seems only natural that strategies will meet some form of local resistance and that policies will retain distinctly national traits (Eriksen 2007). The effects of state-building are thus anything but the one-dimensional results of intended, top-down practices by international actors (Bliesemann de Guevara 2010, 116). Domestic political agency should not be underestimated and must be factored into any analysis of postconflict transition.

The economically weakened, institutionally rundown and ethnically fragmented societies with which the international community is involved are politically and administratively complex. The post-conflict context requires swift and decisive political actions, which in turn cause a dilemma (or even clash) between efficacy and legitimacy (Jarstad and Sisk 2008). International actors often push the domestic elites into taking swift actions that weaken their legitimacy due to the lack of consultations with societal groups (Zürcher et al. 2009). Mansfield and Snyder (2002) point out that institutional mechanisms for accountability must accompany the opening of the political sphere which enables wider participation. 
As Zürcher rightly notes, 'a democratic peace brings with it norms and rules of good governance that restrict the ability of power-holders to reign, extort, and expropriate arbitrarily $(2011,85)$. Thus it must be noted that domestic elites may use the international presence as an opportunity to gain or at least preserve their own power and existence in these new conditions. They attempt to steer the international authority in a particular direction in favour of their own interests. Baskin (2006) supports this claim by noting that it is 'the interaction of international commitment, or its absence, with local capacities and factional hostility that shapes the prospect for successful peace-building' Narten and Zürcher (2009; 2004b). Collaborating with certain groups may also prove to be challenging for the international officials engaged in facilitating financial and technical support.

On the one hand, international actors are key negotiators, proposing, advocating and when endowed with executive powers imposing key solutions to the political challenges faced during the transition period. This involvement has many facets. According to Tansey (2009) this is done through advice, persuasion and conditionality to achieve international norms of democratic governance. On the other hand, domestic actors aim to preserve power, exercise influence and represent their constituents. Consequently, neglecting local elites can decelerate and even spoil the process of improving governance. International and domestic actors present various reactions, cooperating or resisting, depending on the power they have in altering the outcome (Narten and Zürcher 2009). This way the transition process becomes a political market, as Woodward calls it; or a contest for power 'over who rules, who gets to define policies for their group or goals, and above all, the very rules over who rules' (Woodward 2009).

With regard to other levels of government, Barnett and Zürcher (2009) argue for a need to analyze tensions between state elites and sub-national elites and the need that international implementers address their interests separately. Under the assumption that elites are against governance reforms which may lead to democracy, scholars state that reforms implemented during a transition to democracy undermine elites' power (Zürcher 2011). Moving toward a more democratic regime would imperil the very foundations on which political authority in many of these post-war countries rests-an elaborate system of informal governance, of which widespread patronage and corruption are common features (ibid.). Informal governance structures may also exist as a result of societies' and communities' self-organisation. This also applies to particular services, which informal governance structures may continue to provide until a common legal framework is (re)established.

Ignoring existing structures and aims of domestic leaders endanger the stability of the country. Thus, institutional legacy is important for explaining the process and 
success or failure of externally promoted governance reforms. In his study of transition of former-communist countries, Eriksen (2007) highlights former administrative traditions and legacies from the past as an additional factor influencing successful transition towards democracy. However, literature reveals different weights of importance given to the value of path dependency in governance transformations in post-conflict areas. Disagreements exist over the issue whether change towards Western models of governance is possible in nonWestern societies due to their institutional legacy and social values inherited from former authoritarian governing. Chandler notes 'the argument within EU is still often repeated that many states in the SEE region lack sufficient capacity and suffer from historical 'path dependencies' which have undermined the relations between states and their societies' (2010, 7). Consequently, international actors allocate resources in supporting the few domestic 'drivers of change' they can find. Recent analysis of particular policy areas suggests that in successor states of former Yugoslavia capacities of elites and non-state actors vary, but are generally perceived to be low (Fagan, 2010, 2011; Elbasani et al 2012). Nevertheless, their potential for enabling incremental change remains realistic.

In the Western Balkans, former Yugoslav countries are important examples of international involvement in guiding political reforms as well as complex power constellations among governance structures. For this particular region, scholars have drawn attention to the politics of state-building (Chandler 2006; Bieber 2005, 2006; Paris \& Sisk 2009), the dynamics of international-domestic interactions during the establishment of new governance structures (Narten \& Zürcher 2009; Willingen 2009), the impact of democracy assistance on civil society participation in governance (Fagan 2011). International involvement in the Western Balkans is often drawn in parallel to the role of external agents in post-communist Central and Eastern Europe. Literature suggests that democratization efforts in Central and Eastern Europe were already underway, facilitating the work of international donor agencies. The political elite and civil society showed readiness to comply with reforms as compared to Western Balkans where institutions and civil society organisations are weaker and state administration is less effective. This gives the appearance of higher intrusion by international agencies to foster new structures and strengthen civil society's role in reforming institutions (Elbasani, 2012; Fagan, 2005).

Kosovo is a particular case where the international community's protracted presence involved an array of activities and mandates of international agencies which changed over time. The international administration in Kosovo, led by the UN Mission in Kosovo (UNMIK), mandated to maintain peace and security and reestablish government institutions. The European Union was part of this mission charged with economic reconstruction. Mandates changed over time as the political 
issue of Kosovo's final status remained in limbo. Both the UN and EU continue their presence today after Kosovo's declared independence in 2008 with the EU mandated to oversee Rule of Law and strengthen the judiciary whereas the UN has reduced its mission to concern mainly the North of Kosovo.

The variety of international organisations involved in Kosovo as well as everchanging political situation brought about many actors and a wide range of influence in the process. Accountability and partnership lines between actors, international-domestic, central-local, and state-non-state are blurred. A valuable dimension is clearly delineating who are the main leaders promoting governance reforms and endorsing changes in institutions and rules of the game. As Ebel and Péteri highlight 'when too many authorities are involved in the same tasks, none of them is really accountable' $(2008,54)$. The power distribution among these actors also influences the dynamics of interaction between modes of governance hence the necessity to map out the power distribution and locate the main conduits of change. The transition process includes stakeholders at different power positions which are strengthened or shaken due to the impact of state-building (re)distribution of power resources (Bliesemann de Guevara 2010, 116). The opening of doors for certain groups or elites often means the closing of opportunities and power routes for others (ibid.). Interests of domestic parties may be challenged or threatened by new governance structures and processes of decision-making. New modes of governance may present a threat to the survival of networks and power bases of elites. This may lead elites to 'cultivate ties with a subset of society in order to make an implicit bargain- political support in exchange for state jobs or targeted public good' (Zürcher et al. 2009).

\subsection{State-building at the local level}

In a post-conflict context, establishing self-governing and decentralized structures is critical to restore the presence of the state, to ensure stability, demilitarize politics in divided societies and increase interethnic cooperation (Lister and Wilder 2005). Civic engagement in local decision-making builds the foundation for democratic governance at the local level and ensures sustainability of the governance structures. Local government is the first body of public authority the citizen turns to for solving their immediate social problems. It is 'the level of democracy in which the citizen has the most effective opportunity to actively and directly participate in decisions made for all the society' (Sisk 2001, 15). However, in order to secure sustainable democratic local governance, it must be 'integrated into a much broader network of autonomous institutions that function according to basic, agreed-upon political values and the principles of democratic political and social organisation' (Baskin 
2004). This does not undermine the vital role of central government to supervise and assist the change of ways of doing politics. ${ }^{20}$

As explained earlier, literature on state-building suggests that central authorities remain a key agent for the international community. The underlying assumption, both on the academic as well as practitioner's level is that of a trickle-down effect by concentrating efforts at strengthening central government institutions (Manning 2003). Theory suggests that sub-national tiers of government are weaker in claiming changes and asserting their influence on the political developments bearing in mind that few countries transitioning towards democracy have a long-standing tradition of local self-governance (Teune 1995). Post-socialist societies entail characteristic institutional and structural modes of governing and state-society relations. When introduced to 'Western' concepts, the political culture is not particularly conducive to new means of participation and lines of accountability. Importing and implementing new modes of governance is therefore a daring political process. Some mode of governance continues to exist, even in environments of weak central states as governance may occur at multiple levels of societies. Existing and possibly embedded structures of power and authority will be encountered (Eriksen 2007) and interests of political groups will impact the potential and pace of reforms. Supporting local governance by opening up local decision-making to non-state actors improves the capacity of the state to exercise its sovereignty and serve its citizen.

Results of an empirical study on local governance in Mexican municipalities show that the dynamics of the decentralization process are influenced by the hierarchy structures of the country (Grindle 2009). Hooghe and Marks (2001) argue that the dispersion of governance across multiple jurisdictions is both more efficient and normatively superior to centralist states (Hooghe and Marks 2001). This goes in line with the subsidiarity principles of the European Charter of Local Self-Government (1985) under which 'public responsibilities shall generally be exercised, in preference, by those authorities, which are closest to the citizen. Allocation of responsibility to another authority should weigh up the extent and nature of the task and requirements of efficiency and economy'.

Despite the existence of a considerable body of theoretical and empirical studies conducted on the international involvement in the Western Balkans, ${ }^{21}$ the bulk of literature factors only the central state under the assumption that it is the sole driver

\footnotetext{
${ }^{20}$ Hence, policies introducing a devolution of power to local authorities or establishing regional layers of multi-level governance present only a fraction of the bigger picture and should not be treated as a de/facto governance shift.

${ }^{21}$ The international community has been involved with a variety of international missions in four countries: Bosnia and Herzegovina (UNMIBH 1995), Croatia/Eastern Slavonia (UNTAES 1996), Kosovo (UNMIK 1999), Macedonia (EUPOL 2001).
} 
of change. Recognizing its importance in pushing for reforms, this study seeks to identify additional streams of power among organized units, state as well as nonstate driven. Literature on the state-building transition process does not address local governance beyond the function of service delivery to its citizen. The process of promoting change and negotiation between the relevant state and non-state actors at the local level is of paramount importance to successful reforms. Most studies stop at ethnic issues, territorial organisation or factors such as efficiency and accountability in local service provision. The local level is important in the democratization process as it is a key player in the constellation of actors involved in introducing, promoting or challenging forms of governance. Thus reforms concerning local governments must incorporate a broader understanding of statesociety relations.

Local governance, being 'larger' than simply the provision of local services, incorporates the establishment of 'space for democratic participation and civic dialogue' and 'facilitating outcomes that enrich the quality of life of residents' (Shah 2006, 2). Clear and functioning intergovernmental relations between the institutions are crucial to ensure that governance structures enable participation and accountability. Active involvement of citizens in local decision-making is the best practice for attaining the attributes of good governance. Electoral participation and engagement in decision-making processes embrace actions based on certain values and beliefs which need to be instilled in the culture of the community. This is especially challenging in post-socialist environments and post-conflict contexts where state-society relations were never democratically established or have been broken. Chopra and Hohe warn that that 'exclusion of the people from any aspect of state-building will continue to cause costly interventions to founder' $(2004,303)$. Jackson and Scott argue on the same lines of the dangers of the transition process turning into a vicious circle 'where participation is low, so is ownership and government legitimacy, which further reduces participation' $(2007,18)$. Quick-fix approaches, ignoring local capacities and institution-building, can lead to dependency (Brinkerhoff and Mayfield 2005). In addition, low inclusion and ownership of local stakeholders, both state and non-state actors, in the decisionmaking process of drafting main policies will reduce the chances for sustainability and legitimacy of governments through providing services to citizens.

In order to understand and evaluate external impact on local governance, the multidimensionality of governance reform must be taken into account. The conditions set by each party involved and interplay between domestic and international actors are interconnected, thereby creating a complex process of transition. This research unfolds this complexity through an analysis of formal and informal structures of governance as well as through tracing the interaction between both horizontal and vertical links between actors as they exercise power over the process of transition. 
For pluralist competitive politics, strengthening local governance serves as a device for deepening democracy or for opening closed systems to give interest groups space in which to organize, compete and otherwise assert themselves (Manor 1999). Focusing attention only on central institutions risks leaving local governance structures weak and may contribute to new patterns of disconnection, opposition, authoritarianism, fragmentation, and violent conflict (Jackson \& Scott 2007). As studies on Afghanistan indicate, the sub-national administration is often overlooked or neglected by the international community although it 'both shapes and is shaped by complex political dynamics and is part of a broader political process' (Lister \& Wilder 2005, 39). The local level is 'where the political settlement has the most immediate impact on the lives of ordinary citizens' (Manning 2003, 36). Establishing central government institutions which are legitimate in the eyes of the citizen is a crucial factor in state-building. Moreover, a strong local governance within the reach of the population and at the same time valued by it, is also of great relevance in post conflict reconstruction (Hohe 2005). Thus the emphasis of reforms should be on the local level 'as this is where the peace settlement happens' (Jackson 2002, 1-2). Neglecting local governance weakens democracy at the grass-root level and as such endangers the democratization of the country as a whole. Supporting local governance by opening up local decision-making to non-state actors actually improves the capacity of the state to exercise its sovereignty. Studies of municipal performance in South East Europe confirm that municipal efficacy grows with the increasing involvement of social and economic actors in the policy-making process (Petrova 2011). Experience of reform pressure in Central and Eastern Europe shows the impact of policies that lack consideration of and undermine local government. Dezséri and Vida (2008) point out that central governments gave away power to restructure the economy or deal with market problems only to take it away the crisis was over. In the context of CEE where a centralized governance regime was prevalent, new modes of governance were conceptualized as 'layering" (Dezséri and Vida 2008b 2) and reforms did not successfully ensure sustainability of these modes of governance.

\subsection{Conclusion}

This chapter introduced the main concepts to construct the framework for examining local governance in Kosovo and for assessing the various reforms to transform decision-making at the local level. Whereas governance is the overarching framework, this study is situated in a particular angle of governance research, which focuses on governance in a post-conflict context where the international community plays an important role in 'substituting' for limited central authority. 
The chapter advances the position that the ideas of governance, although commonly used to identify the transformation of power at the central state, are nevertheless critical for successful democratic decision making at the local level. For effective local governance to occur, capturing all the normative ideals of subsidiarity, participation and deliberation, then reform at the state level is also vital and as such local governance must be embedded in multi-level governance with effective and accountable institutions. At the local level, this means effective local governance embodies an advanced state of open and efficient decision-making and service delivery with formal and functioning accountability measures in the horizontal and vertical structures of governance. In examining local governance in a context of transitioning democracies, good local governance should embody three critical elements: a vertical devolution of power from central to lower tiers of government, openness of local governance defined by a shift in relations between state and nonstate actors and institutionalised mechanisms must be in place securing accountability of the local level to higher hierarchical state structures thereby reinforcing the role of the state in steering broader development.

The conceptualization of governance by international agencies, in particular the EU, was discussed extensively to emphasize their approach to governance and the way international agencies promote principles of good governance in developing countries. In addition, the literature on state-building provides a more tailored approach to the context of post-conflict transformations through understanding the potential of the international community serving as an external shadow of hierarchy. To complete an inclusive conceptual framework, this chapter also considers the concept of limited statehood, in terms of bureaucratic capacities and contested authority, and the impact these limitations may have on local governance reform. Considering the state limitations, the role of the international community is enhances as substituting for the weak central state. This framework paves the way for an exploration of the local government reforms in Kosovo, the extent to which the international community has influenced these reforms and the factors enabling a shift towards multi-level governance. 


\section{Local governance in Kosovo: A domestic or external drive for local government reforms?*}

\footnotetext{
* An earlier version of this chapter is published as "Decentralisation in Kosovo: Challenges of reforming the local level" in LSEE Research on South Eastern Europe, Papers on Decentralization and Regional Policy, 2014.
} 


\subsection{Introduction}

This chapter introduces Kosovo presenting a brief background to the country and highlighting the key dimensions of local governance in the country. It is structured in two parts. The first part provides the reader with a basic outlook on Kosovo. It presents a detailed review of the trajectory of the main local government reforms undertaken in Kosovo. This also includes an account of the main agencies involved in promoting reforms at the local level. The second half of the chapter looks specifically at evidence from two recent international initiatives designed to enhance local governance practices and promote democratic decision-making at local level. The cases identified in this chapter focus on two external agencies heavily involved in local governance reform: EU and USAID. Semi-structured interviews with donor agencies and representatives of the international community in Kosovo, including the UN Mission in Kosovo, OSCE and International Civilian Office, provide insight on the trajectory of reform in Kosovo and their role in pushing forward strategies for good local governance.

\subsection{Local governance in Kosovo}

Kosovo uses a two-tier government system in which municipalities (komuna/opština) are the basic territorial unit of self-government. ${ }^{22}$ The country's 2008 Constitution ensures minority communities' right to representation at the local level ${ }^{23}$, the right to local self-government and the country's respect for the European Charter of Local Self-Government. The map below presents the current 37 functional municipalities in the Kosovo territory of 1.8 million inhabitants. ${ }^{24}$

\footnotetext{
${ }^{22}$ Constitution of Republic of Kosovo, Article 12.1.

${ }^{23}$ Ibid. Article 62.

24 This map does not portray the municipality of North Mitrovica which was not functional under Kosovo authorities but managed through a presence of the remaining UNMIK mission.
} 
Figure 1. Map of Municipalities in Kosovo

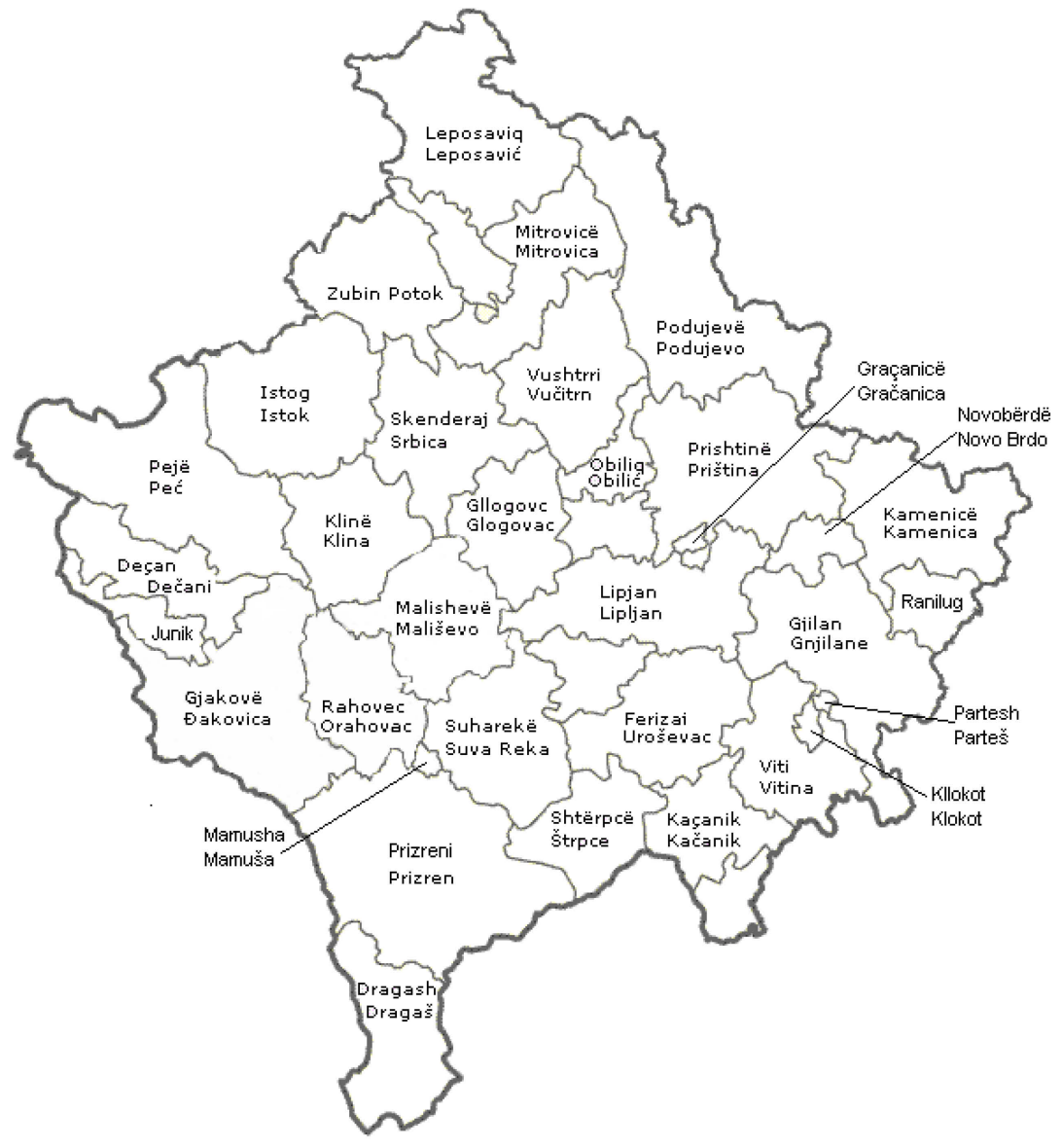

Source: US Embassy in Kosovo (2012)

The Kosovo population is $90 \%$ Albanian and the largest minority is Serbian (est. 7\%) living in various municipalities throughout the country. Other smaller minorities are composed of Roma, Bosniaks, Turks, Gorani, Ashkali, Egyptians and Croats (KSA 2011). The 2011 census in Kosovo failed to include the municipalities in the North of Zubin Potok, Leposaviç/Leposavić and Zveçan/Zvećan. The municipality of North Mitrovica, although announced as a new municipality under the new 2008 legal framework, was not fully established at the time of this research. The 2011 census failed to provide complete information regarding the existing population in the northern part of the country. The map below provides the only official atlas of 
ethnic communities in Kosovo published by the Kosovo Statistics Agency in December 2013. Blue refers to areas composed of more than $90 \%$ of the Albanian ethnicity. The red dots depict the Serbian ethnicity with each dot representing $1 \%$ of the population. The Serbian population is concentrated in the municipalities of Graçanica/Gračanica (near the capital of Prishtina), Partesh/Parteš, Ranillug/Ranilug and Kllokot/Klokot. The green areas show the Turkish population mainly in the new municipality of Mamusha.

Figure 2. Map of ethnicities

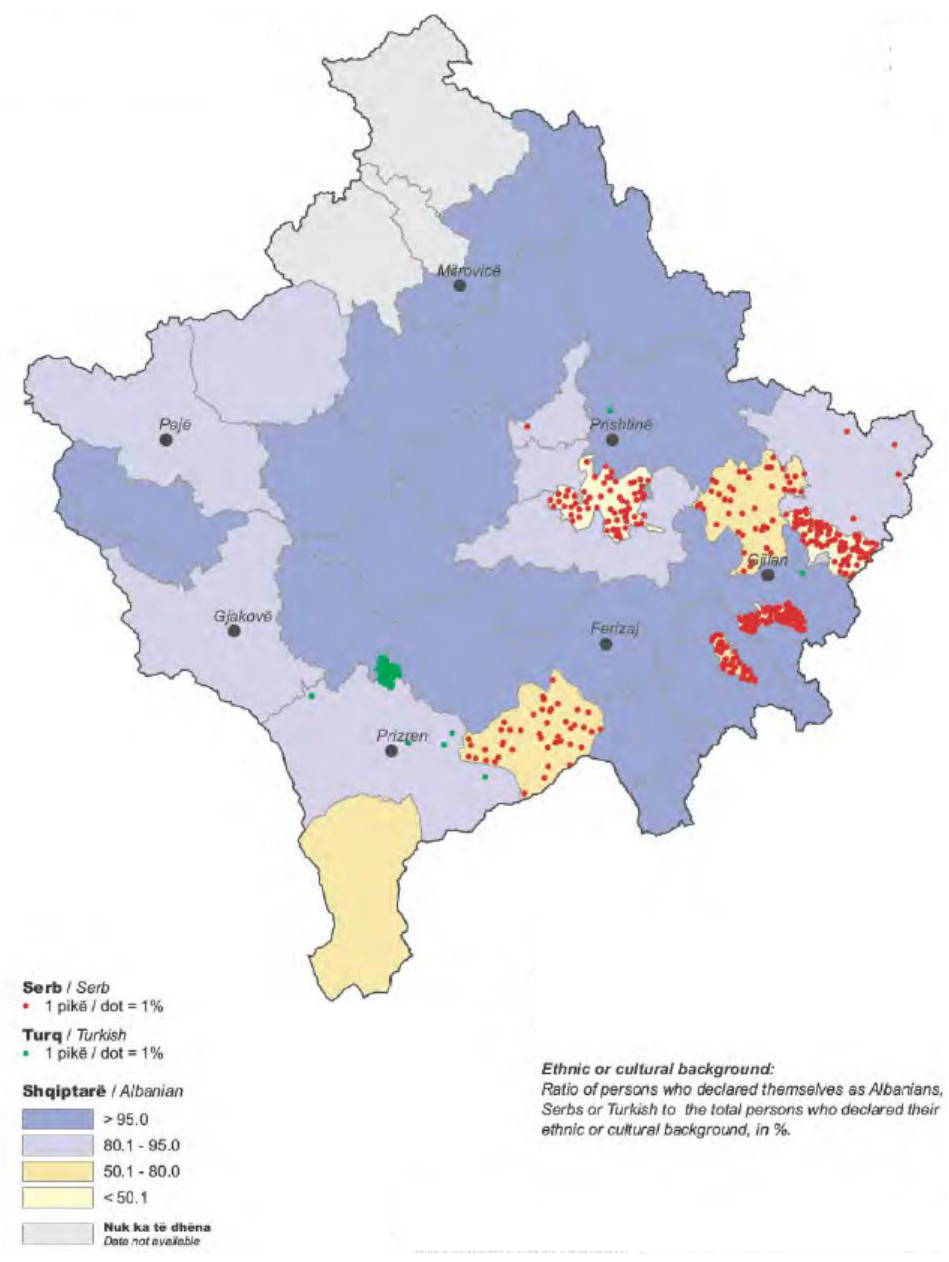

Source: Kosovo Statistics Agency (December 2013). 
Decentralization reforms in Kosovo are fairly recent policies primarily driven by the international community due to political developments in the country. Local own source revenues remain low and local authorities depend on central government grants and international donors to deliver all services required by law (IMF 2011). Between 2006 and 2013, Freedom House rated local governance in Kosovo with an average 5.2 score (Freedom House 2013). ${ }^{25}$ In order to understand this current situation at the local level, it is important to first look into the historical developments in Kosovo.

Formal structures of local administration in Kosovo were inherited from the Socialist Federal Republic of Yugoslavia. Under Yugoslavia, Kosovo had 28 municipalities and a defined capital city of Prishtina. The territory was divided into five regional districts called okruž: Prishtina/Pristina; Peja/Peć; Gjilan/Gnjilane; Zubin Potok/Žubin Potok; Novo Bërda/Novo Brdo and Shtërpca/Štrpce. ${ }^{26}$ In the 1950s Yugoslavia, a system of socialist self-management was introduced throughout the federation that involved the devolution of government functions to the federal republics. The unraveling of these changes throughout Yugoslavia was gradual and the introduction of self-management extended from 1952 to $1965 .{ }^{27}$ In this system municipalities gained a set of administrative and fiscal competences including setting their own taxes and managing own source revenues. Local authorities received earmarked taxes linking charges to specific areas of expenditures. Property-related taxes and fees were the most significant source of revenues. The provincial level shared the tax revenues with local governments through fixed transfer mechanisms (Péteri and Vaillancourt 2007, 22-23).

Within Serbia, Kosovo's status was upgraded in the 1974 Constitution and it became an Autonomous Province within the Socialist Republic of Serbia and thus became a constituent part of the Federation. Nevertheless, according to Sević (2001), the selfmanagement system was 'destroyed by the political supremacy of the League of Communists, the only political party allowed, which was fully centralized up to the republican/provincial level' $(2001,421)$. Government institutions, including the local and regional bodies, were in fact controlled by the provincial level (Péteri and Vaillancourt 2007). The communist party remained in control, exercising a significant role through active interference through the political leadership and

\footnotetext{
${ }^{25}$ Freedom House Nations in Transit ratings are based on a scale of 1 to 7 , with 1 representing the highest level of democratic progress and 7 the lowest.

${ }^{26}$ The UNMIK Administration continued the functions of district courts as the only remaining district institutions in Kosovo. UNNMIK Regulation 2000/45 recognizes only municipalities as a unit of local government.

27 This was followed by a period of self-managed market socialism (1965-1974) when market mechanisms were utilised in many areas, focusing on the activities of the Socially Owned Enterprises operating in the market (Estrin and Petrin 1991).
} 
managers and directors of enterprises at the local level (Mulaj 2009, 15). Ebel and Péteri (2007) have argued that local authorities exercised formal municipal functions as an extended arm of national government control. Local authorities lost control over municipal property and municipal public enterprises became locally managed and state-owned enterprises during the nationalization of local assets under the Milosevic government (Péteri and Vaillancourt 2007, 22).

This period of institutional progress was short-lived within Kosovo and did not reach the advanced institutional development and economic benefits as compared to the other republics of the Federation (Pavlović 2007). Within the legal and constitutional framework, municipalities in Kosovo had the same powers as their counterparts in other republics. However, their development was contingent upon the broader progress in Kosovo. Development in Kosovo lagged behind the other constituent parts of the Federation, mostly as a result of focusing investments in extracting natural resources in the territory (Palairet 2007) ${ }^{28}$. Resources at the local level in Kosovo remained limited under these circumstances. The rise of Albanian mobilization and political reaction against the Serbian regime in 1981 was followed by the abolition of Kosovo's autonomy in 1989 and signaled the end of the selfmanagement socialism period in Kosovo.

Kosovo inherited a formal decentralized local government structure but it also inherited traditional structures and clientelist networks (Sörensen 2009). During the 1990s Kosovo required a centralized mechanism of administration as the main services, education and health were delivered through a parallel system separate from the Serbian led government. Networks of social, political, union, health-care, media and cultural associations provided a lifeline for Albanians in Kosovo in a period of mass dismissals, unemployment and general Serbian repression and discrimination. Thus reliance on clientelist and traditionalist forms of social relations outplayed the role of institutions (Sörensen 2009, 183-193).

This centralized institutional legacy has been continuously identified by both domestic and international agencies as a challenge to state administration and successful implementation of reforms. Centralized hierarchy and weak civic engagement with authorities prevailed for many decades, inhibiting the reestablishment of citizen-state links after 1999. The formation of sub-municipal units called local communities (bashkësia lokale/mesna zajednica), a semi-formal scheme of organization, may have largely influenced a distant relationship with the state (Ebel

\footnotetext{
28 The resources invested through the Federation Fund for Inducing a Faster Development of the Underdeveloped Republics and Region of Kosovo did not succeed in speeding up development in Kosovo and strengthening the economy (Palairet 2007). According to Jović (2001) the Kosovo GDP in Yugoslavia 'although permanently increasing in absolute terms, when measured per head had fallen from 47 to 26 percent of the Yugoslav average in the WWII aftermath' (2001, 102). In 1981, unemployment in Kosovo was 26 percent and reached 59 percent in 1989 (Rogel 2003, 167).
} 
and Péteri 2007). ${ }^{29}$ The decades long culture of parallel institutions, 'a rejuvenation of a Kosovar tradition of local governance and self-management' (Kostovicova 2005), further contributed to local governance functioning outside of central state hierarchy and guidance.

The non-state realm has also undergone dramatic changes in their approach to state institutions and the local government. Under Tito's leadership of Yugoslavia, civil society groups organized along national or religious lines were curtailed. Tito's death in 1980 brought back an association of civil society with larger socio-political movements and added a focus on human rights (Križan 1989). As the political situation deteriorated in the 1980s and 1990s, civil society in Kosovo was associated with the broader national movement for equality and human rights within the Federation of Yugoslavia. Consequently, civil society was closely linked with the civil mobilization and resistance of Kosovo Albanians for independence (Clark 2000; Agani 2012). The post-1999 period in Kosovo changed the understanding of civil society as non-governmental organizations increased in number and took a significant public space as aid recipients.

Following the establishment of a broad international presence in Kosovo in 1999, local government has been subject to a range of reform strategies over the years. Reforms have often been sudden and ambitious, as the process of reforms is not based on a blueprint of a particular Western model (Ebel and Péteri 2007). The UN Mission in Kosovo (UNMIK) abolished former Yugoslav structures and reestablished municipal authorities with a vaguely European-based legal framework. The international community excluded territorial division at the beginning of international administration of the territory and created a unitary institutional structure (Bieber 2004). The UN Security Council Resolution 1244 established the international civilian presence mandating it to perform basic civilian administrative functions and maintain law and order until domestic institutions were set up. Through the UNMIK Resolution No. 1999/14 'On the Appointment of Regional and Municipal Administrators' UNMIK established the first institutionalised authorities across five regions on Kosovo. The mandate of the Regional Administrators included the control, discharge and supervision of functions entrusted to public services and local government bodies in the respective regions. Regional Administrators were granted the highest authority in approving decisions and initiatives of the local government administrations. Coordination of international assistance at the municipal level also fell within the competences of Regional Administrators. One lower level of authority consisted of Municipal Administrators for each municipality.

\footnotetext{
${ }^{29}$ This structure operated under the legal framework of the Federation until the abolition of Kosovo's autonomy in 1989
} 
The framework for establishing the national level Provisional Institutions of SelfGovernment (PISG) in Kosovo was laid out in the UNMIK Resolution No. 2001/9 'Framework for Provisional Self-Government in Kosovo'. This regulation stipulated that "Kosovo is composed of municipalities, which are the basic territorial units of local self-government with responsibilities as set forth in UNMIK legislation" (Article 1.3). Formally the UN Mission decided to abolish previous district level government authorities operating under the Federal Republic of Yugoslavia, and the UN administrators had no formal local counterparts in Kosovo (Report of the Secretary General S/1999/1250 par. 34). However, UNMIK as well as external international organizations used the pre-existing sub-municipal units, which had operated in former Yugoslavia, as a point of contact to help local citizens in implementing projects of reconstruction and development at the local level. After the first local elections in 2000, the international Municipal Administrators appointed local Chief Executive Officers and members of their Municipal Boards. The Chief Executive Officers, Department Directors and personnel were considered the provisional local government. Local Community Offices were established throughout Kosovo to enable UNMIK's objective of having an "intermediary role" between individuals in minority communities and the local administration. The establishment of provisional institutional structures at both the central and local levels followed the first national and local elections held in 2000 and 2001 respectively. As the local structures were established and functioning, consultations with domestic actors increased although final decisions were repeatedly taken by the international Municipal Administrators (Baskin 2004, 14). The UNMIK structure of directing local government administration existed until all municipal structures were established.

A significant factor in the development of local politics was the establishment of local provisional institutions through the appointment of the strongest political parties in an illegitimate process. Choosing local 'partners' was under the discretion of international staff (Interview OSCE 2011). Confusion over municipal competences and clashes over political and economic power between old and new elites contributed to a charged political environment at the local level and damaged accountability. ${ }^{30}$ In the next national elections in October 2004 the Serbian community boycotted the national elections in Kosovo and refused to cooperate with the central government in Prishtina. The election boycott of the Serbian community further diminished the potential of the central government to implement local government reforms (UNSC 2004 S/1999/1250 par. 39). ${ }^{31}$ Concrete steps to decentralize authority, including fiscal decentralization, transfer of public

\footnotetext{
${ }^{30}$ Turnout in local elections dropped from $79 \%$ in 2000 to $53.9 \%$ in the 2002 elections.

${ }^{31}$ Challenges posed by the refusal of Serbian community to participate in Kosovo's local institutions are a separate component of the broader research project and are beyond the scope of this study.
} 
property and reform of public services did not materialize (Hajnal and Péteri 2010). Despite initial de jure devolution of rights to local authorities, several competences were recentralized soon after by the UNMIK administration. In practice, the international administration recentralized particular competencies previously given to municipalities. Municipal Administrators retained broad reserve powers of intervention to ensure that municipal decisions are in compliance with UNMIK mandate. Municipal Administrators are also required to co-sign the budget once it has been through the Municipal Policy and Finance Committee and adopted by the Assembly. Each Municipal Assembly has a prescribed number of elected seats. Additional seats for appointed representatives of minority communities were filled at the UNMIK Special Representative's discretion.

Regulations on local competences and intergovernmental relations changed frequently making implementation of the legislation and policies a challenge. Local government reform, addressed in 2003/2004 with the Standards for Kosovo policy, aimed to introduce local governments to benchmarks of good governance through measures of democratic institutions, rule of law, local development and integration of minorities.

Prior to the political status negotiations, in 2005, the UN Special Envoy Kai Eide recommended that decentralization should be addressed in a wider framework to allow for 'a meaningful devolution of powers and enhanced competences at the local level. Such a framework could include a number of new municipalities where the Kosovo Serbs, in particular, would have a comfortable majority' (UNSC 2005). The violent March riots ${ }^{32}$ of 2004 were a major political shock and prompted the international community to initiate changes in their approach of negotiation with domestic stakeholders. In the Presidential Statement of the Security Council of 30 April 2004, the UN called for "more effective local government through devolution of central non-reserved responsibilities to local authorities" (UNSC 2004). UNMIK invited domestic stakeholders in Kosovo to embark on local government reform and develop concrete proposals for this reform after which the UNMIK Administrative Direction 2005/11 on Pilot Projects approved the establishment of Pilot Municipal Units within existing municipalities. The following Framework for the Reform of Local Self-Government in 2005 did not result in diminishing the disparity between central and local interests and local governments were largely evaluated to fail in achieving standards of good governance. The development of the Framework was a rare domestically owned process as it had a broad range of actors in the drafting process. Yet, it had no significant impact in

\footnotetext{
32 The two days of riots in March 2004 claimed 19 lives, wounded 954 people, displaced 4,100 people, damaged 730 houses and burned, looted or damaged 36 Orthodox Churches, monasteries and other sites (Baskin 2004).
} 
strengthening the role of local authorities by entrusting more political power or fiscal authority in managing local affairs as decisions continued to be made at the central level (Civil Society Member of Working Group for drafting of Framework for LG Reform, Interview 2011).

One of the principal advancements towards democratic local governance was the UNMIK Regulation No. 2007/27 On Municipal Elections enabling the direct election of mayors in municipalities. This enabled measures to strengthen accountability at the local level and breach the embedded political allegiances of political parties who controlled local institutions. Whilst the introduction of direct election of mayors was unanimously welcomed, local leaders perceived the parallel introduction of a unified municipal structure through the new set of policies as a breach of municipal autonomy in decision-making. Annex III on Decentralization, of the Ahtisaari Comprehensive Status Proposal ensured a 'final' push for political, administrative and fiscal decentralization. The significance of power devolution to the local level initiated by the new legal framework adopted in 2008 was undermined by the political clashes between Albanians and Serbs. The advantages of enhanced local decision-making powers became more apparent to municipalities only recently as municipalities began to fully operationalize their aspirations of more competences. Additional municipal competences include enhanced autonomy in using municipal budgets, collection of taxes and enhanced rights for inter-municipal cooperation. Nevertheless, municipalities continue to be deprived of full financial support by the central government for enhanced competences they obtained through decentralization. This undermines the full implementation of fiscal decentralization. Inefficient tax collection by local authorities remained a strong motive for central government to withhold releasing full fiscal authority to local decision-makers. Progress in this particular area was made at the end of 2012 when the central government transferred fiscal powers to municipalities now in charge of setting tax rates and strengthening their most important municipal revenue, the property tax (Freedom House 2013). ${ }^{33}$ Despite the attention given to decentralization following the Ahtisaari Proposal, the central government failed to implement the decentralization policies in their entirety. These included devolving decisionmaking to local authorities regarding higher education and the election of local police chiefs (Freedom House 2013). The most crucial failure was implementing decentralization in the Serb-majority municipalities in the North of Kosovo which is discussed in the following section.

${ }^{33}$ The Kosovo Government approved these changes in its Decision 01/98 on October $29^{\text {th }} 2012$. 


\subsubsection{Limited authority in the North}

The ethnic clash between the majority Albanian population and the Serbian minority has been one of the main political challenges since 1999. The Serbian community's refusal to cooperate with the Prishtina government and integrate in institutions enforced a stark division between the Albanian and Serbian population. This was further exacerbated by a continued reliance on funds from the Serbian state to maintain operations of parallel structures and provide education, health and security services for the Serbian community. This ethnic division between Albanians and Serbs in Kosovo was further enhanced by the physical distinction between the communities as the Serbian was mainly concentrated in enclaves with limited communication between the ethnic groups. The ethnic factor complicated the political and administrative dimensions of local government reforms and largely rendered decentralization measures, amongst the population, as concessions to the Serbian population. Although the Northern municipalities are predominantly Serbian, this only accounts for $30 \%$ the total Serbian population in Kosovo. Kosovo Serbs living south of Ibër/Ibar river in Mitrovica, are scattered in different municipalities. Municipalities north of the Ibër/Ibar river, where the Serb community constitutes the majority, remain out of reach for Kosovo legal and security authorities. The political leadership in these municipalities is elected through elections authorized by the Serbian state and their health and education systems operate in parallel systems separate and uncontrolled by the Kosovo government. The Serbian community refused to participate in the initial local government reforms in 2002 led by UNMIK. The isolation from developments in the rest of the country was further enforced following their refusal to participate in establishing Pilot Municipal Units in 2005 under the Kosovo-government led policy to attract the establishment of minority-led municipalities. The Northern municipalities also politically and socially rejected the subsequent Ahtisaari proposal for highly decentralized units for Serb majority municipalities. Since 1999, Kosovo authorities have been unable to exercise rule of law over the Northern municipalities. Due to the prolonged international limbo over Kosovo's political status the region remained volatile with several violent repercussions against international or Kosovo led initiatives to impose rule and order in that part. The role of NATO -led Kosovo Force (KFOR) troops in charge of securing the borders remained marginal as they awaited a political solution to define the borders. The international security forces concentrated on monitoring the territory up to the Ibër/Ibar river in the city of Mitrovica which divides the Albanian population in the South and Serbian population in the North.

The Serbian community and the Serb political parties in the North, under significant pressure from Belgrade, have so far resisted integrating with Kosovo institutions. 
Although funds flowing from Serbia to Kosovo parallel structures have decreased significantly after the international financial crisis of 2008, the Serbian government funds healthcare and education services in a number of Serb majority areas (Hajnal \& Péteri, 2010; OSCE, 2008). After Kosovo's declaration of independence in 2008, the Serbian government redoubled its efforts to influence the Serbian community in Kosovo allocating 500 million EUR to parallel structures in Kosovo. After Serbia's 2008 parliamentary and local elections, Kosovo Serb leaders in the North began setting up their own local institutions, including a parliament. Serbia committed about 42 million Euros for parallel structures in Kosovo the day after submitting the application for EU Membership in December 2009 (KIPRED 2009).

As the Northern municipalities remained isolated from developments elsewhere in the country, reforms had no substantial influence on the Serbian community. The initial reform policies in 2005 aiming at including Serb citizens in new pilot municipalities failed. Subsequent decentralization efforts were undertaken throughout Kosovo, but failed to include the Serbian dominated municipalities, which remained isolated from these changes. Serbs boycotted Kosovo elections and resigned from government functions although some later agreed to cooperate with Prishtina. After Kosovo's Declaration of Independence in 2008, the Serbian-led municipalities in the North refused to recognize the new political status. The Serbian community located below the Ibër/Ibar river, gradually accepted integration in Kosovo institutions and several political parties participated in elections to lead their new municipalities. Political developments in 2010 brought about a "Strategy for the North of Kosovo" by the International Civilian Office (ICO) in Kosovo proposing the opening a Kosovo government office in an ethnically mixed neighbourhood in the north at the same time as the UNMIK presence in the north was slowly drawing to a close. This initiative endeavoured to integrate the north and marginalize Serbian parallel institutions (Woehrel 2010). Serbia and local Serb leaders rejected the new strategy, which lacked international support from EU headquarters ${ }^{34}$ and the International Steering Group (KIPRED 2012). Kosovo institutions held local elections in November and December 2009, including most of the Serbian majority municipalities foreseen in the Ahtisaari plan. In some areas south of the Ibër/Ibar river, significant numbers of Kosovo Serbs participated. ${ }^{35}$

Establishment of new municipalities proved a great challenge for the Kosovo Ministry of Local Government Administration (MLGA) and ICO. The MLGA met with Serbian community members to assess their readiness for participation in the Municipal Preparation Teams and help establish new municipal structures with

\footnotetext{
34 The European Union quickly distanced itself from the strategy, despite the fact that the ICO representative is also EU Special Representative in Kosovo.

${ }_{35}$ Turnout in Gračanica was $23.62 \%$ where the Independent Liberal Party of Bojan Stojanovic won a majority.
} 
very little success. South of the Ibër/Ibar river, MLGA and ICO succeeded in getting cooperation from local Serbs and by 2010 established initial structures of new municipalities. Since 2010, 5 mayors have been elected belonging to the Serb community which either elected their own mayors or approved coalitions established between Kosovo Serb political parties and Albanian ones. Kosovo-Serbs are also represented by 33 seats in five Municipal Assemblies. The Kosovo Serb political party Independent Liberal Party (SLS) has eight seats in Shtërpcë/Štrpce municipality, 12 in Graqanica/Gračanica and 10 in Kllokot and also two ministers in Kosovo's government (one serving as Deputy Prime Minister for Communities). The Serbian Party of Kosova and Metohija (SKMS) and Serbian Democratic Party of Kosova and Metohija (SDSKiM) each have one seat in the Graqanica/Gračanica municipal assembly and the Serbian Citizen Association won the local elections in the new municipality of Ranillug (IKS 2011, 69).

In 2012, the EU initiated a series of talks between the governments of Kosovo and Serbia mediated by the High Representative for Foreign Affairs Catherine Ashton. Albeit initially technical, the talks nevertheless included political issues between the two countries and resulted in an agreement signed by both Prime Ministers in Brussels on 19 April 2013. The 'Brussels Agreement' included the establishment of an Association for Serb Municipalities in Kosovo and required that the Northern municipalities be included in local elections under the helm of the Kosovo government. The OSCE Mission in Kosovo was tasked to oversee the election process in the Northern municipalities which was disrupted by violent attacks on the election staff. Partial re-votes were organized in mid-November and December (OSCE 2013). The results of this process were highly contested by the broad public in Kosovo who claim the Brussels Agreement further divides the ethnic groups and grants Serbs autonomy without having to recognize Kosovo institutions. ${ }^{36}$

\subsection{Institutions engaged in local governance reform}

In the immediate aftermath of the war in 1999, the international presence in Kosovo increased dramatically to tens of thousands of personnel including the military, diplomatic missions and civilians. An array of international organisations are still present in Kosovo, ranging from the UN and its agencies, European Union, NATO, OSCE and the ICO whose head also serves as the European Union Special Representative. At the outset of their mandates, the international community in Kosovo was mainly concerned with security and reconstruction. As mandates

\footnotetext{
${ }^{36}$ In January 2014, the newly elected Mayor of North Mitrovica, Krstimir Pantić refused to sign the Oath as new mayor because the documents bore the emblem of the Kosovo institutions (B92 News, January $\left.13^{\text {th }}, 2013\right)$.
} 
extended and a variety of donors became involved, activities and projects expanded to cover support for political reforms and economic reconstruction, assisting police and judiciary sector and capacity building of civil society. During the period 19992007, Kosovo received EUR 3.5 billion in donor assistance, two thirds of which came from the European Commission and EU Member States (ECA 2012).

With regards to local governance reforms, the selection and refinement of a local government model has not been straightforward as the process of reforms is not based on a blueprint of an existing Western model (Ebel \& Péteri 2007). International agencies led by the European Union promoted principles of subsidiarity and inclusive decision-making to guide most local reforms. Most significantly, ethnic rights and safeguarding of minority interests became crucial elements of the local government reform process (Gjoni, Wetterberg, \& Dunbar 2010; Monteux 2006; Pickering 2006). Considering Kosovo's European perspective, these structural reforms must be considered within the European integration framework. The European Union, as the largest donor in Kosovo, has had a key role pushing for reforms although often criticized for failing to maximize its conditionality power (Elbasani 2012; Papadimitriou Petrov, and Greiçevci 2007; Papadimitriou and Petrov 2012).

Both European and American agencies funding local governance initiatives demand democratic principles as core foundations of (their understanding of) governance. USAID defines democratic local governance as 'inclusive governing' emphasizing democratic interactions between community members and local authorities. The EU, on the other hand, emphasizes development and defines local governance as follows:

A process of decision making on matters of local/municipal development and the implementation and management of development plans and the provision of basic services through allocation of available resources in order to achieve agreed development goals and targets (Binder, Slits, Stoquart, Mullen, \& Schubert 2008).

In the promotion of external democracy, the European Commission's approach to local government reform and decentralization varies from place to place corresponding to different levels of experience and evolution, in addition to the willingness and commitment of countries to decentralize (Binder et al. 2008). European Commission documents focus on local governance building and the principle that local matters are a responsibility of local councils and stakeholders at the local level. On the other hand, USAID documents on local governance emphasize improved local conditions for governing and for citizen satisfaction. They define local governance as 'more effective governing, increased trust in government, improved services, more robust local economic development, and 
greater involvement of citizens in civic affairs. The existence of the European Charter on Local Self-Government is another distinction with the 'American' approach as it is commonly used by European Commission projects as a guideline.

In the Western Balkans, the EU strategy in member state-building is clearly recognizable considering the promotion of European models and values of local governance including the concept of regionalisation discussed later on the paper. The European Office in Kosovo in particular, focuses on acquis related issues and considering that 'decentralization is not related to acquis, the European Union office does not take an official stance on it' (EUOK interview 2012). According to European Commission representatives in Kosovo, the EU strategy is to work with streams separating work and establishing partnerships directly with municipalities in addition to collaboration with central government ministries. At the central level, the focus is on 'changing policies which are hindering better services and implementation of good practices' (EUOK interview 2012). EU officials are critical of USAID for steering away from general decentralization political processes by concentrating on technical areas such as waste and water management. In addition, EU officials face a general 'passivity' of domestic stakeholders stating:

When it comes to EU, local and central governments will accept anything but the EUOK does not know what is best for Kosovo. We lack a strong counterpart for our work with regards to guiding donors and their funds where the government needs them most (EUOK interview 2012).

This ambiguity creates an environment where international projects and initiatives are redundant and do not match domestic needs. In failing to secure proper implementation of adopted national legislations, government institutions are thus unable to effectively use the available donor funds. Furthermore, lack of clearly defined domestic priorities further enforces the incapacity to absorb new assistance.

In the annual European Commission (EC) Progress Reports on Kosovo, local governance does not receive much focused deliberation and is mentioned superfluously, despite the exhaustive nature of the reports post-2008. The reports however do identify challenges to Kosovo's local governance including weak local administrations and lack of cooperation between local and central level institutions, limited inclusion of minority communities, Serb parallel structures obstructing decentralization and a civil service vulnerable to political interference, corrupt practices and nepotism. Capacities to exercise local competencies and involve civil society organizations in decision-making remain obstacles after 2008. EC reports are critical of the government for lacking a strategic approach for interaction with civil society (European Commission 2008). To help identify its targeting of local governance, the table below presents a detailed look into EU financial assistance. As can be observed, local government reform and decentralization appear as 
crosscutting issues instead of a major policy focus. The data shows an increase in financial assistance after the declaration of Independence in 2008 to its highest amount since 2003. Allocation of $€ 14$ million to local infrastructure supports the establishment of new municipalities and implementation of the new decentralization framework.

Table 1. European Commission financial assistance (numbers in € million)

\begin{tabular}{|c|c|c|c|c|c|c|c|}
\hline Year & 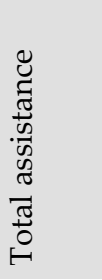 & 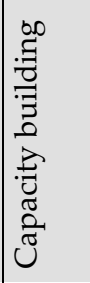 & 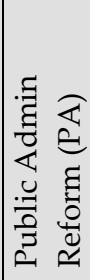 & 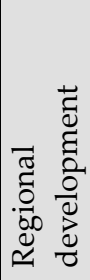 & 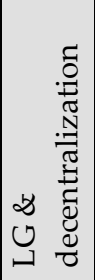 & 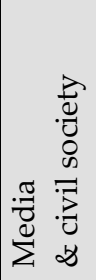 & Notes $^{37}$ \\
\hline 2003 & 49 & - & 5 & - & 1 & 1 & Funds under LG designated for AKM \\
\hline 2004 & 75.4 & 15 & 7 & - & & 1 & - \\
\hline 2005 & 54 & 19.6 & 11 & 6 & - & 1 & $\begin{array}{l}\text { PA funds include support for } \\
\text { AKM }\end{array}$ \\
\hline 2006 & - & - & 8 & - & - & 0.5 & PA funds include strengthening of LG \\
\hline 2007 & 68.3 & - & 5 & - & 12.4 & & $\begin{array}{l}\text { LG funds incl. } 4.4 \text { for institution building } \\
\& 8 \text { for infrastructure }\end{array}$ \\
\hline 2008 & 184.7 & - & 4 & 6.60 & 14 & 2.5 & LG funds for municipal infrastructure \\
\hline 2009 & 106.1 & - & - & 7.8 & 6.5 & 4 & $\begin{array}{l}\text { LG funds for strengthening institutional } \\
\text { capacity }\end{array}$ \\
\hline 2010 & 67.3 & 2 & 5.5 & - & - & - & EC assistance significantly decreases. \\
\hline 2011 & 68.7 & 65.83 & 20.35 & - & - & - & PA funds for 3 years \\
\hline
\end{tabular}

Source: Compiled by author from EC Annual Programs and Multi-Annual Programming Documents (MIPDs).

\footnotetext{
37 Assistance to the Association of Kosovo Municipalities reappears frequently as a channel for supporting local governance structures and strengthening the representation of local interests through this unified mechanism.
} 
Another international agency working in parallel with central and local governments is the OSCE Mission in Kosovo. For a decade, its Local Governance Program provided training and capacity building for local authorities and facilitated cooperation with civil society organizations (Baskin 2004). The OSCE was a key agency for the administration of local and national elections since 2000. Its role in elections shifted after authority was transferred to the Kosovo Central Election Commission in 2008. The OSCE, nevertheless, remained involved, as it was set in charge of facilitating the election process for the Serbian community in North Kosovo. ${ }^{38}$ The OSCE remains a hub of information concerning local governance yet its presence on the ground as well as engagement to continue reforms has decreased since 2008.

International agencies in Kosovo engaged in promoting decentralization in a flexible and unsystematic manner were/are heavily influenced by the political environment. A discrepancy between their objectives and the reality on the ground can clearly be observed in Kosovo. Previous studies have criticized the international agencies by arguing that they focused more on 'the manageability and efficient control' rather than real empowerment of local government units (Hajnal \& Péteri, 2010). According to Grindle $(2004,18)$, there are considerable political payoffs to undertaking governance reforms oriented towards 'tangible benefits in the short term'. Initiatives focusing on improving highly visible services such as garbage collection and security can build citizen trust in government. Nevertheless, the international agencies have approached activities of assisting socio-economic development and institutional capacity building through a central government spotlight; pressing for local government issues mostly for political stability reasons (EC 2005). Using the core executive as a source of state authority, for a decade many initiatives concentrated at the central level.

On the domestic front, the establishment of a Ministry for Local Government Administration (MLGA) in late 2004, after two local elections already took place, demonstrates the bleak vision of central government in guiding local governance. Unfortunately, its existence did not prove significantly valuable to reforms. Since its establishment, the MLGA has acted as an administrative hub for the implementation of local governance reform policies. Rather than initiating reform policies itself, most strategies were drafted in accordance with international donor initiatives providing assistance. Despite its self-perceived role as a leader in strengthening

\footnotetext{
${ }^{38}$ The OSCE involvement in election processes in Kosovo is highly controversial. It's mandate in Kosovo remains 'status neutral' as the organization does not recognize Kosovo's independence. The organization has taken a mediating role serving as a facilitator between Kosovo and Serbia as the latter rejects the Prishtina authority and only accepts the OSCE to organize elections in the Serb-majority municipalities. This role was further complicated as the OSCE facilitated the 2012 Serbian parliamentary and presidential elections for Serb voters in North Kosovo.
} 
local institutional capacities (Maxhuni, Ukimeraj, Vasolli, Ujkani, \& Osmani, 2009), the weak capacity of central government to supervise local authorities, as well as 'contrasting interpretations of legislation on self-government', often block cooperation between central and local authorities (European Commission 2010, 8). The MLGA potential to strengthen intergovernmental relations was not fully utilized and has, in fact, been damaged through the exclusion of municipalities in the drafting process of new legislation. The formal monthly meetings of the Local Government Administration Minister with all mayors have not improved relations between municipalities and central government.

A key institution, which provides a platform for communication for municipal administrations, is the Association of Kosovo Municipalities (AKM). However, despite its long existence and broad membership, AKM was often marred by criticism of municipal delegates and international partners arguing that its lack of interest in advocating for local interests has weakened its role and made it a superficial actor (ICO interview 2011). The AKM has considerable potential to advocate for the interests of municipalities as well as acquire central government attention to issues pertaining to local governance yet this potential is not fully utilized.

\subsection{Case studies}

The second part of this chapter uses two case studies to critically assess the effectiveness of externally driven projects designed to strengthen local governance by opening up the decision-making process and enhancing relations between state and non-state acts. Utilizing primary research data, this section provides an in-depth look at the initiatives of the EU and USAID, analysing their objectives, trajectory of implementation, relations with central and local actors and identifying various constraints to their effectiveness. Factors addressed below include the design and implementation of international initiatives as well as the contextual complexities inhibiting change towards new modes of governance at the local level. The cases illustrate the limits of international engagement in promoting bridges between state and non-state actors from a bottom-up perspective.

After the Declaration of Independence, both the EU and the USAID representations in Kosovo included local governance as an element of their strategies to support socio-political change in Kosovo. Both agencies highlight the importance of the local level in strengthening democratic institutions and ensuring links between government authorities and citizen. 


\subsubsection{EU Regional Economic Development - EURED}

The European Commission project for Regional Economic Development (EURED), a $€ 12.4$ million initiative, aims at promoting a new approach to development by supporting regional cooperation of municipalities and preparing Kosovo institutions for absorption of future EU regional development funds. Although regions are not a constitutional entity in Kosovo, the EURED approach to local governance is entirely dependent on its regional focus. EURED established Regional Development Agencies (RDAs) across five regions to instigate and coordinate economic cooperation between municipalities and private agencies and provide support for the local counterparts as they prepare funding applications. According to EURED officials, the initiative is based on the concept of local ownership. However, interviewee statements that the idea on RDAs was generated in the EURED headquarters contradict the ownership of local counterparts (EURED Interview 2011). This important component of the initiative is thus a result of external ideas produced in Prishtina headquarters.

The RDAs, promoted as inter-municipal institutions, are registered in the host municipality as Non-Governmental Organizations. The status of NGOs for these agencies is a controversial factor considering that signatory authority of signing Inter-Municipal Cooperation Agreements is the respective mayor. Furthermore, mayors of participating municipalities in each region also serve as Board Members of the respective RDAs. This key aspect of EURED is at the same time its most perplexing point. The regional structures are temporary due to the lack of legal backing for regional operations. Cooperation is thus based on inter-municipal agreements signed between each of the municipalities to stimulate economic growth and develop capacities to absorb future international funds including EU IPA funds (EURED 2010).

The aforementioned issues do not entirely undermine the accomplishments of the initiative. First, the focus on development is notable. The lack of a national strategy on development, at the time of EURED initiation, signifies Kosovo's dire policy environment for which EURED attention to development policies is particularly beneficial. Through the additional Socio-Economic Audit Forum, local stakeholders drafted the Regional Economic Development Strategy and Implementation Plans. The Forum was beneficial in enhancing efficiency in drafting new proposals and strategic documents. RDA representatives confirm this by emphasizing that drafting of the Regional Economic Development Strategy and its accompanying implementation plans was "8 months of work for what usually takes 3 years" (RDA South interview, July 2011).

The initiative also contributes to opening up local authorities by strengthening state/non-state cooperation. In terms of advancing new modes of decision-making, 
the most important structures established include the Regional Economic Development (RED) platform encouraging local stakeholders to work together with other municipalities in their region, and the Core Partnership Group which assembles representatives of all municipalities to develop strategic objectives for economic development in their region. Participants include local authorities, business associations, civil society organizations and universities and, as such, provide a positive mechanism of contact and collaboration between diverse sectors. This inclusion of a wide range of actors is beneficial to the local environment as it strengthens communication between local government institutions and non-state representatives. In addition, inter-municipal cooperation is enhanced when local organizations, businesses and local governments jointly produce strategies for developing their respective municipalities. A common vision, in this case promoted under the umbrella of regions, is beneficial provided that it enables shared responsibility and commitment to achieve common benefits. Finally, the EURED grant scheme, which awards proposals developed by regional groups for economic development, enables a cyclical process benefiting participants. Municipalities have shown great enthusiasm in participating in the project, considering it a funding opportunity. Furthermore, this process of cooperation allows pooling of resources and enables a win-win situation for participating municipalities who 'recognize the power of applying as a region as compared to an individual unit' (RDA South interview 2011). EURED advisors consider this as "a free ticket to development" (Interview 2011).

The inter-ethnic environment is another aspect in which EURED mechanisms of cooperation may influence the local level. According to EURED representatives, municipalities with non-Albanian majorities such as Zubin Potok (Serb-majority) and Mamusha (Turkish-majority) have shown exceptional performance in participating in regional forums (RDA South interview 2011). Challenges remain with the boycott of other Kosovo Serbian-majority municipalities especially in the Partnership Group, where other ethnic group delegates have participates. The EURED approach recognizes this challenge but does not entail any solutions or strategies for overcoming this challenge, declaring: "We do not have time to wait for anybody in this open process!" (RDA South Interview 2011).

In the realm of the country's political economy, the institutional legacy of a centralized regime combined with the current weak state constrains the work of local institutions. The changing nature of discussion and 'sharing the spot-light' with other stakeholders may constitute a threat to the political leadership whilst benefiting other actors. Interviewees argue that this process has cast a more passive role for municipal authorities, a role some mayors are struggling to accept (EURED advisor interview, July 2011). This suggests a tendency for local government authorities to resist accepting a stronger role for non-state actors. The case is slightly 
different in host municipalities where RDA offices are located, where mayors tend to assume a stronger role in their regions (EURED advisor interview, July 2011).

At the central level, the partnership with the Department for Regional Development and European Integration within MLGA, does not contribute to advancing EURED objectives, as the Department is not directly responsible for advancing the economic development dimension. One particular sign of embedding the regional development framework within Kosovo institutional structures has been the renaming of the former Department for European Integration into the Department for Regional Development and European Integration. This name change, however, does not significantly alter the limited role of the Ministry itself. Better suited for the development aspect are the Ministry of Economic Development and the Ministry of Trade and Industry which provide for stronger links between central institutions, RDAs and municipalities. At the local level, the leading partners remain the local authorities whose consent and participation is essential for the establishment of RDAs in the first place. RDA agencies also emphasize the importance of engaging with business organisation to enable a successful implementation of RDA objectives. This prioritization of business organisations over other non-state actors overshadowed the potential for empowerment of civil society organisations in the new structures.

A major shortcoming of the project remains the issue of regions, namely aspiring to strengthen structures without backup from national level policies. Internal project deficiencies, including lack of strategies to integrate existing structures to overall development policies, establishment of new administrative layers for RDAs and lack of strategies to overcome challenges are apparent in the EURED case. The future of their already established structures and mechanism, including the RDAs, remained unclear as the project terminated in early 2012. The case study illustrates EU readiness to implement and invest on any venture under the broad aim of strengthening new modes of decision-making. ${ }^{39}$

On the other hand, all platforms established to facilitate meetings and communication between actors encourage municipal authorities to share the 'spotlight' with other actors including the non-state sector. Acquiring the expertise and acknowledging the interests of other parties involved contributes to opening up centralized mechanisms of decision-making commonly used in municipal administrations. The collaborative work in designing economic development strategies for their regions strengthens capacities of both local authorities and nonstate organizations participating. Grants acquired by ECLO (now called EUOK) in awards for high quality projects reward this type of collaborative work

\footnotetext{
39 To integrate the currently administrative functions of RDAs into the larger development strategy, the Ministry of Trade engaged in discussions with European Commission only in 2012.
} 
strengthening municipal commitment for the future. Furthermore, local authorities and actors from the private sector attain opportunities for inter-municipal cooperation, which is recognized and legally regulated.

\subsubsection{USAID Democratic Effective Municipalities Initiative - DEMI}

The second case explored is the USAID Democratic Effective Municipalities Initiative (DEMI) working towards strengthening local governance. USAID involvement in governance reforms has been consistent since early 2000s and its support for local reforms was particularly strong partly out of frustration with efforts to reform central government institutions (Carothers, 1999). The Agency is currently engaged in institutionalising mechanisms for incorporating citizen input and civil society organisations into local decision-making and government oversight (USAID Kosovo 2010).

The DEMI initiative provides technical and financial assistance for carrying out municipal responsibilities. Project officials acknowledge that 'Kosovo has passed the trainings and workshops phase' and so focus on guiding local stakeholders (DEMI interview, July 2011). DEMI objectives include assisting local administrations in setting priorities for service outcomes, engaging citizens constructively in that process, and enhancing their ability to identify necessary improvements to their municipality's systems, processes and human capacity. In order to address citizen participation, DEMI focuses on utilizing existing tools, which proves especially beneficial to the local circumstances. Frequent changes in local administration structures prohibit the creation of institutional knowledge and cause confusion among local officials concerning competences and lines of authority. The project focuses its work on assisting the Committee for Policies and Finances as the most important organ within the municipal administration. DEMI considers the Committee has dire need for advice considering 'their scarce knowledge in how to involve citizens in the decision-making process' (DEMI interview 2011).

Despite the organization's official stance on mentoring during processes of reform, a fundamental part of DEMI's support for local governance is the establishment of two mechanisms to steer local decision-making processes into an open and inclusive model. These are the High Performing Organization model and the Service Improvement Action Plan (SIAP). Firstly, the High Performing Organization model promotes best practices within Kosovo and replicates them in another municipality. Its main objective is structuring existing municipal functions into novel organizational arrangements and inciting new ways of thinking about municipal services. Municipalities exhibiting high performance by meeting set-benchmarks of 
service delivery are rewarded by the DEMI funding scheme. Secondly, the Service Improvement Action Plan (SIAP) facilitates plans for improving public services by including municipal administration together with businesses as well as civil society organizations. SIAP consists of a municipal team charged with developing plans for improving public services. After the mayor establishes the group, participants include businesses as well as civil society which focus on developing actions plans for certain municipal services. The SIAP team in Mamusha municipality has prioritized water supply whereas in Partesh/Parteš the team prioritized garbage collection. In the latter case, the municipality signed a cooperation agreement with the regional company in charge of garbage collection and has invited the civil society to monitor the service performance (DEMI interview 2011). The SIAP model's shortcoming is its resemblance to existing Municipal Committees. According to the Law on Local Self-Government, Municipal Assemblies may establish the Committees on any policy area and invite non-state actors to share their expertise on the matter (LLSG 2008). ${ }^{40}$ Instead of strengthening the Committee's existing functions, DEMI ignored the existing model for coordination. The Municipal Committees mainly utilize their mandate for oversight of the municipal executive branch.

Engaging civil society actors into the process of decision-making is another objective of DEMI activities. The Novobërdë/Novo Brdo municipality is a particular instance of increased citizen engagement and awareness concerning municipal policies. DEMI facilitated a Memorandum of Understanding enabling cooperation between the municipal mayor and the NGO Youth Voice leading to youth activists conducting a survey amongst municipal residents concerning the municipal budgeting process and priorities of the municipality. Survey results, presented to the mayor, showed low participation in budget hearings, low satisfaction with the work of municipal officials and fewer than half of those interviewed were informed about the budgeting process. For the local leadership 'this is the first time that the municipality of Novobërdë/Novo Brdo has conducted a survey to consult citizens on budget planning process as well as the first time to outsource an NGO to increase citizens participation in budgeting process (DEMI 2011). These results are an example of new mechanisms being internalized into municipal administration practices. These cases however prove to be dependent on municipal leaders with political clout over executing new policies (DEMI Interview, July 2011). In practice however, most municipalities have not enabled these mechanisms.

Similar to the previous case study, a grants scheme is a fundamental part of the DEMI project. The grants scheme is a continuation of the previous USAID project on

\footnotetext{
${ }^{40}$ Despite AKM and OSCE resources invested in enabling these structures, Municipal Committees have been established in a limited number of municipalities and do not function on many policy areas.
} 
strengthening local governance - EMI. DEMI awards municipalities for high performance and achieving set benchmarks for efficient public services. This has secured municipal participation in the program and municipalities actively engage in improving their services and designing innovative ideas for new projects. The grant scheme incentivizes municipalities to compete with each other and submit applications for each round of grants for improved performance. This promotion of the model of competition amongst municipalities has proven successful, fulfilling a key objective of USAID to encourage market-based reforms. However, domestic financial support for this model is scarce. The MLGA has declared that it will continue this model of incentives and rewards for municipalities in the future when USAID funds terminate. This is a rather difficult task considering the weakened role of the Ministry portfolio in the government after the majority of decentralization reforms passed the legislation phase.

The institutional legacy within municipal administrations is another challenge for promoting new modes of decision-making. Institutional memory from the Yugoslav centralized administration remains with municipal civil servants, diminishing their commitment to new models of cooperation and including collaboration with other actors (DEMI Interview 2012). In the last decade, many municipalities see political figures remaining active in local politics and thus exercising their influence in various local issues. Former-mayors often persist in exercising political power within institutions thus hindering effective implementation of external initiatives. This persistence of political elites in the public discourse prohibits a change of elites and of the local political culture.

Parallel structures in the Northern region were highlighted as the biggest challenge for the project to reach out to Serbian-majority municipalities. In 2011, DEMI supported collaboration between community leaders and the North Mitrovica Municipal Preparation Team ${ }^{41}$ to implement a community project on cleaning the Ibër/Ibar riverbank. For larger-scale impact, the politically radical groupings amongst Kosovo-Serbs and the ever-strong parallel structures in the North were serious constraints bringing to a halt one component of the DEMI initiative (Interview 2011). By offering proper mechanisms for collaboration between municipalities DEMI intends to bridge these ethnic barriers. One example of this are the informative sessions for Serb-majority municipalities held by larger municipalities such as Peja and Ferizaj offering explanations on administrative aspects of municipal functions.

\footnotetext{
${ }^{41}$ The Municipal Preparation Team (MPT) established by the ICO and the Kosovo government to set-up the foundation of a new North Mitrovica municipality, has been in a state of limbo for several years.
} 


\subsection{Conclusion}

Local governance and decentralization reforms in Kosovo present an interesting and highly complex case of rapid changes at the local level. Changes include restructuring the local administration and the role of the central government in oversight and control. Furthermore, local governance reforms in Kosovo are intertwined with the political situation and influenced by the clashes between the ethnic majority of Albanians and the Serbian minority occurring during Kosovo's post-conflict transition. The reform cycles were not a direct result of the gradual growth of local government power and autonomy. During these shifts towards increased local authority, the local voice was largely unheard during the decisionmaking level at the national level. Local authorities struggled with the rapid increase of competences and responsibilities for providing a range of services to citizens. The challenge in exercising these newly acquired competences was further exacerbated by the delay in fiscal decentralization, which meant that municipality functions were limited by insufficient local resources. Weak capacities to collect own source revenues further restricted effective service delivery. Lastly, except for the 2005 drafting process of the national Framework for Reform of Local Government, non-state actors were not included in the policy-making process and most initiatives remained without civil society input.

Challenges in exercising authority and enforcing rule of law in the Serb-majority municipalities further undermined the successful implementation of decentralization reforms. Lack of cooperation between municipalities in North Kosovo and the rest of the country enforced the isolation of the former and triggered further ad-hoc policy responses from the central government and the international community. The latter was a key player in setting up and promoting these shifts through its aid programs and democracy promotion initiatives. International agencies did not apply a unified approach to local reforms and the lack of a blueprint or model followed the various stakeholders engaged in various programs to strengthen accountability and enhance local capacities in service delivery.

With regard to the two case studies analyzed in the second part of the chapter, five distinctive elements can be identified from the data on international engagement in promoting reform at the local level. First, both initiatives focus on the executive branch with the aim to strengthen core executives in local administrations. Emphasis on representation and participation of municipal officials in forums established with both state and non-state actors suggests the focus is on formal structures of authority, even if they do not exert leadership potential as compared to non-state actors. New mechanisms of coordination and decision-making are thus formalized through secondary legislation or formal decrees of municipal Mayors. New structures such as departments, working groups, forums or partnership units 
are easily established and promoted as successes. The impact of these new structures is twofold. On one hand, formal state institutions are pushed into new realms of decision-making and coordination with non-state actors, modes significantly different from the pre-1999 institutionalised norms. On the other hand, this may lead to more layers of bureaucracy in an already heavily bureaucratized institutional setting with a 'working group fatigue'.

Second, case studies emphasize the clear objective of international initiatives to bridge the divide between state and non-state institutions by securing horizontal modes of cooperation. Civil society organizations and businesses are encouraged to participate in the process of dialogue with municipal representatives to embed open processes of decision-making including non-state actors.

Third, utilizing features of a market model of governance, the external initiatives incite municipalities to compete amongst each other as well as with private firms. The aim is to enhance efficiency and instill a culture of competition for improved service provision. Financial incentives in the form of grant schemes are significant components of both external projects. Considering the lack of local resources in municipalities, donor funding proves to be a significant incentive for municipal actors to actively engage in improving local governance. In particular, the DEMI initiative, by incorporating several elements from previous USAID funded projects on local government, ensures continued interest of municipalities and their affirmation of ideas and mechanisms proposed through the project. By including financial rewards for municipal projects, both DEMI and EURED initiatives secured broad participation of local stakeholders.

Fourth, the initiatives allocate insufficient attention to intergovernmental relations. Relations between local and central government institutions remain underdeveloped and have delayed progress in general. Local authorities continue to feel left out of major policies concerning essential local issues such as competences, functionality of local administration and local development. Local administrations continue to be weak, dependent on central government financing and often confused over the ever changing legal framework and its impact on their responsibilities and competencies. The frequent change of legislation, programs and activities, caused a pervasive confusion and municipal administrations were too often 'left to solve their own issues' (ICO Interview 2011). Considering the weak central state, this further reinforces the gap between government tiers, ignoring the significance of central government authority for guiding the local level into effective governance. Any attempt to bring new modes of decision-making and advance reciprocal support of institutions must incorporate mechanisms to bridge these divides. 
Lastly, the cases illustrate a failure of international agencies to provide clear longterm strategies for embedding these new modes of local decision-making. The lack of national development policies enables a strong presence of EURED principles and interpretations of governance. In addition, the lack of domestic mechanisms for rewarding excellent services offered by municipalities, enables local actors to follow guidelines and interpretations of good governance offered by USAID's DEMI project instead. 
4. Heritage governance in Kosovo 


\subsection{Introduction}

This chapter presents an in-depth analysis of the complex decision-making process in Kosovo's cultural heritage policy. Governance of cultural heritage in Kosovo involves a myriad of actors, which have repeatedly clashed over reforms. Heritage governance in a multi-ethnic society and a post-conflict environment is a highly contentious policy area as it entails a process of redefining notions of statehood and the role of the state. In particular, setting up the legislation on the Historic Center of Prizren is one of the most controversial issues involving the central government, local authorities, civil society and the international community. Focusing the analysis on this specific case study supports claims that cultural heritage always has a local dimension (Riganti and Nijkamp 2004). The cultural heritage case study provides a lens on local governance to investigate the polarization between stakeholders and the efforts of both international and domestic actors to influence the reform process.

Heritage governance is a complex process including competing environmental, economic, social and cultural requirements and it involves a wide circle of stakeholders. Political elites often utilize conservation and interpretation of heritage as a vehicle for identity confirmation (Gregory John Ashworth \& Tunbridge 2000). This enables political elites or leading organizations and interest groups to capture the decision-making environment (Wolferstan 2006). Economic interests also come to the forefront of heritage governance debates including issues such as tourism and commercialization of heritage. As a resource, cultural heritage can become a driver for development and, if properly managed, can enhance the livelihood of its inhabitants. Hence the importance of long-term management strategies and participatory management approaches (Roders \& Oers 2011).

Regulation of cultural heritage management in Kosovo is a recent development in the country's post-war history. The trajectory of establishing heritage management structures is particularly interesting considering the provisions of the Ahtisaari Proposal and the numerous agencies involved. The opposing views between the Kosovo Albanian and Serbian population on the value of monuments and sites underscores the governance of cultural heritage in Kosovo. Cultural heritage poses a minefield in the country's policymaking; its investigation allows us to shed-light on obstacles encountered during heritage governance reform.

Designing and reforming the cultural heritage policy sphere in Kosovo was marked by a centralized decision-making process with extensive involvement of the international community but excluding non-state actors. The process of regulating cultural heritage management in Prizren developed into a complex and politically contentious debate lasting several years, involving actors from all layers of 
government: politicians, bureaucrats, religious leaders and civil society organisations. Prizren citizens view themselves as a heterogeneous community, taking pride in the cultural landscape noted for linguistic and religious diversity. However, the process leading to the adoption of the new Law on the Historic Center of Prizren damaged state-society relations and polarized the local and central government actors. Pressure from the international community on the Kosovo government to adopt new legislation on the historic Center of Prizren raised the issue to the top of the political agenda.

Legacies of conflict have left a deep mark on the cultural identity of the country. Its architectural heritage is frequently divided between "ours" and 'theirs", the latter being associated as 'other' or belonging to 'the enemy' leading to a rejection of its importance. Politics are thus intertwined to facilitate solutions in a deeply divided society. Weak state capacities in this policy field are manifested through weak institutional capacities to implement existing laws, lack of political will to halt illegal construction of buildings, and failure to employ mechanisms to include the Serbian clergy in decision-making. Mechanisms chosen to facilitate decision-making thus focus on getting political leadership on board. Progress in this regard came to the detriment of consensus based decision-making and inclusion of all affected parties, especially local administration and citizens. This led to further centralization of decision-making. Prizren, as the most ethnically mixed city, is a prime example of the politics involved in heritage management and serves as a crossroads between the varying agencies involved in regulating cultural heritage in Kosovo. Local heritage governance clashed with the interests of central government and international agencies. Both the central government and the international community made visible attempts to use cultural heritage as a means to satisfy various interest groups.

Heritage governance reform in the context of Kosovo may be understood as having two goals. The first goal is to secure legitimacy. The central government intervenes to protect heritage in order to promote the state's political and cultural legitimacy and to maintain its authority (Harvey and Braun 1996). On one hand the government requires recognition from the international community overseeing Kosovo's transition process, that it has successfully implemented the Ahtisaari principles and can fully ensure the protection minority communities' heritage. The government maintains a successful completion of Supervised Independence as the highest achievement since the declaration of independence in 2008 thereby requesting legitimation from its own citizens. Furthermore, the state aims to include the Serbian community in the new heritage governance arrangements. Extending authority over the minority population, through a formalized model of coordination and decision-making ultimately endorses the Kosovo state authority and consolidates domestic sovereignty. On the other hand, international agencies seek 
legitimacy of their programs and strive towards the successful completion of their mandate (Kostovicova 2008). The international community in Kosovo has a political mandate therefore its particular use of heritage protection is embedded in the promotion of a multi-ethnic and peaceful post-conflict Kosovo (ICO 2011) ${ }^{42}$. Strengthening the legal framework to secure stability and decrease the likelihood of inter-ethnic clashes is part of this mandate. The European Commission has donated millions of euros through technical assistance to promote cultural heritage as a 'tool for reconciliation and dialogue between communities' (EC IPA 2008). Furthermore, protecting cultural heritage under the universality of human rights umbrella supersedes state sovereignty issues and thereby permits international organizations to act on behalf of protecting heritage sites in areas of conflict (Council of Europe 2012). Concluding the work of supervising Kosovo's independence, required by the Ahtisaari Comprehensive Status Proposal, is a landmark for the international community and its designated International Civilian Office (ICO) in Kosovo.

With regard to the second goal, government institutions may obtain rewards from international organizations for complying and adopting its proposed models of heritage governance thus using cultural heritage protection as a condition for domestic institutions. At the central level, the reward for adopting new legislation on cultural heritage, specifically on the Historical Center of Prizren, is the removal of supervised independence. In its July 2012 Statement declaring the objective to end supervised independence, the International Steering Group specifically requested "to establish the councils foreseen in the Laws on Prizren and Velika Hoča/Hoça e Madhe" (ISG 2012). This may be interpreted as legitimation of its authority and consolidated state capacity. Furthermore, local authorities obtain rewards from central government for adopting reforms. Allegiance to political party directives may bear rewards for mayors and local political party loyalists. Consequently, obstructing reforms and resisting certain policy changes is risky and may produce conflicts and further exclusion from decision-making.

To cover the role and interests of the broad range of actors, primary data was collected through semi-structured interviews with key stakeholders at the central and local level. Interviews were conducted with international organizations directly involved in reforming cultural heritage policies. This is complemented by an analysis of a wide range of secondary data including legislation, reports and policy briefs from international and domestic organizations and official transcripts of Assembly meetings. The following section provides a brief overview of studies on cultural heritage focusing on studies of post-conflict heritage management and

\footnotetext{
42 Acceptance and protection of Kosovo's multicultural diversity is also promoted as a condition for Kosovo's possible future integration into the European Union (Lehne 2013).
} 
regulation. Insight into the historical background to cultural heritage in Kosovo prior to the 1999 war sheds light on reasons why cultural heritage remains a controversial issue. After an analysis of new political and legislative developments in the field following the 1999 war, the main part of this chapter focuses on the cultural heritage management of Prizren and the city's Historic Center. This reveals the multilayered legislation drafting process and the interaction between local, central and international agencies. The last part recaps the important role international agencies have played in this process of regulating cultural heritage in post-war Kosovo.

\subsection{Cultural heritage management in divided societies}

A wide range of literature on heritage governance addresses the challenges of protecting and rebuilding architectural cultural heritage. Studies of Central Europe, on management of cultural heritage in cities such as Weimar, Kaliningrad in Russia, Gdansk in Poland or Eger and Budapest in Hungary, show the complexity and the influence of the region's changing governments and ideologies (Ashworth \& Tunbridge 1999). Countries also differ in their approach to identifying heritage as well as mechanisms chosen for protection. Many countries use all-encompassing laws for the protection of cultural heritage in the widest sense combined with onetier categorization of heritage so as not to discriminate between monuments. Local authorities bear the responsibility of identifying and protecting heritage sites through integrating heritage protection with local and regional urban and development plans, such as UK, Wallonia region of Belgium and Spain (Pickard 2002).

Cities with complex histories of social division have been examples of integrating cultural heritage management within overall development reforms. Heritage governance in Québec regulates authority for the municipal level and provides clear regulatory powers for the central government. The Cultural Property Act adopted in 1972 regulates the authority of each institution. At the national level, the Minister of Culture, Communications and the Status of Women works closely with the advisory 'Commission des biens culturels du Québec' in identifying and protecting Québec's heritage. The Minister may not undertake any decision pertaining to protection of heritage without the Commission's advice. At the local level, municipalities may also identify monuments or heritage sites on their own initiative through adoption of by-laws by the Municipal Council and after obtaining advice from the advisory committee as well. Citizens also have the right to request protection of historic sites or natural districts, which meet the legal criteria for protection. The role of the central government remains important. All interested parties must first obtain a municipal construction permit, after which the official permission from the Minister 
is required. To date approximately 120 Québec municipalities have designated nearly 375 historic monuments (MCCCF 2007). This arrangement provides the local level with significant authority in assessing heritage sites and providing the adequate protection.

In politically contentious areas in post conflict and divided societies it is especially challenging to protect and manage heritage where interest groups may have diametrically opposing views. Heritage conservation may be utilized to serve various political purposes such as constructing a (new) national identity as in the case of Lithuania wishing to part with its Soviet past (Munasinghe 2006) or Spain following the country's civil war (Viejo-Rose 2010). In the case of Belfast, Northern Ireland institutionalised a neutral approach to cultural heritage to alleviate tensions in society (Livingstone and Morison 1995). Jerusalem's Old City is another city entangled in the politics of heritage, used by the Israeli side to legitimize a specific Jewish historical perspective, and justify the current status of Israeli control and political authority (Calame \& Charlesworth, 2009). Heritage protection policies in post-apartheid Johannesburg have introduced transformations of buildings and public space to change the predominant colonialist narrative (Delmont 2004). In the Balkans, the international community was influential in regulating heritage protection as in the case of Mostar in Bosnia. The Dayton Agreement established the Commission to Preserve National Monuments with member representation from both the Federation and the Republika Srpska. Nevertheless, scholars note that the heritage doctrine promoted in Bosnia by UNESCO and the Council of Europe was too reliant on the nation-state as the developer of collective cultural memory and identity, overlooking the significance of group identification in lower tiers of government in Bosnia and Herzogovina (Musi 2012). In this line, Wolferstan (2006) rightly points out that the local heritage discourse should be integrated in heritage governance in post-conflict societies in order to avoid alienating the public and to prevent top-down power structures. These various approaches reflect the complexities of heritage governance in societies using heritage as a means for authenticating their identity, dealing with collective memory and with social divisions.

Studies of governance arrangements in protected areas consider heritage governance best practices those in which all stakeholders affected are involved, and which include mechanisms for civil society participation (Borrini-Feyerabend, Johnston and Pansky 2006). The last decades have shown a decreasing number of cases where the government is the sole manager of heritage areas and an increase in decentralization policies where protected areas have been created at sub-national level (as with the regional natural parks in France), by the private sector (South Africa) or assigned to be managed by NGOs (in Belize) (Ibid., 140). In the case of South Tyrol, the Special Autonomy Statute of South Tyrol gives the provincial level 
the competences for protection and preservation of cultural heritage (Weller and Nobbs 2011). Protected areas established and managed at provincial, regional and local level can be simpler to declare, more flexible in terms of arrangements and budgeting and better suited to the concerns of the local actors. Furthermore, local governance arrangements are best suited for protected areas of limited size and specific local value. Local communities and indigenous peoples are far from 'new" actors in the governance of protected heritage areas. Yet it is important to provide them with formal and explicit recognition of their roles (Borrini-Feyerabend, Johnston and Pansky 2006, 122-138). With regards to the role of religious communities in heritage governance, UNESCO maintains that a sustainable heritage management is the responsibility of all stakeholders concerned and acknowledges the vital role of religious communities in preserving living heritage (UNESCO 2010). Throughout the Middle East and North Africa region, religious institutions own and manage the majority of religious sites thereby making them vital parts of heritage management (World Bank 2001). The World Bank Framework for the MENA Region (2001) emphasized the importance of targeting assistance to strengthen state capacities both at central and local level and to enhance institutionalised structures of cooperation between state and civil society. Thus, the international community's role in heritage protection remains in promoting laws and conventions as a means of addressing threats to heritage which include lack of financial resources, economic and social changes, violence and political conflicts, and lack of or inappropriate state legislation (Rowan and Baram 2004).

Arguing for increased collaboration between actors in cultural heritage management, Aas et al. (2005) maintain that engagement of all interested parties in the decision-making process allows them to take responsibility. Yet, the large number of actors, including authorities, donors, international bodies and interest groups at community level also embodies a conflict of concerns and values (Barakat 2007 , 29). Conflicting views about the definition of cultural heritage and the lack of voters' information weaken the control on political representatives. Politicians may also suffer a shortage of information because of the specificity of the knowledge and expertise required to understand heritage issues. Reforms are thus easier to be promoted if decisions are taken by one decision-maker to avoid higher transaction costs which occur if an agreement has to be reached between different layers of government (Rizzo and Throsby 2006, 1002 - 1007). Nevertheless, when users or common citizens are involved in the new understanding of the use of space and their environment, their participation becomes an integral part of the policy-making process (Tas, Tas, and Cahantimur 2009). Two of the guiding principles in the Council of Europe work in cultural heritage are "the need to involve everyone in society in the ongoing process of defining and managing cultural heritage and to recognize the role of cultural heritage in the construction of a peaceful and 
democratic society" (Council of Europe 2005). When dealing with historic units within cities, it is especially important to integrate the social discourse into the urban planning mechanisms. As local perceptions evolve over time, so the city accommodates the local understanding of heritage. Imposing strict protection mechanisms risks turning cities into spaces incapable of change (Hammond, 2005). On the opposite side of the spectrum, inclusion of non-state organisations or heritage NGOs is based on the assumption of their benevolence and contribution to heritage protection. The extensive involvement of these NGOs in the region begs the question of their downward accountability.

\subsection{Cultural heritage in Kosovo: A background}

For a relatively small territory of roughly ten thousand square kilometers, Kosovo possesses an extremely rich heritage. Its archaeological heritage dates from the Neolithic period onwards, with evidence from the Copper, Bronze and Iron ages, Roman Antiquity and Early and Late Mediaeval periods (Pickard 2008; UNESCO 2005). According to UNESCO "the extraordinary concentration of cultural monuments from prehistoric to modern times attests to the historic continuity of life in Kosovo and to the artistic creativity of its inhabitants" (2003). Prizren, the second largest and most ethnically heterogeneous city, is home to a significant part of this rich heritage. Its population consists of Kosovo Albanians, Turks, Bosnians, Kosovo Serbs and Roma, Ashkali and Egyptian (RAE) communities.

Occupied by various powers throughout history, its architecture was heavily influenced by the Empires and Kingdoms ruling it. During the medieval period, many Byzantine, Roman-Catholic and Serbian Orthodox monuments were built. Vernacular architecture such as traditional residential buildings including stonetower houses (kulla) and lodgings (konak), bridges, fortresses and urban Centers are part of the cultural heritage (UNESCO 2003). When the region was integrated into Serbia in the late twelfth century, Serbs proceeded to establish an extensive cultural and religious presence, including a number of important Orthodox churches, monasteries and palaces at Peja, Prizren and Visoki Decani (Herscher 2010). During the Ottoman rule, which started in 1495, Prizren developed as a cultural Center within Kosovo and benefited from its geographical position linking trade within the empire. In the centuries of Ottoman rule over the Balkans, a large part of the population in Kosovo converted to Islam. Dozens of mosques and monuments were built across the country, including many in Prizren (Gülersoy et al. 2008). After falling under the Austro-Hungarian Empire in the $17^{\text {th }}$ century, Prizren was conquered again by the Ottoman Empire and in 1868 became the capital for Prizren vilayet (province) which included all of Kosovo proper as well as neighboring regions. In 1878, the Albanian National League was formed in Prizren also known as 
the Prizren League (Malcolm, 1998). Prizren thus became an important establishment of an Albanian political and military movement to resist the Ottoman Empire. Throughout the $20^{\text {th }}$ century, Prizren remained a politically important Center for Albanian nationalism in the struggle for independence after being reconquered by the Kingdom of Serbia under which Kosovo was annexed by Serbia (CHwB 2011). The latter lost control of the territory until 1945 during Germany's occupation in the Second World War. Kosovo then became part of Serbia as an Autonomous region within the larger Yugoslav Federation. In socialist Yugoslavia, until the late 1970s, the role of the Serbian Orthodox Church (SOC) was drastically reduced and religious heritage sites received very little funding and attention. Out of the circa 3000 heritage sites identified in Kosovo in the period 1999 until 2005, only 425 monuments and sites were officially listed during Yugoslavia between 1947 and 1990 (MCYS, 2010). One of these monuments, the Prizren League House later became a museum. Following its reconstruction after Serbian forces destroyed it during the 1999 war, the Prizren League House was a great income-generating source for the municipality as one of the highest earning tourist venues in the city.

In the past, heritage protection in Prizren was a community obligation without proper detailed legislation and there were no plans for the development of the historic Center. As national institutions were established in the 1950s including the national Bureau ${ }^{43}$ for the Protection of Monuments and the Museum of Kosovo, preservation of cultural heritage was limited to individual buildings, including specific monuments or archeological sites. During the early stages of planned urban development, there was minimal understanding of the conservation of historic environments, which led to the decay and demolition of many important heritage sites (Pickard, 2008). The historical core of the city of Prizren was officially declared a protected area in 19564. Between 1968 and 1974, several specific studies and proposals were completed to document the protection and rehabilitation of the historic center. The 1974 Yugoslav Constitution ${ }^{45}$ brought about improvements to the institutional structure in heritage management for Kosovo and allowed for developing local expertise through the newly established University of Prishtina. The state Bureau was established in Prizren in 1967 facilitating a link between the city and the higher ranks of the Yugoslav Federation. At the federal level the main legislation in force was the 1977 Law on the Protection of Cultural Monuments (Hoxha 2008).

\footnotetext{
${ }^{43}$ Often referred to in documents as 'Institute'.

${ }_{44}$ During the 1940s and 1950s, an education system was developed allowing for the use of Albanian language.

${ }^{45}$ Kosovo remained part of the Serbian Republic, but was elevated to a full constitutive element of the Federation with its own constitution and Assembly.
} 
Regulations on heritage required the Urban Planning Department in the Municipality of Prizren to seek the Bureau's consent for each intervention in the historic zone prior to issuing a permit. From the 1960s until 1981 the Bureau was the most important institution with regards to heritage in Prizren. The Provincial Institute for the Protection of Monuments existed in Prishtina, whilst at the state level the highest decision-making body was the Belgrade based Coordination Center of the Federal Republic of Yugoslavia and of the Republic of Serbia for Kosovo and Metohija (UNESCO 2003). Throughout these ranks, confusion over regulatory responsibilities occurred between local and national institutions, weakening the implementation of heritage preservation (Pickard 2008).

The historic Center in Prizren was nominated to the UNESCO World Heritage List in 1972, however the nomination process was not successful and the Prizren historic Center became dilapidated ( $\mathrm{CHwB}$ 2002). In later decades, most of the monuments and sites in the heritage inventory compiled by these institutions included medieval monuments. The Serbian government focused their funding on maintaining particular Orthodox religion sites considering their proclamation as part of the Serbian identity and culture (Shoshi 2012).

These mechanisms were in place until the late 1980s. The rise of Milosevic to power and an increase in Serbian nationalism led to restrictions on rights of Albanians (Sörensen 2009). ${ }^{46}$ This political shift in Serbia enabled a stronger role for the SOC. The nationalist agenda built on the presence of the SOC in Kosovo as proof of Serbian supremacy and rights over the territory in Kosovo. This solidified the Church's role as guardian of 'endangered Serbs in Kosovo' (Herscher 2010). Serbian Orthodox heritage throughout Kosovo became a significant part of the national rhetoric linked with Serbian identity and rights over the territory. Thus, heritage was utilized for political motives throughout the following two decades (Cultural Heritage Expert Interview, January 2013). As the Balkan expert Susan Woodward (2000) stated in an analysis of Yugoslavia's decomposition:

[In] a political context in which identities and states are being reformed, redefined, and reconstituted, as well as borders redrawn, the case of Kosovo has been especially charged, serving as a catalyst or instrument of reformulations throughout former Yugoslavia and the wider region.

The Serbian government invested in building new Orthodox religious sites throughout Kosovo's territory often to the detriment of local vernacular sites or Islamic monuments. Therefore, the Kosovo Albanian population perceived the

\footnotetext{
46 Political relations between Serbia and Kosovo are beyond the scope of this research. However, it suffices to note that Kosovo Albanian opposition towards the Serbian state preceded the Milosevic regime and was exacerbated during 1990s (Sörensen, 2009: p. 189).
} 
expansion of Orthodox architecture as "colonization" and the churches being "political" rather than an expression of religious freedom. Albanian resistance to Serbian control included acts of vandalism against Serbian Orthodox churches and monasteries. "If architecture legitimated Serbia's claim to Kosovo, then damage to that architecture became damage to that claim" (Herscher and Riedlmeyer 2000, 111). With the revocation of Kosovo's autonomy in 1989, the political situation in Kosovo deteriorated significantly. The expulsion en masse of Kosovo Albanians from public institutions and the abolishment of the use of the Albanian language in university education led to the establishment of a parallel education system. Lack of contact between the Albanian and Serb population became the norm as school and university buildings were prohibited for Albanians (Kostovicova 2005). Protection of cultural monuments was seized by the Serbian government as one of the pretexts for its decision to impose direct rule on Kosovo (Herscher and Riedlmayer 2000). Exclusion of Kosovo Albanians from state institutions prohibited knowledge flow and advancement in their training in cultural heritage (Pickard 2008). Within the heritage management structures, such as the Institute for Protection of Monuments and the regional institutes in different cities, a number of Albanian staff did remain employed; however, not in leading or managerial positions. This division between those who "remained part of the system" and those expelled from it became a divisive issue amongst Albanians after 1999, hampering cooperation in the heritage policy field (Heritage Expert Interview, 2013).

Closing access to university for Albanian students was a major hindrance preventing new generations from developing local expertise. The Department of Architecture at the University of Prishtina proved extremely valuable to the heritage field in Kosovo in the post-1999 period as they were continuously involved as technicians in excavations and studies of archaeological sites in Kosovo. As violence escalated in 1998 and war broke out in 1999, a large number of heritage sites were damaged or destroyed. Serb forces attacked mostly mosques and Islamic religious sites as well as old bazaars and historic monuments associated with KosovoAlbanians. Artifacts and objects belonging to the Museum of Kosovo as well as documentation of the Provincial Institute for the Protection of Cultural Monuments in Prishtina were taken during the withdrawal of Serbian military forces and state administration in June 1999 (UNESCO 2003). Together with the artifacts, a great body of knowledge and expertise was also drained from Kosovo institutions as Serbs were no longer included in the state administration after 1999. Retaliation acts of Kosovo Albanians, which led to the damaging or destruction of Orthodox religious sites, further damaged cultural heritage in the country. 


\subsection{Cultural heritage governance since 1999}

Following the adoption of UN Security Council Resolution 1244, the UNMIK administration annulled the discriminatory legislation enacted in Yugoslavia between 1989 and 1999. This included annulment of the 1994 Yugoslav Law on Cultural Property (Hoxha 2008). The lack of legal protection, left heritage sites bare and subject to attacks and damage through unregulated restoration or nearby building work. The international administration didn't provide any replacement institutional framework after annulling the 1990s legislation. In 2001 UNMIK led a wave of recentralizing services from the municipal to the central government level and the regional Institute for Protection of Monuments in Prizren (IPMP) ${ }^{47}$ came under the auspices of the Ministry of Culture, Youth and Sport (MCYS). This centralization of authority obstructed the work of the IPMP by restricting its access and involvement in the consultation process at the local level (CHwB 2011). UNMIK retained cultural heritage protection as a reserved right, however later transferred authority at the policy level to the Ministry. MCYS was also in charge of cultural heritage in Prizren as there were no regional branches of the government mandated to deal with cultural heritage in the Prizren municipality. This management of cultural heritage excluded Orthodox religious sites, which were outside of Kosovoled responsibility since 1999. Whilst KFOR soldiers provided physical protection of these sites for several years, the religious buildings were managed by religious communities and by the Serb population living in enclaves (EC/CoE 2004). This put cultural heritage in a limbo state, on the periphery of national policy agendas and without proper attention from the central government. Considering the already weak local capacities, centralization of authority on heritage management made the situation worse. This was especially true for the city of Prizren where a large number of the heritage sites are concentrated and financial resources are urgently required to halt the deterioration of monuments and buildings. The division of decision-making authority, between the clergy of Serbian Orthodox Church and Serbian population on one side and the Albanian state authorities on the other, further damaged inter-ethnic relations.

In the decade following 1999, the Council of Europe released declarations and conducted evaluation missions on Kosovo's cultural heritage. Reports from the Council of Europe and its Parliamentary Assembly called for awareness on protecting endangered cultural heritage and recommended the decentralization of culture management responsibilities as a mechanism of enhancing peaceful coexistence amongst ethnicities (CoE 2001). UNESCO reports noted 'a marked indifference towards the cultural heritage of the 'other' as a dominant phenomenon' in Kosovo (EC/CoE 2004). Of particular importance, was the emphasis placed on the

\footnotetext{
${ }^{47}$ Since 2010 called the Center for Protection of Monuments.
} 
requirement to build local capacities where 'a large number of dedicated professionals with great expertise, working in local institutions, have been isolated, undermined and under-funded for many years" (CoE/PA 2001, 1; CoE 2001).

The outbreak of violent riots in March 2004 caused considerable damage to heritage sites throughout the country. In the riots 34 religious and cultural heritage sites (Orthodox churches, monasteries, cemeteries, funerary chapels and some traditional houses) were damaged or destroyed (CoE 2004). The riots confirmed cultural heritage as a national issue and further damaged inter-ethnic relations as a result of which the international administration maintained a centralized approach to heritage governance. Its management and authority over protecting heritage sites thus required more attention from the central government and received priority with international administration agenda. UNESCO increased its attention to heritage in Kosovo with its 2004 report after a fact-finding mission designed in cooperation with the Government of Serbia and Montenegro and UNMIK. The report stresses the role of cultural heritage 'as a potent symbol of the identity of peoples and as a factor of reconciliation' (UNESCO 2004). ${ }^{48}$ The organization proposed enhanced international recognition of the country's heritage through the inclusion of several monuments in the World Heritage List as a mechanism for deterring future attacks.

Following the March 2004 riots, access to Serbian Orthodox heritage sites was restricted with checkpoints guarded by the international forces KFOR (Wolferstan 2007). This was a catalyst for international agencies in Kosovo to design mechanisms of communication between the Kosovo authorities and the Serbian Orthodox Church to enable conservation and reconstruction of damaged sites. The central government and UNMIK allocated financial assistance and many religious sites were reconstructed as an attempt to dilute the inter-ethnic tension. The Reconstruction and Implementation Commission (RIC) was established through a Memorandum of Understanding between the Kosovo Ministry of Culture, Youth and Sports, the Serbian Orthodox Church, Belgrade representatives of the Republic Institute for the Protection of Cultural Monuments to reconstruct 34 Orthodox religious sites damaged or destroyed during the riots. The SOC pulled out from the collaboration soon after but joined again in May 2005.49 The RIC, led by the Council of Europe, remained the only existing mechanism where the Serbian Orthodox Church and Kosovo authorities formally discuss cultural heritage issues (ICO

\footnotetext{
48 A permanent committee of UNESCO experts tasked with annual monitoring of cultural heritage in Kosovo is also recommended in the report. Another UNESCO mission visit in May 2005 specifically for Prizren with regard to the Church of Bdgorica Ljeviska showed the significance of Prizren heritage.

${ }_{49}^{4}$ The first MoU was signed in June 2004 and the second MoU signed in May 2005.
} 
2011a)..$^{50}$ The RIC, however, did not include other undestroyed heritage sites in the country and thus remained a separate mechanism from other heritage management structures.

As the new legal framework, drafted and adopted by Kosovo authorities and promulgated by UNMIK administration grew, definitions and regulations over cultural heritage management became clearer. Nevertheless, proper implementation of the legislation remained a big challenge. Cultural heritage was defined and protected by a legislative framework that includes the Law on Spatial Planning (2003-14) in 2003, Law on Cultural Heritage (02/L-88) adopted in 2006 and seven legal acts adopted by the Ministry of Culture, Youth and Sports in 2008. The Ministry of Youth, Culture and Sports developed a List of Cultural Heritage monuments and buildings in 2012. The Ministry List includes 930 protected buildings of cultural heritage, emergency interventions for 16 heritage buildings and rehabilitation of many other buildings with special historical values. ${ }^{51}$ However, the document was never sent to the Kosovo Council for Cultural Heritage for approval and thus Kosovo remains without a national inventory (OSCE, 2012). Already in the Law on Cultural Heritage, it was made clear that requests for constructing buildings within a protected zone be submitted for consideration to the competent institution, which has a veto over granting such permission. ${ }^{52}$ At this time, the competent institutions included the municipal spatial and urban planning departments. At the national level, the Institute for Protection of Monuments led by the Ministry of Culture, Youth and Sports, the Ministry of Environment and Spatial Planning remained the most important central government institutions in heritage governance.

The Law on Cultural Heritage also introduced a new institution into the governance structure, namely the Kosovo Council for Cultural Heritage (KCCH) as an independent agency serving as the highest professional organ to identify and value heritage sites, evaluate projects on heritage conservation proposed by other institutions and to integrate cultural heritage in spatial, urban and rural development plans. The Council's late establishment, years after the adoption of the Law on Cultural Heritage, the delayed appointment of its members ${ }^{53}$ and lack of

\footnotetext{
${ }^{50}$ The international community failed to broaden the scope of the RIC to include all of Kosovo heritage resulting in the ICO to search for future mechanisms of heritage management that include the SOC in decision-making.

51 According to the Medium-Term Expenditure Framework 2013 - 2015, (April 2012, 7). Furthermore, the Government Meeting Session of August 1st 2012, states that Ministry of Youth, Culture and Sports has a Strategy for Protection and Promotion of Cultural Heritage 2012 - 2017 and a Strategy for Integrated Conservation 2012 - 2017.

52 Article 7.17, Law On Cultural Heritage Law No. 02/L-88.

53 Setting up of members of the KCCH was not regulated by law but by a decision of the Kosovo Assembly Committee on Education, Science, Technology, Culture, Youth and Sport in 2007 (Kosovo
} 
renewed mandates for Board Members by the Kosovo Assembly damaged the weak protection of cultural heritage in the country. This showed a lack of professional expertise in treating the issue during political debates that ensued after Declaration of Independence. The KCCH role, nevertheless, remains advisory a factor which the ICO outlined in its reports on the implementation of heritage protection in Kosovo (ICO 2011).

During the 2006 - 2007 Vienna negotiations on the Kosovo final political status between the Kosovo and Serbian government, protection of Serbian Orthodox heritage was a key issue in the agenda. Receiving broad national attention in Kosovo, the enhanced protection of Orthodox heritage sites was largely perceived as a political compromise to receive international support for resolving the political status. The resulting Ahtisaari Comprehensive Proposal for the Kosovo Status Settlement included a chapter on heritage protection, outlining tools for securing the requests of the Serbian community and their cultural rights. The main recommendations of the Ahtisaari Proposal concerned international supervision on enhanced decentralization to local authorities, minority rights and protection of the Serbian Orthodox Church. Addressing specifically the role of the Serbian Orthodox Church in Kosovo, state authorities are required to consult the SOC regarding the promotion of the Serbian Orthodox heritage for touristic, scientific, educational or any other public purposes (Annex V, Article 1.7). Furthermore, the establishment of Special Protective Zones prevents adverse development around Serbian Orthodox heritage sites. The agreement of the SOC is necessary for any activities in the Special Protected Zones including constructions, public gatherings or urbanization of land (Annex V, Article 4.1.2). The Ahtisaari Proposal also addresses specifically the establishment of a protective zone for the Historic Center of Prizren. Article 4.1.7 assigns the task of establishing a protective zone for the Historic Center to the municipal authorities of Prizren in cooperation with the Implementation Monitoring Council - IMC. The Ahtisaari provisions do not address explicitly a requirement for a separate national law for Prizren, but does request increased protection of cultural and religious sites of minorities. To ensure these protection mechanisms are implemented with the interest of the Serbian Orthodox Church in mind, the Proposal stipulates the requirement for cooperation between the existing Reconstruction Implementation Commission and the new structure Implementation Monitoring Council (IMC) (Annex V, Article 5.6).

Declaration of Independence in February 2008 and the adoption of the Ahtisaari Proposal by the Kosovo Assembly initiated a series of innovations concerning

Assembly, 2007). In 2009, 2 members of the KCCH (Enis Kervan of the Kosova Turkish Democratic Party and Branislav Grbić of New Democracy Party) were also elected Members of the Kosovo Assembly representing a conflict of interest as the Assembly approves the KCCH Board and budget (KDI, 2009). 
heritage governance. Monitored and steered by the International Civilian Office in Kosovo, the process of adopting the new legislation was fast-paced and largely blocked public debates on sensitive issues. However, as the Ahtisaari Proposal was recognized as the 'price' for Independence, its provisions were to a degree accepted by the public. The Kosovo Assembly applied Rule 61 of the Rules of Procedure Work Regulation permitting an accelerated procedure for law approval. ${ }^{54}$ The rule was first enforced in February 2008 following the Declaration of Independence and repeatedly used until the new Constitution came into force in June 2008. Citizens were left out of this process with the government claiming that the new legislation was an obligation towards the international community to confirm Kosovo's commitment to protection of minorities (GAP Institute 2010). The Kosovo Constitution was the only legal act which received public discussion through public debates organized throughout the country.

Cultural heritage became the Center of politically infused tensions with the adoption of the Law on Special Protected Zones in 2008. Its definition of Special Protected Zones (SPZ) received wide criticism from civil society who rejected the authority granted to the Serbian religious organizations as a de-facto endorsement of extraterritoriality. The 'special' character of the SPZ is to ensure communication between representatives of the Serbian Orthodox Church and municipalities on decisions concerning constructions and activities in the protected zone (ICO 2011, 14). The municipality, bearing responsibility for implementing the SPZ provisions in its territory, is required to seek the agreement of the Serbian Orthodox Church regarding Prohibited and Restricted Areas prior to issuing a permit. Adopting this particular clause may be considered a breakthrough in the political environment as it secures a role for the SOC in decision-making. Yet the cooperation of the Serbian Orthodox Church was not secured by the adoption of the Law as cooperation presupposes recognition of Kosovo-led institutions by the latter, a political issue which remains unresolved.

Prizren Municipal Department for Urban Planning contributed in the drafting of the Law on Special Protected Zones, which includes many sites in Prizren. Early proposals of the Law were considered problematic considering the veto power given to the Serbian Orthodox Church. According to interviewees from the Municipal Department for Urban Planning 'the Serb Orthodox Church was assigned authority to decide on construction in a large perimeter surrounding its premises which would block $1 / 3$ of all conservation sites, even those not belonging to SOC' (Prizren Urban Planning Department Interview, June 2012). The final adopted Law introduced 45 SPZ in the Kosovo territory, with most of them concentrated in South

\footnotetext{
${ }_{54}$ With the new Kosovo Assembly Work Regulation adopted on April 29th 2010, the rule is now found under Article 84.
} 
and West Kosovo. The Prizren and Shtërpcë/Štrpce area include two clusters of SPZs namely the Historic Center of Prizren and the village of Velika Hoča/Hoçë e Madhe.

Resulting from the Ahtisaari provisions, an additional key element of the Law on Special Protected Zones was the introduction of the Implementation Monitoring Council (IMC), in charge of overseeing the implementation of key cultural heritage legislation. The role of the IMC is specifically linked to the protection of Serbian religious and cultural heritage in Kosovo. It remains within the IMC mandate to facilitate a resolution of disputes between the SOC and the central or local authorities with regard to implementation of the law. ${ }^{55}$ This mandate includes oversight of the Historic Center of Prizren. The head of the ICO, the International Civilian Representative (ICR) is mandated to institute the Implementation Monitoring Council.56 The IMC was formally established in 2011 to include as members the Ministry of Culture, Youth and Sports, the national Kosovo Institute for Protection of Monuments based in Prishtina, the Institute for Protection of Monuments based in Leposavič, the Serbian Orthodox Church and international stakeholders (OSCE 2010). Its functions have not been fully established bar a limited member consultation process. The ICO mandate concluded without the full functionalization of the ICO (ICO 2011) presenting a critical deficiency in securing a functional system of decision-making involving all the stakeholders.

Despite the existing legal framework on heritage, institutional weaknesses in heritage management continue to include limited coordination of stakeholders, weak capacities and lack of institutional cooperation (Hoxha and Thaçi 2012). The Kosovo government must provide for the necessary state mechanisms to ensure proper protection of endangered sites. This requirement is exacerbated by a lack of direct UNESCO monitoring. The latter's role is diminished since heritage sites in Kosovo proper continue to be registered under the Serbian state authority. All these factors supported the claim of the central government led by the ICO that additional legislation specifically for preserving the heritage in Prizren would benefit heritage preservation. It also supported their approach to lead the process. The following section analyses in detail the characteristics of heritage in Prizren and the drafting process of the new law regulating the Historic Center of Prizren. Structures were designed to remove the authority of municipal authorities over cultural heritage management in Prizren due to the danger that other ethnicities (SOC) would be excluded from decision-making.

\footnotetext{
${ }_{55}$ Articles 4.1.1. and 4.1.2 of the Law on Special Protected Zones.

${ }^{56}$ Article 7.4, Annex V of the Ahtisaari Comprehensive Proposal.
} 


\subsection{The Historic Center of Prizren: A city within a city ${ }^{57}$}

Cultural heritage in Prizren is unique as it embodies the diversity of its population. The historic zone in Prizren includes vernacular architecture, the Prizren Castle as well as Islamic and Christian religious sites. Initially, the historic zone as defined before 1999, covered most of what is protected today. Post-war illegal construction, as was the case throughout Kosovo, damaged a considerable part of the historic monuments. After the local Prizren Institute for the Protection of Monuments (IPMP) failed to receive support on its request for a moratorium on all construction in the historic zone, the municipality adopted a general Urban Plan of Prizren in 2004 (CHwB 2011, 163). The Prizren Municipality Memorandum of Understanding with the expert organization Cultural Heritage without Borders $(\mathrm{CHwB})$ initiated the process of establishing (or redefining) the Historic Center of Prizren in 2006. It was only in 2008, after the declaration of independence, with the adoption of the Urban Regulatory Plan for the Historic Center of Prizren that the city was finally equipped with its own set of regulations on the Historic Center. The municipal Regulatory Plan resulted from a four-year process of designing the Conservation and Development Plan for Prizren. This Plan standardized all construction types in the Historic Center including regulating preservation and permit issuance for new construction. The municipal Urban Planning Department was in charge of issuing permits after receiving the advice of the Prizren branch of the Institute for Protection of Monuments. Prizren municipality is the only city in Kosovo with a conservation plan integrated in their urban development strategy. Considering the lack of a national development strategy, this is considerable achievement for the local community. The $\mathrm{CHwB}$ declared in 2011 that the Historic Zone of Prizren "represents one of the most protected urban, architectural and historic cores in Kosovo" (CHwB 2011, 163). Nevertheless, during the last years international agencies lobbied for increased protection of the Historic Zone. ${ }^{58}$

The drafting process for the new Law on the Historic Center of Prizren started in 2008 with the establishment of the Inter-Ministerial Working Group. This elevated the Historic Center of Prizren to a higher legal status. Following a framework

\footnotetext{
57 The concept of a historic city, as noted by Ashworth and Tunbridge $(2000,9)$ entails "urban forms from the past that have survived into the contemporary city'. Historic cities are part of the citizen's daily environment and thus integrated in their understanding of their space and surrounding. Within larger municipal units, historic Centers are regulated with specific legal acts enabling preservation of the past as well as securing adaptability with urban development. Construction restrictions are highly regulated within the space of historic cities as well as within a certain radius surrounding the sites. These mechanisms of regulating activities within and around historic Centers support the continuation of life in a historic Center without disturbances from modern developments, which might interfere with the preserved identity of the community.

${ }_{58}$ Upon the adoption of new heritage protection measures, the Albanian-ethnic group were vocal about 'losing out' to the Serbian side.
} 
document designed by the ICO, the Ministry of Environment and Spatial Planning officially led the drafting process with the ICO steering the entire process. The Working Group in charge of facilitating the drafting process involved both the central and local authorities. It was led by the Ministry of Environment and Spatial Planning and co-chaired by a representative from the Urban Planning Department of Prizren municipality. This mechanism included representatives of line Ministries, international organizations such as the ICO as well as UN-Habitat and the organization Cultural Heritage without Borders for its expertise on the field. The $\mathrm{CHwB}$ represented the only local based non-government organization working on cultural heritage invited to participate in the drafting process.

The data suggests that several issues obstructed the drafting process. Obstacles included the collapse of the government in 2009 and a six-month institutional crisis, which left several ministries without leadership. According to the ICO it was as a result of this crisis that their organisation initiated the drafting process for a set of laws deriving from the Ahtisaari Proposal, arguing that "[their] leadership was a result of the government collapse and there was no partner on the other side" (ICO Interview, August 2012). In the government Inter-Ministerial Working Group, the ICO pushed forward the drafting process arguing that a higher level of protection is easier to implement if regulated, "if it's not within a structure and legal system, it doesn't exist" (ICO Interview, August 2012). This evidence suggests the crucial impact of the ICO in this process and the importance given to institutionalising mechanisms for heritage governance. Furthermore, despite recent developments towards decentralization and increased political powers at the local level, the ICO stance in the Working Groups had a clear inclination towards centralizing instruments for control over polarizing issues such as heritage. Interviewees from local counterparts referred to the ICO role as a 'shadow leader' closely monitoring the legislation drafting process and negotiating with the Minister of Environment and Spatial Planning whenever opposition arose within the Working Group $(\mathrm{CHwB}$ Interview, September 2012). During the drafting process, the ICO particularly defended issues concerning the Serbian Orthodox Church, a politically contentious issue in the country considering their refusal to accept Kosovo's independence. According to one member of the drafting team, "some issues were so political we could not get past them in the Working Group" (CHwB Interview, September 2012).

According to interviewees, additional obstacles in the drafting process concerned lack of information sharing and coordination between the local and central government (CHwB Interview, September 2012). Furthermore, municipal officials' lack of expertise was brought up by interviewees as another factor impeding adequate tackling of issues $(\mathrm{CHwB}$ Interview 2012). These presented major challenges, which marred the entire process from 2008 until the final adoption of the Law in 2012. Despite having a municipal official from the Urban Planning 
Department Co-Chair the Ministerial Working Group, municipal officials, including the Prizren mayor, ${ }^{59}$ criticized the drafting process for lacking proper dissemination of information to all parties (MESP Interview, 2012). The CHwB admitted receiving pressure from civil society organizations in Prizren to reveal information about the undergoing process at the Working Group (CHwB Interview, 2012). Leaked information to the civil society, in the form of a draft law being discussed in the working group, finally drew the attention of national media, which broadcast continuous declarations from civil society organizations objecting to the content of the draft law being discussed. This affected the centralized mechanism established by the Ministerial working group. The latter developed into a reactive model of working in attempts to incorporate comments indirectly without addressing issues directly or attempting direct communication with the institutions and organizations voicing objections. These objections concerned a lack of transparency and a restricted law and policy-making process exclusive to civil society. Objections were also raised due to a feared 'ethnicization'60 of decision-making in heritage management with a bias towards the protection of Serbian Orthodox sites.

The new Law on the Historic Center of Prizren (Law on Prizren) introduced a new decision-making process on heritage in the municipality. One of the key innovations is the establishment of a seven-member Council for Cultural Heritage within the Historic Center to ensure representation of all groups of society. Civil society as well as religious communities in Kosovo, including the Catholic Church, the Serbian Orthodox Church and the Islam Council is represented in the Council for Cultural Heritage. ${ }^{61}$ Other minorities such as Bosnian, Turkish, and RAE communities are not referenced or represented. The Municipal Assembly appoints representatives of civil society within the Prizren community. ${ }^{62}$ Civil society was especially critical with regards to including religious communities in a decision-making body. Other religious communities in Prizren questioned the act of singling out certain religions over others. Despite the heavy criticism displayed, the establishment of a Council on Cultural Heritage may entail benefits, in bringing together actors from all sides of a

\footnotetext{
${ }^{59}$ This may be attributed to the clashes between the Municipal Assembly, which refused to approve the new Law on Prizren and the Mayor who was under political pressure from his party, the PDK to approve the law.

${ }^{60}$ Ethnicization refers to the establishment of boundaries and identification of cultural heritage as ethnicheritage. This has broader social and political implications in a society.

${ }^{61}$ Clarifying a misunderstanding by the media and civil society, MESP officials stated in the interview that religious organizations may appoint a representative from outside their organization as member of the municipal Council on Cultural Heritage.

${ }^{62}$ In April 2013, the Prizren Municipal Assembly appointed three civil society representatives to become the first members of the Council. The Network of Cultural Organisations in Prizren announced that these individuals were the only applicants to the Municipal Assembly and did not represent the civil society of Prizren (RROK, 2013).
} 
fragmented society. This is particularly unique for religious authorities, which may be excluded from such institutions.

State actors, on the other side, utilized the political stance of the Serbian Orthodox Church against recognizing the function of Kosovo-led institutions as validation for their argument that the inclusion of religious institutions harms heritage management in Prizren as a whole. The Ministry of Environment and Spatial Planning, although agreeing to the complexity added by including religious groups in the decision-making process, kept to the requirements resulting from the Ahtisaari Proposal arguing: "We had to include them in the council; and it is an obligation" (MESP Interview 2012).

Regulating the process of decision-making, the Law on Prizren introduces several key steps involving a range of institutions to review requests and complaints regarding the Historic Center of Prizren. The key phases of decision-making are outlined as follows:

1. All requests including construction, destruction or adaptation of property are initially submitted to the Municipal Urban Planning Department. A copy of the request is submitted to the Council for Cultural Heritage, which monitors the entire process.

2. If one member of the Council does not agree [with giving the license to the requesting party], there is additional consultation between the parties involved.

3. In the case where this consultation process fails to satisfy all members of the Council, the municipal Urban Planning Department requests approval for its decision from the Institute for Monument Protection in Prizren.

4. The request is submitted to the Ministry of Environment and Spatial Planning whilst the Ministry of Culture and the Council for Cultural Heritage receive copies of the file.

5. The central government must take the final decision.

6. If the complaining party disagrees with the decision, the case is taken to court.

Requests related to the Serbian Orthodox Church must be submitted to the Implementation Monitoring Council through the central government institutions, namely the MESP and MCYS. Complaints issued by the Serbian Orthodox Church, on the other hand, are treated by a separate mechanism. Since the SOC itself is a member of the Council for Cultural Heritage, their own complaints are directed to the Ministry of Environment and Spatial Planning and are also submitted to the Council for Implementation and Monitoring. This mechanism ensures fair treatment 
of their requests and complaints. In the latter case, the MESP acknowledges it as a breakthrough that complaints are not directed only to the local Council for Cultural Heritage but must be sent to the central government as well. If the complaining party is unsatisfied, then the dispute goes to court. Prior drafts mandated the local Council for Cultural Heritage as the final decision-maker (MESP Interview 2012). This particular issue, settled under Article 18 of the new Law, was included as a final attempt of the MESP to ensure that objective procedures are put in place that respect the Ahtisaari proposal and do not undermine Kosovo institutions. International Civilian Representative Peter Faith finally accepted these amendments despite the initial resistance from other ICO representatives in the Inter-Ministerial Working Group (MESP interview 2012). From opposing organizations, such as the Prizren Coalition of NGOs for the Prizren Historic Center, these new mechanisms were perceived by Prizren civil society organizations as enabling a "City within a City" model. According to them, the new law will allow a model of decision-making that can be blocked at the heart of the Municipality with religious communities able to veto against the authority of elected representatives of the Municipality (Ceku, 2012). The Kosovo Council for Cultural Heritage agrees that the new law on the historic zone creates a "special administrative unit within the municipality of Prizren" (KCCH 2011). This constrains functional and efficient local governance. The municipal government faces a great challenge in implementing a law which its Municipal Assembly has refused.

In August 2011, the Kosovo Assembly processed the draft Law on the Historical Center of Prizren with an accelerated procedure. It was expected to pass it immediately after its first reading in the plenary session, as was practice with a number of laws related to the Ahtisaari Proposal. However, strong opposition from the functional Assembly Committee for Agriculture, Forestry, Environment and Spatial Planning in charge of proceeding the draft Law led to the draft law being refused. Members of the Committee accredited part of their objections to the draft law the criticism they received from civil society organizations, associations and the Islamic community in Kosovo. Other objections related to the content of the draft law refusing to identify cultural heritage with one ethnicity. Lastly, MPs publicly addressed the political pressure of central government on the voting process and objected to 'blind compliance' to international community requests ${ }^{63}$ (Kosovo Assembly, 23.08.2011). During the second reading of the draft Law on Prizren, in April 2012, MPs denounced the government for interfering in parliamentary procedures by distributing instructions to MPs on how to vote for each amendment

\footnotetext{
${ }^{63}$ During the session, one MP declared: "We have now entered this process, and it has turned into an obligation considering that it was even mentioned in the Progress Report". The 2011 Progress Report on Kosovo of the European Commission noted that the two laws on Prizren and Hoçë e Madhe/Velika Hoča have not been adopted (EC 2011, 22).
} 
proposed to the text. ${ }^{64}$ Political conditionality was reiterated during the Prime Minister's address during the final voting session at the Kosovo Assembly when Prime Minister Thaçi declared that "the closure of international supervision of independence depends on our adoption of the last laws deriving from the Ahtisaari package. $[\ldots .$.$] the ending of supervised Independence is on your hands today"$ (Kosovo Assembly, 20.04.2012). The central government repeatedly drew parallels to the adoption of the Ahtisaari Package stating that the passing the new legislation secured independence and international recognition (Kosovo Assembly, 2012).

\subsection{The politics of reforming heritage governance}

The trajectory of the legislation drafting process was marred by centralized decisionmaking and lack of transparency. Instead of a reinforced role of central state institutions securing a stronger emphasis on accountability and oversight of heritage governance, the drafting process solely stressed national political interests overriding those of local interest groups. This was further damaged by the Kosovo Assembly procedures in force. Compared to the procedures used to pass the set of new legislation following the Declaration of Independence in 2008, the Law on Prizren did not fit within the urgent process of adopting the Ahtisaari legislation. Yet, the Kosovo Assembly again applied accelerated procedures to speed up the adoption of the Law on Prizren, as requested by the executive. The new law proposal did not have to follow the expedited process and would have benefited from an open dialogue with non-state actors and a broader inclusion of other interest groups. To avoid a prolonged public discussion about the Prizren law, and its possible rejection, the central government raised the urgency of adopting the legislation. The Kosovo Assembly thus utilized Rule 61 when dealing with the proposed Law on the Historic Center of Prizren.

From a local point of view, complaints on the process from the municipality of Prizren were wide ranging. In September 2011, after the Government initially passed the draft Law on the Historic Center to the Kosovo Assembly, the Prizren Municipal Assembly released a declaration against the current version of the draft law. This revealed a clash between the legislative branch of the municipality and the officials from the Department of Urban Planning, which had participated in the Working Group in Prishtina and were involved in drafting the Law. This lack of one unified voice for Prizren harmed their arguments with the line ministries and the ICO. According to an interviewee from the Prizren administration 'municipal

\footnotetext{
${ }^{64}$ During his speech in the Assembly, the Prime Minister recognized the existence of these instructions and referred to them as government suggestions to MPs concerning the amendments to the draft law (Kosovo Assembly, transcript of Assembly session on April 20 th 2012).
} 
officials were marginalized and their comments to the Inter-Ministerial Working Group were often not respected'65 (Prizren Department of Urban Planning Official, Interview 2012). On the other side, members of the Ministerial Working Group declared many comments received from the municipality did not properly address issues of the Law and were not included in the draft (MESP Interview 2012). The latter's stance coincides with reports on weak municipal capacities in drafting bylaws and integrating municipal policies. The previous experience of the Municipal Urban Planning Department in developing the 2008 Conservation and Development Plan for the Historic Center did not cover politically sensitive issues such as the involvement of the Serbian Orthodox Church.

Research conducted suggests that municipal officials tend to be submissive towards Ahtisaari matters and many of them renounced any opposition towards the central government initiation for a new law for Prizren. Interviewees failed to mention that since 2008, the Law on Special Protective Zones already granted an important role to the Serbian Orthodox Church and required the municipality to seek the latter's consent in matters concerning Orthodox heritage. This was a result of a lack of information on the Ahtisaari requirements. Officials from the municipal Urban Planning Department accepted the necessity for introducing the new legislation specifically for the Historic Center due to the country's obligations to fulfill Ahtisaari requirements. Interviewed municipal officials assert that the central government ministries were obliged to follow Ahtisaari guidelines and it is the municipality's obligation to implement the law once it is adopted' (Official from Prizren Department of Urban Planning, Interview June 2012). Other officials suggest that the Law was prioritized simply to fulfill Ahtisaari requirements even if it did bring "new layers of structures upon existing structures" (Prizren Department of Urban Planning, Interview August 2012). These new layers, however, may obstruct an efficient government. Notwithstanding their key role of implementing the technical aspect of the new Law on the Historic Center, municipal officials from the Department for Urban Planning acknowledge the pressure of politics:

Whilst the Municipal Assembly conducted politics, our requests concerning the draft Law were cut short. We worked for two years on the draft Law, yet in the end an older version was sent to us (Interview, June 2012).

Threats and other forms of pressure from affected parties also had a direct influence on the work of the municipal administration. According to the Director of Urban Planning Department, during his participation in the drafting of the Law on the

\footnotetext{
65 According to a municipal official the drafts received from the working group came back to the municipality without any changes to reflect the municipality's concerns, stating "the drafts we received came back unchanged" (Prizren official Interview 2012).
} 
Historic Center he was sued seven times with the objective 'to obstruct his work' (Director of Department of Urban Planning, Interview, June 2012).

From a national point of view, clashes between institutions existed in Prishtina as well. New legislation is broadly accepted by the central government, which criticizes municipalities for failing to implement their current regulations and spatial plans (MESP Interview 2012). The national Kosovo Council for Cultural Heritage took the contrary position, arguing in a report, that new legislation was not necessarily the solution. The $\mathrm{KCCH}$ criticized the lack of transparency in the drafting process. This reaction demonstrated a public rupture of this national institution with the Ministry of Environment and Spatial Planning (MESP) and ICO. The KCCH maintains that the said Law does not derive directly from the Ahtisaari Proposal. The Proposal does not specify it in the list of legislation required from the document. Instead the Ahtisaari proposal requests a Law on Selection of Protected Zones. Secondly, the decision-making authority is given to a Committee representing religious institutions instead of a professional body. Thirdly, the Law on Special Protected Zones discriminates in its definition of cultural heritage worthy of protection by favoring cultural heritage monuments and sites belonging to the Serbian community. The $\mathrm{KCCH}$ rightly acknowledges that cultural heritage deserves protection as national treasures, protected by the state. Yet, they argue, demarcating exclusive rights of the Serbian Orthodox Church (SOC) violates the principle of heritage as a public good by discriminating against certain types of heritage as 'undeserving' of protection. The $\mathrm{KCCH}$ opposition does not denote a refusal of additional legislation or regulatory means to manage cultural heritage. It is rather a denunciation of the exclusion of certain areas of cultural heritage and the current focus on the interests of the Serbian community. At the outset, the ICO invited the $\mathrm{KCCH}$ in the drafting process (KCCH Interview, January 2013) however after the $\mathrm{KCCH}$ opposition to the content of the draft Law, it was excluded from the process.

The role of the $\mathrm{KCCH}$ in the drafting process seems to have been curtailed by three factors. First, cultural heritage did not become a priority on the political agenda until 2011 - 2012; consequently, establishment of the $\mathrm{KCCH}$ was delayed. Although the Law on Cultural Heritage was adopted in 2006, which required the establishment of the Kosovo Council for Cultural Heritage, the latter was officially mandated in 2009. The President of the $\mathrm{KCCH}$ stated that she learned of her appointment to the Council through the newspapers instead of via a formal notification by the Assembly (KCCH Interview, January 2013) points to the red tape in Kosovo's administration. Extensive layers of bureaucracy and lack of communication are apparent in the collaboration process between political and professional staff across institutions in heritage management. Timely functionalization of existing agencies would strengthen the role of the Center and 
successfully increase its power through implementing legislation. Second, the $\mathrm{KCCH}$ declared its objection to the draft Law on the Historical Center of Prizren and was not involved by other institutions. This relates to the third factor pertaining to the $\mathrm{KCCH}$ role in heritage governance. The ICO points to the $\mathrm{KCCH}$ as an advisory body to the Kosovo Assembly (ICO, 2011) whereas the $\mathrm{KCCH}$ maintains that it is mandated with executive and oversight powers over other institutions working in heritage management (KCCH Interview, 2013). Nevertheless, considering it is the highest-ranking professional institution in the field, and the duration of the drafting process, the $\mathrm{KCCH}$ plays a significant role in legitimizing the new law. The $\mathrm{KCCH}$ presence during meetings of the Assembly Committee once the draft law reached the Assembly was rather a symbolic acceptance of its role without serious considerations of its criticism. In disregarding the opinion of the $\mathrm{KCCH}$, the Kosovo government and Kosovo Assembly clearly violate the authority of a state institution and weakened the legitimacy of the process.

The challenging drafting process of the new legislation on Prizren combined with the political pressure exercised throughout the institutional hierarchy, tests overall accountability in local governance. At the national level, exclusion of the Kosova Council on Cultural Heritage, mandated by law to oversee all matters on cultural heritage, inhibits oversight of the decision-making process from the Kosovo Assembly. Furthermore, it weakens cooperation between the legislative and executive branch. At the local level, providing religious institutions with veto powers within decision-making bodies, such as the local Council on Cultural Heritage is an obstacle to local decision-making. According to civil society representatives, the double representation of the Serbian Orthodox Church in the local Council as well as higher ranks of institutions overseeing the implementation of the Law inhibit functional local institutions and weaken accountability lines (Civil society representative, Interview 2012). According to local officials, assigning veto rights for religious communities in the city is a paradox considering that 'Muslim, Catholic and Orthodox communities are responsible for the biggest illegal constructions damaging areas of heritage' (Director of Prizren Department of Urban Planning Interview, June 2012). ${ }^{66}$ These conditions imply an enhanced risk that religious communities in Prizren misuse their power within the Council. The lack of clear oversight mechanisms of the work of the council further enhances these risks.

Adding to the existing heavily bureaucratic system, the Historic Center of Prizren has a series of institutions and actors monitoring and protecting it. This includes an Urban Planning inspection team and inspectors for culture from the central

\footnotetext{
${ }^{66}$ Similar acts have occurred in Bosnia and Herzegovina as well where illegal religious objects were built to demonstrate dominance of one ethnicity over the other fortifying tension between the ethnic groups (United States Department of State, 2010).
} 
government whereas inspectors for construction work on behalf of the municipality. The Council for Cultural Heritage and the Implementation Monitoring Council will be in charge of oversight of the historic zone as will be the regional Institute for Protection of Monuments. This existence of several layers of institutions might incite citizens to bypass the Urban Planning Department in the municipality and reach directly the Council further weakening the local authorities' link with citizens.

Municipal administration, the mayor and the Municipal Assembly were all confronted with a challenging political environment to approve the new law. Municipal officials view their concessions to the draft Law as a bargaining tool to secure central government funding for implementing the Law. According to the Urban Planning Director, "the Ministry of Environment and Spatial Planning is sponsoring the Law, they are obliged to secure financial costs as well" (Director of Prizren Department of Urban Planning Interview, June 2012). However, financial resources and their significance in implementing the new legislation did not receive sufficient attention from either party. Despite the 'outcry' of the central government to pass the new legislation on the Historic Center of Prizren, it failed to allocate financial means to the municipality of Prizren to implement the new competences and set up the institutions. The lack of local financial resources also challenges local budgeting for the establishment of the Committees and Councils foreseen by the new Law on the Historic Center of Prizren. Prizren officials blame the central government for weak planning abilities due to the lack of a financial plan when the law was drafted. On the other hand, the ICO maintains that fines listed in the Law on Spatial Planning and Law on Construction should be doubled for any violation within the Historic Center of Prizren (ICO 2011b). The latter stance is problematic considering the limitation of municipalities to set new taxes. The ICO utilized its oversight authority again in August 2012, issuing a Memo to the Minister of Finance raising the issue that "adequate funds have not been transferred to the municipality of Prizren" (MESP, Interview 2012).

\subsection{International agency involvement}

Involvement of international agencies in issues of cultural heritage in Kosovo is a fundamental part of heritage governance. Professional organizations such as UNESCO were fundamental in drawing attention to the damaged heritage especially in the immediate post-war phase. However, due to the lack of recognition of Kosovo's independence by the UN, UNESCO's role was further limited and under the shadow of Serbian institutions or the UNMIK administration. ${ }^{67}$ Kosovo's sites registered on the World Heritage List still figure as Serbian properties.

67 UNESCO's intervention in Kosovo dates back to 2003 with preliminary reports on a 'Multi-ethnic 
Since the Declaration of Independence in 2008 the ICO took a steering role at the outset of the process, setting itself as a principal actor in the heritage discourse. The ICO represents a norm-setter due to its political clout to interpret the Ahtisaari Proposal and monitor its implementation. It utilized its authority as an oversight institution guarding Kosovo's independence to drive the process. Its mandate in overseeing Kosovo's state institutions became the highest condition over Kosovo authorities to adopt legislation deriving from the Ahtisaari principles. However, as its mandate drew to a close in 2012, the ICO interpretation of its role became subject to the success of Kosovo institutions adopting the 'final' obligations towards the international community. The ICO mandate includes monitoring the implementation of the Ahtisaari package yet in the process of adopting the Law on the Historic Center of Prizren, the ICO maintained that its main role was to secure the adoption of the Law (ICO Interview, 2012) with its implementation monitoring being a task for the remaining European Union Representative in the country. This showcased the ICO focus on norm setting rather than establishing sustainable mechanisms of cooperation between the fractured parties.

Foreign embassies in Kosovo also took a role in this particular matter with the Greek Ambassador serving as spokesperson and interlocutor for the Serbian Orthodox Church. The SOC does not recognize the Kosovo-led institutions and therefore did not participate in direct communication with the central government authorities. The Greek Ambassador in Kosovo was strongly opposed by domestic stakeholders for upholding requests that every activity affecting the property of the Serbian Orthodox Church should require a request to the SOC and the latter's consent.

The previously adopted Law on Special Protective Zones reiterates the Ahtisaari provisions requiring consultations with the Serbian Orthodox Church regarding activities concerning Orthodox heritage. Bearing in mind the ICO promoted the Ahtisaari Proposal as the basis for proposing a new specific Law on the Historic Center for Prizren, it failed to clarify to all interest groups that the provisions of Special Protective Zones stipulated certain requirements for Prizren heritage management. Considering the political sensitivity of the issue, a national law regulating heritage management in the Historic Center of Prizren was considered necessary and legally binding for all state institutions rather than a municipal bylaw. Nevertheless, considering the lack of authority of both central and local government to enforce legislation, newly adopted legislation does not ensure its successful implementation.

culture in danger' (UNESCO 2003) assessing the nature and extent of damage to buildings of heritage value during the UNMIK administration (Dumper \& Larkin, 2012). Dumper and Larkin (2012) studies of Jerusalem's divided heritage also show limitations of UNESCO's mandate with state political sensitivities hindering its praxis. 
Immediately after the war the Kosovo International Management Group carried out damage assessment for the European Commission issuing the 'Kosovo Damage Assessment' report with evaluations for repair on listed and public buildings. Technical projects in cultural heritage were numerous and included foreign universities and governments, various professional organizations such as Cultural Heritage without Borders as well as the experts from the Council of Europe and European Commission. The latter institutions included Kosovo in their 'Integrated Rehabilitation Project Plan / Survey of the Architectural and Archaeological Heritage' (IRPP/SAAH) for countries of South East Europe. Their Kosovo program focuses in prioritizing a list of monuments and sites requiring immediate attention. The report was finalized after the March 2004 riots and called on the European agencies to restore and protect cultural heritage in Kosovo. Through its cooperation with UNMIK and the Ministry of Culture, Youth and Sports, the Council of Europe was continuously involved in establishing the legal framework on heritage and remained a key institution in this sphere. However, due to the increasing involvement of the ICO and the political pressure to finalize the Ahtisaari-based legislation, the CoE was excluded from the drafting of the new Law on the Historic Center of Prizren. This showcased the political power of the ICO to lead the reform process and the drawbacks of the existing decision-making system. Nevertheless, government institutions, both at central and local level, bear responsibility for refusing to give civil society a role in the drafting process, thereby widening the gap in trust between state and non-state actors.

\subsection{The civil society opposition}

Criticism from civil society organizations and experts led to a public schism between the ICO and the central government on one side and the civil society in the other. An activist states, "We received information about the drafting process through informal channels, as the ICO and the central government completely shut us out" (Civil society representative, Interview March 2012). Utilizing all institutionalised mechanisms, civil society organizations in Prizren organized and posed a strong opposition to the new legislation being drafted. Criticizing the lack of transparency in the drafting process, the Civil Society Coalition in Prizren gathered ten thousand signatures of Prizren inhabitants and submitted a request to the Kosovo Assembly for recognition of the 'citizen's voice'. According to the leader of the Civil Society Coalition:

An entire society has declared itself against this law. Civil society, citizens, business community of Prizren, Municipal Assembly of Prizren, Kosova Council for Cultural Heritage, Institute for Protection of Monuments, Architects Association of Kosovo, opposition parties, Kosovo Assembly 
Spatial Planning Committee, intellectuals and experts of cultural heritage have all voiced their strong opposition to the law. (Civil society representative, Interview March 2012).

However, with the exception of publicized letters of opposition from the $\mathrm{KCCH}$ and the Islamic Council of Kosovo, opposition from other institutions was often mild. According to the ICO, due to political constraints, government representatives often altered their stance outside of the Working Group meetings when discussing with media (ICO interview 2012). In the later stages of the drafting process, comments received from the civil society were considered beneficial to the drafting process although they were received informally and outside of the official Working Groups. Officials from the Ministry of Environment and Spatial Planning maintain that this criticism of the draft law brought certain sensitive issues on the discussion table of the Working Group (MESP Interview 2012). Although this suggests a minor success of civil society, it nevertheless demonstrates the exclusive and centralized decisionmaking mechanisms in force.

Failure to involve citizens during the drafting process was also evident in the lack of public meetings organized by the Ministerial Working Group. The ICO maintains its stance that it is the government's responsibility to include citizens in the decisionmaking process and that "the national level government should have done more to go out and talk to the people, not the ICO" (ICO Interview, August 2012). According to the latter, publication of the draft Law on the Historic Center of Prizren was delayed because of the lack of internal agreement within members of the Working Group (ICO Interview, August 2012). A few meetings were organized at the local level, however they were restricted to solely invited guests thereby distorting the meaning of public meetings. This further limited the broader participation of citizens. The ICO presence at the meetings held in local communities demonstrates attempts to influence the citizens and symbolizes the political importance and international backing of these laws (KCCH Interview, 2013). Furthermore, public hearings were organized while the draft law was in the Assembly thus prohibiting any further comments as a result of the public hearings. ${ }^{68}$

The most organized local opposition came from the Prizren Ad-hoc Coalition on the Protection of the Historic Center, composed of a dozen non-governmental organizations working in the municipality. These included EC Ma Ndryshe (Different Emancipation), Fondacioni për Trashëgimi Kulturore (Cultural Heritage Fund), Forumi për Trashëgimi Kulturore (Forum for Cultural Heritage), Academy for Training and Technical Assistance, NGO, the Prizren branch of Kosovo Democratic Institute, GreenArt, X40, EUIRC, Ura e Artit (Art Bridge), Durmish

\footnotetext{
${ }^{68}$ One public debate was hosted by Ministry of Environment and Spatial Planning in Prizren on October
} $20^{\text {th }}, 2011$. 
Asllano, ICEC, Old Timer Club Prizren and Shoqata e Bjeshkatarëve Sharri (Hiking Association). Half of the organizations involved are professionally engaged in the cultural heritage field or conduct activities related to culture in Prizren. These organisations mainly represent the Albanian majority population and the Turkish community. The majority of member organizations work with encouraging citizen participation in local decision-making. The professional expertise on cultural heritage issues is based on the few organizations which have worked on the field. The coalition member organizations working on cultural heritage promotion and informed on heritage issues were already active in the city during the development of the municipal Conservation and Development Plan. The leading organization of the Ad-hoc Coalition, EC Ma Ndryshe, is an active local organization in Prizren civil society especially engaged in monitoring the work of municipal authorities. Its role in heading the coalition was important in raising the interest of the broader public and involving the national media in the discussion on the Prizren Law. The Ad-hoc Coalition received support from Prishtina based NGOs and think tanks and was widely represented in national media debates.

Civil society members of the Prizren Ad-Hoc Coalition initially accused the ICO of imposing its false interpretation of the Ahtisaari provisions and rejected the ICO claim for a new legislation regulating specifically the Prizren Historic Center. Their position altered during the course of developments calling on both local and central governments to open the decision-making process and improve the possibility of properly implementing the new law. Coalition member NGOs informed on cultural heritage issues led the petition process and organized protests in Prizren to show dissatisfaction on the exclusion of local civil society during the drafting process. The petition signed by ten thousand Prizren citizens was delivered to the Kosovo Assembly on September 19th, 2011. It was organized immediately after the Kosovo Government resubmitted the draft Law on Prizren to the Kosovo Assembly a week after the latter had rejected the first draft. The petition's main clause stated the following:

The drafting of a Law on the Historic Center of Prizren must be an inclusive process involving all interest groups. This type of law may not grant privileges to specific groups, specifically to religious communities (FES 2011).

The Kosovo Assembly disregarded the petition signed by Prizren inhabitants on the draft Law and the petition was not mentioned in the two plenary sessions of discussions on the draft Law on Prizren. Whilst organizations monitoring the work of the Assembly Committees were present during the Committee meetings on the draft Law, there was lack of communication between civil society organizations working on this particular issue and the Assembly Committee. The Prizren civil 
society Coalition addressed the Kosovo Assembly through an open letter appealing to the Assembly for 'inclusion of the interested organizations in the drafting process from beginning to end' (EC Ma Ndryshe, October 2011).

Similarly, civil society representatives argue that the Presidency ignored the civil society and the voice of the people stating, "we hoped the President will not sign the new Law, as a recognition of the will of society" (Interview 2012). Despite this opposition, the law was finally adopted in the Kosovo Assembly in April 2012. Due to the Law's adoption as part of the Ahtisaari Package, its status was elevated into a 'fundamental' law requiring a double majority in the Kosovo Assembly for its amendment. This is a critical benchmark difficult to meet considering the lack of inter-ethnic cooperation in the Assembly.

\subsection{Conclusion}

Discussion on heritage governance in Kosovo is not limited to conservation mechanisms and schemes for integrating heritage protection with local development plans but rather includes a political economy dimension, highlighting it as a politically contentious issue in Kosovo's transition. The long legacy of conflict between Kosovo Serbs and Kosovo Albanians has harmed cultural heritage in the country through neglect and deliberate attacks. The expectations of the Kosovo Serbs and the Kosovo Albanians concerning cultural protection differ significantly. Clashing meanings of this heritage have also undermined most attempts to portray a common culture and identity. UNMIK advertisements promoting reconciliation often used cultural heritage sites as means to draw attention to a common culture and common identity. As the Kosovar scholar Edi Shukriu argues, monasteries and Orthodox churches require political solutions instead of programs solely directed to increasing visits to these sites (Shukriu 2008). The refusal of the Serbian Orthodox Church to cooperate with Kosovo-led institutions, including the local government in Prizren, has further undermined progress towards inclusive mechanisms of decision-making and further solidified the involvement of international agencies as mediators.

The drafting process for the new Law on the Historic Center of Prizren was a centralized decision-making process. With limited information sharing amongst both central and local actors and exclusive towards non-state actors, this process developed an environment in which state institutions are increasingly viewed as unresponsive to citizen demands. Prizren citizens consider themselves as an inclusive community, taking pride in the cultural landscape noted for linguistic and religious diversity. The process leading to the adoption of the new Law on the 
Historic Center of Prizren damaged state-society relations and polarized the local and central government actors.

Overall, the governance process was flawed due to a series of factors. ICO acted as an imposing agency and utilized its authority as an oversight institution guarding Kosovo's independence to drive the process and pressure domestic institutions. The international community insistence on a centralized decision-making process goes against their strong advocacy for decentralization in the last years and undermines the role of the local in the process. In addition, the previously adopted Law on Special Protective Zones reiterates the Ahtisaari provisions requiring consultations with the Serbian Orthodox Church regarding activities concerning Orthodox heritage. Bearing in mind the ICO promoted the Ahtisaari Proposal as the basis for proposing a new specific Law on the Historic Center for Prizren, it failed to clarify to all interest groups that the provisions of Special Protective Zones stipulated certain requirements of consultations for Prizren heritage governance. Considering the political sensitivity of the issue, a national law regulating heritage governance in the Historic Center of Prizren was valued necessary and legally binding for all state institutions rather than a municipal by-law. However, the establishment of new structures and institutions, such as the Council for Cultural Heritage within the Historic Center of Prizren, without a functional Implementation Monitoring Council at the central level can have dire consequences for the municipality of Prizren. Lastly, the ICO promoted Special Protective Zones for providing a necessary link between the Serbian Orthodox church and municipalities. However, it resorted to facilitating SOC negotiations only at the central level considering the latter's refusal to recognize municipal authorities.

The absence of a central government direction for the cultural heritage policy holds back reforms at the local level. Furthermore, the Ministry of Environment and Spatial Planning and the ICO established themselves as the main gatekeepers in the entire process. As leading members of the Inter-Ministerial Working Group in charge of drafting the legislation, their lack of transparency and centralized decision-making deepened the divisions with local stakeholders including political groups and civil society organisations. The central government, including the Ministry of Environment and Spatial Planning failed to include civil society actors as well as the Kosovo Council for Cultural Heritage. Their role as leaders of the Ministerial Working Group was pivotal in setting the tone for the draft Law on Prizren. Their decision to maintain a centralized Working Group without access to information from outside agencies stirred opposition from non-state institutions.

Other barriers to improve the decision-making process were weak institutional capacities at the local level. This concerns the failure to protect heritage sites in Prizren according to existing municipal urban planning and development 
regulations. Failure to implement proper protection against illegal construction damaged their role in exercising local autonomy and efficiently implementing their competences. Municipal authorities lacked sufficient understanding of the role of the SOC as a specific actor in Kosovo's post-Independence political landscape. Opposition to the new Law on Prizren's Historic Center was heavily based on the premise that it gave the SOC privileged rights in the management of the Historic Center. However, these rights were already requested with the 2008 Law on Special Protective Zones in which Prizren heritage is listed. The final adopted Law on the Historic Center enhanced the decision-making role of other religious communities, by establishing membership of three main religions in the new municipal Cultural Heritage Council.

The exclusion of important institutions such as the Kosova Council of Cultural Heritage and the Council of Europe from meetings of the Working Group, is a clear display of the centralized mode of decision-making. ${ }^{69}$ There was a broad perception among domestic stakeholders that the ICO was responsible for the success or failure of this particular set of Ahtisaari-based laws. However, this argument is utilized for the political benefit of Kosovo authorities. Domestic stakeholders are able to resign their responsibilities and "blame" the ICO for any failures. Consequently, the lack of accountability for failing to implement the new legislation weakens local governance and impairs successful reforms in heritage management.

During the legislation drafting process, political pressure became a norm and included ICO demands on the government to finalize the draft law as well as pressure from the central government on the municipality of Prizren to accept the new legislation. Its reserved right to interpret the Ahtisaari Comprehensive Status Proposal fortified the ICO's influence. In promoting a new law specifically for the Historic Center of Prizren, the ICO in fact supersedes the Ahtisaari principles, which put the Prizren municipality in charge of establishing the historic zone. Pressure to push forward policies and legislation reform does not leave room for broad discussion and public involvement. According to a member of the Working Group, the prevailing concern was "to approve the law because it is our obligation towards the international community, regardless if we implement it or not" $(\mathrm{CHwB}$ Interview, September 2012). Instead of using these shifts as opportunities to strengthen protection of cultural heritage, this stance perpetuates a state of limbo and ex-ante sets the new legislation up for failure.

\footnotetext{
${ }^{69}$ A similar example of this practice is the government's refusal to acknowledge the Kosovo Assembly authority when it resubmitted the draft Law, unchanged, to the Assembly in mid 2011. The draft Law was returned to the government requesting changes a week before its resubmission (Civil society representative, Interview March 2012).
} 
Integrating local responses in decision-making has the significant benefit of restoring trust in institutions. Partnering with subnational actors benefits the implementation of reforms as well as knowledge flow. Particularly in cultural heritage management, the central government may benefit from the local materials, skills and know-how (Barakat 2007). However, both central government and international actors often fail to build partnership with local initiatives and thereby decrease chances of successful reform. In the Kosovo case, this partnership was difficult to form and communication between different institutions was very problematic due to differing interests. Excluding key institutions from the legislation drafting process risks the potential for successful implementation of the law once it is adopted. The civil society leaders refuse the new legislation and have clearly stated their readiness to block the implementation by advocating the boycott of the new Council by civil society representatives (Civil society representative, Interview March 2012).

This environment constrained full cooperation and damaged trust in institutions and overall transparency. In an already burdened bureaucracy and weak state capacities these shortcomings inflict lasting damage especially in relation to localcentral cooperation. The process of drafting legislation on heritage management in Kosovo exhibits a paradox of governance reforms. Pressure from international agencies to enhance regulation in fact harmed transparency and accountability. Weak cooperation between local and central authorities as well as between state and non-state institution undermined the progress of functional and inclusive heritage governance, which includes the Serbian Orthodox Church. Attempts to strengthen state authority without opening up the process of decision-making risks led to the implementation of the new legislation failing thus perpetuating the state's weakness.

Cultural heritage is understood as the process and relation between people and their environment and thus entails an aspect of cultural continuity. As such, heritage governance must allow for flexibility and adaptability over time in order to adapt to and reflect the changes that occur within society. The requirement of a double majority to change the national legislation on the Historic Center of Prizren limits the adaptability of heritage protection mechanisms and their relationship with the citizens of Prizren. 
Appendix 4A. Chronology of drafting process events

2008

2010

2011

27 July 2011

10 August 2011

22 August 2011

23 August 2011

1 September 2011

9 September 2011

19 September 2011

January 2012

20 April 2012

09 July 2012

17 August 2012
Inter-Ministerial Working Group established

Kosovo Assembly establishes Kosovo Council for Cultural Heritage

Implementation Monitoring Council is established

Kosovo Government approves Draft Law on Prizren and submits it to Kosovo Assembly

Kosovo Government votes on Draft Law on Village Hoca e Madhe (this is declared as the last Law required by the Ahtisaari package)

Assembly Committee for Agriculture, Forestry, Rural Development, Environment and Spatial Planning recommends to the Assembly the Draft Law on Historic Center of Prizren not be adopted and is sent back to the government for revisions.

Kosovo Assembly votes on first reading of draft Law on Historic Center of Prizren. MPs voted 44 for the law and 46 against. Draft law is rejected and goes back to Government.

Kosovo Government Meeting, Prime Minister approves the Draft Law on Prizren and (re) submits it to Kosovo Assembly

Municipal Assembly of Prizren declaration against the (current version of) draft Law on the Historic Center of Prizren

Prizren Coalition of NGOs for Prizren submits petition results to Kosovo Assembly.

Prizren Coalition organized protest in Prizren

Kosovo Assembly approves Law on Historic Center of Prizren with a series of amendments

Law comes into effect after being signed by the Kosovo President.

Government approves Concept Note on new Draft Law on Cultural Heritage 
Appendix 4B. Institutional structure of cultural heritage management

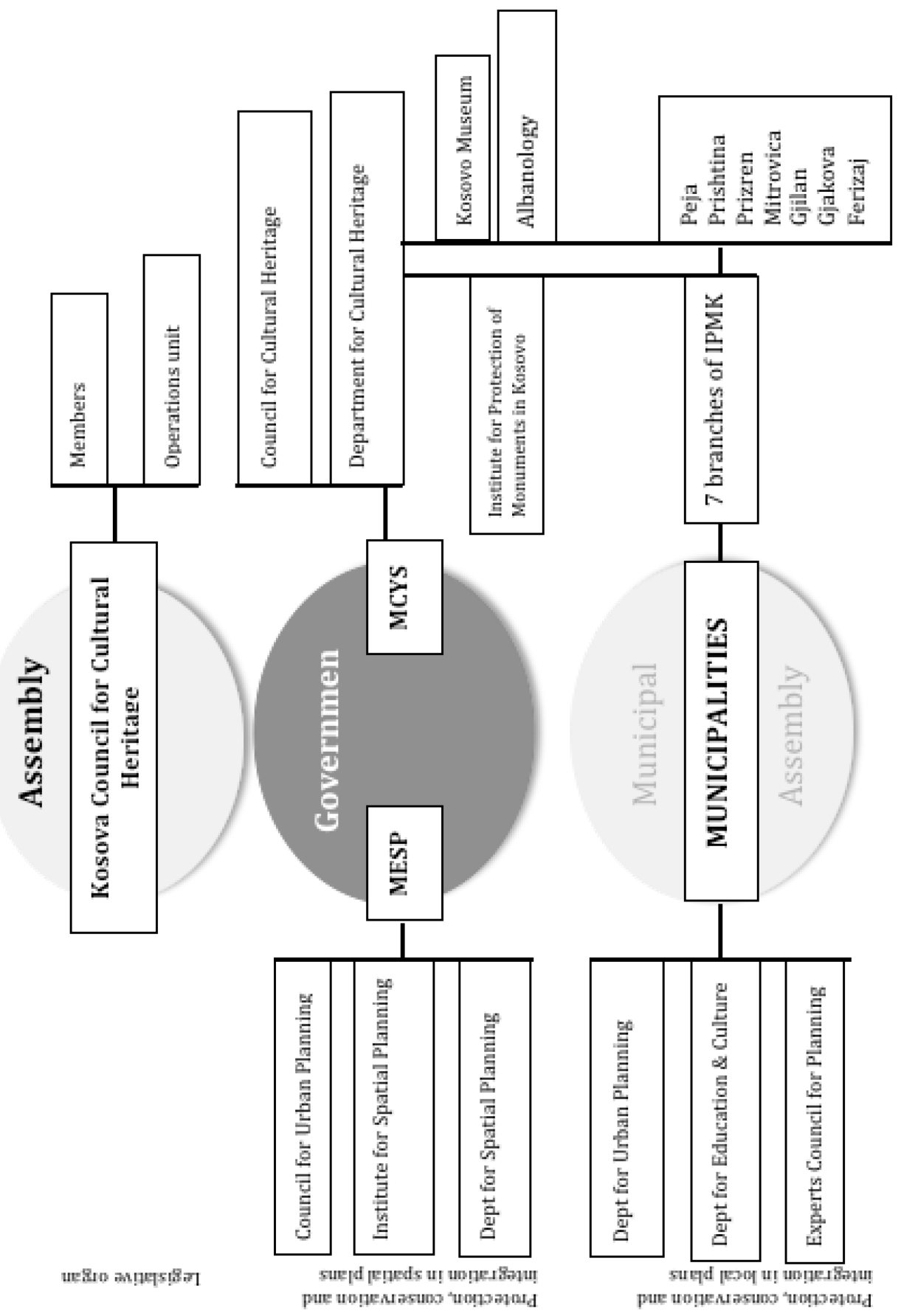


5. The young (unemployed) Europeans: enabling youth participation in local decision-making 


\subsection{Introduction}

This chapter explores the structure and agency of state authorities and civil society organisations promoting youth engagement in local decision-making. Focusing on youth policy allows us to examine the vast evidence of new interaction between national and local state institutions and non-state structures established to promote youth engagement. This policy area helps articulate the extent to which the formation of new mechanisms for civic participation has enhanced youth engagement. The chapter explores how these new processes of collaboration have transformed the government stance towards youth policy and their representative structures and vice-versa. The youth sector is explored because of the high degree of variation between municipalities regarding how local authorities and civil society organisations respond to change.

The chapter investigates the potential that the externally driven initiative of establishing Youth Action Councils in municipalities has in engaging young citizens in local decision-making processes. It evaluates the various factors enabling such an engagement including the significance of close relations between civil society leaders and the municipal leadership for effective cooperation. Furthermore, it explores the assumption that political leadership support to the cause of youth participation is more likely to secure strong partnerships with youth organizations. Lastly, effective collaboration is contingent upon an active approach of civil society organizations as well as an openness of civil servants towards non-state agencies. To enable an in-depth study of the factors influencing relations between government institutions and civil society actors, a series of municipalities were selected with a varying degree of cooperation between youth structures and municipal authorities and varying levels of efficacy of local institutions.

The first section of the chapter explores the key policies on youth and provides an institutional mapping of the most important structures in youth participation. This is followed by an analysis of the role of Youth Action Councils as a new local endeavour for engaging young citizen in local activities. The final section offers indepth information on three case studies showcasing the work of Youth Action Councils in various municipalities with differing results.

The legal framework supports youth engagement in decision-making processes. New legislation and regulations present opportunities for youth organisations to engage and address their concerns with state institutions. The establishment of municipal youth councils is a novel approach to recognizing the power of a significant part of the population in the country. However, weak enforcement and implementation were one of the biggest challenges throughout the municipalities. Over the recent years, various initiatives to promote youth engagement have been introduced yet the effectiveness of these initiatives is contingent upon various 
factors. Central government attention to the youth sector is important in aligning the interest of domestic and international agencies working with youth. Local leadership and political support from the municipal mayors proves important in advancing new mechanisms of cooperation in local decision-making. In addition, the drive of local civil servants and youth organisations to collaborate across the state/non-state realm are also crucial for embedding a new culture of collaboration between youth and municipal authorities.

\subsection{Case study: engagement of young Europeans}

According to the Kosovo Statistics Agency, half of the Kosovo population is under the age of 25. Kosovo has the largest youth share of total population in Europe. The 2011 elected central government is also marked by the young age of its cabinet members. Adversely, Kosovo has the highest unemployment rate in Europe and Central Asia at $45 \%$ with youth particularly vulnerable to unemployment and poverty (World Bank 2008). The workforce belonging to the age group $15-24$ who are part of the workforce, $55.3 \%$ are unemployed. In addition, $35.1 \%$ of the same age group are not active in education, work or training. Finally, young Kosovars are twice as likely to be unemployed when compared to older citizen (KSA 2011, 9). This data points to an emergent situation affecting a particularly vital part of the population. With approximately 30.000 Kosovar young adults entering the work force annually, in practice, this means they enter the ranks of the unemployed (UNDP 2006). Lack of practical work, including internships or seasonal jobs makes them inexperienced for work. In addition, there is no regulated recognition for voluntary work, whether in the community, non-government organizations, associations or the like. The international promotional campaign for Kosovo launched in late 2009, to promote Kosovo in the international media, sought to brand Kosovo as a newly independent, democratic nation, focusing on the power of its young population. The slogan 'Kosovo: The Young Europeans' seemed disingenuous and was criticised by civil society considering the dire role of youth in the country and their lack of education and employment opportunities.

According to UNICEF studies in Kosovo, the young population has a limited impact on the decision-making processes for to two reasons, namely that institutions rarely feel obliged to respect youths' right to participate, and young people do not consider participation a civic responsibility (UNICEF/IKS 2010). This is accompanied by the young population's perceptions of their own weakness and inability to have an impact on their socio-political environment. Data from 2006 public opinion polls show around 80 percent of young citizens surveyed declaring they cannot have any impact on the affairs and issues happening in their municipality (UNDP 2006). Youth eagerness to participate is also dependent on 
Kosovo institutions establishing channels to engage youth to advocate for their interests. For a decade after the 1999 war, youth activism was not particularly regulated. The Kosovar Youth Council (KYC) was founded in 1999 as an attempt to revive a culture of voluntarism (CoE 2011). The 1990s was a period when so-called institutional voluntarism did exist in Kosovo. Throughout that decade, a parallel government provided various services to the Albanian population through a large volunteer movement in the country. The extent and type of volunteering changed significantly after 1999. International organizations began providing many of the services that volunteers had been responsible for and a large number of local NGOs were established to help increase effective service delivery (UNDP 2006).

\subsection{Policies and institutions working on youth participation}

With the establishment of the Ministry of Culture, Youth and Sports (MCYS) in 2002 a central government institution was given the role of adopting policies to empower youth. The Youth Department, within MCYS, is the leading institution in the field, responsible for policy development and coordination of all institutions working on youth. The Youth Department works closely with five Youth Directorates in the largest municipalities and maintains links to municipal-level Directorates of Culture, Youth and Sport. Many of the municipal youth programs are implemented through youth NGOs. The Department is also responsible for the regulation of youth organizations, youth networks and Youth Centers in municipalities. Throughout the years, some donor agencies have agreed to fund activities of Youth Centers through the Ministry's Youth Department.

The Kosovo government addressed specific youth policies at the national level in 2003. The Department for Youth within the Ministry of Culture, Youth and Sports developed a series of policy papers delineating basic activity areas. These included issues such as youth employment and participation in decision-making, which were later incorporated into youth policies promoted by the Ministry. In 2003-2004, the Department of Youth, supported by the United Nations Children's Fund (UNICEF) and the German Development Cooperation Agency (GIZ), in cooperation with the International Council on National Youth Policy (ICNYP) and a team of local lawyers in Prishtina, started working in the first draft of the Law on Youth Empowerment and Participation. Based on the results from both these processes, the Ministry's Department of Youth proposed the development of a Kosovo Youth Strategy and Action Plan (KYSAP) in order to meet the needs of the young population. The new policy was finally adopted by the Ministry of Culture, Youth and Sports in May 2009. Its design and development involved various youth organizations such as the Kosovo Youth Network (KYN). A number of conferences were organized at the regional and local levels to ensure an active role for young people and their 
organizations in the process of drafting and implementation of the KYSAP. The drafting stage included a number of events, conferences and roundtables. In particular, there were continuous consultations with youth and youth organizations. During the drafting stage of the Kosovo Youth Strategy and Action Plan there were also consultations with the members of the Kosovo Assembly and the process was also presented to the Committee for Education, Science, Technology, Culture, Youth and Sports. Meetings were held with representatives of youth forums of political parties in Kosovo.

The lack of an institutional framework for youth participation was identified as a key factor in the first conference on KYPAP held on November 2005. According to participants, many of whom represented youth NGOs, there is insufficient cooperation between youth NGOs and the Government of Kosovo. They argued that Kosovo youth is excluded from the decision-making process and youth groups and organizations are not regularly invited to relevant discussions that affect their lives (UNICEF/IKS 2010).

The KYSAP policy aimed to ensure support for the youth sector at a local level by enabling collaboration between municipal authorities and youth organizations in drafting and implementing local youth policies and action plans. The strategy addresses six subject areas that affect the lives of the young population including youth participation, education, employment, health, human security and culture, sports and leisure time activities. It aims at improving the situation of young people from 15-24 years of age by involving all relevant governmental and nongovernmental institutions in exploring and meeting the needs of youth and by finding ways and mechanisms to increase youth participation in the decision making process in Kosovo. KYSAP encourages cooperation between youth organizations and the Government, between all the Ministries dealing with youth related activities and between central and municipal bodies to strengthen youth policies and programs. The Youth Statement in the KYPAP strategy addresses the impact of unemployment as follows:

Unemployment and its impact on young people are serious issues that affect the development and wellbeing of Kosovo youth. In a region where there is high youth unemployment, young people must be recognized as a resource for progressive economic development; therefore, the Government should create mechanisms to ensure that young people are involved in the economic development strategies, and that youth issues are considered as a priority (KYSAP 2009, 12).

To facilitate the work between line ministries, the Inter-Ministerial Council on Youth was established. The primary role of the Council is advising the KYSAP implementation body (Article 7.1 KYSAP). Line ministries, members of the Council 
(including the Ministry of Education, Science and Technology, the Ministry of Labor and Social Welfare, the Ministry of Health, and others) are obliged to meet periodically to give advice and supervise the KYPAP implementation phase. Upon successful establishment of all Youth Action Councils in the country, the InterMinisterial Council will be transformed into a co-management council where the Kosovo Youth Action Council representatives will sit together with ministries' representatives. In practice, the Inter-Ministerial Council did not convene with the main collaboration functioning directly between the national Youth Action Council and the Ministry.

Drafting of the Law on Youth Empowerment and Participation (Nr. 03/L-145) started in 2003; however, the process dragged on for many years. The Law on Empowerment and Participation of Youth was finally adopted in September 2009 and represented the strongest commitment by the government to youth inclusion to date. Kosovo is one of only a few countries with a Law on Strengthening Youth Participation. Addressing citizen of ages between 15 and 24, the law encourages the setting up of formal mechanisms to empower youth participation regular participation of youth, in particular by drafting and implementing sectional policies related to the interests of young people. The law was an important step in supporting youth participation in decision-making processes, outlining central and local government responsibilities towards youth and organizations representing their interests and promoting the importance of voluntary work. The law also outlined obligations for institutions in recognizing Youth Centers. The Kosovo Youth Strategy and the Kosovo Youth Action Plan adopted in November 2009 complemented the new Law. In addition, the Ministry of Culture, Youth and Sports adopted a series of Administrative Instructions (AI) in 2010 to facilitate the implementation of the new law. These include the Administrative Instruction On Responsibilities and Procedures of Establishing and Functioning of Youth Action Councils in Kosovo (9/2010), Administrative Instruction on Youth Voluntary Work (10/2010), Administrative Instruction on licensing of Youth Centers (11/2010) and Administrative Instruction On Non-formal Education for Youth.

At the local level, youth policy falls within the competences of the Directorate in charge of education, culture, youth and sports. Competences of the Municipal Directorate for Culture, Youth and Sports include organizing public debates on development of culture, youth and sports, and supporting local groups, clubs, associations or other forms of organizations. It is required to closely cooperate with other institutions within the municipality as well as link with other regions. The Directorate reports to the mayor and may also be asked to report to committees of the Municipal Assembly. Within the Directorate, the Sector for Youth normally employs only one official in charge of youth policy. The youth sector is responsible for counselling, information dissemination, developing local policies, strategies and 
actions plans for youth. In most municipalities, municipal officials working on youth policy have been engaged with the administration for many years. Thus officials have established relations with leaders of youth organizations, particularly organizations that have been active for many years. This relationship proves important in maintaining contact and developing collaboration. The leadership of many non-governmental organizations remains the same thus enabling a lasting relationship between municipal officials and certain civil society leaders.

Existing public surveys suggest those young citizens are not knowledgeable regarding the existing legal framework and policies on youth. Survey data from 2010 shows that the overwhelming majority of Kosovo citizen, of $64 \%$ are not aware of the Kosovo Youth Action Plan (UNDP 2010). At the local level, municipalities differ not only in setting up structures of cooperation between authorities and civil society organisations, but also in the efficacy of exercising their mission and conducting activities. Among those young citizens aware of the work of their Municipal Youth Offices, the municipalities of Gjilan, Prizren, Prishtina and Peja enjoy the highest number of young people satisfied or very satisfied with their work $(38 \%, 33 \%, 31.5 \%$ and $30 \%$ respectively) 70 (UNDP 2010).

The international community has contributed in developing the country's youth policy through its technical assistance and financial contributions for youth projects, organizations and the functioning of Youth Centers. There are several international organizations engaged in youth empowerment and working towards strengthening the role of youth in decision-making. Throughout the last 13 years, active organizations in the field of youth policy have included UNICEF, World Bank, The German Society for International Cooperation (Gesellschaft für Internationale Zusammenarbeit - GIZ), the Swedish International Development Cooperation Agency (SIDA) and OSCE. A two-year project from SIDA focused on capacity building and aimed at specializing municipal staff on youth issues. UNICEF was an important agency in assisting the drafting of the Law on Youth Empowerment, developing the strategy and action plans and drafting of the Ministry's Administrative instructions. In recent years, USAID has also addressed the policy field with specific projects such as Youth and Education (USAID Kosovo, n.d.). In 2010, the British Council also initiated its "Active Citizens" project to strengthen youth participation in the country. It focuses on six municipalities including Hani i Elezit, Kamenica, Gjilan, Podujeva, Gjakova and Viti (British Council, n.d.). During this period, the OSCE Mission in Kosovo assisted the establishment of thirteen Municipal Youth Assemblies as a mechanism to mobilize youth in activities of importance to them. The OSCE Mission in Kosovo is mandated with human rights protection and

\footnotetext{
70 The key areas in which young people want to see their Municipal Youth Office focusing on are: trainings for youth ( $80 \%)$ and employment and education for youth $(63 \%$ each).
} 
promotion, democratization and security and public safety sector development. The OSCE hosted its first conference on youth empowerment in 2011 to support the establishment of central- and local youth action councils in Kosovo. The main aim of the OSCE initiative is enabling democratic institutions and increasing youth participation in decision-making. The OSCE, with the largest presence at the local level amongst the international organizations working in Kosovo, was already extensively involved in strengthening capacities of local institutions. According to the OSCE, their engagement aims at "involving young people in the actual decisionmaking processes by giving them a say in the long-term planning and the creation of policies" (OSCE Senior Official, Interview June 2012).

Initially, GIZ commenced the establishment of local Youth Action Councils (YACs) in a number of municipalities as well as the establishment of the National Youth Action Council (NYAC). The national and local YACs invited the OSCE to provide their assistance after the initial phase of cooperation with the GIZ. The OSCE involvement was based on offering technical assistance, providing trainings and capacity building activities. In 2010 the OSCE got involved with establishing YACs in municipalities where they didn't exist and their collaboration at national level followed in 2011. The establishment of the YACs in 31 municipalities as consultative bodies was an accomplishment of the project (OSCE Democratization Official, Interview June 2012). The OSCE commitment in each municipality is facilitated by the organization's presence in the field and familiarity with municipal administrations and youth community. Most importantly, establishing cooperation with the municipal Directorate of Education, Culture and Youth set up a formal channel of communication between the parties.

\subsection{Youth Action Councils}

Youth Action Councils are registered as NGOs operating in their respective municipalities and they represent a network of active local youth organizations. They are interest groups representing youth interests in their municipalities. The Councils are advisory bodies on youth issues for all local institutions (AI 9/2010). According to the OSCE, these types of structures are more effective in presenting a unified stance before municipal authorities, given that the municipal mayor may call upon the YAC when there are requests for advice on the youth sector (OSCE official, Interview May 2012). For these relations to take place, municipal authorities must formally recognize the YAC as a partner to enable their cooperation. The official recognition by the municipality is valid for 2 years. According to the OSCE, recognition by mayors brings about some responsibilities towards YACs and enables the survival of these structures. Official recognition of the Youth Action Council established in the municipality obliges local authorities to invite the YAC to 
meetings of committees and debates relating to youth issues. The municipality's official Activity Plan is often drafted with the help of YAC members. According to OSCE officials, 'the OSCE has helped by getting state institutions to recognize these new structures' (OSCE official, Interview 2012). To increase citizen participation and invite youth organizations to join these structures, public awareness campaigns were held throughout the country.

In this initiative, particular attention was given to newly established municipalities where YAC members complained that municipal officials lack capacities and knowledge on youth rights and legislation. Kosovo authorities do not commonly recognize a process of knowledge transfer from non-state actors onto municipal authorities. Having members of successful Youth Action Councils provide municipal Youth Officials with training would present a novel approach in the country. According to the OSCE Head of Mission, "the fact that the Councils are now regularly meeting with the municipal representatives and that many municipalities were willing to finance at least some youth-related activities, are positive signs [...] local and central level institutions have started to address their concerns and respond to their initiatives and requests" (OSCE, 2012). There are 22 Youth Action Councils in the country. Some of these structures have not yet received their official certificates from the Ministry of Public Administration and thus do not figure as legal entities. All YACs are required to register as NGOs to apply for formal recognition by their respective municipalities. Municipalities such as Kamenica and Viti do not have certificates yet. The YAC of the new municipality of Graçanica/Graćanica has already been established and received its recognition from the municipality (Interview National YAC, April 2013).

One of the challenges in exercising activities in the youth sector is the lack of facilities preventing municipal authorities in exercising youth activities, inhibiting cooperation between youth organisations themselves as well as impeding young citizen from accessing institutions. Once the municipality fails to deliver the services it is legally obliged to provide, it depends on youth organizations themselves to find the necessary facilities. In some instances the local Youth Action Councils signed a Memorandum of Understanding (MoUs) with the municipal Education Directorate to utilize schools for activities. This encourages sharing facilities to cut costs and pushes municipalities to allow new actors to use existing municipal resources. Youth Action Councils in towns have more access to resources whereas villages have limited access to resources as well as municipal officials. Only nine municipalities in remote areas have youth clubs and these are used by the local YAC for their activities.

Data from interviews suggests that the lack of financial sustainability for YACs is a significant challenge for enhancing youth participation. The formal recognition by 
the municipal government, and the approval of the Youth Action Plans by the Municipal Assembly, do not necessarily secure financial resources for local YAC functions. Once financial assistance is secured from local government, this is restricted to funding the YACs counselling and advising activities. Local Youth Councils, as well as YACs in general, are not permitted to receive funding from municipalities to implement projects. ${ }^{71}$ During 2012, the Ministry of Finance, Ministry of Local Government Administration and Ministry of Culture, Youth and Sports initiated discussions for a separate code for YAC and Youth policies specifically. This would raise the importance of youth policy at the national level and grant higher budgets and allow for better budget planning in municipalities. Furthermore, it would enable YAC in municipalities to lobby more concretely for budget allocation for their activities. At the central level, the Ministry of Culture, Youth and Sports has offered to take over financial assistance for capacity building of Councils to ensure sustainability of the YAC structures. However, their concrete actions in this direction are to be verified after the OSCE decrease in their assistance (OSCE Interviews, June 2012). Furthermore, the World Bank with its Kosovo Youth Development Program has also been actively involved in capacity building of existing Youth Centers offering grants for establishing new resource Centers in the country (CoE, 2011). Whereas these large donor organizations channel their funds through the Ministry of Culture, Youth and Sports, at the local level budgeting support for youth activities and support for Youth Action Councils in municipalities is not regulated through a separate budget code. Allocating a budget for youth depends on the success of the Municipal Youth Officer advocating for a higher budget within the municipal Directorate for Youth.

Despite the challenges, positive outcomes from YAC activities have emerged. Throughout Kosovo, many local YAC adopted their Action Plans in 2012 and achieved approval from their respective Municipal Assemblies. Considering the big differences between the levels of capacities in YAC in different municipalities, especially urban and rural, 'stronger' YAC are encouraged to help weaker ones. According to the OSCE, YACs are encouraged to share documents, translations and strategies with each other (OSCE Senior Official, Interview June 2012). This instils horizontal cooperation and knowledge transfer amongst municipalities. An active approach by municipal officials to develop their own capacities and expertise on youth engagement is important for the municipality's success and a continuous improvement of local youth policies. The Gjilan case shows the importance of this

\footnotetext{
${ }^{71}$ According to OSCE interviewees local organizations belonging to YAC are mistakenly applying for project implementation assuming that "counseling' and "advising" are insignificant activities thus they want to implement larger projects as well. This is more a sign of their lack of understanding of procedures and of their own role (OSCE Interviews, June 2012).
} 
active approach, which resulted in exchanging information and experience with other municipalities. In 2012, the Gjilan Youth Official hosted a regional conference inviting eight municipalities to discuss youth policies and exchange ideas on mechanisms for engaging youth in decision-making. In cooperation with UNDP, the same official also organized conferences at the national level to enable collaboration between municipalities. Participants in these events included mayors, Directors of the Municipal Directorate for Culture, Youth and Sports, representatives of youth organizations etc. According to the Youth Official, colleagues from other municipalities are not creative and lack initiative, and stating "they have to come up with ideas on how to engage youth (Interview, April 2013). The Gjilan Youth Official also participated in and competed a certified program on youth engagement. Out of the 25 other participants included, there were representatives from the Ministry of Culture, USAID, SIDA, UNDP and NGO representatives working on youth (Gjilan Youth Official Interview, April 2013).

Other examples of successful activities include engaging youth volunteers in various YAC. One example is the YACs involvement in the countrywide initiative "Let's Do It Kosovo (Clean Up)". This helped in raising awareness and promoted the image of YAC throughout the country. "People now recognize YAC. Now they're recognized as a force, a movement" (OSCE Official, Interview June 2012). Other notable cases of cooperation include the municipality of Podujeva where the Youth Action Council was very active in 2011 when harsh winter conditions led to a state of emergency. The municipal mayor, together with YAC activists, cleaned the streets of the municipality. In comparison, the capital of Prishtina has shown the highest resistance in opening up its meetings and collaborating with YAC. The Policy and Finance Committee in Prishtina refused permission to NGOs to participate in its meetings, despite this being a legal requirement of all municipal authorities (INPO Interview June 2012).

At the central level, the national YAC cooperates with the Ministry of Culture, Youth and Sports. OSCE officials describe the Department of Youth, within the MCYS, as very cooperative, who have 'helped as much as they could' (OSCE Official, Interview June 2012). The Ministry contributed with financial resources to cover expenses for the offices of the National YAC. In 2012, the national Youth Action Council adopted a development strategy. However, the OSCE argues, the YAC still lacks experience considering its recent establishment. This weakens their role as partners for local authorities, which is necessary to influence government institutions. Similar to civil servants in the executive branch, new MPs in the Kosovo Assembly are not informed about youth issues nor about the work of Kosovo National Youth Action Council. According to the OSCE, the YAC must engage and direct its activities towards informing and influencing the work of these institutions. One of these activities concerns the age definition of young in the existing 
legislation. YAC in Kosovo are lobbying to change the law to increase the age and enable guardianship of existing capacities. As one OSCE interviewee states, 'capacity building is going to waste since older members of Councils can no longer contribute after they reach the age-limit" (OSCE Official, Interview June 2012).

Another type of local institution developed for engaging youth is that of youth centers. From 2000 until 2010, 31 municipal-level youth centers in Kosovo were established and financially supported by donors, which included GTZ, OSCE, UNDP and UNICEF. They have played an important role in the informal vocational education of youth by organizing courses in foreign languages, information technology, journalism, tailoring and other subjects, as well as seeking to increase employment opportunities. In a few municipalities, new buildings were built to house youth centers or existing buildings were modified to enable activities. In many cases the centers were established without cooperation with central institutions, often bypassing local authorities. They faced structural problems that challenged their work of reaching out to young people. Without their own budget, they relied on funds from MCYS and international organizations and depended on municipal support for free use of facilities and utilities. Very few of the municipalities offered them office space and funded certain expenses like electricity and water (UNICEF/IKS 2010). This led to many youth centers becoming dysfunctional due to the lack of facilities and funding for activities. Renewed efforts by youth organisations and municipal authorities were required to reactivate youth centers. The capital of Prishtina, as the biggest municipality and the highest concentration of civil society organizations, the absence of space for youth activities was a major constraint. As the municipal Youth Official declares, the lack of a designated space for the municipal youth center was a big challenge for many years (Prishtina Municipal Youth Official Interview, April 2013).

Youth centers offer facilities for programs and activities for young people. Youth centers also require an official license from the municipal Directorate for Culture, Youth and Sports, as stipulated by the Administrative Instruction No. 11/2010. In 2011 there were 25 youth centers operating throughout 36 Kosovo municipalities. Youth centers are usually hosted in building facilities allocated by the local government and are run by NGOs. The Centers focus on matching their programs to the interests of high-school students, who may also be willing to pay for additional educational skills such as computer and language skills (CoE, 2011). The youth centers also serve as a meeting point for youth organizations to coordinate their work. Youth centers enable municipalities to identify active youth organizations in the municipality more easily. To what extent this contact is further developed into partnerships and closer collaboration depends both on the initiative of the youth organizations and the interest of the municipal Youth Official. 
Consistent with the Law on Youth, local Youth Action Councils are responsible for exploring available facilities for youth centers as well as seeking financing from the municipality to fund their activities (Article 12.5). ${ }^{72}$ The AI outlines the municipality competence in licensing the youth centers and their obligation to finance the Center. The licensing process involves the municipality evaluating the capacities of applicant NGOs, providing support and issuing the license for the operation as a youth center with the purpose of providing and ensuring quality of youth services in the relevant municipalities. All NGOs working mainly on youth and registered with the Ministry of Public Administration have the right to request licensing as a youth center. Each municipality must license and fund at least one public youth Center. Based on the requests received, and the needs evaluated in the municipality, authorities can license other youth centers as well, but are not obliged to ensure their sustainability. Municipal obligations are further stipulated under Article 10 of the Administrative Instruction, stating as follows:

After the licensing, the Municipal Assembly takes an obligation based on article 7 of the Law on Youth Empowerment and Participation [....] to ensure space, human and financial resources for at least one youth public Center that enables continuous activity of the youth Center in the implementation of the above-mentioned paragraphs.

Under this legal framework, municipalities are obliged to provide financial resources for the youth center. However, the financial sustainability of youth centers remains a big challenge as the centers struggle to fund their activities from a combination of municipal budget allocations and donor grants. Few youth centers were functionalized after the adoption of the Administrative Instruction on Recognition of Youth Centers. The MCYS is a leading actor and has authority over municipal counterparts that may be used to convince municipalities to offer these services.

Over the last few years, international organizations have increased attention in establishing youth centers in municipalities that still lack them. The World Bank is leading this endeavour with its long-lasting project on youth development and financing of 14 youth centers throughout the country. This initiative, including running costs for operating a building, relieve the municipality of financial burdens on its budget and should therefore serve as a boost for municipal administration attention on youth policies and an increase in youth projects. Notwithstanding the adoption of initiatives and policies on youth participation, in practice they fail to reach the desired outcomes by reaching the Kosovo youth and increasing their

\footnotetext{
72 Article 1.4 of Administrative Instruction on Licensing of Youth Centers, defines Youth Centers as the functional space for the exercising of youth actions licensed by the Municipal Directorate responsible for the youth.
} 
participation rates. The legislation fails to effectively specify when participation is necessary and clearly delineate how participation could be achieved. These decisions are left to the subjective judgment of institutions and their employees (OSCE Official, Interview June 2012). In addition, lack of youth willingness to engage and actively participate defies existing attempts to change their relations towards state institutions. Surveys throughout the least years continue to show a significantly low number of young people actively participating in some form in their municipality. A 2011 study shows donor organizations specifically dedicated to youth declaring that Kosovo youth organizations lack capacities in writing successful project applications and thereby fail to gain financial support for their activities. For those already engaged in the process, there is a lack of opportunities to strengthen their role and participation whereas others argue the young population does not sees existing opportunities. A lack of interest amongst young people is a broader challenge throughout the country. A 2010 UNDP survey reveals that $80 \%$ of young Kosovans do not belong to a youth organization or a youth project or initiative with less than $20 \%$ with volunteer work experience. The main ways youth engage and participate include taking part in public discussions, being a beneficiary of NGO initiatives and being involved in implementing NGO projects (UNDP, 2010). A lack of recognition for their activities and engagement is discouraging to an already alienated youth (KAHCR 2011). Few YAC were attending public sessions of municipal assemblies, municipal security-council meetings etc. The YAC are not utilizing existing mechanisms of participation. Kosovo youth still feel that they have very limited influence on decision-making processes. Empowering youths' greater participation in decision-making processes remains a long- term development challenge facing Kosovo society. Those engaged and active in their communities are often set back by the lack of support from municipal authorities and perceived lack of understanding from politicians in their municipality (UNICEF/IKS 2010). Examples of this include municipal authorities' refusal to act upon signed petitions organized by young citizens or municipal officials' statements that decisions over their municipality are not the job for youth organizations (Focus Groups data in UNICEF/IKS 2010). These actions discourage young citizen from engaging in local organizations. However, these examples showcase only part of the picture as they focus on visible capital investments for particular youth interests. Less visible outcomes resulting from collaboration between youth organizations and state authorities may receive less attention. Prioritizing policies benefiting the interest of young citizen also constitutes a considerable achievement.

The absence of clear institutional obligations for the municipal government in the current legislation leaves policy implementation subject to their political will. This undermines the opportunity to shift towards new the decision-making norms. In 
addition, lack of information amongst the youth sector on existing mechanisms of participation remains a barrier to pass for a group of young citizens who are not completely aware of their rights. It remains challenging to change the decisionmaking norms in a traditional and patriarchal society, where the voice of young unemployed citizens is not valued.

Political pressures from municipal leadership directed towards youth leaders account for a major constraint in developing a balance of power and fostering democratic relations between state and non-state actors. Municipalities of Skenderaj and Deçan, led by the biggest political parties in the country are similar cases of political pressure. According to the National YAC, the Deçan Youth Official attempted to exercise political pressure on the YAC leader through attempts to convince the YAC to join the political party leading the municipality. These attempts to politicize the cooperation are a challenge for youth engagement and risk for deterring other youth activists and organizations from getting involved. Instead of promoting a culture of policy feedback from non-state actors to ensure continuous improvement of municipal services, officials may benefit from more 'silent' mechanisms of partnership. This secures a state of uncontested power of municipal authorities and the leadership amongst non-state institutions remains unchallenged. Interviewees from the National YAC confirm this when evaluating Prishtina as a non-active municipality maintaining the status quo by not engaging with other youth organizations and not pushing for changes within the leadership of YAC; 'it suits them to have followers' (Permanent Secretary of National YAC Interview, April 2013).

There are a series of best cases, in which local Youth Action Councils have established strong cooperation with municipalities and the latter have responded with support. These include the municipalities of Gjilan, Lipjan, Kaçanik, Podujeva, Hani i Elezit and Istog (OSCE Senior Official, Interview June 2012; Permanent Secretary of National YAC Interview, April 2013). The Gjilan region of 11 municipalities was quick to establish youth Action Councils. The OSCE highlights Gjilan as the most successful case in working with youth. The Gjilan municipal Youth Official is recognized as 'one of the best in Kosovo' (OSCE Democratization Official, Interview June 2012). The municipality of Gjilan is the first one in Kosovo to adopt a regulation on voluntarism. During annual regional conferences held in the country, which gather civil servants in municipalities who deal with youth, the Gjilan Youth Official trained colleagues from other municipalities. This established a broad cooperation between municipal civil servants. On the other side, Ferizaj, Prishtina, Deçan and Dragash are considered unsuccessful cases in establishing strong collaboration between municipal authorities and Youth Action Councils (Interviews with National YAC, April 2013). 
According to representatives of the National Youth Action Council, the initiative of youth organizations is detrimental to their success in promoting youth participation in decision-making. Government officials and the political leadership may be supportive of developing and implementing youth policies, however, in the absence of an active youth organization network, these policies will fail to reach the desired target group.

Leadership of Youth Action Councils in various municipalities has been challenged by municipal administrations. The latter refuses to formally recognize the local YACs, accusing them of being politically biased. According to the OSCE, similar allegations exist of the local YAC leadership supporting opposition parties rather than parties leading the municipality (OSCE official, Interview May 2012). Peja municipality struggled to establish cooperation due to allegations of political bias of YAC leader. Furthermore, disparities in capacities and expertise on the policy issues have also contributed to a sense of rivalry between local authorities and civil society organizations, each arguing about the others' deficiencies. According to the National YAC, local YACs have higher capacities in than Youth Officials working in municipalities. The latter are not aware of the new law and the four accompanying administrative instructions regulating the work of Youth Centers, Youth Action Councils and work with volunteers. Considering the workload, Youth Officials rarely work solely on youth policies. However, these relations sometimes lead to challenges in recognizing the other's power to influence the decision-making process. According to the National Youth Action Council, local YACs with more capacities and information 'believe they are more powerful than the official and do not necessarily need the municipal administrations approval and support for their activities' (NYAC Interview, April 2013).

According to the leader of the National Youth Action Council at the central level, an active approach of lobbying is utilised to promote youth interests and 'as a result of this lobbying, the Ministry of Culture, Youth and Sports included the National YAC in its budget lines. The National YAC is thus in the Ministry's budget for the next 5 years' (Interview, April 2013). The National YAC as the highest structure representing youth interests in the country receives recognition from the Ministry of Culture. The Ministry's formal recognition of the National YAC was completed on 12 th August 2012. According to the Head of the National Youth Action Council, the date for recognition, the International Day of Youth, was coordinated with the MCYS in order to raise awareness for youth participation. The formal recognition is valid for 2 years and the YAC structures do not need to apply for another process of recognition. According to the YAC, Council representatives are invited to all meetings of the Ministry, including the drafting of the Ministry Strategy development for 2013 - 2015 (Interview, April 2013). 
In recognition of the leadership shown in his municipality, the Gjilan YAC leader was elected to head the National Youth Action Council in 2011. To promote youth engagement at the central level, the Head of the National YAC declared that continuous lobbying has resulted in signing Memorandums of Understanding with a series of Ministries in the central government. In the last two years the National YAC met with 15 Ministers and established Memoranda of Understanding with the Ministry of European Integration and the Ministry of Diaspora. The National YAC is invited to ministerial meetings when youth is discussed and does participate in developing policies relevant for youth (National YAC Interview, April 2013). These actions resulted in several positive outcomes for the work of the National YAC, most importantly of which was a stronger partnership between the YAC and the central government. The cooperation with the Ministry of Foreign Affairs resulted in funding, enabling the National YAC to join the European Youth Council. In addition, the National YAC cooperates with the Ministry of Environment to secure provision of access to buildings for people with wheelchairs. This active approach is also visible with regards to broadening international cooperation of the National YAC. According to the National YAC, cooperation with other countries such as Lithuania, Norway and Turkey were realized to further expand the recognition of Kosovo institutions amongst international partners (National YAC Interview, April 2013).

Within the National YAC, there are clear attempts to build the organization based on an inclusive approach by selecting the leadership to represent different groups within the youth sector. The leadership structures include one Deputy President from the ranks from the public University of Prishtina to represent student interests; one Deputy President for Diaspora, a Deputy President for Communities and one Deputy for overseeing the work of local Youth Action Councils in municipalities. In addition, one member of the Board represents the interests of organizations for people with disabilities.

To increase the outreach to a larger number of young citizens, the National YAC is lobbying to change the age group defined as young. The limited age group targeted by the Law on Youth Participation addresses youth as aged 15 to 24. The amendment proposal is to include citizens up to the age of 30 . This would enable a longer usage of the knowledge accumulated on young citizens. Furthermore, the National YAC is working in amending the legal framework on youth, which is ambiguous on municipal obligations for supporting YACs. Efforts are underway to explicitly state municipal obligations to financially support the local YAC (National YAC Interview, April 2013). 


\subsection{The Gilan model}

The municipality of Gjilan has been actively involved in engaging the youth sector since 2003, when the municipality utilized employment application forms to match young citizen with employment opportunities. In 2004, a decision from the Gjilan mayor launched the Active Volunteers Form for young individuals giving ID cards of volunteers to 25 young citizens allowing them to participate in municipal administration meetings and to communicate with municipal administration to get an experience on how the administration works. The volunteer work was rewarded with various vouchers for entertainment activities as an incentive to encourage broader participation. Since 2010, this process is regulated through the Administrative Instruction on Voluntary Work. The Municipal Assembly approved the regulation in 2012 making Gjilan the only municipality with such a program. The Gjilan Youth Action Council has 27 youth organizations and represents the largest youth organizations under its umbrella. The local YAC has a General Assembly with representatives of these 27 active organizations. The Council structures include a President, 2 Deputies, and 15 members of the Board. The structure of the YAC depends on how the YAC President organizes the Council.

In the Gjilan municipality case, close relations with the municipal mayor prove to be one of the most important factors in the success of the YAC. In other municipalities, Youth Action Councils mainly communicate with municipal Youth Officials, Heads of Directorate or Municipal Assembly members. In the case of Prishtina, the local YAC communicates occasionally with the deputy mayor. By contrast, in Gjilan, a strong cooperation exists between the local YAC leader and the mayor. According to the Gjilan YAC leader, the municipal mayor was an example of cooperation, supporting all activities organized by the YAC and responding to YAC requests (Interview, April 2013). Whereas the Gjilan Youth Official reports to meeting youth organizations on a monthly basis, the head of the YAC and the mayor have more frequent informal meetings. The YAC leader states,

I received the Mayor's approval for every activity organized, more than the

Director's [approval]. I met the Mayor every weekend. In addition to the municipal Youth Official and the Culture, Youth and Sports Director, the Mayor was almost always present at our activities (Interview, April 2013).

Other counterparts in the municipal administration are the Youth Division/Sector, the municipal Directorate for Culture, Youth and Sports, the Municipal Assembly Committee on Youth and Culture. This mutual understanding is evident as the leader of the Gjilan YAC declares 'During my mandate, the municipality gave as much as they had' (Interview, April 2013). A bleaker picture is presented by the municipal Youth Official who states that 'the municipal leadership did not have 
political interest in supporting youth. Extensive lobbying was necessary to gain their support' (Interview, April 2013).

According to local YAC interviewees, representatives of the YAC are invited to participate are invited to participate during municipal assembly meetings. Openness towards inclusion of youth organizations also exists in the municipal administration which formally invites the YAC for municipal meeting dealing with youth. In other municipalities, such as Prishtina, this is not the case, thus formal mechanisms established to secure youth participation are not equally enforced in different municipalities. Implementing the formalities as requested by the current legislation, allows for the municipality to embed the new decision-making process into the daily working process of the administration. In municipalities that do not exercise a formal recognition of partnership with the YAC, this partnership is subject to the will of municipal officials, which may change and thus does not constitute an institutionalised form of cooperation.

The close cooperation between the YAC and the political leadership resulted in further success stories with the re-functionalization of the municipal youth center in Gjilan. According to the YAC leader, the Council formally requested the mayor to reinstate the youth center which functioned briefly in 2006. Due to lack of funds and the absence of a facility to operate in the youth center did not continue its services for many years. However, with the leadership of the YAC, the lack of a designated facility for the municipal youth center did not deter youth organizations from meeting and organizing activities. The Youth Action Council offered its offices for the services of the youth center to avoid losing funding from the World Bank, which was specifically earmarked for youth centers. According to the YAC leader, the support of the municipal mayor was important for the successful completion of these activities (Interview, April 2013). The resulting outcome in gathering funds from donors and approval by the municipal mayor come as a result of the pressure from non-state actors rather than the municipal administration improving their services due to internal objectives of improving efficiency and fulfilling their legal obligations.

Another important factor influencing the success of YAC in Gjilan is the active approach of both the YAC leadership and the municipal official. In this case, both state and non-state actors actively engaged to connect with other stakeholders and to further develop a partnership between them. Through cooperation with various donor organizations, the YAC leader used the relationship with the municipal mayor to gain funds for youth organizations and ensure these funds benefit the youth. In addition, the municipal Youth Official has reached out to youth organizations to ensure continuous support for civil society, improving trust in 
formal institutions and consequently helping secure the sustainability of youth participation mechanisms in the municipality.

According to the YAC in Gjilan, the initiative and cooperation of local youth organizations in Gjilan has helped develop capacities of youth organizations through successful implementation of various local projects and increased participation in the municipality decision-making process (Interview, April 2013). The YAC in Gjilan has also strengthened its role amongst its members through an inclusive approach including a variety of youth organizations in the network. These include the association representing blind people, persons with disabilities, the association of deaf persons and minority communities of Roma, Turkish and Serbian ethnicity. In cooperation with OSCE, the YAC conducted a survey in Gjilan municipality to gauge the awareness of YAC activities amongst young citizen. Amongst youth in Gjilan, $40 \%$ of respondents are aware of the existence of the YAC and have heard about youth activities suggesting a fair presence of YAC and its activities amongst young citizen. To the credit of the municipal administration, it must be noted that even before the adoption of the new legislation, Gjilan fairs best in opinion pols in informing citizen about its youth activities. In 2010 the municipal youth office was ranked highest in a poll documenting citizen awareness of municipal youth activities (UNDP 2010). This active approach by local officials benefits the municipality in further advancing youth policy. Efforts to develop new mechanisms for youth engagement are also underway in Gjilan. The municipal Youth Official also engaged in developing a program on youth in the community, which addresses issues such as communication, conflict mitigation, cooperation etc. The aim is to establish a formal licensing mechanism for youth workers and to promote this as an occupation or a job in the community. Reaffirming their role in the governance structure, municipal government representatives state that 'the municipality is the connecting bridge between youth organizations and donors, the central government Ministries' (Gjilan Youth Official, Interview April 2013). The municipality also lobbies for funds for youth NGOs in Gjilan from international donor organizations.

At the time of this research, the municipal administration did not have funds to implement the municipal Action Plan 2013 - 2015. According to municipal officials, the lack of a specific budget code for youth within the municipal budget program demands extensive lobbying within the Directorate to secure funding for youth activities. A separate budget code specifically designed for youth would secure long-term funding and thus allow for better planning and implementation of policies. Whereas in other municipalities, government institutions may be reluctant to accept obligations towards the local Youth Action Councils, in the case of Gjilan, obligations towards the local YAC are a direct consequence of the formal process of recognition. As this process is delineated in the Administrative Instruction on 
Recognition of Youth Action Councils, there is no uncertainty in the legal framework. Within the municipal administration itself the legal obligations are recognizes through the statement that 'with the formal recognition from the mayor the municipality is obliged to fund the local YAC' (Gjilan Youth Official interview, April 2013).

\subsection{The case of Prishtina and Ferizaj}

The municipalities of Prishtina and Ferizaj are cases in which a strong partnership between local government and non-state youth institutions has not been successful. Several interviewees highlight Prishtina municipality for its centralized decisionmaking and lack of information sharing with citizen and NGOs (EURED Interview, 2011; INPO Interview 2012; INPO 2013). Civil society organizations monitoring the work of the municipality have reported on the failure of municipal authorities to inform citizens about Municipal Assembly meetings. ${ }^{73}$

In 2013, the municipal budget for subsidies and transfers of the Directorate of Culture, Youth and Sports was 250.000 Euro (GAP, 2013). Due to the lack of a separate budget code for the Directorate within the municipal administration, the funds are distributed as subsidies for youth organizations. According to both the municipal administration as well as representatives of the Youth Action Council, insufficient financial resources have challenged their work (Prishtina Youth Official Interview April 2013).

The Prishtina Youth Action Council was established in November 2008 supported by Prishtina municipality officials, the Ministry of Culture, Youth and Sports, the Director of the municipal Youth Directorate and the GIZ Program Representatives. The Prishtina YAC includes 17 organizations and informal groups represented in YAC involved in the youth sector. ${ }^{74}$ It also organizes youth groups in 20 villages of Prishtina municipality. The YAC has a President, Board and YAC Members Assembly. In addition to the YAC, there is also a Youth Center in Prishtina. Until 2013 , this functioned on private property rather than a municipal assigned property but the municipal authorities covered the expenses. The Administrative Instruction

\footnotetext{
${ }^{73}$ Article 38 of the municipal Statute requires the municipality to inform citizen through public announcements in venues highly frequented by citizen and through use of media. However, the only announcement for a municipal assembly meeting was published on the web-site one day before the event. During 2012, no citizen attended Municipal Assembly meetings of Prishtina municipality (INPO 2013).

${ }^{74}$ In the municipality of Prishtina $17 \%$ of citizens are aged between 15 and 24 (KSA, 2013). The municipality of Prizren has a similar demographic structure with $19 \%$ of its young population belonging to the age group 15 - 24. Own calculations based on Kosovo Statistics Agency results of 2011 Census.
} 
on Youth Centers provides the framework for bigger municipalities to designate more than one facility as youth sub-centers if required to serve a larger territory.

In 2011 the Prishtina YAC registered as an NGO according to the new legal requirements. The Administrative Instruction on Recognition of YAC obliges the latter to register as NGOs. Despite the YAC registering as an NGO in 2011 municipal authorities did not provide formal recognition for the local YAC until late 2013. Prior to the registration as an NGO, the local Council received funding from municipal authorities on the accounts of one of its member organizations. Since 2011 the municipality has funded them directly using the YAC account as an NGO. Institutional support from the municipality was in the form of financial support for YAC projects and exchange of ideas. According to the YAC, their activities entail mostly discussions, roundtables, debates with youth and information dissemination. The YAC also conducted an opinion poll research to gather information on youth needs in communities in Prishtina. The research was undertaken by YAC Prishtina and the results are used by the Prishtina administration.

According to the leader of the Youth Action Council, since its inception in 2008, the YAC and Prishtina municipality have had excellent relations (Interview, March 2013). In 2013, the municipal Directorate for Culture, Youth and Sports supported the reorganization and re-election process in the YAC leadership. The previous leadership was re-elected and continues to head the Prishtina YAC. However, the fact that there has been no change in leadership of the youth organisations poses the risk that the youth sector is being monopolized by certain non-governmental organizations. The lack of change in leadership harms the process of establishing broad cooperation between state and non-state actors and risks power capture by civil society actors which have the resources and have already established links with municipal authorities. The requirement within the Youth Action Structures obliging youth organisations to hold periodic elections would bypass such power capture. This deficiency is criticized by the National Youth Action Council, which maintains that change is needed within each YAC in the country. According to the Permanent Secretary of the National YAC, 'a rotation of responsibilities should be enabled within each YAC; more youth organizations must get the chance to learn from the process and lead others' (Interview, April 2013).

Nevertheless, according to interviews from both sides, mutual trust and cooperation can be observed from Prishtina officials and the Local Youth Action Council. According to the Prishtina Youth Official, the municipal administration has benefited from the local Youth Action Council, which has "contributed in drafting municipal youth policies as well as reviewing youth projects" (Prishtina Youth Official, Interview April 2013). Regular consultations between municipal officials and the YAC have thus become the norm in the work of Prishtina administration 
and these new structures are consulted on issues pertaining to youth. Amongst achievements in youth policy, municipal officials cite the promotion of voluntarism, integration of marginalized groups and capacity building activities for youth organizations (Prishtina Youth Official Interview April 2013). However, these close relations do not amount to numerous projects or youth activities. In addition, the municipal government did not formally recognize the local Youth Action Council. In December 2012, the Municipal Assembly of Prishtina adopted the Local Youth Action Plan for the years 2013 - 2015. The foreseen budget for youth policies is a total of $€ 253.000$ until 2015. The municipal Directorate for Culture, Youth and Sports plans its medium-term activities and support for youth NGOs based on this budget recognizing its limitations.

In contrast to Gjilan municipality, where the YAC was more active in setting up activities and lobbied for municipal administration approval and support, "the lack of capacities and absence of initiatives from youth organizations made the [Ferizaj] YAC a weaker partner" (Ferizaj Youth Action Council Interview, April 2013). In this case, municipal institutions utilize the YAC for their own plans and activities. In the municipality of Ferizaj, the YAC consists of 20 members consisting mainly of individual young activists as opposed to youth organizations. The local YAC was established in 2008 at the initiative of Ministry of Culture, Youth and Sports during a one-year project to initiate the establishment of YACs throughout Kosovo. In the absence of instructions on how to register the youth councils, the Ferizaj YAC initially functioned as an informal group serving as an umbrella network for a group of activists. It registered as an NGO in 2011 and received formal recognition by the municipal authorities in 2012 .

In June 2008, the municipality of Ferizaj supported YAC with offices and logistics. Municipal authorities also offered the facilities to establish a Youth Center, which together with the YAC network is used by the municipality to organize youth activities. The Youth Center in Ferizaj was under the management of the municipality. This centralized approach to limiting the resources available for the youth sector prevents openness of governing institutions and fails to empower youth organisations. Whilst activities were organized by the YAC, the management remained with the municipality. Small-scale projects in the amounts of $1000-2000$ euros were available to hold activities in the youth center. The YAC developed its Action Plan whilst the municipality adopted the Youth Action Plan for 2010 - 2013. Frequent meetings between the actors were possible due to the YAC working in office facilities within the municipal administration. The former YAC leader accounts that 'daily meetings were possible since the office was in front of the municipal Youth Official at the municipal administration' (Interview, April 2013). Despite these frequent meetings, the former YAC leader declares that municipality staff was insufficient to realize its mandate on youth policy and the local YAC lacks 
capacities in project management (Former Head of Ferizaj YAC Interview, April 2013).

Similar to Prishtina municipality, limitations of the current mechanism promoted in municipalities include the failure to facilitate a change in leadership of YAC where key actors within YAC usually win projects. A rotating system of leadership within existing YAC is necessary, as it would allow change and development (Former Head of Ferizaj YAC Interview, April 2013). The Central YAC maintains that the municipal administration in Ferizaj is cooperative however the lack of unity of youth organizations has hindered their cooperation (National YAC Interviews, April 2013). According to representatives of the National YAC, the legal framework provides young people with plenty of opportunities to access decision-making. These past years have been important in advancing youth policy and pushing forward youth participation (National YAC Interviews, April 2013). It is up to youth organizations themselves to understand their role in the community and impact decision-making in their society. With the current legal framework, voluntary work is also recognized as work experience. Thus activities to increase volunteer work in communities must be utilized to attract more youth participation.

\subsection{Conclusion}

Kosovo's large young population faces the overwhelming issue of unemployment. Reforms in the youth sector must be integrated within national strategies addressing this larger policy issue. The case studies explored in this chapter highlight the challenges in achieving progress in youth participation in an environment of limited capacities of local authorities and a broad detachment from local decision-making processes. The case studies reveal instances of success in which several factors align to achieve progress in youth empowerment at the local level.

Despite a fluctuating approach towards youth policy throughout the last decade, this chapter illustrates the existence of opportunity structures for local agents working in the youth sector. Obligations set in the new national legislation and adopted regulations at the local level present a first step towards increasing participatory initiatives and ultimately influencing the power distribution among actors. The legal framework promotes a process of collaboration requiring decisionmaking processes to open up towards non-state actors. These developments contribute to a new cooperative approach towards state institutions and enable an inclusive system in which the agency of non-state actors is formally recognised and supported.

What makes youth engagement in local decision-making processes a particularly interesting field is that its advancement depends on a series of factors coming into 
play. The country's demographics, with half of the population under the age of 25 , made youth a pertinent topic amongst a variety of actors. In recent years, the Ministry of Culture, Youth and Sports (itself headed by a young politician), placed youth policy as an important issue at the top of the agenda giving it higher attention than previous governments. Drafting and adoption of new legislation specifically on youth as well as a national strategy addressing youth issues such as education, employment and participation, advanced youth onto the political agenda. International agencies, whose programs on youth were sporadic and addressed a variety of sectors, made their resources available and responded to the need to establish and build new structures at the local level solely for advancing youth interests in the local agenda. Amongst local governments, some municipalities displayed leadership and support in implementing mechanisms for partnership with civil society organisations working on youth. Due to the interplay of these factors, youth policy achieved momentum in favour of advancing youth participation and establishing mechanisms for young citizens to address their municipalities; making this case study a particularly interesting paradigm.

Nevertheless, as the case studies in this chapter suggest, weak enforcement and implementation are amongst a series of constraints in achieving successful youth engagement throughout all municipalities. In addition to lack of financial resources, cited as a hindrance to implementing youth projects, the lack of proper oversight is also a challenge. The central Inter-Ministerial Committees are not effective, thus failed policy implementation at municipal level is not monitored. This lack of oversight deepens the weakness of the local administration. Lack of capacities extends an absence of oversight from Municipal Assemblies as well. Without proper expertise on environmental policy, social service provision and youth engagement, members of the Municipal Assembly fail to hold the local executive accountable.

In addition, the risk of politicization is evident in the case of youth engagement. Political cleavages and a politicized environment hamper the development of a culture of collaboration across institutions and social groups. In addition to breaking rules of impartiality within municipal administration, these processes put pressure upon citizens to align themselves with political parties in order to achieve change in their communities. The politicization of the partnership between non-state actors and municipal authorities obstructs the development of a sustainable cooperation based on institutional lines.

The willingness of local authorities to accept new mechanisms of coordination and collaboration with non-state actors varies between municipalities. Some municipalities are inclined to accept enhanced participation by civil society organizations when recognizing their expertise and resources in a policy area. Bestcase models presented above suggest willingness by certain municipal officials to 
collaborate with civil society actors and promote shared decision-making. As youth interests are channelled through formal structures such as the Youth Action Council, municipal officials can easily identify partners for implementing municipal youth projects. Formal recognition by municipal authorities also enables youth organisations to utilise the formal process of collaboration and approach municipal officials to address issues of concern.

To secure attention from municipal authorities, and increase their impact on local decision-making processes, effective collaboration with local authorities is contingent upon an active approach of civil society organizations. Persistence of organizations, such as the Youth Council in Gjilan to engage in communication and build relations with municipal authorities was necessary for successful cooperation. The case of Gjilan also suggests that close relations between civil society organisations and the municipal mayor are more likely to secure a strong partnership

Interviewees present a conviction that 'the other' partner lacks capacities and resources to advance youth engagement in decision-making. This perception is held on both sides, with municipal officials arguing that civil society organisations are incapable of successfully managing and implementing projects whilst youth organisations stress that local authorities lack expertise in drafting adequate regulations concerning youth. In some municipalities, the perception amongst the youth organisations is that their organisations are more equipped to analyse and develop programs to engage youth than their municipal counterparts who, by their very nature, must deal with a broader variety of issues and are consequently not able to concentrate solely on youth.

The presence of international agencies also serves as an incentive for municipal authorities to accept opening up discussions and sharing the spotlight with civil society organisations. However, these incentives are unsustainable as donor agencies relinquish the responsibility to local authorities to fund local structures as obliged by the new legislation or seek other financial resources. 


\section{Developing local partnerships in environment and welfare services}




\subsection{Introduction}

This chapter explores the cooperation between state and non-state actors in the field of environment and welfare services. It investigates how the channels of cooperation were established and evaluates to what extent these have enabled a changing dynamic of power at the local level. The chapter reviews the extent to which there has been a change in the approach of local institutions towards nonstate actors and vice-versa. The case studies presented here highlight the importance of active civil society organizations to instil change at the local level. Civil society organisations, when mobilized, can present a strong interest group lobbying for change at the local level. Persistence of civil society organizations to build channels of cooperation with local authorities showcases their leadership and drive to improve local conditions. However, successful implementation of projects initiated by civil society organisations depends on a number of factors amongst which is the openness and cooperation of local authorities and the capacity to influence policies. The impact of civil society organisations is challenged, as their capacities are limited, due to insufficient funds and lack of qualified experts.

During Kosovo's decentralization process, social services were the latest competences to be decentralized to lower tiers of government. An intricate system of devolution and decentralization of authority, with some decisions still taken at the central government, has made governance of welfare schemes extremely complex and difficult for local institutions. New modes of cooperation between local authorities and non-government organisations show a shift towards state institutions accepting a more open approach towards non-state actors in 'helping' to deliver services to persons with disabilities. This marks a considerable achievement towards broadening the scope of actors responsible and active in local governance. In this policy sector there are a series of factors in place, which enabled the emergence of a partnership in service delivery between municipal authorities and non-state actors. These include the importance of an active civil society organisation with expertise on the needs of Persons with Disabilities taking

initiative and approaching local authorities for cooperation and the support of donor organisations.

In the environment sector, extensive efforts have been undertaken to adopt new legislation influencing the lines of authority and accountability between central and local government. However, weak implementation of the legal framework at the local level has stalled progress in the sector. Throughout municipalities, new initiatives driven by international agencies promote formal channels of inclusion of civil society organisations in the local decision-making processes. To explore to what extent these initiatives have an impact in fostering a partnership between 
local authorities and non-state actors, four municipalities are explored with varying results.

Throughout the two policy sectors, external assistance proves an extremely important factor in getting the commitment of local stakeholders and ensuring their participation in the process. For the implementation of new deliberative participation mechanisms in environmental governance, the technical and financial assistance of the Kosovo based organisation Regional Environmental Center (REC) was vital whereas the partnership with Save the Children proved important in securing collaboration between HandiKOS and local authorities in offering services for the disabled.

In the first part, this chapter focuses on environmental governance delineating the process of drafting municipal plans for environmental protection. The Local Environmental Action Plan is a new mechanism established to prioritize local policies and projects in environment. The second part of the chapter focuses on welfare services and presents an analysis of collaboration between local authorities and a non-governmental organisation in service provision. In this sector, several municipalities have established cooperation with the organisation HandiKOS to provide free services for Persons with Disabilities.

\subsection{Case Study on Environmental Governance}

According to UN-Habitat, Kosovo faces serious social and economic impacts 'from poorly managed polluting activities and could make huge gains from remedial actions to protect and restore the quality of the environment' (UN Habitat, 2012, 15). Within broader environmental problems in the country, smaller scale issues within municipalities do not receive much attention. Kosovo has made several important strides in drafting and issuing laws and administrative instructions on general environmental protection, nature protection, energy, mining, agriculture, and forestry; drafting environmental standards on air emissions and liquid effluent, as well as drinking water quality; and enhancing its environmental institutional capacity, such as setting up the Ministry of Environment and Spatial Planning (MESP) as well as the Kosovo Environmental Protection Agency (KEPA). ${ }^{75}$ Despite these achievements, the 2008 Functional Review of Kosovo institutions, showed the huge volume of work required to bring Kosovo in line

\footnotetext{
${ }^{75} \mathrm{KEPA}$ is an agency established under the authority of the Ministry of Environment and Spatial Planning. It is responsible for professional, supportive, scientific, and research tasks including environmental monitoring, environmental information management, and research. KEPA also runs KHMI as well as the Institute for Nature and Environmental Protection of Kosovo, and has three environmental directorates: for monitoring, for information systems, and for programs and reports (World Bank 2012).
} 
with the EU directives, especially issuing administrative instructions. According to the European Commission, enforcing environmental legislation also remains a steep challenge (European Commission 2011).

The main responsibility for environmental protection and management lies with the Ministry of Environment and Spatial Planning (MESP) responsible for setting the country's environmental policy. MESP was established in 2002 and consists of an Environment Department for nature protection, waste management, air protection, and industrial issues and a Water Department. The environmental inspectorate is under the MESP responsibilities as well. According to the European Commission Progress Report, the MESP has few resources, however, and its already low budget has been further decreased in 2011, presenting heavy challenges to its role in environmental management and policy setting (EC 2011). Professional weakness in the inspectorate, lack of implementation and enforcement of rules for environment protection further weaken its role leading to accusations from Kosovo think-tanks that licensing had produced more harm to the environment instead of serving as a protecting shield (Forum 2015 2012).

\subsection{The legal framework}

During the past decade, Kosovo adopted a broad range of legislative measures regulating environmental protection. The legislation delineates state obligations towards resource management and involves central government and local authorities to exercise their role in planning, conservation and protection of resources. This includes the Law on Environmental Protection (No. 03/L-025), which promotes a healthy environment for Kosovo's population gradually aligning it to EU standards for environment. The Law tasks the Ministry for Environment and Spatial Planning with main responsibilities for drafting environmental protection strategies, whilst municipalities are responsible for applying the basic principles of environmental protection. The Law on Environmental Protection also promotes public access to information and citizen's right to participate in decision-making processes. In order to stimulate public participation on activities related to environmental protection, the Law stipulates provisions for public access to information, and participation of public in decisionmaking processes in strategic impact assessments, Environment Impact Assessments, processes for water license and integrated license issuance, and issuing legislation. The Law on Environmental Impact Assessment (No. 03/L-024) regulates procedures for identification, assessment, reporting, and administration of the environmental impacts of a proposed project, to provide all relevant information on the environment for decision making by MESP for issuing its environmental consent. Other pieces of the legal framework include the Law on 
Waste Management (No. 02/L-30), Law on Water (No. 2004/24), Law on Air Protection (No. 2004/30), Nature Conservation (No. 02/L-18) and Law on Agricultural Land (No. 02/L-26). The legal framework aims to improve resource management, setting standards for use and administration of the various sectors assigning responsibilities to central government institutions and local authorities.

In addition to the legislation, the government adopted a Kosovo Environmental Strategy (KES) and a National Environmental Action Plan (NEAP) 2006-10 aiming to improve the quality of the environment in Kosovo by setting up priority activities for the environment sector. Both policies were updated and approved in 2011. The Kosovo Environmental Strategy 2011-21 identifies priorities and sets goals for environmental sustainability in Kosovo. The government also adopted a national Strategy on Waste Management 2011 - 2020 prepared and issued by the Ministry of Environment and Spatial Planning in 2011 and including the first waste management strategy in Kosovo (World Bank 2012).

Despite these actions, according to the European Commission, the adopted legislative framework still remains far from European standards in the area of environment and climate change. Implementation and enforcement of existing legislation is poor as environment and climate change continue to be a low priority in the policy agenda (European Commission 2011). Kosovo's functional budget classification does not show environmental protection as a separate category, unlike the EU. Despite the rise of government spending at both central and municipal level on environment during 2007-10, the budget devoted to the sector is insufficient to meet Kosovo's huge environmental challenges, in particular the considerable investments needs in infrastructure (European Commission 2011). Furthermore, World Bank studies over the years report on weak accountability stipulating that, in addition to insufficient financial resources at municipal level, weak planning and execution of environmental projects are inhibiting progress (World Bank 2012).

The central government has made efforts to assign several environmental protection responsibilities to local administrations. Municipalities are responsible for environmental protection, monitoring, and management of natural resources within their boundaries (SIDA 2009). Each municipality has an environmental unit, typically within the Directorate of Urban Planning, usually consisting of only one or two officials. For example, the Directorate of Urban Planning, Construction, and Environmental protection has responsibilities for pollution reduction, protection of natural resources within municipal boundaries, monitoring, issuance of construction permits and ensuring compliance, as well as the administrative functions on ensuring proper land use. The range of municipal obligations now include fully applying the principles of environmental protection, as well as to 
ensure cooperation with MESP for preparation of plans for protection of the environment and sustainable development within their territory; enforce laws and inspect enforcement of the laws related to the protection of environment and sustainable development within their territory; prepare and provide information related to the protection of the environment and sustainable development for citizens; and plan for the protection of the environment and sustainable development within municipality territory. Municipal institutions are responsible for issuing municipal authorizations and municipal environmental permits. Permits target industrial development, infrastructure projects, urban construction, mining, and agriculture and forestry. Considering the already limited municipal resources, the transfer of responsibilities to local authorities added to the burden of local officials.

According to the Regional Environmental Center, there is political will at central government level, to place rules and standards on environment protection. The challenge, nevertheless, remains at the local level in getting municipalities to draft and enact local spatial plans and ensure environment protection (REC, 2011). To assist local governments in enacting their responsibilities, a variety of international agencies are engaged in improving municipal environmental governance. Local officials report a series of successful projects implemented in cooperation with international organisations. These include annual evaluations on environment impact (accomplished with the assistance of World Health Organisation); initiating standards for performance measurement (USAID); developing urban and municipal development plans (MIGROS); increasing green space within municipality (UN-Habitat); developing the sewage management plan etc. (Mitrovica Environment Official, Interview June 2012). New working groups established with international assistance facilitated the development of new plans such as the Service Improvement Action Plan and the Local Waste Management Plan. The aforementioned external initiatives have also supported the work of environmental organisations.

In 2010, the DFID funded Functional Review and Institutional Design of Ministries (FRIDOM, 2010) identified approximately 30 nongovernmental, community and civil society organisations active in Kosovo with around 2,800 members, working on issues of environmental education and awareness, environmental legislation, nature protection, rural development, and sustainable development. As is the case throughout the country, the work of environmental nongovernmental organisations remains donor driven, though in some instances there has been cooperation between these organisations and MESP. Environmental organisations are scattered throughout municipalities with some concentrated in larger cities where more resources are available and enable an environment of establishing NGOs. Environmental NGOs are more visibly active in municipalities with critical 
environmental issues such as Obilic, or where an active citizenry is more common in the local culture as in Prizren. Smaller municipalities lack an active civil society working on environment issues. In instances where local governments do exhibit readiness to involve non-state actors, they choose to cooperate with Youth Action Councils and active youth organisations in the absence of environmental organisations. Whereas this is a constructive approach to open up the municipal decision-making by reaching out to civil society organisations, it does not substitute the need for developing non-state actors with a specific profile on environmental issues. Furthermore, collaboration with organisations not specializing in the field of environment may enable civil servants within municipal Directorates to exercise more power due to their knowledge and expertise on the policy sector.

\section{4. $\quad$ REC collaborations and developing of Local}

\section{Environmental Action Plans}

The Regional Environmental Center (REC) focuses on supporting government institutions for efficient environmental management, building capacities of government officials in environmental governance and promoting transparency. REC also works in providing information and education for civil society actors and organisations and organizes capacity building mechanisms for local environmental organisations. Its focus is on assisting mobilization and development of nongovernmental environmental organisations. REC established a specific fund scheme to assist local environmental organisations in building their capacities, and developing projects on urban environment. As an incentive for participation, grants of up to 5000 euros are awarded to organisations to enable their activities. REC focuses on establishing cooperation channels between civil society and central government authorities. As a result of this work, REC facilitated a Memorandum of Understanding signed between the Ministry of Environment and Spatial Planning and environmental organisations. According to REC officials, the low number of specialized organisations working on environment is an obstructive factor in establishing sustainable relations with the government stipulating the absence of environmental organisations in the signing of the MoU itself (REC Interviews, June 2012). REC maintains that existing organisations are disorganized and often present diverging interests despite working in the same field, stating, "This lack of strong networks weakens their role in the eyes of local government officials; advocacy for the particular policy issues becomes dependent on a few CSOs who continue to carry on the torch" (REC Expert on Local Initiatives and Civil Society Support, Interview June 2012). On the ground, REC argues that government support is scarce, with "both the government and civil society 
organisations calling upon the MoU when necessary for their own interests" (REC Expert on Local Initiatives and Civil Society Support, Interview June 2012). This weakens the impact of the Memorandum of Understanding revealing its lack of obligations towards the signing parties.

In efforts to maintain contact with civil society organisations, the Ministry of Environment compiled a list of CSOs for contact according to Ministerial needs. Yet, these relations are based on individual cases. According to REC officials, government officials and certain organisations can have "very good" relations, which benefit the latter in obtaining support letters or approved projects (REC Project Officer, Interview June 2012). A new initiative amongst environmental organisations is the request for a Ministry official designated specifically for cooperation with civil society. This would clarify the point of contact for all actors and facilitate the work of the Ministry in keeping information of active environmental organisations. REC officials argue this would also ensure the professionalism of the staff by concentrating capacities instead of continuing with the current method of vague responsibilities amongst staff. Lack of capacities includes lack of knowledge and professional expertise on environmental issues. REC Interviewees report cases when Ministry officials in charge of environment were not aware of existing regulations adopted by the Ministry (REC Interviews, June 2012). According to REC, administrative neglect also present challenges in the Ministry exercising its role effectively. This includes the Ministry's current database of civil society organisations working in environmental protection and their contacts, which remains limited and does not include updated information on organisations, occasionally leading to new representatives of civil society organisations missing opportunities of meeting Ministry officials due to invitations being sent to former leaders. As stated by REC, similar problems exist elsewhere in the central government administration, as line ministries are uninformed about profiles of civil society organisations (REC Interviews, June 2012). This leads to an inconsistent approach towards civil society organisations as those working in environment are left out of important Ministerial discussions, even though the latter are open for broader participation.

At the Ministerial level, according to REC officials, MESP officials consider civil society organisations as intruders to their work. In 2010, upon a REC invitation to MESP to join the organisation in fieldwork, Ministry of Environment officials rejected the offer expressing the claim, "You have taken this job from us; otherwise we would have done it ourselves" (REC Expert on Local Initiatives and Civil Society Support, Interview June 2012). A similar approach of disapproval towards the role of civil society exist at the local level as well where civil society organisations are confronted with a preconception amongst municipal officials that the later is being used to extract information and they don't benefit from anything 
(REC Interviews June 2012). These declarations show a wide gap between the two sides. On the other hand, there are successful cases of cooperation where positive outcomes are clear, as in the case of developing the National Environmental Plan, for which the Ministry of Environment cooperated with REC. As part of this plan, REC cooperated with the Environment Protection Agency, in implementing the Water Pollution Cadastre project.

REC has established programs in assisting local authorities to develop their environmental policies. In a new effort in this field, REC signed Memorandums of Understanding with ten municipalities to develop their Local Environmental Action Plans. The aim of this initiative is to broaden the public inclusion and ensure participation of civil society organisations, businesses and active citizen in the decision-making process. Specific attempts are made to invite citizens with different backgrounds to public hearings of municipal authorities. REC has placed one coordinator in each of the ten municipalities to help establish close collaboration with local actors.

Issues such as unclear division of competences and roles within government agencies, are visible in the municipal Directorate in charge of the environmental sector. Establishing relations with the municipal Directorate in charge of environment is challenging for civil society organisations as information regarding the Environment Official is undisclosed. Citizens lack information on where they can address their concerns regarding environmental issues. As one REC official declares, "I had to use my own personal networks and connections to reach the Mayor of Prishtina so he can help us contact the administration" (REC Expert on Local Initiatives and Civil Society Support, Interview June 2012). Relying on personal networks to reach municipal administration is a hurdle for any organisation and prevents establishment of formal links between state and nonstate agencies. In 2007, REC started a broad initiative to enhance collaboration between the various institutions involved in environmental governance. Drafting of the Local Environmental Action Plan was announced as the LEAP project. The Local Environmental Action Plan is a strategic document at the local level, which brings together the interests and values of community members, and defines priorities on environmental protection. The LEAP initiative's prime objective is to achieve collaboration between institutions and encourage citizen participation in decision-making processes. It intends to develop local capacity, both of the local authorities as well as other stakeholders working on environmental issues. LEAP goals include improving environmental planning at the local level through an inclusive approach and wide citizen consultation as well as increasing transparency with the LEAP document approved by municipal government and municipal assembly. To achieve its goal in improving environmental management, LEAP will contribute to ensure central government directives; strategies and action 
plans get implemented at the local level. The LEAP drafting process thus includes joint efforts from all actors to increase coordination about implementing existing and new policies. Lastly, LEAP aims to enable the municipal administration to address and channel investments in environment protection. The initiative was implemented in two rounds during 2007 until 2010 and the second round, which continued until 2013. REC Regional Coordinators worked directly with municipalities to facilitate the Working Group responsible for drafting the LEAP policy.

For the LEAP initiative at the local level, municipalities identify concrete objectives including defining and prioritizing environmental problems in the municipality, raise public awareness on environmental issues, increase the engagement of the municipal office in charge or environmental protection, capacity building of local NGOs in developing and leading projects in environmental protection, ensure financial resources for environmental protection at the local level and strengthen local economy to enable implementation of ecological standards (Klina municipality LEAP 2011). Developing Local Environment Action Plans is a municipal legal obligation deriving from the Law on Environment Protection. The LEAP initiative started with five beneficiary municipalities including Ferizaj, Gjakova, Gjilan, Klina, Peja. In July 2011, ten beneficiary municipalities signed Memorandums of Understanding with the Regional Environment Center in Kosovo. The ten municipalities were chosen based on recommendations from the Swedish International Development Cooperation Agency (SIDA), based on an assessment of their environment circumstances as well as inclusion of newly established and minority municipalities. Municipal authorities established Working Groups on Environment as well as a Coordinating Group to facilitate the work of municipal staff and civil society organisations. The Coordinating Group, as the highest level in the municipal administration hierarchy, reported to the mayor. The role of the Working Group was to prioritize actions in the municipality. Members of the Working Group include a municipal representative, an official in charge of gender issues, one municipal official for European integration, an NGO and a public enterprise representative. The role of CSOs also included surveying community members to evaluate their opinion on environmental issues and their priorities.

The challenge of drafting and implementation of environment protection plans is in finding the way not to destroy existing ecosystems, to advance economic stability of the community and to enable a better quality of life of local citizen. To address these challenges at the local level, joint work in development is necessary. Participation of all parties from the local community, local institutions, civil society, public and private enterprises, media and communities in drafting of LEAP have a decisive importance in its subsequent implementation. 
Representatives of local government are obliged to enable participation in local decision-making. According to the facilitator, LEAP is an inclusive process and a democratic forum in which parties represent their interests (REC 2011). However, REC interviewees declare that not all members of the forums were equally acceptable of other actors. In some instances, municipal coordinators had tendencies to overrule other members in the Working Group demonstrating power over the issues at hand (REC Expert on Local Initiatives and Civil Society Support, Interview June 2012).

LEAP is prepared with data from a wide public, including municipal working groups and finalized by experts on environmental governance. It determines short and medium-term environmental priorities. Opinion polls of communities and engagement of Civil Society Organisations - REC selected nine CSOs from the participating municipalities to cover the process of drafting the Local Environment Action Plan. Data gathered through opinion polls of citizen in the municipalities is distributed to the Working Group members to clarify the public perception on environmental issues. REC promotes this approach as an inclusive mechanism proposing projects for environmental issues that address diverse community segments.

Successful completion of developing the Local Environmental Action Plan was followed by investment projects in each municipality, co-financed between the donor organisation Swedish International Development Agency (SIDA) and the municipalities. The closing Regional Conference LEAP for Sustainability in South East Europe included a call to sign the Aalborg Commitments (for local sustainability). The municipality of Klina became the first Kosovo local government unit to sign the Aalborg Commitments. Overall, successful completion of the first LEAP project, triggered high interest amongst municipalities and further promoted environmental governance and management at the local level. The initiative raised local interest in putting environmental issues in the policy agenda. The second round of the LEAP project covers ten municipalities which include Deçan, Fushë Kosovë, Graçanica/Graćanica, Hani i Elezit, Istog, Junik, Mitrovica, Obiliq, Partesh/Parteš and Podujeva. At the central level, REC cooperates with the Ministry of Environment, Spatial Planning and the Ministry of Local Government Administration to facilitate the work of the LEAP 2 project.

Cooperation with REC was beneficial as it facilitated the work of municipalities in setting priorities in environmental issues and provided training for the Environment Working Group and the local Coordinating Group in developing projects. Highly valuable was also the financial assistance, through the cofinancing grant provided for the irrigation of municipal green space, chosen as highest priority project. Establishing and successfully completing cooperation 
between the Environment Working Group members is highlighted as a positive outcome of the REC - LEAP initiative (Mitrovica Environment Official, Interview June 2012).

In cooperating with newly established municipalities, REC officials recognize the lack of capacities in municipal administration. New municipalities also show greater interest for cooperation with external agencies than bigger municipalities. However, accepting mechanisms of cooperating with local civil society organisations was a challenge in these institutions. Municipalities showed own initiative to develop their Local Environment Plans but there was no representation of other actors. After effective lobbying by the REC partner, municipal authorities agreed to draft the document together with civil society representation (REC Official, Interview June 2012).

Power struggles exist within municipal authorities as well as between government and other agencies. According to REC officials, inside the local government structure, the Directorate for Environment is marginalized (REC Interview June 2012). Lack of capacities within municipal administration and unclear division of responsibilities between inspectorate and administration staff are most apparent in Prishtina municipality (Interview June 2012). Despite the largest population and the widest areas of competences it exercises, Prishtina municipality does not posses the financial resources to provide all the services requested by its citizen and by law. Hence, the municipality would greatly benefit from allowing more information sharing with civil society organisations, especially in the area of environmental governance where specific expertise exists and is willingly shared.

The following section investigates several municipalities with a varying degree of cooperation with civil society in developing the Local Environmental Action Plan. Whereas Podujeva and Obiliç municipality are chosen as best cases, municipalities of Mitrovica and Gjakova entail a more challenging environment prohibiting effective cooperation between state and non-state actors. Interviewees include officials from the local government administration that cooperated with REC in designing the Local Environmental Action Plan as well as representatives of environmental NGOs or other active civil society organisations working in the municipality. In the case where municipalities do not have environment officials, interviews were conducted with heads of Directorate of Urban Planning which oversees environmental policy.

\subsection{Podujeva: An example of cooperation}

The municipality of Podujeva is hailed as a best case of cooperation between municipal institutions and environmental organisations (REC Interviews, 2012). 
The municipal Environment Official comes from a civil society background once heading the local environmental NGO 'EkoVizioni'. This should provide municipal authorities with an advantage to communicate and reach out to nonstate actors, promoting a culture of openness in decision-making processes. For the design of the Local Environmental Action Plan in Podujeva, municipal authorities established cooperation with several local environmental NGOs including the Local Action Group ${ }^{76}$ as well as the Associations of Local Businesses 'Llapijan", Association of Beekeepers 'Llapi' etc. Adopting the LEAP document in June 2012 is cited as one of the latest achievements in the municipality (Municipal Environment Official Interview, April 2013). Other achievements include increasing green space in the municipal territory, implementing existing local regulations on environment protection as well as executing programs for citizen awareness on environment protection. The municipal Directorate for Environment employs an Environment Official and an Inspector for Environment to cover the responsibilities.

In general, cooperation with civil society actors is mostly based on activities such as debates, discussion roundtables, public cleaning campaigns and development of local policies and reports on environment. The municipal Environment Official refers to a prolific civil society contribution, which is 'extremely important for local governance' (Interview, April 2013). Mechanisms to improve existing modes of cooperation include increasing financial assistance for local NGOs and support for their projects on environmental protection (Podujeva Environment Official Interview, April 2013). According to the municipal official, a challenge of efficient implementation of projects is the lack of human resources and professional capacities of local environmental NGOs. However, their motivation to contribute to the municipality receives high regard in the municipal administration (Environment Official Interview, April 2013).

The municipality faces a set of environmental challenges including inefficient wastewater management and waste collection systems and lack of citizen awareness on environment protection. Similar to all other municipalities examined, Podujeva officials also consider lack of funds one of the biggest challenges in implementing environmental policies. As the Environment Official states, 'the municipal budget is far from fulfilling municipal requirements and we realize that many projects are unfeasible' (Interview, April 2013). Financial incentives are also used in the partnership with REC to ensure that local authorities adopt the Local Environment Action Plan. Adoption of LEAP policy is conditioned with a grant of

\footnotetext{
76 The Local Action Groups are another type of non-governmental structures established in 2005 and 2006 with the initiative of the Ministry of Agriculture and Forestry and the assistance of UNDP to enable rural development. The groups are registered as NGOs and belong to a National Network for Rural Development.
} 
40.000 EUR from REC enabling the implementation of a high priority environment project. Municipal co-financing is another condition for the grant (n.n., 2012). To increase financial resources available for environmental projects, Podujeva municipality has established cooperation with international agencies considering donor contribution extremely important in improving local environmental governance (Environment Official Interview, April 2013).

\subsection{Obiliç}

According to REC assessments, Obiliç municipality, one of the municipalities with most environmental problems in the country, is also a successful case in establishing cooperation with environmental organisations in the municipality (REC Interviews, 2012). The municipality deals with a list of environmental issues in its territory, including pollution caused by housing the biggest power plant in the country. Issues include air and noise pollution, endangerment of forests and agricultural land, degradation of land, lack of clean water and treatment of sewage etc. However, the Environmental Protection Directorate has managed to achieve successful implementation of programs in the environment sector which include an increase of green areas in the municipality, efficient management of waste and citizen education on environmental protection (Director Interview, April 2013). The Directorate for Environment Protection is in charge of developing and implementing environmental policies, promoting environment protection, conducting research and evaluation of risks to the environment, developing strategies and budgets for raising citizen awareness and education of the public on environmental issues as well as coordinating work with donor agencies investing in environment. The Directorate is in charge of cooperating with other stakeholders including central government line ministries, the private sector and civil society actors with the aim of promoting environmental protection policies.

Cooperation with civil society organisations has mainly focused on community outreach and information dissemination to citizen on environmental issues, organisation of public debates and education and awareness raising campaigns on environment protection through manifestations such as Earth Day. According to the head of Directorate, the municipality has been open in inviting local NGOs to meetings during the policy development stage as well as during preparation of environmental reports and design of strategies on environment protection (Head of Directorate Interview, April 2013). Considering the inclusion of a number of civil society organisations, the Local Youth Action Councils are also invited to participate in discussing local policies of education, health, environment etc. In the case of Obiliç, the local YAC was a member of the working group developing the Local Environmental Action Plan. As said by the municipal Director of the 
Directorate for Environmental Protection, their participation was important in identifying environmental issues in the municipality that require attention (Interview, April 2013). The municipality adopted the LEAP policy in May 2012.

Similar to the municipality of Podujeva, municipal officials in Obilic perceive environmental NGOs to lack human resources in providing a higher contribution. Obiliç municipal officials consider these organisations to require capacity building to improve their project management skills as well as increase their potential for contributing to develop local environmental policies. Whereas current cooperation with civil society is evaluated as good, more financial assistance should be made available for local NGOs to improve municipal cooperation with their civil society partners (Directorate Director Interview, April 2013). According to the municipal authorities, lack of resources within the administration is a major challenge in its work on environmental policy hindering a wider range of activities. Minimal access to international donor funds as another challenge for municipal authorities in successfully implementing policies (Directorate Director Interview, April 2013).

According to the Directorate leader, good cooperation with the Regional Environmental Center contributed to facilitating the development of the Local Environmental Action Plan through the use of professional methodologies for policy design. Upon completion of the LEAP document, the municipality of Obiliç received financial support for a series of projects from the Regional Environmental Center including funding for the waste management program and increase of green spaces in the territory financed by REC and SIDA.

\subsection{Mitrovica}

Drafting of the Local Environment Action Plan in Mitrovica included five civil society organisations. As reported by municipal officials, the cooperation between municipal authorities and civil society actors is exemplary and resulted in the municipality incorporating their ideas into the LEAP document (Mitrovica Environment Official, Interview June 2012). Environment is one of the key policy areas in which the local government has integrated collaboration with civil society actors into the local activities. Biggest challenges in further developing the municipality's work in environmental protection, as outlined by municipal officials, include harmonizing local regulations with the national legislation. Additionally, lack of clear delineation of competences and responsibilities between central and local government continue to challenge development and successful implementation of local policies (Interview June 2012).

In the case of Mitrovica, responses from civil society organisations contradict those of municipal authorities. According to interviewees from civil society, the 
relationship between environmental NGOs and local government authorities contains many challenges. The local NGO participating in the drafting of the Local Environmental Action Plan, "EkoTrepça", organizes activities primarily on environmental protection and argues that environmental policy is not a priority in the local policy-agenda (Director of NGO EkoTrepça Interview, April 2013). According to the NGO representative, municipal authorities are reluctant to accept proposals and initiatives from civil society due to their conviction that municipal officials posses higher expertise on environmental issues whereas in reality "the municipal Environment Directorate has insufficient human resources to design local policies (Director of NGO EkoTrepça Interview, April 2013). The LEAP drafting process also included disputes between the NGO representatives and municipal officials over priorities set out in the new Action Plan. The NGOs favoured selecting priority projects reflecting citizen needs, as observed through public opinion polls conducted during the design process. However, the final decision on selecting priority projects was taken by municipal authorities supporting other priorities of environmental governance. Demands of NGO representatives for more decision-making authority suggest an unrealistic approach towards the local policy-making process as the municipal officials retain the right to set up. On the other hand, the functioning of the Working Groups established to design similar policies may enable discussion over certain issues yet maintain a dominant role for municipal authorities. The vote of civil servants representing authority's interests outweighs that of other members. Despite these challenges, the organisation cites the establishment of an Environmental Directorate within the Municipal Assembly of Mitrovica as one of the biggest achievements. This increases the attention given to environmental policy within the municipal administration and encourages Assembly Members to monitor the implementation of the LEAP policy.

With regards to the capacities of the NGO EkoTrepça itself, the four members also include former employees of the Trepça mine in Mitrovica. ${ }^{77}$ The organisation also engages volunteers for its activities in the municipality. Main activities done in collaboration with the municipal Environmental Protection Directorate include awareness raising campaigns and information dissemination for environmental protection and volunteer initiatives for street cleaning. To strengthen the impact on local decision-making, the head of NGO EkoTrepca argues that environmental organisations need to establish networks of cooperation and improve their expertise on environmental issues.

\footnotetext{
77 Only one member of the organisation has a University degree (Director of NGO EkoTrepça Interview, April 2013).
} 


\subsection{Gjakova}

In the municipality of Gjakova, the main local policies on environmental sector include the Local Environmental Action Plan 2009 - 2015 and the Regulation on Environmental Protection. The municipality deals with a series of environmental issues, including the lack of systematic monitoring system for air, water and land pollution, a heritage of heavy industrial waste, land erosion, illegal logging and waste management. In the Gjakova case, REC collaborated mainly with the Director of the Urban Planning Directorate, which oversees the environment sector. Other counterparts include the Mayor and the Chair of the Municipal Assembly. The Working Group in charge of drafting the LEAP document included local civil society organisations. According to the REC Coordinator, cooperation with civil society organisations depends on the latter's initiative and application for projects. Whilst the municipal administration is open to inviting organisations in meetings, debates and include them in the policy-design process, the latter's involvement depends largely on the organisations' capacities and initiative to collaborate. According to REC, environmental organisations must develop a joint strategy prioritizing their approach to local environmental issues and thus strengthen their potential to access decision-making processes and have an impact (REC Coordinator, Interview, May 2013). Another obstacle hindering the work of civil society is the lack of funding for environmental issues, which according to the REC Coordinator, prohibits the establishment of more environmental organisations.

On the civil society side, we find a different outlook on rapports with municipal authorities. According to the MAR Kosovo Center for Sustainable Development, cooperation with municipal authorities has decreased in the last years, especially since the change of the political leadership in the last local elections. Contact with municipal officials remains rare considering the organisation is not invited to attend meetings, debates or discussions on environmental policy. The organisation was not invited to participate in the development of the Local Environmental Action Plan. In addition, the lack of projects and funds has also diminished the motivation of the organisation's members and activists (Interview, May 2013). As stated by MAR representatives, municipal authorities have selective approaches towards civil society organisations and do not promote a broad and open approach for cooperation (Interview, May 2013). Cooperation with other civil society organisations has also decreased in the last years, considering the lack of funds for the NGO Forum established in Gjakova, which served as a facilitator between the various active organisations.

MAR was established in 2001 as an environmental NGO profiling its work early on when civil society organisations were being established throughout the country. In 
2005 it added sustainable development to its main activities and works primarily in sustainable economic development, environmental protection and social issues. The aim of the organisation is to promote issues of sustainable development, to impact local policies through representing citizen interests and lobby for the implementation of adopted regulations at the local level. It seeks to promote mechanisms of cooperation between local authorities, NGOs, the business community and citizen. With three permanent staff members equipped with postgraduate degrees, and external collaborators, the organisation argues that its capacities and expertise are sufficient to contribute to local environmental policy (MAR Director Interview, May 2013). Before cooperation ceased in 2007, according to the interviewee, "MAR established good working relations with the Municipal Assembly during the development of business plans for the Business Incubator, which is part of the priorities foreseen in the Strategy for Local Economic Development in Gjakova municipality" (MAR Director, Interview, May 2013). The organisation also cooperated with the Directorate for Culture, Youth and Sports to develop an online platform to facilitate communication and information dissemination between the municipal Directorate and the Youth Center in Gjakova. Receiving project funding mainly from international donor organisations, financial assistance from local government is non-existent. According to the organisation's leadership the municipality has limited human resources and professional capacities to develop adequate environmental policies for the needs of the municipality' (Interview, May 2013).

Considering the limited number of environmental NGOs working at the local level, 'excluded' organisations such as MAR which have been active for more than a decade constrain relationships that bridge state-society divides. Municipal authorities must change their approach towards civil society and 'adopt a more proactive approach in establishing cooperation with NGOs, in particular with environmental organisations.

\subsection{Case Study: Provision of Welfare Services}

Kosovo has three main social assistance programs including cash transfer systems to households, war veterans' benefits and disability pensions for working age people who have disabilities and are unable to work. The social assistance scheme attempts to fill the gap created by the absence of other types of benefits, such as child benefit, sickness benefit and unemployment benefit. The central pension system provides a minimal level of assistance to retired persons. Workers below 55 years of age are mandated to place $10 \%$ of their wages into the Kosovo Pension Savings Trust. The European Commission reports on dire conditions of persons 
with disabilities, who are faced with little access to employment, goods and services, transportation and education (European Commission, 2012b). The necessity for improving the coverage and efficiency of the social protection system, particularly in respect of the needs of children, persons with disabilities, and elderly persons, has been highlighted in the 2009 European Commission Communication "Kosovo - Fulfilling its European Perspective" and its 2011 Progress Report. In addition, a major cross-cutting issue identified in the Multiannual Indicative Planning Document 2011-2013 is the requirement that equal opportunities and non-discrimination of minority and vulnerable groups (including children, disabled and elderly people) will find consideration in all aspects of EU-funded activities. The Ministry of Labor and Social Welfare has developed, with EU support, an Action Plan 2011 - 2012/13 for the implementation of the Sectoral Strategy. The operational objectives include an increase in the ability of central and local authorities to provide services based on EU practice, and development of alternative ways and means of service provision (MLSW, 2011). One of these alternatives is service provision in collaboration with civil society organisations.

In the neighbouring countries, municipal social services to Persons with Disabilities (PwD) are delivered through contracting groups. In Kosovo, municipalities largely lack capacities to provide these services themselves. According to the national Strategy and Action Plan on Human Rights, there are approximately 150,000 people with disabilities in Kosovo who suffer from pervasive exclusion in their everyday life, whether it is in terms of access to health care, the right to equal education, equal employment opportunities, or participation in political and public life (OPM, 2008). The Kosovo Human Development Report published by UNDP in 2010 identified people with disabilities as one of the most marginalized social groups in Kosovo. The report warns that this group is "at great risk of becoming Kosovo's invisible population unless they are moved quickly up the policy prioritization ladder and are made the primary focus of Kosovo's development agenda" (UNDP 2010). A 2011 survey, commissioned by the OPM Office for Good Governance, shows that only 1 percent of the population identified as Persons with Disabilities receive support for children with the average amount being around $103 €$, which suggests a call for effective implementation of the Law for Supporting Families with Children with Disabilities (OPM 2011a). 


\subsection{Policies addressing Persons with Disabilities}

Welfare services are listed amongst the five priority policy areas of the central Government Program 2011-2014 (OPM, 2011b). However, international monitoring agencies as well as local advocacy groups have criticized the government for failing to improve provision of services to Persons with Disabilities. Lack of financial resources for central government and municipalities has challenged welfare services for Persons with Disabilities. The process of decentralization of social services began in January 2009 based on the new Law on Local SelfGovernment approved in 2008. According to the Ahtisaari Plan principles, adopted in national legislation, decentralization of social welfare services is foreseen to ensure efficiency and fair protection of all community members. Article 17 of the Law on Local Self-Government outlines municipal responsibilities to include provision of family and other social welfare services, such as care for the vulnerable, foster care, child care; elderly care, including registration and licensing of these care Centers, recruitment, payment of salaries and training of social welfare professionals. After the adoption of the legislation, in February 2009, the Ministry of Labor and Social Welfare signed a Memorandum of Understanding with the Ministry of Local Government Administration, Ministry of Finance and Kosovo municipalities to initiate devolution of authority in provision of social care. The MoU initiated a transfer of responsibility for Centers for Social Work (CSW) to municipal administration and provision of overall responsibility for social services to Municipal Directorates for Health and Social Welfare. However, this initial transition did not secure the transfer of all competences, including particular services provided to children, the elderly and to Persons with Disabilities (PwD). Examples include residential services, subsidies to NGOs, foster care allowances, allowances for children with disabilities and the Centers for Social Welfare in Leposavić, Zubin Potok and Zveçan/Zvečan. The delivery of these services continued through institutions which are under the direct responsibility of the Ministry of Labor and Social Welfare (MLSW) (European Commission, 2012a). This partial decentralization of responsibilities complicated the policy-making process as financial decisions were taken at central level with implementation at the lower tier of government. Provision of residential services for persons with disabilities remained fully centralized whereas benefits for families with children with permanent disabilities were deconcentrated (Joshua \& Dzhygyr, 2011). Municipal officials struggled with understanding the existing differences between delegated functions and deconcentrated tasks, which caused confusion over lines of hierarchy and accountability measures. Recognizing the need for clarifications and an improved delineation of duties amongst central and local government levels, the National Disability Action Plan 2009 - 2011 outlined a set of activities. These include placement of additional expert member within the local administration, 
specifically for issues of inclusion of Persons with Disabilities, publishing of guides on municipal competences and capacity building activities for municipal staff (OPM, 2009). The varying types of decentralized tasks also made budget classifications complex as some staff salaries remained under the Ministry of Labor and Social Welfare and others covered by municipal budgets. Since 2009, a transitional intergovernmental financing scheme included a specific grant for social services allocated to municipalities. As of 2012, the Medium Term Expenditure Framework of 2012 - 2014 incorporated the specific funds in the General Grant.

In 2001, the Kosovo non-governmental organisation, HandiKOS, developed a guide document for policymaking for Persons with Disabilities to serve the institutions and ministries especially during policy drafting. One of the main requests of the document was the establishment of an Advisory position to the Prime Minister concerning Persons with Disabilities in addition to a specific Office for People with Disabilities. Whilst the latter was not accepted, the Advisory position was set up and became functional. However, meetings between the Advisor and HANDIKOS, or other civil society organisations were not requested. Bar the establishment of a new function, this action, did not result in setting up formal cooperation with civil society organisations working with persons with disabilities. At the national level, the Kosovo Council of Persons with Disabilities (KCPD) was established in 2006 and represented an advancement of national policy recognizing the requests and needs of Persons with Disabilities. The Council is the highest state body representing PwD in charge of monitoring all laws that have to do with Persons with Disabilities to check the compliance with their rights and protections. The KCPD is co-chaired by the Deputy Prime Minister and a representative from Persons with Disabilities and includes members of 5 to 7 line ministries. The KCPD enables adequate representation of $\mathrm{PwD}$ and was an attempt by the government to expand opportunities for participation in decision-making. On establishing the KCPD, HandiKOS states, "We thought we have achieved quite a strong mechanism" (Director, Interview March 2012). The Disabled Persons Organisations (DPOs) network, an umbrella organisation representing PwD interests was part of the national KCPD demonstrating a well-organized network of civil society. However, consultations and inclusion of the DPO network was partial and fragmented as a result of government's attitude that the issue of disability is a matter of social, educational and health policies (Coalition Equal Opportunity 2007). Overall, the Council failed to become completely functional holding only three meetings since 2006 without any concrete steps resulting from them.

In 2011, the Prime Minister's Office for Good Governance, Human Rights, Equal Opportunities and Gender Issue (OPM/OGG) reinitiated the establishment of the 
Kosovo Council of Persons with Disabilities. The new structure was established without a clear break from the previous policy. Civil society organisations representing Persons with Disabilities expressed doubt that this government action will have an impact in their lives. As stated by HandiKOS, 'the fact that protection is stated in the law, or that a Council exists, does not matter in reality' (HandiKOS Director, Interview March 2013). Failure to implement existing regulations and enforce mandates of government structures, weaken the role of government in providing services and ensuring trust in state institutions. HandiKOS representatives emphasize that, at the central level, informal channels are the most important mechanisms of reaching government institutions. Adding to these challenges within existing mechanisms of work of central government officials, civil society contribution is challenged by administration delays such as late notifications for workshops with government officials (HandiKOS Director, Interview March 2012).

In 2007, the Coalition of Organisations of People with Disabilities in Kosovo "Equal Opportunity" published a National Report for People with Disabilities in Kosovo declaring that Persons with Disabilities are united on their aim to mobilize, organize and create a powerful civil movement of organisations, controlled by persons with disabilities. In the movement for disability rights the main objective is the introduction of disability as a human rights and development issue in general. This leads to recognition and acceptance of the disability as a natural part of the life, and persons with disability as equal citizens who enjoy equal rights and responsibilities $(2007,12)$. However, despite these declarations and several initiatives of coalition building, in practice the biggest challenge in having an impact on current processes is the lack of cooperation between $\mathrm{PwD}$ organisations themselves. Civil society itself is not very strategic to convince municipalities to strengthen cooperation. The HandiKOS Director (Interview March 2012) states:

We are not very clear on our requests and not organized as much as we should be. When looking to establish cooperation with us, local governments evaluate how organized we are. How strong is our internal strength. If they see we are fractions, they have reasons to avoid their obligations towards us. Municipal authorities (specifically Prizren Mayor told us) "come to us when you get organized. We can't help each organisation separately.

$\mathrm{PwD}$ organisations promote their own interests and lobby for fulfilling interests of specific communities. Organisation representatives believe this weakens their position when asking for cooperation with local authorities. Lacking a joint platform with main priorities for all organisations is a barrier to pushing forward 
requests. This is harming a strengthening of rapport between CSOs and local authorities.

The existing legal framework leaves the relationship between civil society and local government in a volatile state. There are no clear regulations adopted specifically for strengthening the cooperation. In the Persons with Disabilities issue, civil society can initiate the establishment of a Committee, a structure with civil society, directors of directorates etc. The committee role is advisory and their existence is sustained as long as there is interest of civil society. The Committee can present proposals to municipal organs (to executive side or the Municipal Assembly) to solve a particular issue. Municipalities have the possibility to establish the Committee for Persons with Disabilities to ensure implementation of local policies for PwD. It is the role of civil society to sustain the existence of these mechanisms with ideas, programs, and suggestions on issues (HandiKOS Drenas, Interview March 2012).

The UK Department for International Development was a key institution providing guidance and assistance to the central government during the process of decentralizing social services. Support to the decentralization of social care services included strengthening the capabilities of municipalities and Centers of Social Welfare to meet priority needs. DFID helped establish a National Policy Advisory Committee to develop financial and administrative coherence for the decentralization of social care services. It also improved the capacities of the central government to develop an intergovernmental financing system and budget formula for social care services. Additionally, the project strengthened management systems by improving technical and organisational links between planning, policy and budgeting for social care services. Despite the series of efforts undertaken to facilitate the process, a DFID study of the transition process identified several challenges including weak coordination amongst institutions, insufficient financial resources for decentralized Centers for Social Welfare to provide services, excessive administrative and managerial demands placed on the Centers by the central authorities and weak coordination between municipal Directorates of Health and Social Welfare, Centers for Social Work and NGOs (Joshua \& Dzhygyr 2011).

\subsection{Offering services at municipal level}

According to HandiKOS, a core of its activities differentiates them from other civil society organisations working with Persons with Disabilities, specifically its capacity to offer services for children and adults. In relation to state institutions, HandiKOS interviewees declare that 'local authorities are reluctant to fully 
recognize the services offered to PwD' (HandiKOS Drenas, Interview March 2012). At the central level services provided by HandiKOS are not officially recognized. At the local level, HandiKOS is an exemplary case in pushing municipalities to accept free services from HandiKOS. Despite the long existence of HandiKOS, as a leading civil society organisation for Persons with Disabilities, assistance of international agencies was instrumental in establish cooperation between municipal authorities and HandiKOS. In the municipalities where HandiKOS established cooperation, this was achieved with the help of international agencies promoting that local authorities enact formal mechanisms of cooperation with CSOs. Interviewees argue, without the role of international donor agencies, "we would have not achieved this [...] so we have used these advantages of having international backing to lobby for more attention from municipal authorities" (HandiKOS Drenas, Interview March 2012). HandiKOS provides assistive devices and primary physical and psychosocial rehabilitation services through its 14 Community Based Rehabilitation Centers and 12 Local Offices located throughout Kosovo. Another important service offered is counselling for parents of children with disabilities on rights of $\mathrm{PwD}$ and providing assistive devices for children and adults with disabilities. HandiKOS maintains a database registering around 18.000 children and adults with disabilities (with physical and combined disabilities) in the country. The HandiKOS Local Office in Drenas includes around 1350 members using the Community Based Rehabilitation Center for various services.

Agreements for collaboration are established between HandiKOS and the mayors of municipalities of Drenas, Suharekë, Malisheva and Gjilan. Four Community Based Rehabilitation Centers are co-funded by the organisation in partnership with the local government. In these municipalities the Mayor recognizes the organisations' role in delivering services for Persons with Disabilities. An important factor in establishing this collaboration was that HandiKOS services already entailed their own infrastructure, relieving the municipality of obligations to devote its own resources. According to the local HandiKOS Manager in Drenas "this assisted municipal authorities Municipalities get the idea to contract us since we already have our buildings, and we transport the children with our own vehicles' (Interview March 2012). In these cases, municipalities agreed to recognize HandiKOS as a service provider under the umbrella of municipal welfare service provision. The Centers offers particular attention to children ages 1 to 16, providing them with extensive physical and psychosocial rehabilitation services. Parallel to this, HandiKOS has extensively lobbied for inclusion of children with disabilities in the regular schooling system. Advocating to the local government has reached success in establishing three additional classes in the Krajkova village primary school "28 November". This is a considerable achievement. 
In Drenas, HandiKOS maintains that the organisation offers better services than the municipal administration (Interview, March 2012). The agreement for collaboration is signed in the form of a one-year temporary Memorandum of Understanding between HandiKOS, Drenas municipality (Directorate for Health or in bigger municipalities they have Social Welfare Directorate) and partner organisations. HandiKOS reports to the Municipal Directorate. The municipality has allocated financial resources for operational costs whilst HandiKOS covers employee payments, transportation, building etc. In the case of donor financing, those external funds are used to cover staff salaries. The municipality contribution is limited to financing operating services of the facilities. Disagreements regarding execution of personnel salaries have complicated the implementation. According to HandiKOS, the personnel in charge of delivering the service must be compensated by the municipality (HandiKOS Drenas Manager, Interview March 2012). Municipal authorities have disagreed, arguing against payments for staff due to bureaucratic implications for their administration. According to municipal officials, hiring the staff requires approval deriving from a formal Municipal Decision. However, this remains a misconception from the local government's side. Legislation regulating decentralized services at the local level allow for contractual relations between local authorities and other agencies. Organisations can apply to the tender and offer services. Objections by municipal staff may be mechanisms to avoid additional responsibilities to an already heavily burdened administration.

According to HandiKOS, municipalities have the will to help civil society, but fail to fulfil their obligations in accordance with agreements or contracts signed. These failures render Memorandums of Understanding futile. For example, Prishtina municipal authorities failed to functionalize the Committee for Persons with Disabilities, despite its proclamations to enact the policy. In the case of Malisheva municipality, local authorities have agreed to cover service provision expenses in the amount of 5.000 EUR but later retracted their commitment declaring to have signed the agreement to keep the interest of the donors (HandiKOS Drenas Interview, March 2012). According to HandiKOS representatives, legal measures have not been taken in these cases stating,

We have never chosen to go to court over these issues considering that we need to save the relations of cooperation with municipalities... we can't ruin the little cooperation we already have (HandiKOS Interviews, March 2012).

HandiKOS officials argue that their persistence and intervention to offer services is important to establish cooperation with municipal authorities, using arguments that their organisation has capacities for offering better and cheaper services than the municipality (HandiKOS Drenas Interview, March 2012). 
Other municipalities have shown the opposite results, as in the case of Ferizaj, where municipal authorities established a formal Committee dealing with Persons with Disabilities. The Committee is formally recognized with a decision from the Municipal Assembly. It is established to enable collaboration between members of political parties represented together with NGOs organisations for Persons with Disabilities. The Committee has adopted an Action Plan and serves as a formal mechanism through which the Committee has taken responsibilities.

\subsection{Conclusion}

The case studies examined here were chosen to investigate the factors determining progress in bridging state-society cooperation. They illustrate the existence of a variety of mechanisms and efforts to establish formal links between state structures and civil society actors. With a varying degree of success across policy areas and across municipalities, efforts are made to institutionalise mechanisms of cooperation between local government and civil society through establishment of Working Groups, Committees and Councils. The evidence suggests the requirement of institutionalising new networks in order to ensure their sustainability. The emerging result is a critical number of active agents, state and non-state actors, incrementally pushing forward change at the local level. These developments present the establishment of a new social structure which aims at integrating into the local political culture by engaging local politicians and decision-makers.

Nevertheless, a set of challenges is encountered in formalizing cooperation between government authorities and civil society organisations. In the case of environmental governance, failure to enforce existing legislation weakens local governance. With regard to service provision for Persons with Disabilities, weak implementation of existing mechanisms of cooperation inhibits further development of progress across state and non-state lines. Lack of implementation of Memorandums of Understanding; raise the question as to their validity and their wide use across policy areas in Kosovo.

The lack of a clear delineation of competences and responsibilities between central and local government continue to challenge development and successful implementation of local policies. Implementation of new legislation remains a big challenge for local administrations due to institutional capacity and financial constraints. The case studies show that lack of human resources and significant financial constrains prohibit development of cooperation between municipal governments and civil society organisations. 
Effective collaboration with local authorities is contingent upon an active approach of civil society organisations to secure attention from municipal authorities, and increase their impact on local decision-making processes. The various examples from municipalities suggest a weak network of civil society organisations, which weakens their advocacy role before municipal authorities. Persistence of organisations, such as HandiKOS in Drenas, to engage in communication and build relations with municipal authorities was necessary for the successful cooperation. Stronger networks of civil society organisations increase their chances of accessing municipal institutions and exercising an impact on the decisionmaking process. These networks, however, required civil society organisations to prioritize good relations with local authorities against their mission to hold the local government accountable.

In some municipalities, government institutions exhibit an open approach towards civil society inclusion and their contribution to local decision-making processes. However, civil society organisations still encounter a resistant environment in other municipalities where civil servants are reluctant to accept input from nonstate actors. In environmental governance and welfare service provision, the data suggests that civil society participation in the early stages of policy-making such as selecting priorities for the municipality, increased the latter's chance in influencing the end result. This provides opportunities for these agencies to share the spotlight and shift local decision-making towards a more open and inclusive format. Municipal authorities become accustomed to collaborating with civil society representatives and discussing policy priorities in joint working groups.

Conditionality set from international or external agencies, in establishing partnerships was a necessary factor for the cooperation between state and nonstate actors to occur. This suggests a lack of trust of local governments in the capacities of non-governmental organisations and a lack of commitment to change the mode of working at the local level. The presence of international agencies proves necessary in establishing the link between local government institutions and non-state organisations but insufficient in guaranteeing a successful implementation of cooperation. Financial incentives in the form of grants for municipal projects serve as a key motivate the local government. Technical assistance of international agencies accompanied by funding schemes and grants for implementing youth, environmental and social welfare projects remain a necessary condition for maintaining the parties interested in working together. Use of donor financial resources remained a key incentive for the interest and participation of municipalities. Co-financing schemes maintained the interest of local institutions and contributed to successful implementation of new projects. 
7. Conclusion 
This research has analysed the process of transforming power and reforming decision-making at the local level in Kosovo. The empirical chapters examined the progress in establishing and implementing new mechanisms of cooperation between state and non-state actors in the field of heritage, youth, environment and social services and the extent to which these mechanisms have introduced and sustained a new decision-making process at the local level. This was undertaken through a series of case studies. The findings of the study are presented along two dimensions namely first to convey the changes that took place in Kosovo's local governance structures and second to delineate what factors enabled those changes.

The most important finding of the study is that local government in post-conflict Kosovo is changing and instances of good governance are occurring at the local level. Evidence from the case studies suggests a moderate achievement towards broadening the scope of actors responsible and active at the local governance. Developments at the local level in the last decade reveal an involvement of nonstate actors in the decision-making process for the first time. At the local level, there seems to be evidence of some reconfiguration of power enabling incremental change. The emerging result of local government reform in Kosovo is a critical number of active agents, state and non-state actors, incrementally pushing forward change at the local level. The data suggests that a moderate shift towards good local governance has occurred.

Notably, the research suggests that the involvement of non-state actors and their relative empowerment vis-à-vis local state actors enables a new decentralized type of decision making at the local level. This is seemingly the case even when the capacities of state actors are low or negligible, and where the central administration is reluctant to transfer authority and reform. Where this is less the case is in instances in which the international community enforces a centralization of authority at the central level and systematically excludes non-state actors, as discussed on Chapter 4 on heritage governance.

The empirical evidence presented in this study suggests that there are several key variables for explaining the changes in local governance in Kosovo. The interplay of these factors is particularly complex in Kosovo and there is much at stake in terms of success or failure of local government reform. The three most important variables concern the significance of international agencies' resources and strategies on local reform, the mobilization of civil society efforts to strengthen networks with local authorities and the leadership of local elites and their willingness to pursue reforms. Local government reform in Kosovo is affected by the wider dynamic of statehood and nation-building and by the particular involvement of the international community in this process. Local government reforms have been predominantly an externally driven process. With regards to 
the establishment of new networks at the local level, the evidence presented in Chapters 3, 5 and 6 suggest that the local level has partially embraced shifts towards open decision-making and a new approach towards collaboration and networking with non-state actors. Notwithstanding the importance of the leadership of civil servants to implement successful local governance reforms, evidence indicates that local civil society capacities and networks are vital in driving change at the local level. The research demonstrates that the power distribution at the local level varies across policy areas. In certain policy spheres, the local government is more open towards non-state actors whereas in other policy spheres higher centralization of authority is prevalent, despite the high decentralization measures taken. The case study on youth participation suggests that reforms only succeeded when a combination of external pressure and domestic leadership occurred together with active participation by civil society. In the case of heritage governance, a highly centralized legislation drafting process showcased the international community and central government dominating the decision-making process.

What is striking from the evidence is the existence of opportunity structures for local agents, particularly those engaged in the policy sectors of regional development, youth participation and environmental governance. These opportunity structures are predominantly a product of international intervention and their initiatives at the local level. The empirical data points to a set of conditions that appear to enable the advancement of state and non-state networks. Evidence clearly points to a powerful role of highly mobilized civil society demonstrating their influence for mobilization and resisting imposition of policies either from domestic authorities or the international community. The active advocacy of civil society organizations and their persistent efforts towards establishing partnerships with local authorities advances their interests and puts policy issues on the local political agenda. Persistence of organizations, such as the Youth Councils and HandiKOS to engage in communication and build relations with municipal authorities is necessary for successful cooperation in different policy areas. Furthermore, civil society organisations, when mobilized, can present a strong interest group lobbying for change at the local level. What weakens the potential impact that civil society can have at the local level is the resources they possess. The more capacity and resources, the more pressure they can exert. One of the key capacities seems to be a clear leadership amongst organizations themselves. Responses from municipal authorities working on environment, welfare services and youth suggest that local officials find it easier to cooperate with civil society organizations when there is a leader to negotiate with. Along the same lines, stronger networks of civil society organisations seem to increase their chances of accessing municipal institutions and exercising an impact on the 
decision-making process. In the case of heritage, networks of civil society organizations were active at the local level with the establishment of the NGOs' Coalition for Prizren. This mandated the attention and reaction of government agencies to acknowledge the role of civil society in the heritage reform process. On the contrary, the lack of agreement and network between civil society organizations advocating for improved services for People with Disabilities weakened their position vis-à-vis government agencies. Organisations are thus reliant on their individual capacities to gain access to the decision-making cycle.

Bearing in mind the complexity of actors and interests on the ground, the case study on youth empowerment, illustrates how progressive change is contingent upon a combination of external incentives, the active participation of civil society organizations, and the leadership or willingness of local elites. In addition, the case study of local service provision to Persons with Disabilities suggested that strengthening ties with local elites required civil society organisations to prioritize good relations with local authorities against their mission to hold the local government accountable. The civil society relationship with local elites and the way local politics operates seems to be an important variable. For civil society to exercise this pressure, however, their efforts must meet a local administration inclined to cooperate with non-state actors. Thus, notwithstanding the resources available for civil society organisations, their relationship with local elites is conditional upon local officials willing to share power. The leadership of local officials and the political will of municipal mayors determine the pace and outcome of progressive change.

Overall throughout the case studies explored, conditionality set from external agencies in establishing partnerships was a necessary factor for the cooperation between state and non-state actors to occur. The case study research data in Chapter 6 reveals that even where international agencies are not at the forefront of reforms, their presence serves as a guarantee to engage stakeholders in reforms. Both the municipal administration and civil society members stated that international backing for certain programs was pivotal in embarking on new partnerships with state/non-state actors.

The involvement of the central government in steering the process appears to be an intervening variable. When there are strong civil society organizations and the local administration is successfully implementing reforms, the central government role is necessary but not critical to drive change. However, if the policy reform is politically contentious, as in the heritage case, then the central government role becomes a key player in the reform process. This is manifested through their role in designing and enforcing modes of governance or in their role as gatekeepers in centralizing decision-making to the central level. The case of heritage suggests that 
the leadership of the political elite in municipalities weakens with the pressure of central government and the international community. This pressure was absent in the regional development, youth, environment and welfare cases studied in Chapters 3, 5 and 6 .

Another significant finding is that from the perspective of the local, the central state has a limited reach in various policy areas. This is primarily a result of the weak implementation of existing legislation and the weak oversight mechanisms to ensure compliance of local authorities to the legal framework. The cases discussed in Chapters 3 and 6 concerning regional development, environmental governance and welfare services point to this limited steering role of the central government. By comparison, the case of youth empowerment discussed in Chapter 5 suggests that the moderate attention given to the youth sector by the Ministry of Culture, Youth and Sports aligned with the interest of local elites and civil society organizations as well as with the engagement of international agencies which made their resources available for the sector.

The empirical data points to a weak implementation of legislation on local reform and instances of vague delineation of powers and authority between central and local governments. The ambiguities and omissions in the legal framework undermined the work of local authorities and diminished the potential impact these reforms can have on the local communities. Insufficient administrative capacities at the local level also hinder municipal authorities to implement reform programs successfully, particularly funding partnerships with non-state actors. Throughout the empirical chapters, the case studies suggest that the lack of human resources and significant financial constrains prohibit development of cooperation between municipal governments and civil society organisations. However, in some instances, local officials resist opening up decision-making processes to include civil society actors due to their assumption that the latter are incompetent and inexperienced to contribute to local policy.

One of the most significant issues related to the work being done at the local level is the extent to which internationally led initiatives for local governance reform address institutionalization of new modes of governance. Evidence in the field of heritage and environmental governance, suggest that existing local structures were ignored and overridden during the implementation of new initiatives at the local level. This approach risks leading to a multiplication of structures at the local level and overburdens the local administration who deals with already limited resources. Complex bureaucracy and formal rules of local government institutions also deter citizens from approaching formal local decision-making (Pratchett 2004).

With regards to sustaining participation in the decision-making system, there is evidence in the field of regional development and environmental governance that 
civil society participation in the early stages of policy-making such as selecting policy priorities for the municipality, increased the latter's opportunity to influence the outcome and strengthens the cooperation between these organizations and local authorities. Institutionalizing these practices and reiterating them over time ensures their integration into the daily politics at the local level (Skelcher and Torfing 2010). In an environment of ever-changing legislation and local leadership, it is important to ensure that other stakeholders have access to decision-making processes even after the support of international agencies ends.

The case studies explored point towards a tendency for multiplicity of formal institutional structures and mechanisms enacted through legislation. This approach overburdens the local administration, already under limited capacities and struggling with fulfilling its increasing responsibilities. Parallel to strategies for putting in place mechanisms to improve decision-making, attention must be paid to functionalization of existing structures and enhancing capacities of local agencies to ensure implementation of policies. The impact on the local level thus also depends on how the initiative is framed and its substantive focus. Furthermore, the evidence shows that international initiatives on local governance pay insufficient attention to strengthening intergovernmental links between local and central government institutions and as such fail to empower central state agencies in exerting a shadow of hierarchy. This gap between the local and the central undermines implementation of policies. Despite decentralization policies in place, a clear division between local autonomy and national control is not established in Kosovo. As local governments remain dependent on financial support from the national budget, any initiative to reform the local must attempt to strengthen accountability mechanisms and oversight from the central government. This research challenges the existing view in literature that the local level is best left to develop once a strong core central government is secured and its effects 'trickle down' to the lower tiers. It emphasizes that local governance change is critical when institutionalized mechanisms are in place securing accountability of the local level to higher hierarchical state structures thereby reinforcing the role of the state in steering broader social and economic development.

Historic legacies of state authority remain a factor in the functioning of the local administration. The Yugoslav institutional legacy is still to be found in the local administration and the political culture. The changes introduced at the local level in the last decade and a half have undoubtedly confronted the expectations of the local administration in serving citizen and cooperating with non-state actors as well as the way citizens interact with local government agencies. Nevertheless, within municipalities, institutions of decision-making and policy-enforcement are slow to change. Institutional change is gradual and evolutionary, particularly at the local level (Easterly 2008, 95). 
The case studies discussed in Chapter 5 and 6 on youth empowerment, environmental governance and services for Persons with Disabilities suggest that some municipalities are more likely to accept enhanced participation by civil society organizations when recognizing their expertise and resources in a policy area. In addition, the environmental governance case suggests that joint design of local strategies for action, where non-state actors are participants from the onset of the project, increase the commitment of all actors. This is also the case in the evidence discussed in Chapter 3 where the drafting of regional development projects by local authorities jointly with business representatives and nongovernmental organisations ensured their commitment in the process.

The evidence presented throughout Chapters 3 to 6 suggests that local and central government authorities have not completely acknowledged the changes in their power resulting from decentralization. The central government addressed decentralization and local governance reforms under pressure from international community conditionality, rather than as a requirement for strengthening local participation and subsidiarity. At the same time, the influence of the discourse on minority rights and political settlements for minorities undermined attempts to promote good local governance as an objective on its own. Thus, despite structural and institutional opportunities and change, there is a time lag and a slow response coming from the local level.

Another issue raised by the study concerns that as the international community exerts its external shadow of hierarchy on domestic politics, they also may capture power. Due to the multiplicity of actors, the lines between who should be exercising power is blurred. This weakens the legitimacy of actions taken by government authorities and the role of the international community. Furthermore, lack of legitimacy hampers implementation of new policies at the local level as citizen lack trust in these institutions. This was made evident in the case study of heritage governance in Chapter 4. External attempts to design and promote new institutional structures without opening the decision-making process lead to the loss of legitimacy of the proposed legislation which in turn perpetuates the state weakness. Considering the controversy and resistance to implement legislation resulting from the new Law on Prizren, the international agencies focused their efforts in getting the political leadership on board thereby neglecting other stakeholders. The ICO, in particular, did not respect the Council of Europe (2005) principles about involving society in the process of designing heritage management mechanisms. Despite this, within Kosovo, the ICO strengthened its role as a norm setter by maintaining an exclusive authority in interpreting the Ahtisaari Proposal and the legislation emanating from it. 
In terms of relating the findings of this study to broader discussions within political science regarding the limits and impact of external initiatives on postconflict countries, this study does not argue against international intervention in building good local governance. Instead, it suggests that more attention should be given to ensuring the sustainability of new modes of governance at the local level and to reinforcing the role of the central government.

Engaging with emerging democracies more effectively is the new frontier of the developmental challenge. Introducing and promoting new mechanisms of collaboration between local authorities and civil society organisations is a key advantage of externally steered initiatives at the local level. However, their successful completion depends on local authorities and civil servants accepting these mechanisms as a new way of doing politics. Long-term strategies of international agencies remain difficult to implement in a politically dynamic and often contentious environment. Nevertheless, successful implementation of local governance initiatives depends on their integration within local structures and durability after completion of donor assistance. As shown in the case studies, this is rarely the case in the municipalities examined. With the existence of international donors, ready to invest in programs and initiatives for enhancing good local governance, local authorities should advocate their own agenda and steer donations in particular issues which need attention. Accepting any and all donor projects does not lead to direct improvement of conditions at the local level. Local authorities must avoid situations cited by the European donors in Prishtina proclaiming that local partners "accept any project that comes from the EU" (ECLO interview 2012).

Finally, this study does not argue against international assistance and intervention in policy reforms. Instead, it suggests that more attention should be paid to structural reform at the local level enhancing local conditions conducive to successful implementation of policies instead of merely funding short-term projects. Furthermore, a more balanced approach should be taken towards reforms improving both central and local governance through strengthening intergovernmental relations. Reinforcing the role of the state is crucial in enabling new governance at the local level. The role assigned to the central government must be one of safeguarding the rules of the game. Establishing formal mechanisms of communication and collaboration between state and non-state groups solidifies the structures and empowers both sides. When the state capacity to offer services is weak, the foundation of new reforms is volatile. At the central level, weakness of state authorities embodies the failure of the central government in regulating, guiding and incentivizing local stakeholders to advance local governance. 


\section{References}

Agani, M. (Ed.). (2012). Civil Society in Kosovo since 1999. Prishtina: Centre for Political Courage, University of Prishtina.

Allen, R. and Tommasi D. (2001). Managing Public Expenditure: A Reference Book for Transition Countries. OECD.

Andersson, K. P. and Ostrom, E. (2008). Analyzing Decentralized Resource

Regimes from a Polycentric Perspective. Policy Sciences, 41(1), 71-93.

Andrew, C. and Goldsmith, M. (1998). From Local Government to Local

Governance: And beyond? International Political Science Review 19(2), 101117.

Andrews, M. (2010). Good Government Means Different Things in Different Countries. Governance 23(1), 7-35.

Ashworth, G. J., and Tunbridge, J. E. (1999). Old cities, new pasts: Heritage planning in selected cities of Central Europe. GeoJournal, 49(1), 105-116.

Ashworth, G. J., and Tunbridge, J. E. (2000). The Tourist-Historic City: Retrospect and Prospect of Managing the Heritage City. Routledge.

Bache, I. and Matthew V. Flinders. (Eds.) (2004). Multi-level Governance. Oxford: Oxford University Press.

Baillie, B. (2012). Divided Memory: The Reification of Ethnicity in Post-conflict Vukovar. Cultural Heritage in Postwar Recovery (25). Divided Cities/Contested States Working Paper Series.

Bartlett, W., Mileković, S. and Monastiriotis, V. (2013). Decentralization Paradigms in South East Europe: An Introduction. In W. Bartlett, S. Mileković \& V. Monastiriotis, (Eds.). Decentralization and Local Development in SEE: Studies in Economic Transition (pp. 3-28). Basingstoke: Palgrave Macmillan. 3-28.

Baskin, M. (2004). Developing local democracy in Kosovo. Stockholm: International IDEA.

Bennett, A. (2008). Building Communities, Bridging Gaps: Alexander George's Contributions to Research Methods. Political Psychology 29(4), 489-507. 
Beukenholdt-ter Mors, T., \& Noppe, P. (2000). Sweden: Deepening Democracy. In H. Daemen \& L. Schaap (Eds.), Citizen and City: Developments in fifteen local democracies in Europe (pp. 37 - 57). Rotterdam: Center for Local Democracy (CLD).

Bevir, M. (2010). Democratic Governance. Princeton, N.J.: Princeton University Press.

Bevir, M. (2011). Governance as Theory, Practice, and Dilemma. In M. Bevir (Ed.), The Sage Handbook of Governance (pp. 1-16). Thousand Oaks, CA: Sage Publications.

Bevir, M. (2009). Key concepts in governance. Sage Publications.

Bevir, Mark, and R. A. W. Rhodes. (2003). Interpreting British governance. Routledge.

Bieber, F. (2004a). Institutionalizing ethnicity in the western Balkans: managing change in deeply divided societies. European Center for Minority Issues.

Bieber, F. (2004b). Power Sharing as Ethnic Representation in Postconflict Societies: The Cases of Bosnia, Macedonia, and Kosovo. In A. Mungiu-Pippidi \& I. Krastev (Eds.), Nationalism after Communism: Lessons Learned (pp. 231-48). Budapest/New York: Central European University Press.

Bieber, F. (2010). Power sharing after Yugoslavia. Functionality and Dysfunctionality of Power Sharing Institutions Post-war Bosnia, Macedonia and Kosovo. In From Power Sharing to Democracy Post-Conflict Institutions in Ethnically Divided Societies (pp. 85-103). Montreal/Ontario: McGill/Queens University Press.

Bieber, F. (2012). Reconceptualizing the Study of Power-Sharing. Sudosteuropa 60 (4): 526-535.

Bieber, F., \& Sokolovic, D. (2001). Reconstructing multiethnic societies: the case of Bosnia-Herzegovina. Ashgate.

Binder, J. K., Slits, P., Stoquart, R., Mullen, J., \& Schubert, C. B. (2008). Towards an EU approach to democratic local governance, deentralization and territorial development: Background paper (No. 2007/147439). European Commission.

Bland, G. (2011). Considering Local Democratic Transition in Latin America. Journal of Politics in Latin America, 3(2), 65-98.

Bliesemann de Guevara, B. (2010). Introduction: The Limits of Statebuilding and the Analysis of State-Formation. Journal of Intervention and Statebuilding $4(2), 111-128$.

Bovens, M. (2005). The Concept of Public Accountability. The Oxford handbook of public management, 182. 
Börzel, T. (2005). Conceptualizing New Modes of Governance in EU Enlargement.

Brussels: NewGov - New Modes of Governance Project. (Accessed June 17, 2011) http://www.eu-

newgov.org/database/DELIV/D12D01_Conceptualizing_NMG_in_EUEnlargement.PDF.

Börzel, T. (2007). European Governance - Negotiation and Competition in the Shadow of Hierarchy. In UNSPECIFIED, Montreal, Canada.

Börzel, T. (2009). Coping with accession to the European Union: new modes of environmental governance. Basingstoke: Palgrave Macmillan.

Börzel, T. (2009, April 16). The EU Promotion of Good Governance in Areas of Limited Statehood. In ERD Workshop Transforming Political Structures: Security, Institutions, and Regional Integration Mechanisms. Florence: European University Institute. Retrieved from:

http://erd.eui.eu/media/borzel.pdf.

Börzel, T. (2010). Governance with/out Government: False Promises or Flawed Premises? In Berlin: Kolleg-Forschergruppe (KFG), The Transformative Power of Europe. Freie Universität Berlin.

Börzel, T. (2010). The Transformative Power of Europe Reloaded. The Limits of External Europeanization (No. 11). Berlin: Kolleg-Forschergruppe (KFG) „The Transformative Power of Europe“, Freie Universität Berlin. Retrieved from http://www.polsoz.fuberlin.de/en/v/transformeurope/publications/working_paper/WP_11_Febr uary_Boerzel1.pdf

Börzel, T. (2011). When Europeanisation Hits Limited Statehood: The Western Balkans as a Test Case for the Transformative Power of Europe. Berlin: KollegForschergruppe (KFG) The Transformative Power of Europe. Freie Universität Berlin. Retrieved from: http://www.polsoz.fuberlin.de/en/v/transformeurope/publications/working_paper/WP_11_Febr uary_Boerzel1.pdf.

Börzel, T., and K. Heard-Lauréote. (2009). Networks in EU Multi-level Governance: Concepts and Contributions. Journal of Public Policy 29(02), 135-151.

Börzel, T., and T. Risse. (2010). Governance without a state: Can it work? Regulation \& Governance 4(2), 113-134.

Börzel, T., and T. Risse. (2000). When Europe Hits Home: Europeanisation and Domestic Change. European Integration Online Papers http://eiop.or.at/eiop/pdf/2000-015.pdf (Accessed June 17, 2011). 
Braithwaite, J. (1999). Accountability and governance under the new regulatory state. Australian journal of public administration, 58(1), 90-94.

Brancati D. (2006). Decentralization: Fueling the fire or dampening the flames of ethnic conflict and secessionism? International Organization 60(03): 651-685.

Brinkerhoff, D. W., and J. B. Mayfield. (2005). Democratic governance in Iraq? Progress and peril in reforming state-society relations. Public Administration and Development 25(1), 59-73.

Brinkerhoff, D. W. (2005). Rebuilding Governance in Failed State and Post-Conflict Societies: Core Concepts and Cross-Cutting Themes. Public Administration and Development, 25(1), 3-14.

British Council. (n.d.). Active Citizens: Globally Connected Locally Engaged. Retrieved from http://activecitizens.britishcouncil.org/

Brown, K. (2009). Do We Know How Yet? Insider Perspectives on International Democracy Promotion in The Western Balkans. Seattle: The National Council for Eurasian and East European Research. Retrieved from http://www.ucis.pitt.edu/nceeer/2009_822-02g_Brown.pdf

Bryman, A. (2008). Social Research Methods. Oxford University Press, Incorporated.

Bunce, V. (2004). Is Ethnofederalism the Solution or the Problem? In A. MungiuPippidi \& I. Krastev (Eds.), Nationalism after Communism: Lessons Learned (pp. 179-97). Budapest/New York: Central European University Press.

Burema, L. (2013). Decentralization in Kosovo: Defusing Ethnic Tensions or Furthering Ethnic Isolation? In W. Bartlett, S. Malekovic, \& V. Monastiriotis (Eds.), Decentralization and Local Development in South East Europe (pp. 100 - 117). Basingstoke: Palgrave Macmillan.

B92 News. (January 13th, 2014). "North K. Mitrovica Mayor refuses to verify mandate". Retrieved from:

http://www.b92.net/eng/news/politics.php?yyyy=2014\&mm=01\&dd=13\&n av_id=88950.

Calame, J., \& Charlesworth, E. R. (2009). Divided Cities: Belfast, Beirut, Jerusalem, Mostar, and Nicosia. University of Pennsylvania Press.

Caplan, R. (2002). A new trusteeship? The international administration of war-torn territories. Oxford: Oxford University Press.

Caplan, R. (2004). International Authority and State Building: The Case of Bosnia and Herzegovina. Global Governance 10(1), 53-66. 
Carothers, T. (1999). Aiding democracy abroad: the learning curve. Carnegie Endowment.

Chandler, D. C. (2006). Empire in denial: the politics of state-building. London: Pluto.

Chesterman, S. (2004). You, the people: the United Nations, transitional administration, and state-building. Oxford: Oxford University Press.

Chesterman, S., M. Ignatieff, and R. C. Thakur. (2005). Making states work: state failure and the crisis of governance. Tokyo: United Nations University Press.

Chopra, J. (2002). Building State Failure in East Timor. Development and Change, 33(5), 979-1000.

Chopra, J., and T. Hohe. (2004). Participatory Intervention. Global Governance 10(3), 289-306.

CHwB. (2011). Conservation and Development Plan for the Historic Zone of Prizren: Advantages and Challenges of Implementation. Prishtina: Cultural Heritage without Borders.

Cisar, O. and J. Navratil (2011). Transaction Politics: Networks of Czech Social Movement Organisations Twenty Years after Communism. Unpublished manuscript.

Clark, H. (2000). Civil Resistance in Kosovo. London: Pluto Press.

Council of Europe. (2005). Framework Convention on the Value of Cultural Heritage. Faro: Council of Europe for Society. Retrieved from:

http://conventions.coe.int/Treaty/en/Treaties/Html/199.htm.

CoEDM. (2003). Council of Europe decentralization mission in Kosovo (CoEDM) - Final Report. Brussels: Council of Europe.

CoR, (2009). The White Paper on multi-level governance. EU Committee of the Regions. Brussels: Council of Europe.

Crook, R. C., \& Manor, J. (1998). Democracy and decentralisation in South Asia and West Africa: Participation, accountability and performance. Cambridge University Press.

Crook, R., \& Manor, J. (2000). Democratic Decentralization (OEC Working Paper Series No. 11). Washington DC: The World Bank.

Dalton, R. J., Scarrow, S. E., \& Cain, B. E. (2003). Democracy Transformed?: Expanding Political Opportunities in Advanced Industrial Democracies. Oxford University Press. 
Daoudy, Marwa. 2009. State-building. In V. Chetail (Ed.). Post-conflict peacebuilding: A lexicon. Oxford: Oxford University Press.

Denters, B. and L. Rose (2005). Comparing Local Governance: Trends and Developments. London: Palgrave.

Della Porta, D. and M. Diani. (2006). Social Movements: An Introduction. Oxford: Blackwell.

Dezséri, K., and K. Vida. (2008). Multi-Level Governance - The Eastern Versions. NewGov - New Modes of Governance Project. Policy Brief. Retrieved from http://www. eu-newgov. org/database/PUBLIC/Policy_Briefs/NEWGOV_ Policy_Brief_no17. pdf.

Diamond, L. (2005). Lessons from Iraq. Journal of Democracy 16(1), 9-23.

Doornbos, M. (2001). 'Good Governance': The Rise and Decline of a Policy Metaphor?. Journal of Development Studies 37(6), 93-108.

Doornbos, M. (2003) "'Good Governance": The Metamorphosis of a Policy Metaphor'. Journal of International Affairs 57(1), 3-17.

Doornbos, M. (2010) 'Failing States or Failing Models?: Accounting for the Incidence of State Collapse.' Technology Governance. Working Papers in Technology Governance and Economic Dynamics 27. Tallin: Tallin University of Technology.

Doyle, M. W., and Sambanis, N. (2000). International peacebuilding: A theoretical and quantitative analysis. The American Political Science Review 94(4), 779801.

Doyle, M. W., and Sambanis, N. (2006). Making War and Building Peace: United Nations Peace Operations. Princeton University Press.

Duncan, C. (2007). Mixed outcomes: The impact of regional autonomy and decentralization on indigenous ethnic minorities in Indonesia. Development and Change 38(4): 711-733.

Dumper, M., \& Larkin, C. (2012). The politics of heritage and the limitations of international agency in contested cities: a study of the role of UNESCO in Jerusalem's Old City. Review of International Studies, 38(01), 25-52.

Dzihic, V. (2007). Prospects for the Europeanisation of State-Building Efforts in Kosovo and Bosnia. Foreign Policy in Dialogue, 8(23), 25.

Džihić, V., \& Segert, D. (2012). Lessons from "Post-Yugoslav" Democratization Functional Problems of Stateness and the Limits of Democracy. East European Politics \& Societies, 26(2), 239-253. 
Eagleton-Pierce, M. (2010). On the Genesis of the Concept of 'Governance': A postbureaucratic perspective. British International Studies Association (45). http://www.bisa-ipeg.org/papers/46_eagleton_pierce.pdf (Accessed September 16, 2011).

Easterly, W. (2008). Institutions: Top-Down or Bottom-Up? American Economic Review. 98(2): 95-99.

Ebel, R. D., \& Péteri, G. (2007). The Kosovo Decentralization Briefing Book. Kosovo Foundation for Open Society.

ECA. (2012). European Union Assistance to Kosovo related to the Rule of Law (Special Report No. 18/2012). Luxembourg: European Court of Auditors. Retrieved from http://eca.europa.eu/portal/pls/portal/docs/1/17766744.PDF

Elbasani, A. (Ed.). (2012). European Integration and Transformation in the Western Balkans: Europeanization or Busines as Usual? London: Routlege.

Enroth, H. (2011). Democratic Governance - By Mark Bevir. Governance 24(2), 395398.

Eriksen, S. (2007). Institution building in Central and Eastern Europe: Foreign influences and domestic responses. Review of Central and East European Law 32(3), 333-369.

European Commission. (2001). European Governance: A White Paper (No. COM(2001) 428). Brussels: European Commission.

European Commission. (2011). Kosovo (under UNHCR 1244) 2011 Progress Report (SEC(2011) No. 1207). Brussels: European Commission. Retrieved from http://ec.europa.eu/enlargement/pdf/key_documents/2011/ks_rapport_201 1_en.pdf

European Commission. (2012a). 2012 Annual Programme: Improvement of social services, labour conditions and social dialogue (No. 02-2012/01). Brussels: European Commission. Retrieved from http://ec.europa.eu/enlargement/pdf/kosovo/ipa/2012/ipa_2012_pf2_social _development_final.pdf

European Commission. (2012b). Kosovo Analytical Report 2012 (SWD (2012) 339).

Brussels: European Commission. Retrieved from

http://ec.europa.eu/enlargement/pdf/key_documents/2012/package/ks_ana lytical_2012_en.pdf

European Council of Ministers. (2006). The EU Approach to Democracy Promotion in External Relations: Food for Thought. Retrieved from http://www.democracyassistance.eu 
Evans, P. B., Rueschemeyer, D., \& Skocpol, T. (Eds.). (1985). Bringing the state back in (Vol. 3). Cambridge: Cambridge University Press.

Fagan, A. (2005a). Taking stock of civil-society development in post-communist Europe: Evidence from the Czech Republic. Democratization, 12(4), 528-547.

Fagan, A. (2005b). Civil society in Bosnia ten years after Dayton. International Peacekeeping 12(3), 406-419.

Fagan, A. (2008). Global-Local Linkage in the Western Balkans: The Politics of Environmental Capacity Building in Bosnia-Herzegovina. Political Studies $56(3), 629-652$.

Fagan, A. (2010). Europe's Balkan Dilemma: Path's to civil society or statebuilding. London: I.B.Tauris.

Fagan, A. (2011). EU assistance for civil society in Kosovo: a step too far for democracy promotion? Democratization 18(3), 707-730.

FES. (2011). Raporti i Progresit: Made in Kosova (Progress Report: Made in Kosova).

Friedrich Ebert Stiftung, Prishtina. Retrieved from: http://www.fesprishtina.org/wb/media/Publications/2011/Made\%20in\%20Kosovo\%202011 \%20\%28Shqip\%29.pdf

Finkel, S. E., Pérez-Liñán, A., Seligson, M., \& Tate, C. N. (2008). Deepening Our Understanding of the Effects of US Foreign Assistance on Democracy Building. Final Report. Nashville: Vanderbilt University.

Fortna, V. P. (2004). Does peacekeeping keep peace? International intervention and the duration of peace after civil war. International Studies Quarterly 48(2), 269-292.

Fukuyama, F. (2004). State-building: governance and world order in the 21st century. London: Cornell University Press.

Forum 2015. (2004). Kosova Five Years Later: What is the Agenda for the Future? Prishtina: Kosovo Foundation for Open Society.

Forum 2015. (2012). Environmental Mosaic - 4 Case Studies Challenge the Governance! Prishtina: Kosovo Foundation for Open Society.

FRIDOM. (2010). Functional Review of Institutional design of Ministries in Kosovo. Prishtina: DFID.

Fung, A. (2006). Varieties of participation in complex governance. Public Administration Review, 66(s1), 66-75. 
GAP. (2013). Si i shpenzon shteti paret tona? (How the state spends our money?). GAP Institute. Retrieved May 1, 2013, from http://www.institutigap.org/spendings/?prishtine/2013\#/ /prishtine/subve ncionet-dhe-transferet/kultura--rinia-dhe-sportet

GAP Institute. (2010). Rule 61 (Policy Brief). Prishtina: GAP Institute. Retrieved from http://institutigap.org/repository/docs/Rule_61.pdf

George, A. L. and Bennett, A. (2004). Case Studies and Theory Development in Social Sciences. Cambridge: MIT Press.

Geurtz, C., \& Van de wijdeven, T. (2010). Making Citizen Participation Work: The Challenging Search for New Forms of Local Democracy in The Netherlands. Local Government Studies, 36(4), 531-549. doi:10.1080/03003930.2010.494110

Ghani, A., and C. Lockhart. (2008). Fixing failed states: a framework for rebuilding a fractured world. Oxford University Press.

Gibson, J., and Hanson, P. (1996). Decentralization and Change in Post-Communist Systems. In J. Gibson \& P. Hanson (Eds.), Transformation from Below: Local Power and the Political Economy of Post-Communist Transitions (pp. 303-313). Cheltenham: Edward Elgar Publishing.

Gjoni, R., Wetterberg, A., \& Dunbar, D. (2010). Decentralization as a conflict transformation tool: The challenge in Kosovo. Public Administration and Development, 30(5), 291-312.

Goetz, K. H. (2008). Governance as a Path to Government. West European Politics 31(1), 258-279.

Goetz, K. H. (2006). Territory, Temporality and Clustered Europeanisation. Annual State of the Art Paper, WP II/III, Team 5, Deliverable 15. Retrieved from http://www.ihs.ac.at/publications/pol/pw_109.pdf.

Goodwyn, J. and J. M. Jasper. (2003). The Social Movements Reader: Cases and Concepts. Oxford: Blackwell.

Green, A.T. (21 February 2007). Democracy and Donor Funding: Patterns and Trends. Paper presented at the EES Noon Discussion, Woodrow Wilson Center for International Scholars, Washington,DC, http://www.dgmetrics.com/docs/ParsingDonorFunding.pdf (Accessed September 5, 2011).

Grindle, M. S. (2004). Good enough governance: poverty reduction and reform in developing countries. Governance 17(4), 525-548. 
Grindle, M. S. (2007). Good enough governance revisited. Development policy review, 25(5), 533-574.

Grzegorz Grosse, T. \& Kolarska-Babińska, L. (2008). New Modes of Governance in

New Member States. New Modes of Governance Project. Policy Brief Nr. 25.

Retrieved from http://www.eu-

newgov.org/database/PUBLIC/Policy_Briefs/NEWGOV_Policy_Brief_no25 .pdf.

de Guevara, B. (2004). External State-Building in Bosnia and Herzegovina. A Boost for the (Re-) Institutionalisation of the State or a Catalyst for the Establishment of Parallel Structures?. Seventh International Seminar Democracy and Human Rights in Multiethnic Societies, Institute for Strengthening Democracy, Konjic, Bosnia and Herzegovina.

Hadiz, V. R. (2007). The Localization of Power in Southeast Asia. Democratization, 14(5), 873-892.

Hajnal, G., \& Péteri, G. (2010). Local reform in Kosovo: Final Report. Prishtina: Forum 2015.

Hammond, A. (2005). The danger zone of Europe" Balkanism between the Cold War and 9/11. European Journal of Cultural Studies, 8(2), 135-154.

Harvey, D., \& Braun, B. (1996). Justice, nature and the geography of difference. Wiley Blackwell.

Héritier, A., and D. Lehmkuhl. (2011). New Modes of Governance and Democratic Accountability. Government and Opposition 46(1), 126-144.

Hohe, T. (2002). The Clash of Paradigms: International administration and local political legitimacy in East Timor. Contemporary Southeast Asia, 24(3), 569590.

Hooghe, L., and G. Marks. (2003). Unraveling the Central State, but How? Types of Multi-Level Governance. The American Political Science Review 97(2), 233243.

Hooghe, L., and G. Marks. (2001). Multi-level Governance and European Integration. Rowman \& Littlefield.

Hoxha, G. (2008). Kosovo. In Robert Pickard (Ed.), Analysis and Reform of Cultural Heritage Policies in South-East Europe. Strasbourg: Council of Europe.

Hyden, G. (1999). Governance and the Reconstitution of Political Order. In R. Joseph (Ed.). State, Conflict, and Democracy in Africa, Boulder: Lynne Rienner. 
ICO. (2011). Implementation of Special Protective Zones for Religious and Cultural Heritage in Kosovo: Progress Report. Prishtina: ICO. Retrieved from http://www.ico-kos.org/data/Image/SPZ_Progress_Report_Final_EV.pdf

Ignatieff, M. (2003). Empire Lite: Nation-building in Bosnia, Kosovo and Afghanistan. London: Minerva.

IMF (2010) TEC Kosovo RC3: Request for TA in Fiscal Decentralization EP 1011. International Monetary Fund.

Irvin, R. A., \& Stansbury, J. (2004). Citizen Participation in Decision Making: Is It Worth the Effort? Public Administration Review, 64(1), 55-65.

Jackson, P., \& Scott, Z. (2007). Local Government in Post Conflict Environments. Oslo: UNDP Commissioned Paper. Oslo Governance Center.

Jacoby, W. (2006). Inspiration, Coalition, and Substitution: External Influences on Postcommunist Transformations. World Politics 58(04), 623-651.

Jamal, M. A. (2012). Democracy Promotion, Civil Society Building and the Primacy of Politics. Comparative Political Studies 45(1), 3-31.

Jarstad, A. K., \& Sisk, T. D. (Eds.). (2008). From War to Democracy: Dilemmas of Peacebuilding. Cambridge: Cambridge University Press.

Jessop, B. (2001). Bringing the State Back In (Yet Again): Reviews, Revisions, Rejections, and Redirections. International Review of Sociology: Revue Internationale de Sociologie 11(2), 149-153.

Jessop, B. (2002). Governance, Governance Failure, and Meta-Governance. In Heinelt, H. (Ed.), Participatory Governance in Multi-Level Context: Concepts and Experience. (pp. 33-58). Opladen: Leske and Budrich.

Jessop, B. (2004). Multi-level Governance and Multi-level Metagovernance: Changes in the European Union as Integral Moments in the Transformation and Reorientation of Contemporary Statehood. In I. Bache and M. Flanders (Eds.). Multi-level Governance. Oxford: Oxford University Press.

Jones, S. (2006). Making place, resisting displacement. Conflicting national and local identities in Scotland. In Littler J. and Naidoo R. (Eds.). The politics of heritages, the legacies of race. (pp. 94 - 114). London: Routlege.

Joshua, L., \& Dzhygyr, Y. (2011). Efficient Allocation of Resources for Decentralized Provision of Social Services in Kosovo. Department for International Development DfID/UKaid. 
Jović, D. (2001), The Disintegration of Yugoslavia: A Critical Review of

Explanatory Approaches. European Journal of Social Theory 4(1), 101 - 120.

Kaufman, D., Kraay, A. and Zoido-Lobatón, P. (2000). Governance Matters: From Measurement to Action. Finance and Development 37(2), 10-13.

Kaufmann, D., Kraay, A. and Mastruzzi, M. (2005). Measuring governance using cross-country perceptions data. MPRA Paper 8219, Munich: University Library of Munich.

Kaufmann, D., Kraay, A. and Mastruzzi, M. (2009). Governance Matters VIII: Aggregate and Individual Governance Indicators 1996-2008. Technical report. Washington DC: World Bank.

KDI. (2009). Raporti në mes të agjencioneve të pavarura dhe kuvendit të Republikës së Kosovës. Prishtina: Kosova Democratic Institute. Retrieved from http://www.kdi-kosova.org/download/permbledhje.pdf.

KDI. (2009). Decentralizimi në Kosovë: Përvojat nga komunat e rajonit të Prizrenit.

Prishtina: Kosova Democratic Institute. Retrieved from http://www.kdikosova.org/publications/decentralizimi.pdf

KIPRED. (2004). Local Government and Administration in Kosovo (Policy Research Series No. 4). Prishtinë: KIPRED.

KIPRED. (2009a). Decentralization in Kosovo II: Challenges of Serb majority municipalities (Policy Brief No. 16). Prishtinë: KIPRED.

KIPRED. (2009b). Kosovo at a crossroad: Decentralization and the creation of new municipalities (Policy Brief No. 14). Prishtinë: KIPRED.

KIPRED. (2011). Menaxhimi publik: Analizë e bordeve të ndërmarrjeve publike dhe agjencive të pavarura (No. 2011/6). Prishtinë: KIPRED.

KIPRED. (2012). Vizioni gjithëpërfshirës për Veriun: Mundësia e fundit (No. 2012/02). Prishtinë: KIPRED.

KLGI. (2010). Decentralizimi dhe Reforma e Qeverisjes Lokale: I qartë në letër i turbullt në praktikë. Rasti i Kosovës. Prishtinë: Friedrich Ebert Stiftung.

KLGI. (2011). Decentralization: A heavy weight to be carried out. Struggling to move from consolidation of local democracy to better service delivery. Prishtinë: Friedrich Ebert Stiftung.

Kosovo Assembly. (2007, April 3). Procesverbal i mbledhjes së Komisionit për Arsim, Shkencë, Teknologji, Kulture, Rini e Sport mbajtur më 03.04.2007. Kosovo Assembly. Retrieved from http://www.assemblykosova.org/common/docs/proc/proc_2007_04_03_al.pdf. 
Kosovo Assembly. (2012, April 20). Transkript i mbledhjes plenare të Kuvendit të Republikës së Kosovës mbajtur më 20.04.2012. Kosovo Assembly. Retrieved from http://www.assemblykosova.org/common/docs/proc/trans_s_2012_04_20_10_4169_al.pdf.

Kostovicova, D. (2005). Kosovo: the politics of identity and space. Routledge.

Kostovicova, D. (2008). Legitimacy and International Administration: The Ahtisaari Settlement for Kosovo from a Human Security Perspective. International Peacekeeping 15(5), 631-649.

Krasner, S. D. (1984). Approaches to the State: Alternative Conceptions and Historical Dynamics. Comparative Politics 16 (January), 223-246.

Krasner, S. D. (2005). The Case for Shared Sovereignty. Journal of Democracy 16(1), 69-83.

Krastev, I. (2003). Bringing the State Up. International Conference: Interethnic Relations in the Western Balkans: Problems, Instruments and Prospects for the Future. Suedosteuropa Gessellschaft., Berlin. Retrieved from: http://www.suedosteuropa-gesellschaft.com/pdf-berlin/krastev.pdf.

Križan, M. (1989). Of "Civil Society" and Socialism in Yugoslavia. Studies in Soviet Thought, 37(4), 287-306.

KSA. (2013a). Estimation of Kosovo population 2011. Prishtina: Kosovo Statistics Agency. Retrieved from http://esk.rksgov.net/eng/images/files/ESTIMATION\%20of\%20Kosovo\%20population\% 202011.pdf.

KSA. (2013b). Kosovo Census Atlas. Prishtina: Kosovo Statistics Agency. Retrieved from http://esk.rks-gov.net/publikimet/cat_view/8popullsia?orderby=dmdate_published.

KSA. (2012). Rezultatet e anketes se fuqise punetore 2012 ne Kosove (2012 Results of the Labor Force Survey in Kosovo). Prishtina: Kosovo Statistics Agency. Retrieved from: http://esk.rks-gov.net/publikimet/cat_view/16-tregu-ipunes?orderby=dmdate_published.

Lecours, A., and G. Nootens. (2009). Dominant nationalism, dominant ethnicity: identity, federalism, and democracy. Peter Lang Pub Inc.

Lehne, Stefan. (2013). Kosovo and Serbia: Toward a Normal Relationship. Carnegie Policy Outlook. Retrieved from http://carnegieendowment.org/2012/03/13/kosovo-and-serbia-towardnormal-relationship/a2do?reloadFlag=1. 
Levi-Faur, D. (2012). From 'Big Government' to 'Big Governance'. In D. Levi-Faur (Ed.). The Oxford Handbook of Governance. (pp. 3-18). Oxford: Oxford University Press.

Linz, J., \& Stepan, A. (1996). Problems of Democratic Transition and Consolidation: Southern Europe, South America, and Post-Communist Europe. Baltimore: Johns Hopkins University Press.

Lister, S., and A. Wilder. (2005). Strengthening subnational administration in Afghanistan: technical reform or state-building? Public Administration and Development 25(1), 39-48.

Lister, S. (2009). Changing the Rules? State-Building and Local Government in Afghanistan. Journal of Development Studies 45(6), 990-1009.

Lynn, Jr., L. E. (2010). Governance. Public Administration Review Foundations of Public Administration Series. Retrieved from: http://www.aspanet.org/public/ASPADocs/PAR/FPA/FPA-GOVArticle.pdf.

Lynn, L. E. (2010). Has governance eclipsed government? In R. F. Durant (Ed.). The Oxford Handbook of American Bureaucracy. (pp. 669 - 690). New York: Oxford University Press.

Malcolm, N. (1998). Kosovo: A Short History. London: Macmillan.

Mani, R., and J. Krause. (2009). Democratic Governance. In V. Chetail. (Ed.). Postconflict Peacebuilding: A Lexicon. Oxford: Oxford University Press.

Manning, C. (2003). Local level challenges to post-conflict peacebuilding. International peacekeeping, 10(3), 25-43.

Manning, C. (2007). Party Building on the Heels of War: El Salvador, Bosnia, Kosovo and Mozambique. Democratization 14(2): 253-272.

Marcou, G. (2007). Legal Framework and the European Charter of Local SelfGovernment. In Ebel, R. D., and Péteri, G. (Eds.). (2007). The Kosovo Decentralization Briefing Book (pp. 49-58). Kosovo Foundation for Open Society.

Marks, G. and L. Hooghe. (2004). Contrasting Visions of Multi-Level Governance." In I. Bache and M. V. Flinders. (Eds.). Multi-level Governance. (pp. 15-30). Oxford: Oxford University Press.

Maxhuni, A., Ukimeraj, R., Vasolli, B., Ujkani, E., \& Osmani, A. (2009). Organization and function of local government in Kosovo (1999 - 2009). Prishtina: MLGA; AKM. 
Mayntz, R. (2004). Governance im modernen Staat. In A. Benz (Ed.). Governance. Regieren in komplexen Regelsystemen. (pp. 65 - 76). Wiesbaden: VS Verlag fuer Sozialwissenschaft.

MCCCF. (2007). The protection of Québec's heritage: The Cultural Property Act. Québec: Ministère de la culture, des communications et de la condition féminine.

Mckenna, D. (2011). UK Local Government and Public Participation: Using Conjectures to Explain the Relationship. Public Administration, 89(3), 11821200.

Michels, A., \& De Graaf, L. (2010). Examining Citizen Participation: Local Participatory Policy Making and Democracy. Local Government Studies, 36(4), 477-491.

MLSW. (2011). Sectoral Strategy Action Plan 2011 - 2012/13. Prishtina: Ministry of Labour and Social Welfare. Retrieved from http://mpms.rksgov.net/Portals/0/Aktiviteti\%20javor/Plani\%20Aksional\%20Strategjise\%20 Sektoriale\%202011-2013\%20Anglisht.pdf

Montero, A. P., and Samuels, D. (2004). Decentralization and democracy in Latin America. Notre Dame: University of Notre Dame Press.

Monteux, C. A. (2006). Decentralization: The New Delusion of Ethnic Conflict Regulation? International Journal on Multicultural Societies, 8(2), 162-182.

Mulaj, I. (2009). Self-management Socialism Compared to Social Market Economy in Transition: Are there Convergent Paths?. OrdnungsPolitisches Portal (OPO) Discourses in Social Market Economy. Diskurs 2009 (8). Retrieved from http://www.ordnungspolitisches-portal.com/Diskurse/Diskurse_200908.pdf

Musi, M. (2012). The international heritage doctrine and the management of heritage in Sarajevo, Bosnia and Herzegovina: the case of the Commission to Preserve National Monuments. International Journal of Heritage Studies, 118. doi:10.1080/13527258.2012.709191

n.n. (2012, June 29). Kuvendi miratoi Planin Lokal të Veprimit në Mjedis (Municipality adopted Local Environment Action Plan). Komuna e Podujevës. Retrieved from http://kk.rks-gov.net/podujeve/News/Kuvendimiratoi-Planin-Lokal-te-Veprimit-ne-Mjedis.aspx

Narten, J. (2008). Post-Conflict Peacebuilding and Local Ownership: Dynamics of External-Local Interaction in Kosovo under United Nations Administration. Journal of Intervention and Statebuilding, 2(3), 369-390. 
Narten, J. (2009). Dilemmas of Promoting Local Ownership: The Case of Postwar Kosovo. In R. Paris and T. D. Sisk. (Eds.). The Dilemmas of Statebuilding: Confronting the Contradictions of Postwar Peace Operations. (pp. 252-283). New York, NY.: Routlege.

Narten, J., \& Zuercher, C. (2009). Peacebuilding is Interaction: Explaining the Outcomes of Postwar Democratic Transitions. In APSA Annual Meeting Toronto (pp. 3-6).

Newman, J. (2005). Participative governance and the remaking of the public sphere. In J. Newman (Ed.), Remaking Governance: Peoples, Politics And the Public Sphere. The Policy Press.

OECD. (2001). Citizens as Partners: OECD Handbook on Information, Consultation and Public Participation in Policy- Making. Paris: Organisation for Economic CoOperation and Development (OECD).

OPM. (2008). Strategy and Action Plan on Human Rights of Republic of Kosovo 2009 2011. Prishtina: Office of the Prime Minister. Retrieved from http://www.kryeministriks.net/zck/repository/docs/Human_Rights_Strategy.pdf

OPM. (2009). National Disability Action Plan for the Republic of Kosovo 2009 - 2011.

Prishtina: Office of the Prime Minister. Retrieved from http://www.cooperazioneallosviluppo.esteri.it/pdgcs/download/Kosovo_P lan.pdf

OPM. (2011a). Broad Survey of Persons with Disabilities in Kosovo. Prishtina: Office of the Prime Minister. Retrieved from http://www.kosovo.undp.org/repository/docs/2011/PWD_English.pdf

OPM. (2011b). Programi i qeverisë së Republikës së Kosovës 2011 - 2014 (Government Program of the Republic of Kosovo 2011 - 2014). Prishtina: Office of the Prime Minister. Retrieved from http://www.kryeministriks.net/repository/docs/Programi_i_Qeverise_shqip_.pdf

OPM. (2013). Vendimi për ndryshimin e ligjit për kufinjtë e komunave (Decision on Amendments to the Law on Municipal Borders). Prishtina: Office of the Prime Minister. Retrieved from http://www.kryeministriks.net/repository/docs/Vendimet_e_mbledhjes_se_132te_te_Qeverise_2013.pdf (15 August 2013).

Osborne, S. P. (Ed.). (2010). The new public governance?: emerging perspectives on the theory and practice of public governance. New York: Routlege. 
OSCE. (2008). Relationship between Central and Local Authorities in Kosovo. Legal, Administrative and Fiscal Aspects. Prishtina: OSCE Kosovo.

OSCE. (2010). Community Rights Assessment Report Second Edition. Prishtina: OSCE Kosovo.

OSCE. (2012). Community Rights Assessment Report Third Edition. Prishtina: OSCE Kosovo.

OSCE. (2013). OSCE successfully concludes election facilitation in four northern Kosovo municipalities. Press Release. Retrieved from: http://www.osce.org/kosovo/109098.

Ottaway, Marina. (2002). Nation Building. Foreign Policy (132), 16-24.

Ottaway, M., \& Carothers, T. (2000). Funding virtue: civil society aid and democracy promotion. Carnegie Endowment.

Palairet, M. (2007). The Inter-Regional Struggle for Resources and the fall of Yugoslavia. In Cohen, L. and Dragović-Soso, J. (Eds.). State Collapse in South-Eastern Europe: New Perspectives on Yugoslavia's Disintegration. West Lafayette: Purdue University Press.

Papadimitriou, D., Petrov, P., and Greicevci, L. (2007). To build a state: Europeanization, EU actorness and state-building in Kosovo. European Foreign Affairs Review, 12, 219.

Papadimitriou, D., \& Petrov, P. (2012). State-building without Recognition: A Critical Retrospective of the European Union's Strategy in Kosovo (19992010). In A. Elbasani (Ed.). European Integration and Transformation in the Western Balkans: Europeanization or Business as Usual? London: Routlege.

Papadopoulos, Y. (2007). Problems of democratic accountability in network and multilevel governance. European Law Journal 13(4), 469-486.

Pavlović, M. (2010). Kosovo under Autonomy: 1974 - 1990. In Ingrao, Ch. and Th. A. Emmert (Eds.). Confronting the Yugoslav Controversies: A Scholars' Initiative. (2nd Edition). Purdue University Press, (pp. 49 - 80).

Péteri, G. and Vaillancourt, F. (2007). Local Government in Kosovo. In Ebel, R. D., \& Péteri, G. (2007). The Kosovo Decentralization Briefing Book. Kosovo Foundation for Open Society, (pp. 19 - 32).

Peters, B. Guy, and J. Pierre. (1998). Governance Without Government? Rethinking Public Administration. Journal of Public Administration Research and Theory 8(2), 223 -243. 
Peters, B. Guy, and D. J. Savoie. (2000). Governance in the Twenty-first Century: revitalizing the public service. McGill-Queen's Press.

Petrova, T. (2011). Citizen Participation in Local Governance in Eastern Europe: Rediscovering a Strength of Civil Society in the Post-Socialist World? Europe-Asia Studies, 63(5), 757-787.

Petrova, T. and S. Tarrow. (2007). Transactional and Participatory Activism in the Emerging European Polity: The Puzzle of East Central Europe. Comparative Political Studies 40(1), 74-94.

Pickard, Rob (Ed.). (2008). Analysis and Reform of Cultural Heritage Policies in SouthEast Europe. Strasbourg: Council of Europe.

Pickard, Robert. (2002). A Comparative Review of Policy for the Protection of the Architectural Heritage of Europe. International Journal of Heritage Studies, 8(4), 349-363.

Pickering, P. M. (2006). Generating social capital for bridging ethnic divisions in the Balkans: Case studies of two Bosniak cities. Ethnic and Racial Studies, 29(1), 79-103.

Pickering, P. M. (2007). Peacebuilding in the Balkans: The View from the Ground Floor. Ithaca, N.Y.: Cornell University Press.

Pickering, P. M. (2010). Assessing international aid for local governance in the Western Balkans. Democratization, 17(5), 1024-1049.

Pickering, P. M. (2012). Gauging the Impact of State-Building at the Local Level in the Western Balkans. In S. L. Woodward, D. Kostovicova, \& V. BojicicDzelilovic (Eds.), Research on State-Building in the Western Balkans: Comparative Methodologies (pp. 565-573). Regensburg: Institut für Ost- und Südosteuropaforschung.

Pouligny, B. (2000). Promoting democratic institutions in post-conflict societies: giving diversity a chance. International Peacekeeping 7(3), 17-35.

Pouligny, B. (2005). Civil Society and Post-Conflict Peacebuilding: Ambiguities of International Programmes Aimed at Building 'New' Societies. Security Dialogue 36(4), 447-462.

Pouligny, B. (2009). Local Ownership. In V. Chetail (Ed.). Post-Conflict Peacebuilding: A Lexicon. Oxford: Oxford University Press.

Rhodes, R.A.W. (1997). Understanding governance: policy networks, governance, reflexivity, and accountability. Open University Press, Buckingham/Philadephia. 
Rhodes, R.A.W. (2007). Understanding Governance: Ten Years On. Organisation Studies 28(8), $1243-1264$.

RIINVEST. (2000). Establishment and Functioning of Local Government Institutions in Kosova. Prishtina: RIINVEST Institute for Development Research.

Risley, P., and T. D. Sisk. (2005). Democracy and United Nations Peace-building at the Local Level: Lessons Learned. Policy Options on Democratic Reform. Stockholm: International IDEA.

Risse, Thomas. (2004). Global Governance and Communicative Action. Government and Opposition 39(2), 288-313.

Risse, T. (2012a). Governance in Areas of Limited Statehood. In Levi-Faur, D. (Ed.). The Oxford Dictionary of Governance. Oxford: Oxford University Press.

Risse, T. (2012b). Governance Configurations in Areas of Limited Statehood: Actors, Modes, Institutions and Resources. SFB-Governance Working Paper Series (39).

Risse, T., \& Lehmkuhl, U. (2006). Governance in areas of limited statehood-new modes of governance. Berlin: Kolleg-Forschergruppe (KFG) „The Transformative Power of Europe“, Freie Universität Berlin.

Roders, A. P., \& Oers, R. van. (2011). World Heritage cities management. Facilities, 29(7/8), 276-285.

Rogel, C. (2003). Kosovo: Where it all began. International Journal of Politics, Culture and Society, 17(1), $167-183$.

Rosenau, J. N. (1995). Governance in the Twenty-First Century. Global Governance 1, 13.

Rosenau, J. N., and E. O. Czempiel. (1992). Governance without government: order and change in world politics. Cambridge: Cambridge University Press.

Rothchild, D., and P. G. Roeder. (2005). Dilemmas of state-building in divided societies. In P. G. Roeder and D. Rothchild (Eds.). Sustainable Peace: Power and Democracy after Civil Wars: Volume 15. (pp. 1-25). Ithaca, NY: Cornell University Press.

Rothstein, B. (2011). The Quality of Government: Corruption, Social Trust and Inequality in a Comparative Perspective. Chicago: Chicago University Press.

Rothstein, B. (2012). Good Governance. In D. Levi-Faur (Ed.). The Oxford Handbook of Governance. (pp. 143-154). Oxford: Oxford University Press. 
RROK. (2013, April 22). Reagim në lidhje me emërimin e tre anëtarëve të parë të Këshillit të Trashëgimisë Kulturore. Rrjeti i Organizatave të Kulturës në Prizren.

Scharpf, F. W. (1997). Games real actors play: Actor-centered institutionalism in policy research. Westview Press.

Scharpf, F. W. (2001). European Governance: Common Concerns vs. The Challenge of Diversity. Cologne: Max-Planck-Institut für Gesellschaftsforschung.

Schimmelfennig, F., and H. Scholtz. (2008). EU Democracy Promotion in the European Neighbourhood. European Union Politics 9(2): 187-215.

Sević, Z. (2001). Local government in Yugoslavia. In E. Kandeva (Ed), Stabilisation of Local Governments. Budapest: OSI/Local Government and Public Service Reform Initiative.

Siegle, J., and P. O'Mahony. (2006). Assessing the merits of decentralization as a conflict mitigation strategy. Paper for US Agency for International Development, Office of Democracy and Governance. Bethesda: Development Alternatives, Inc. Retrieved from: www. dai. com/pdf/Decentralization_as_a_Conflict_Mitigation_Strategy. pdf.

Sisk, T.D. (2001). Democracy at the local level: The international IDEA handbook on participation, representation, conflict management, and governance. Stockholm: International IDEA.

Sisk, T. D. and R. Paris. (2007). Managing Contradictions: The Inherent Dilemmas of Postwar Statebuilding. New York: International Peace Academy.

Skelcher, C., \& Torfing, J. (2010). Improving democratic governance through institutional design: Civic participation and democratic ownership in Europe. Regulation \& Governance, 4(1), 71-91.

Smith, B. C. (2007). Good Governance and Development. New York: Palgrave Macmillan.

Soifer, H. (2008). State infrastructural power: Approaches to conceptualization and measurement. Studies on Comparative International Development 43(3-4), 231251.

Sørensen, Eva. (2006). Metagovernance. The American Review of Public Administration 36(1), 98 -114.

Sörensen, J. S. (2009). State collapse and reconstruction in the periphery: Political Economy, Ethnicity and Development in Yugoslavia, Serbia and Kosovo. Berghahn Books. 
Sterland, B. (2006). Civil Society Capacity Building in Post-Conflict Societies: The Experience of Bosnia and Herzegovina and Kosovo (Praxis Paper \# 9). Oxford: INTRAC.

Stoker, G. (1998). Governance as theory: five propositions. International social science journal, 50(155), 17-28.

Stoker, G. (2004). Review Essay: Governing as Governance by Jan Koiman. International Public Management Journal 7(3), 439 - 442.

Stroschein, S. (2008). Making or breaking Kosovo: Applications of dispersed state control. Perspectives on Politics, 6(04), 655-674.

Sullivan, H., Knops, A., Barnes, M., \& Newman, J. (2004). Central-local relations in an era of multi-level governance: the case of public participation policy in England, 1997-2001. Local Government Studies, 30(2), 245-265.

Tansey, O. (2007). Process Tracing and Elite Interviewing: A Case for Nonprobability Sampling. PS: Political Science \& Politics 40(4), 765-772.

Tansey, O. (2009). Regime-Building: Democratization and International Administration. New York: Oxford University Press.

Turner, M. (2006). From commitment to consequences: Comparative experiences of decentralization in the Philippines, Indonesia and Cambodia. Public Management Review, 8(2), 253-272.

UN Habitat. (2012). Prizren Municipal Development Plan 2025: Strategic

Environmental Assessment (SEA) Report. Kosovo/Estonia: UN Habitat Pristina Office. Retrieved from http://www.unhabitatkosovo.org/repository/docs/SEA_Prizren_draft_786745.pdf

UNDP. (2006). Youth: A new generation for a new Kosovo. Kosovo Human Development Report. Prishtina: UNDP Kosovo.

UNDP. (2010). Youth Volunteerism in Kosovo: An Opportunity to Learn. Prishtina: UNDP. Retrieved from http://www.ks.undp.org/repository/docs/englishonline.pdf

UNESCO. (2003). Cultural Heritage in Kosovo: A multi-ethnic Cultural Heritage in Danger. UNESCO.

UNESCO. (2004). Cultural Heritage in Kosovo: Protection and Conservation sLئ⿴囗十 Multi-Ethnic Heritage in Danger (Mission Report No. 2). Venezia: UNESCO. Retrieved from www.unesco.org/culture/heritage/ kosovo1 
UNESCO. (2005). Address by Mr Koïchiro Matsuura, Director-General of UNESCO, on the occasion of the International Conference of Donors for the Protection and Preservation of Cultural Heritage in Kosovo (No. DG/2005/079). UNESCO.

United States Department of State. (2010). 2010 Report on International Religious Freedom: Bosnia and Herzegovina. Retrieved from http://www.state.gov/documents/organization/171686.pdf

USAID Kosovo. (n.d.). Youth and Education. Retrieved from http://transition.usaid.gov/kosovo/eng/program_youth.html

Van de Walle, S., \& Scott, Z. (2009). The Role of Public Services in State- and NationBuilding: Exploring Lessons from European History for Fragile States (GSDRC Research Paper). Governance and Social Development Resource Center.

Wedel, J.R. (2001). Collision and collusion: the strange case of Western aid to Eastern Europe. Palgrave Macmillan.

Woehrel, S. (2006). Kosovo and US Policy. In Library of Congress Washington DC Congressional Research Service.

Wolferstan, S. (2006). Undertaking a heritage ethnography in Kosovo. UCL Institute of Archaeology, 17.

Wolferstan, S. (2007). Community participation in heritage in post-conflict Kosovo. Promoting democracy, dialogue and reconciliation through cultural heritage. In Selected papers from the Third Annual Ename International Colloquium (pp. 283 - 289). Ghent: Ename Center for Public Archaeology and Heritage Presentation.

Woods, D. (1994). Elites, Ethnicity, and Home Town Associations in the CoteDivoire - an Historical-Analysis of State-Society Links. Africa 64(4), 465483.

Woodward, S. (2000). Kosovo and the Region: Consequences of the Waiting Game. The International Spectator, 35(1), 35 - 48.

Woodward, S. (2002). Local Governance Approach to Social Reintegration and Economic Recovery in Post-conflict Countries: The Political Context for Programs of UNDP/UNCDF Assistance. Retrieved from http://www.theipa.org/publications/woodward.pdf

Woodward, S. (2007). Does Kosovo's Status Matter? On the International Management of Statehood. Südoseuropa, 55(1), 1-25.

Woodward, S. (2007). Is Democracy Possible in the Balkans? On Preconditions and Conditions in Bosnia, Kosovo and Serbia (NCEEER Title VIII Program). 
Seattle: The National Council for Eurasian and East European Research.

Retrieved from https://www.ucis.pitt.edu/nceeer/2007 820-

$20 \mathrm{~g}$ Woodward.pdf

Woodward, S. (2009). A Case for Shifting the Focus: Some Lessons from the Balkans. In M. Fisher \& B. Schmelzle (Eds.), Building Peace in the Absence of States: Challenging the Discourse of State-Failure. Berghof Handbook Dialogue No. 8 (pp. 47 - 56). Berlin: Berghof Research Center.

Woodward, S. (2011). Varieties of State-Building in the Balkans: A Case for Shifting Focus. In B. Austin, M. Fischer, \& H. J. Giessmann (Eds.), Advancing Conflict Transformation. The Berghof Handbook II (pp. 315 - 335).

Opladen/Framington Hills: Barbara Budrich Publishers.

Yanacopulos, Helen. (2005). Patterns of governance: the rise of transnational coalitions of NGOs. Global Society 19(3), 247-266.

Yin, R. K. (2009). Case Study Research: Design and Methods. SAGE Publications.

Youngs, R. (2007). Democracy as Product Versus Democracy as Process. In M. van Doorn and R. von Meijenfeldt (Eds.). Democracy: Europe's Core Value? (pp. 67-68). The Hague: Eburon Delft.

Zürcher, C. (2011). Building Democracy While Building Peace. Journal of Democracy $22(1), 81-95$.

--------."Hasi me dy komuna: të Gjonajve dhe të Rugovës" (Has with two municipalities: Gjonaj and Rugova). (2013, May 27). Koha Ditore. Prishtina.

\section{Legislation}

\section{UNMIK Regulations}

(UNMIK regulations and Administrative Directives are retrieved from the UNMIK Official Gazette: http://www.unmikonline.org/regulations/index reg 2003.htm. All documents were last accessed February 27, 2014).

UN Security Council Resolution 1244. S/RES/1244 (1999). 10 June 1999. Retrieved from http://www.unmikonline.org/Documents/Res1244ENG.pdf.

UNMIK Resolution No. 1999/14 'On the Appointment of Regional and Municipal Administrators'. 21 October 1999. 
UNMIK Regulation No. 1999/24 'On the Law Applicable in Kosovo', 12 December 1999. 27 October 2000.

UNMIK Regulation No 1999/01, ‘On the Authority of the Interim Administration in Kosovo'. 25 July 1999.

UNMIK Regulation No. 2000/9, 'On the Establishment of the Administrative Department of Local Administration'. 3 March 2000.

UNMIK Regulation No. 2000/39, 'On Municipal Elections in Kosovo'. 8 July 2000.

UNMIK Regulation No. 2000/45 ‘On Self-Government in Municipalities of Kosovo', 11 August 2000.

UNMIK Regulation No. 2000/54, 'Amending UNMIK Regulation No. 1999/1, As Amended, On the Authority of the Interim Administration in Kosovo. 27 September 2000.

UNMIK Resolution No. 2001/9 'Framework for Provisional Self-Government in Kosovo'. 15 May 2001.

UNMIK Regulation 2002/11, 'On the Municipal Elections in Kosovo'. 10 June 2002.

UNMIK Regulation No. 2003/11 'Amending UNMIK Regulation No. 1999/14 On The Appointment of Regional and Municipal Administrators'. 17 April 2003.

UNMIK Regulation No. 2004/50, 'On the Establishment of New Ministries and Introduction of Posts of Deputy Prime Minister and Deputy Ministers in the Executive Branch'. 2 December 2004.

UNMIK Regulation on establishing Ministry of Local Government Administration

UNMIK Administrative Direction 2005/11, 'On Pilot Projects. Implementing UNMIK Regulation 2000/45 On Self-Government of Municipalities in Kosovo'. 22 July 2005.

UNMIK Regulation No. 2007/27, ‘On Municipal Elections in Kosovo'. 29 August 2007.

UNMIK Regulation No. 2007/29, 'On Amendments to the Constitutional Framework for Provisional Self-Government in Kosovo'. 4 October 2007.

UNMIK Regulation No. 2007/30, 'Amending UNMIK Regulation No. 2000/45 On Self-Government of Municipalities in Kosovo'. 16 October 2006.

UN Security Council. S/2005/635. 'Kai Eide Report'. 7 October 2005. Retrieved from http://www.unosek.org/docref/KaiEidereport.pdf. 
UN Security Council. S/2007/168/Add.1. Comprehensive Proposal for the Kosovo Status Settlement. 26 March 2007. Retrieved from

http://www.unosek.org/docref/Comprehensive_proposal-english.pdf.

\section{Kosovo legislation}

(Laws adopted by the National Assembly of Kosovo are retrieved from two webpages of the Official Gazette: http://www.gazetazyrtare.com/ and http://gazetazyrtare.rks-gov.net/ as well as the Assembly page: http://www.assembly-kosova.org/?cid=2,191. All documents last accessed March 3, 2014).

Law No. 02/L-17, 'On Social and Family Services'. 2005.

Law No. 2003/14, 'Spatial Planning'. 2003.

Law No. 03/L-022, ‘On Material Support for Families of Children with Permanent Disability. 2008.

Law No. 03/L-024, ‘On Environmental Impact Assessment'. 2009.

Law No. 03/L-025, ‘On Environmental Protection' 2009.

Law No. 03/L-039, ‘On Special Protective Zones'. 2008.

Law No. 03/L-040, 'On Local Self-Government'. 2008.

Law No. 03/L-041, 'On Administrative Municipal Boundaries'. 2008.

Law No. 03/L-047, 'On the Protection and Promotion of The Rights of

Communities and Their Members in Kosovo. 2008.

Law No. 03/L-048, 'On Public Financial Management and Accountability'. 2008.

Law No. 03/L-049, ‘On Local Government Finance’. 2008.

Law No. 03/L-072, ‘On Local Elections in the Republic of Kosovo'. 2008.

Law No. 03/L-087, ‘On Publicly Owned Enterprises'. 2008.

Law No. 03/L-089, 'On Amendments To The Law On Administrative Municipal Boundaries'. 2008.

Law No. 03/L-145, 'On Youth Empowerment and Participation'. 2009.

Law No. 02/L-88, 'Cultural Heritage' 2006. 
Law No. 04/L-066, ‘On Historic Centre of Prizren' 2012.

Law No. 04/L-081, ‘On Amending and Supplementing the Law No. 02/L-17 On Social and Family Services'. 2012.

Kushtetuta e Republikës së Kosovës (Constitution of the Republic of Kosovo). 15 June 2008. Retrieved from http://www.kryeministriks.net/repository/docs/Kushtetuta.e.Republikes.se.Kosoves.pdf.

\section{Secondary legislation}

Administrative Instruction No. 9/2010, 'For Responsibilities and Procedures of the Establishment and Functioning of Youth Action Councils in Kosovo'. 2010. Retrieved from http://www.mkrs-ks.org/repository/docs/U.A._Nr._92010_per_pergjegjesite_dhe_procedurat_e_themelimit_te_Keshillave_te_Vep rimit_Rinor_ne_Kosove.pdf.

Decision Nr. 01/32 of the Government of Republic of Kosovo. (2013, May 28).

Office of the Prime Minister of the Republic of Kosovo. Retrieved from http://www.kryeministri-

ks.net/repository/docs/Vendimet_e_mbledhjes_se_132te_te_Qeverise_2013.pdf

Decision Nr. 01/35 of the Government of Republic of Kosovo. (2011, September 1). Office of the Prime Minister of the Republic of Kosovo. Retrieved from http://www.kryeministri-

ks.net/repository/docs/Vendimet_e_mbledhjes_se_35te_te_Qeverise_2011.pdf

Decision Nr. 03/26 of the Government of Republic of Kosovo. (2011, July 27). Office of the Prime Minister of the Republic of Kosova. Retrieved from http://kryeministri-ks.net/repository/docs/Vend.mbl._26-te.pdf

OPM. (2008). Strategy and Action Plan on Human Rights of Republic of Kosovo 2009 2011. Prishtina: Office of the Prime Minister. Retrieved from http://www.kryeministriks.net/zck/repository/docs/Human_Rights_Strategy.pdf

OPM. (2009). National Disability Action Plan for the Republic of Kosovo 2009 - 2011. Prishtina: Office of the Prime Minister. Retrieved from http://www.cooperazioneallosviluppo.esteri.it/pdgcs/download/Kosovo_Pla n.pdf 
OPM. (2011a). Broad Survey of Persons with Disabilities in Kosovo. Prishtina: Office of the Prime Minister. Retrieved from http://www.kosovo.undp.org/repository/docs/2011/PWD_English.pdf

OPM. (2011b). Programi i qeverisë së Republikës së Kosovës 2011 - 2014 (Government Program of the Republic of Kosovo 2011 - 2014). Prishtina: Office of the Prime Minister, Government of Republic of Kosova. Retrieved from http://www.kryeministriks.net/repository/docs/Programi_i_Qeverise_shqip_.pdf 


\section{Nieuw bestuur onder beperkte soevereiniteit: de lokale regeringshervorming in Kosovo}

\section{Samenvatting}

In dit onderzoek wordt gefocust op de lokale regeringshervorming in Kosovo. Het perspectief op de lokale besluitvorming, de toewijzing en afdwinging ervan, alsook de talrijke internationaal gedreven hervormingen om Kosovo's overgang naar democratische soevereiniteit te ondersteunen, weerspiegelen een complex en relevant onderzoeksportaal. De kernvraag van deze scriptie betreft de omstandigheid dat, terwijl het rijk van de lokale politiek sinds het uiteenvallen van Joegoslavië onderhevig is geweest aan structurele hervormingen, zwakke institutionele capaciteiten blijken te zijn blijven bestaan. Dit uit zich vooral in hardnekkige niveaus van ondermaatse implementatie van de wetgeving en de mislukte transformatie van bestaande structuren. Hoe kan dit verklaard worden? Welke factoren bepalen het verloop en het tempo van verandering? Wat zegt dit over de hervormingen, de internationale tussenkomst en het specifieke geval Kosovo? Wat de democratische transformatie van de lokale besluitvorming betreft, houdt het hervormingsproces meer in dan alleen de deconcentratie van macht. Wat ook vereist is, is het vestigen van toegangspunten waardoor ook nietoverheidsactoren betrokken kunnen worden bij de besluitvorming. Daarom wordt er in deze scriptie geprobeerd te identificeren in welke mate er een opbouw van macht en autoriteit is geweest bij zowel statelijke als niet-statelijke actoren. Deze scriptie is gebaseerd op een verkennend onderzoeksontwerp van een casestudy en gebruikt een proces-volgende methode om 'within-casestudies' te verkennen. Primaire gegevens zijn verzameld door middel van diepgaande interviews met de belangrijkste betrokken partijen, die ter plekke uitgevoerd zijn in Kosovo.

In hoofdstuk drie wordt een gedetailleerde achtergrond van Kosovo geschetst en wordt het traject van de lokale regeringshervorming in het land in de periode voor en na 1999 gevolgd. Volgend op de vestiging van een brede internationale aanwezigheid in Kosovo in 1999 is de lokale regering over de jaren onderhevig geweest aan een reeks hervormingsstrategieën. De hervormingen zijn verstrengeld met de politieke situatie en beïnvloed door de gevechten tussen de etnische Albanese meerderheid en de Servische minderheid. Moeilijkheden om gezag uit te oefenen en de rechtsstaat af te dwingen in de gemeentes met een Servische meerderheid hebben de succesvolle implementatie van decentralisiehervormingen ondermijnd. In de context van een zwakke centrale regering met beperkte capaciteiten en een betwiste autoriteit en rechtsbevoegdheid heeft de internationale 
gemeenschap een externe schaduw van hiërarchie geworpen op het lokale niveau. Wanneer en waar ze plaatsgevonden hebben, zijn de decentralisatie en de hervorming van de lokale overheid in Kosovo het product van conditionaliteitsdruk van de internationale gemeenschap.

In de vergelijkende analyse in het tweede deel van hoofdstuk drie wordt er gefocust op de hervormingsprogramma's van de lokale overheid die geleid zijn door de twee grootste donors in Kosovo, het Agentschap voor Internationale Ontwikkeling van de Verenigde Staten (USAID) en het Programma van de Europese Unie (EU) voor Regionale Economische Ontwikkeling. Uit de analyse blijkt dat deze initiatieven de nadruk leggen op participatie en het vestigen van formele autoriteitsmechanismen en daarmee voortdurend proberen om de kloof te overbruggen tussen statelijke en niet-statelijke instituten door horizontale samenwerkingsmanieren te verzekeren. In het hoofdstuk worden de twee belangrijkste nadelen van deze programma's geïdentificeerd, waaronder het gebrek aan langetermijn-strategieën en de onvoldoende aandacht die wordt besteed aan de versterking van intergouvernementele relaties en verticale samenwerkingsmanieren.

Van hoofdstuk vier tot zes worden casestudy's voorgelegd van vier beleidsgebieden die de impact van de hervorming van de lokale overheid onderzoeken door het vestigen van institutionele samenwerkingsmechanismen tussen statelijke en niet-statelijke agentschappen. In hoofdstuk vier wordt gekeken naar erfgoedbestuur, de laatste jaren een van de meest betwiste onderwerpen in de Kosovaarse politiek omdat het een proces van de herdefiniëring van de noties van soevereiniteit en de rol van de staat met zich meebrengt. Het onderzoekt de machtsstrijd binnen een uiterst ingewikkeld web van actoren, waaronder internationale agentschappen, de centrale regering, lokale autoriteiten, maatschappelijke en religieuze gemeenschappen, die allemaal proberen om de mechanismen van erfgoedbescherming te beïnvloeden. In dit hoofdstuk wordt de controversiële opstelling van de nieuwe stedelijke wet met betrekking tot het historisch centrum van Prizren onderzocht en wordt een wetgevingsproces aangetoond dat beïnvloed is door gecentraliseerde besluitvorming en een gebrek aan transparantie. De uitsluiting van belangrijke nationale en lokale actoren heeft ertoe geleid dat er weerstand is ontstaan tegen het hervormingsproces en heeft de legitimiteit van zowel de internationale betrokkenheid als van de centrale regeringsautoriteit geschaad.

In hoofdstuk vijf wordt het geval van jeugdparticipatie op het lokale niveau gekozen om het potentieel van lokaal leiderschap te illustreren bij de bevordering van jeugdbeleid door een actieve aanpak. In dit hoofdstuk wordt geïllustreerd dat er opportuniteitsstructuren bestaan voor lokale agenten die in de jeugdsector 
werken. In verband met de demografie van het land waarin de helft van de bevolking jonger dan 25 jaar is, prioriteert de centrale regering beleidsvormen die jeugdparticipatie in de lokale besluitvorming ondersteunen. Nieuwe wetgeving heeft de jeugd op de politieke agenda gezet en heeft beschikbare middelen aangeboden, ingezet door internationale agentschappen om nieuwe structuren op het lokale niveau te bouwen en daarbinnen de belangen van de jeugd te bevorderen. De gemeenten hebben blijk gegeven van leiderschap en ondersteuning bij de implementatie van mechanismen voor partnerschappen met maatschappelijke organisaties die met de jeugd werken. Door de wisselwerking van deze factoren heeft het jeugdbeleid vooruitgang geboekt ten gunste van de bevordering van jeugdparticipatie en het vestigen van mechanismen voor jonge burgers om zich tot hun gemeentes te richten. Dit maakt deze casestudy een bijzonder interessant paradigma.

In het laatste empirische hoofdstuk worden het milieubestuur en de welzijnszorgverlening onderzocht. Bij het milieubestuur verleent een grondige analyse van de mechanismen van het opstellen van lokale milieuprogramma's inzicht in nieuwe samenwerkingsvormen tussen lokale autoriteiten en maatschappelijke organisaties. De hier gepresenteerde casestudy's benadrukken het belang van actieve maatschappelijke organisaties om verandering teweeg te kunnen brengen op het lokale niveau. Maatschappelijke organisaties kunnen, wanneer gemobiliseerd, een sterke belangengroep vertegenwoordigen die lobbyt voor verandering op het lokale niveau. De bereidheid van maatschappelijke organisaties om samenwerkingskanalen met de lokale autoriteiten op te bouwen toont hun leiderschapspotentieel voor de verbetering van de lokale omstandigheden. In het tweede deel van het zesde hoofdstuk wordt de welszijnszorgverlening bekeken en worden de factoren geïllustreerd die bijdragen tot succesvolle samenwerkingsprogramma's voor dienstverlening aan mensen met een handicap. Door te focussen op de specifieke diensten die aangeboden worden door HandiKOS worden in het hoofdstuk de uitdagingen onderzocht van het opzetten van partnerschappen tussen maatschappelijke organisaties en gemeentelijke autoriteiten. De door internationale of externe agentschappen gestelde conditionaliteit was bij de oprichting van partnerschappen een noodzakelijke factor voor het ontstaan van samenwerking tussen statelijke en nonstatelijke actoren. Dit suggereert een gebrek aan vertrouwen van de lokale overheden in de capaciteiten van niet-gouvernementele organisaties en een gebrek aan engagement om de manier van werken op het lokale niveau te veranderen. De rol van internationale agentschappen blijkt noodzakelijk te zijn om de link te leggen tussen lokale overheidsinstellingen en niet-statelijke organisaties maar niettemin onvoldoende om een succesvolle implementatie van de samenwerking te garanderen. 
In het laatste hoofdstuk worden de belangrijkste bevindingen van het onderzoek en hun implicaties voor hedendaagse studies en de praktijk belicht. Wat vooral opvalt uit het materiaal dat in deze studie wordt voorgelegd is dat er opportuniteitsstructuren bestaan voor agenten, vooral voor die welke betrokken zijn in de beleidssectoren van regionale ontwikkeling, jeugdparticipatie en milieubestuur. Deze opportuniteitsstructuren zijn hoofdzakelijk een product van de internationale tussenkomst en hun initiatieven op het lokale niveau. Bovendien suggereert het onderzoek dat de betrokkenheid van niet-statelijke actoren en hun relatieve empowerment tegenover lokale statelijke actoren een nieuw gedecentraliseerd besluitvormingstype op het lokale niveau mogelijk maakt. Dit is kennelijk zelfs het geval wanneer de capaciteiten van statelijke actoren laag en verwaarloosbaar zijn en waar het centraal bestuur onwillig is om autoriteit over te dragen en aarzelend staat tegenover hervormingen. Dit is minder het geval in omstandigheden waarin de internationale gemeenschap de centralisatie van een autoriteit op het centrale niveau afdwingt en systematisch niet-statelijke actoren uitsluit. Het materiaal dat in de empirische hoofdstukken naar voren wordt gebracht, suggereert dat de lokale en centrale gezagsdragers de veranderingen in hun macht tengevolge van decentralisatie niet volledig erkend hebben. De centrale regering heeft de decentralisatie en hervorming van het lokale bestuur doorgevoerd onder druk van de voorwaarden van de internationale gemeenschap, in plaats van als een eigen vereiste om de lokale participatie en subsidiariteit te versterken. Ondanks de structurele en institutionele opportuniteiten en veranderingen is er dus een vertraging en trage respons van de kant van het lokale niveau. 


\section{Biography}

Ilire Agimi has studied political science, public administration and international affairs. At MGSoG her fields of interest included multi-level governance and institutional reform, international aid and democracy promotion in fragile and post-conflict environments. While at MGSoG, Ilire served as teaching assistant in the MPP program, online instructor for GPAC2 as well as Seminar Series Coordinator.

Prior to joining the PhD program in Public Policy Analysis, Ilire worked for several years in the practitioner arena and has a broad experience in policy analysis. Ilire has worked both with civil society organizations as well as with a broad range of international agencies including USAID and DFID advising the Kosovo government on decentralization reform, performance management for public services, security sector reform and minority integration. Ilire is co-founder of the Kosovo-based think-tank Centre for European Policy and Politics where she led projects on the political economy of fiscal decentralization in the Balkans. Until 2009, Ilire was lecturer at the Master Program on Civil Society and Local Development at the University of Prishtina.

In 2014, Ilire was invited as a Visiting Scholar at the Harriman Institute, Columbia University in New York. 


\section{MGSoG Dissertation Series}

Kristine Farla

Empirical Studies on Institutions, Policies and Economic Development

MGSoG Dissertation Series, nr 38 (2013)

Marina Petrovic

Social Assistance and Activation in the Pursuit of Happiness:

Shedding New Light on Old Policy Solutions to Social Exclusion

MGSoG Dissertation Series, nr 37 (2013)

Laura Torvinen

Assessing Governance Assessments; The Case of Mozambique

Governance Assessments in the Context of Aid Effectiveness Discourse

MGSoG Dissertation Series, nr 36 (2013)

Biniam Egu Bedasso

Institutional Change in the Long Shadow of Elites

Essays on Institutions, Human Capital and Ethnicity in Developing Countries

MGSoG Dissertation Series, nr 35 (2013)

Sepideh Yousefzadeh Faal Deghati

Childhoods Embargoed

Constructing and Reconstructing Multidimensional Child Poverty in Iran 1984-2009

MGSoG Dissertation Series, nr 34 (2013)

Robert Bauchmüller

Investing in Early Childhood Care and Education:

The Impact of Quality on Inequality

MGSoG Dissertation Series, nr 33 (2013)

Martin Rehm

Unified Yet Separated

Empirical Study on the Impact of Hierarchical Positions within Communities of Learning MGSoG Dissertation Series, nr 32 (2013) 
Dorcas Mbuvi

Utility Reforms and Performance of the Urban Water Sector in Africa

MGSoG Dissertation Series, nr 31 (2012)

Lina Salanauskaite

Distributional Impacts of Public Policies:

Essays in Ex-Ante and Ex-Post Evaluation

MGSoG Dissertation Series, nr 30 (2012)

Esther Schüring

To Condition or not - is that the Question?

An Analysis of the Effectiveness of Ex-Ante and Ex-Post Conditionality in Social Cash

Transfer Programs

MGSoG Dissertation Series, nr 29 (2012)

Joe Abah

Strong Organisations in Weak States

Atypical Public Sector Performance in Dysfunctional Environments

MGSoG Dissertation Series, nr 28 (2012)

Zina Samih Nimeh

Social Citizenship Rights: Inequality and Exclusion

MGSoG Dissertation Series, nr 27 (2012)

Lenka Eisenhamerová

Legitimacy of 'Humanitarian Military Intervention'

MGSoG Dissertation Series, nr 26 (2011)

Sonila Tomini

Informal Payments for Health Care Services in Albania

MGSoG Dissertation Series, nr 25 (2011)

Jinjing Li

Dynamic Microsimulation in Public Policy Evaluation

MGSoG Dissertation Series, nr 24 (2011)

Aziz Atamanov

Rural Nonfarm Employment and International Migration as Alternatives to Agricultural

Employment:

The Case of Kyrgyztan

MGSoG Dissertation Series, nr 23 (2011) 
Frieda Vandeninden

Poverty Alleviation: Aid and Social Pensions

MGSoG Dissertation Series, nr 22 (2011)

Juliana Nyasha Tirivayi

The Welfare Effects of Integrating AIDS Treatment with Food Transfers:

Evidence from Zambia

MGSoG Dissertation Series, nr 21 (2011)

Agnieska Ewa Sowa

Who's Left Behind? Social Dimensions of Health Transition and Utilization of Medical Care in Poland

MGSoG Dissertation Series, nr 20 (2011)

Emmanaouil Sfakianakis

The Role of Private Actors in the Provision of Public Goods with Applications to Infrastructure and Financial Stability

MGSoG Dissertation Series, nr 19 (2011)

Siu Hing Lo

White Collars Green Sleeves

An Interonganizational Compariso of Deteminants of Energie-Related Behaviors among Office Workers

MGSoG Dissertation Series, nr 18 (2011)

Treena $\mathrm{Wu}$

Constraints to Human Capital Investment in Developing Countries:

Using the Asian Financial Crisis in Indonesia as a Natural Experiment

MGSoG Dissertation Series, nr 17 (2011)

Henry Espinoza Peña

Impact Evaluation of a Job-Training Programme for Disadvantaged Youths:

The Case of Projoven

MGSoG Dissertation Series, nr 16 (2011)

Florian Tomini

Between Family and Friends

Understanding the Interdependency of Private Transfers

MGSoG Dissertation Series, nr 15 (2010) 
Michał Polalowski

The Institutional Transformation of Social Policy in East Central Europe:

Poland and Hungary in comparative and historical perspective

MGSoG Dissertation Series, nr 14 (2010)

Maha Ahmed

Defining, Measuring and Adressing Vulnerability:

The Case of Post Conflict Environments

MGSoG Dissertation Series, nr 13 (2010)

Pascal Beckers

Local Space and Economic Success

The role of spatial segregation of migrants in the Netherlands

MGSoG Dissertation Series, nr 12 (2010)

Victor Cebotari

Complicting Demands in Ethnically Diverse Societies

Ethnopolitical Contention and Identity Values in Europe

MGSoG Dissertation Series, nr 11 (2010)

Dennis Gyllensporre

Competing and Complementary Perspectives on the EU as a Crisis Management Actor:

An Examination of the Common Security and Defence Policy through the Lenses of

Idealism and Realism

MGSoG Dissertation Series, nr 10 (2010)

Judit Vall Castello

Business Cycle and Policy Effects on Labour Market Transitions of Older and Disabled

Workers in Spain

MGSoG Dissertation Series, nr. 9 (2010)

Keetie Roelen

False Positives or Hidden Dimentions: the definition and measurement of child poverty

MGSoG Dissertation Series, nr. 8 (2010)

Denisa Maria Sologon

Earning Dynamics in Europe

MGSoG Dissertation Series, nr. 7 (2010) 
Melissa Siegel

Money and Mobility: Migration and Remittances

MGSoG Dissertation Series, nr. 6 (2010)

Jessica S. Hagen-Zanker

Modest Expectations: Causes and effects of migration on migrant households in source countries

MGSoG Dissertation Series, nr. 5 (2010)

Mirtha R. Muniz Castillo

Human Development and Autonomy in Project Aid: Experiences from four

bilateral projects in Nigaragua and El Salvador

MGSoG Dissertation Series, nr. 4 (2009)

Christiane Arndt

Governance Indicators

MGSoG Dissertation Series, nr. 3 (2009)

Britta Augsburg

Microfinance - Greater Good or Lesser Evil?

MGSoG Dissertation Series, nr. 2 (2009)

Geranda Notten

Measuring and Managing Poverty Risks

MGSoG Dissertation Series, nr. 1 (2008) 